\title{
Acreditação e avaliação de programas de residência médica : concepção internacional e proposta de um modelo nacional
}

\author{
Tese apresentada à Faculdade de Medicina da \\ Universidade de São Paulo para obtenção do Título de \\ Doutor em Ciências \\ Programa de: Ciências Médicas \\ Área de concentração: Educação e Saúde \\ Orientadora: Profa. Dra. Maria do Patrocínio Tenório Nunes
}

(Versão corrigida. Resolução CoPGr 6018/11 de 1 de novembro de 2011. A versão original está disponível na Biblioteca da FMUSP).

São Paulo 
Dados Internacionais de Catalogação na Publicação (CIP)

Preparada pela Biblioteca da

Faculdade de Medicina da Universidade de São Paulo

Creprodução autorizada pelo autor

Santos, Renato Antunes dos

Acreditação e avaliação de programas de residência médica : concepção internacional e proposta de um modelo nacional / Renato Antunes dos Santos. -- São Paulo, 2016.

Tese(doutorado)--Faculdade de Medicina da Universidade de São Paulo. Programa de Ciências Médicas. Área de Concentração: Educação e Saúde.

Orientadora: Maria do Patrocínio Tenório Nunes.

Descritores: 1.Educação médica 2.Internato e residência 3.Avaliação de programas e projetos de saúde 4.Acreditação 5.Planejamento em saúde 6.Gestão em saúde

USP/FM/DBD-193/16 
“Alice- But I don't want to go among mad people.

Cat - Oh, you can't help that, we're all mad here. I'm mad. You're mad. Alice - How do you know l'm mad?

Cat - You must be, or you wouldn't have come here."

"Alice - Would you tell me, please, which way I ought to go from here?

Cat - That depends a good deal on where you want to get to.

Alice - I don't much care where.

Cat - Then it doesn't matter which way you go."

Alice in Wonderland, Lewis Carroll 
Para Daniela, minha esposa e eterna namorada, que tem vindo comigo em meu caminho sem nunca duvidar.

"Eu sei e você sabe, já que a vida quis assim Que nada nesse mundo levará você de mim Eu sei e você sabe a distância não existe Que todo grande amor só é bem grande se for triste

Por isso, meu amor, não tenha medo de sofrer Pois todos os caminhos me encaminham pra você

Assim como o oceano só é belo com o luar Assim como a canção só tem razão se cantar Assim como uma nuvem só acontece se chover Assim como o poeta só é grande se sofrer Assim como viver sem ter amor não é viver Não há você sem mim, eu não existo sem você"

Vinicius de Moraes

Para minhas filhas Sofia e Helena que me ensinam como um coração já pleno de amor pode crescer a cada dia, caber mais, fazendo-me sentir infinito.

Para meus pais, Ademir e Marisa, e meu irmão, Felipe, que me ensinaram e ensinam o amor e a amar. 
Agradecer;

Desde os que me ensinaram o gosto e a curiosidade pelo mundo ainda tão pequeno. Os que me ensinaram a arte, a ciência e o ofício da medicina. Os que me ensinaram a imensidão e a profundidade da psiquiatria. Os que me ensinaram a pesquisar, aprender, ensinar.

Citar seus nomes nunca seria o bastante (e certamente seria injusto com tantos). Cito aqui em seus nomes minhas orientadoras Patrô e Linda, mulheres incríveis em minha vida. Exemplos de vida (modelos) em seus mundos tão diferentes, mas tão semelhantemente desafiam a vida e a sociedade, provando cotidianamente que podemos ser melhores sempre.

Nomeio aqui Simone, Angélica, Claudia, Melissa e Audrey pelo suporte e ajuda na USP e McGill.

Agradeço a Sociedade Brasileira de Neurocirurgia nos nomes dos Professores Gabarra, Colli, Paulo Mello e Cid.

Nunca é demais agradecer minha família. Meu avô Severino que me despertou na infância a curiosidade científica sobre o Parkinson, meu avô João por sua intelectualidade e gosto pela leitura, minhas avós Natália e Albina por seu carinho, honestidade e seu gosto pela medicina (e pelo café). Pelo apoio de meus tios, tias, primos e primas, sogros Laerthe e Deborah, cunhados Alice e Fábio que a vida me fez tão próximos aqui no peito, mas, por vezes, distantes na geografia.

Obrigado. 


\section{ÍNDICE}

\section{Lista de Tabelas}

Lista de Figuras

Lista de Fluxogramas

Resumo

Abstract

Résumé

Preâmbulo: A Jornada............................................................................. 1

CAPITULO I: Sobre residência médica, acreditação e poder ........................... 6

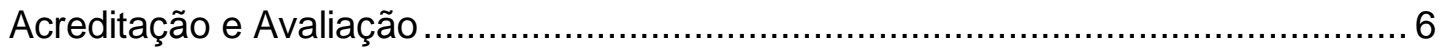

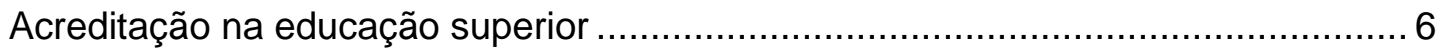

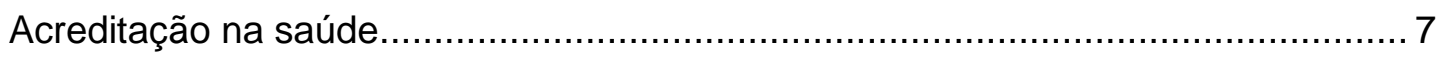

A educação médica............................................................................. 8

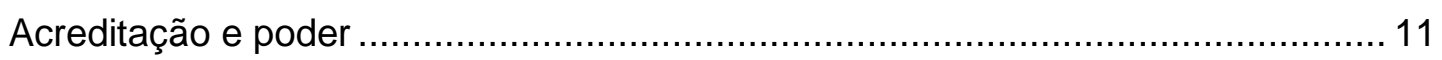

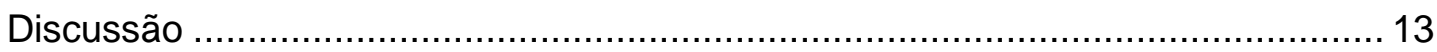

CAPÍTULO II: Educação Médica no Mundo .............................................. 15

A importância das concepções internacionais ...................................................... 15

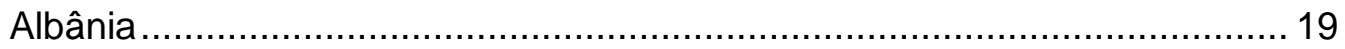

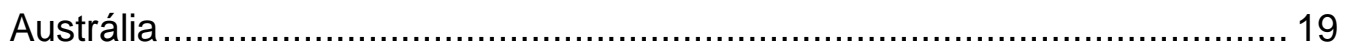

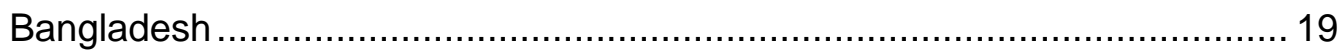

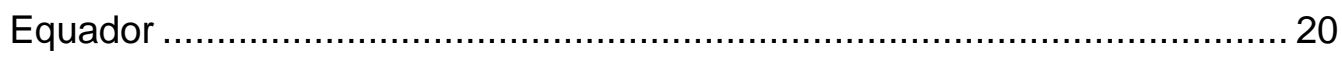

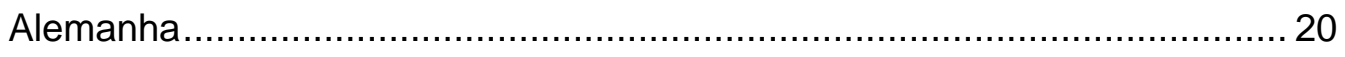

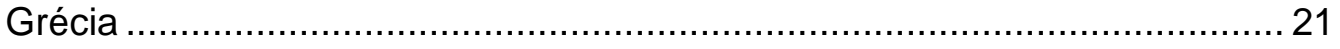

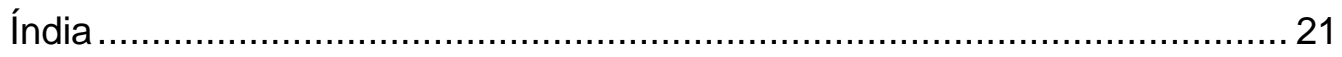

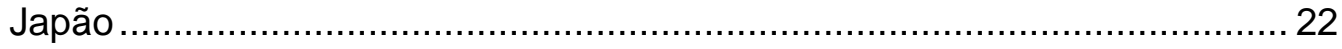

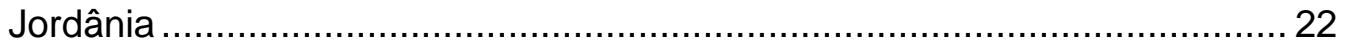

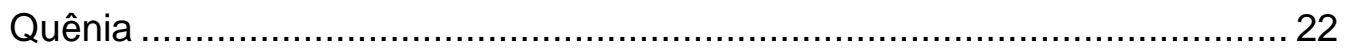

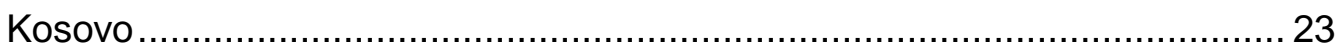

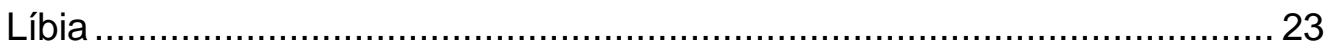

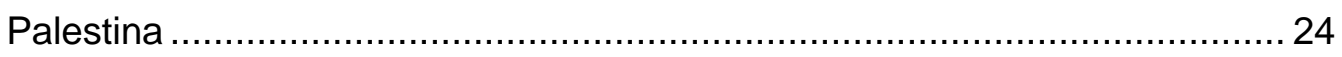

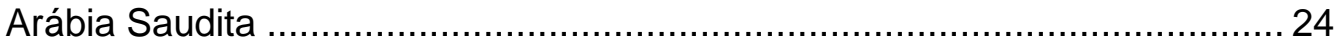

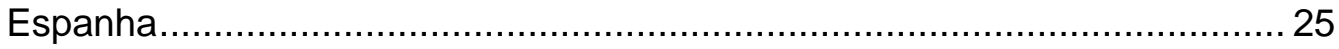




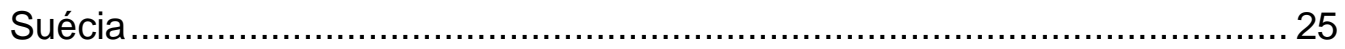

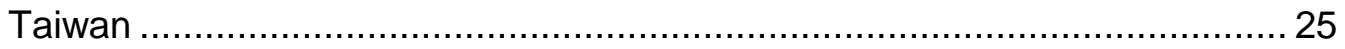

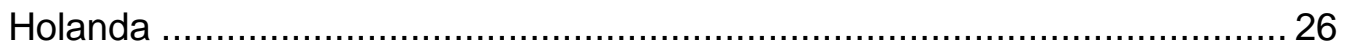

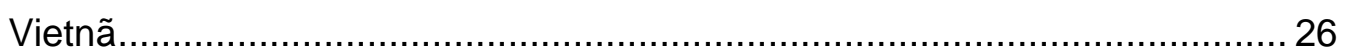

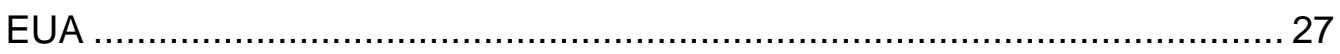

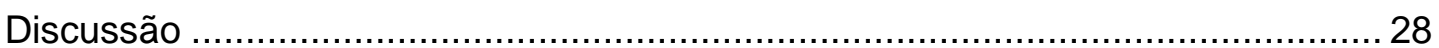

Capítulo III: Lições aprendidas com modelos de Acreditação da Residência Médica na América do Norte ................................................................... 29

Lições do modelo de Acreditação da Residência Médica nos EUA (Accreditation Council for Graduate Medical Education- ACGME).......................... 29

Lições do modelo de acreditação da residência médica no Canadá (Royal College of Physicians and Surgeons of Canada - RCPSC) .................................. 32

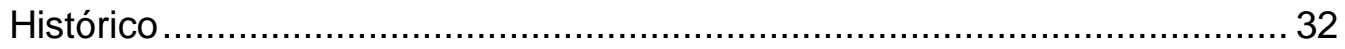

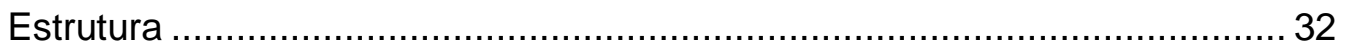

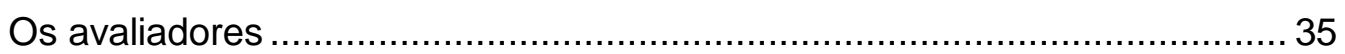

O comitê de acreditação .................................................................. 36

Capítulo IV: A relação entre qualidade e acreditação de programas de residência - percepções dos avaliadores .................................................... 41

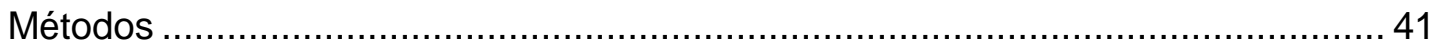

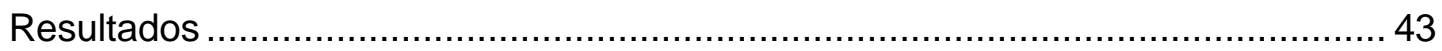

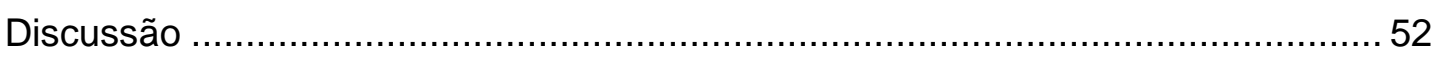

Capítulo V: O Comitê de acreditação ................................................... 55

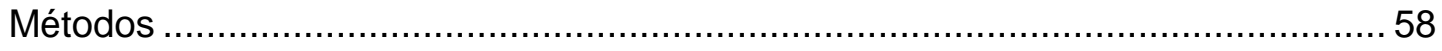

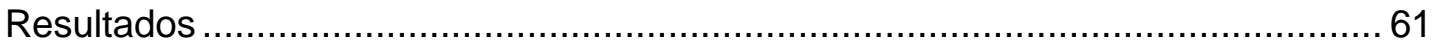

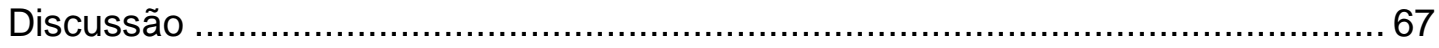

Capítulo VI: Revisão Interna - Um Estudo de Caso..................................69 69

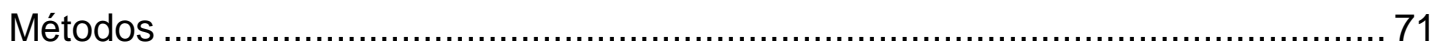

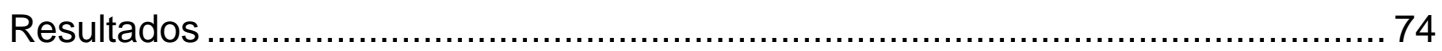

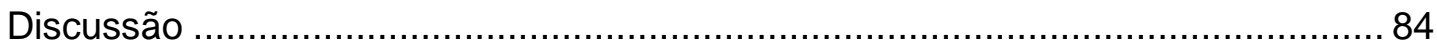

Capítulo VII: Brasil - Aspectos Gerais e a Educação Médica ....................... 88

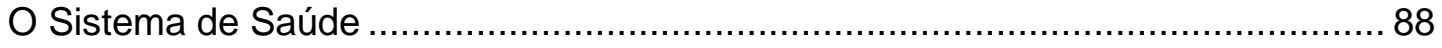

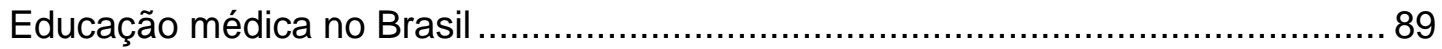

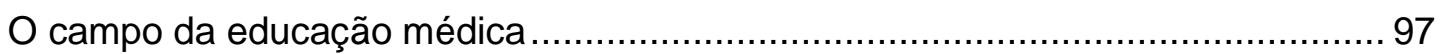


Capítulo VIII: Brasil - A formação médica especializada: Os Cursos de Especialização e Residência Médica

Especialização e residência médica .................................................................. 100

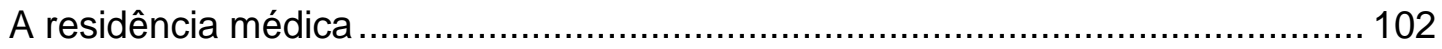

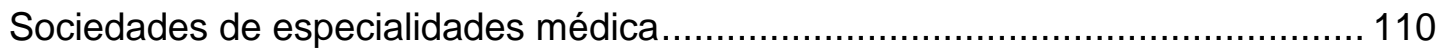

Capítulo IX: O impacto da avaliação conjunta dos programas de residência médica pela CNRM e SBN

A Sociedade Brasileira de Neurocirurgia (SBN) e o Projeto Piloto de Avaliação

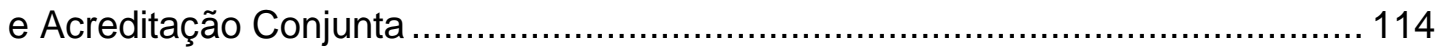

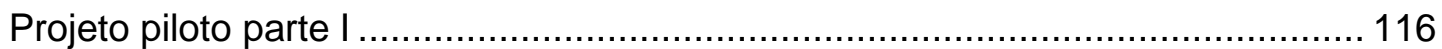

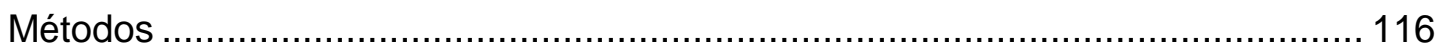

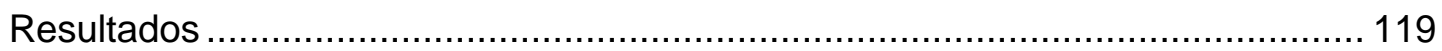

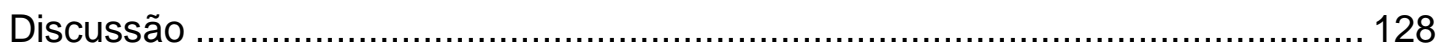

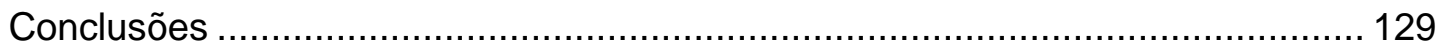

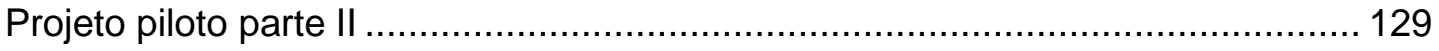

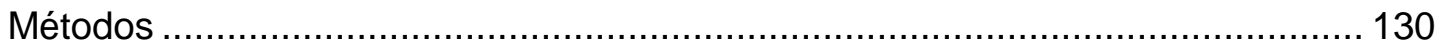

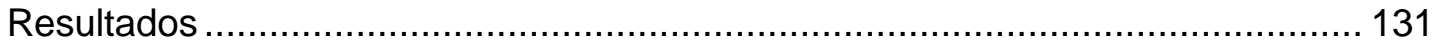

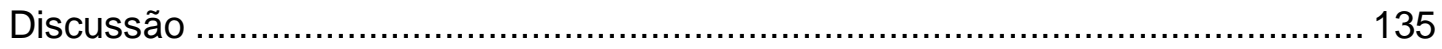

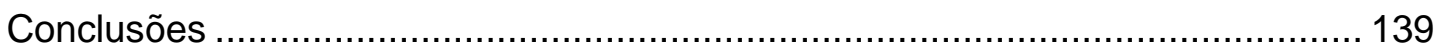

Capítulo X: Influências e comparações de modelos de Acreditação de Programas de Residência Médica.............................................................. 141

A formação médica e o provimento de profissionais............................................. 141

Residência médica de qualidade ................................................................... 142

Os modelos dos EUA, Canadá e Brasil comparados........................................... 143

Resultados em um Plano Nacional de Avaliação e Acreditação ..................... 147

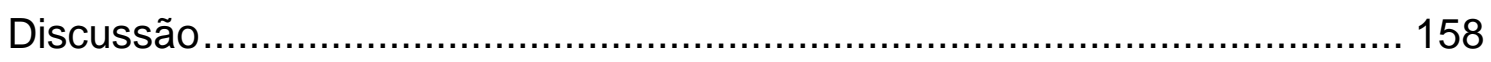

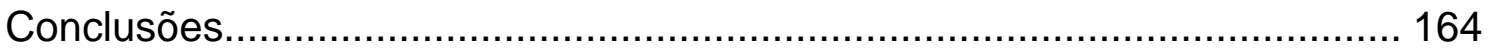

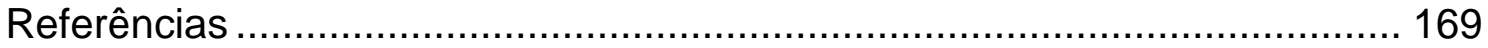

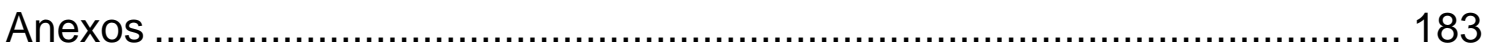




\section{Lista de Tabelas}

Tabela 1 - Planilha de custos para gestão dos PRMs nos Estados Unidos por meio da Accreditation Council for Graduate Medical Education discriminando ações e valores correspondentes ................................. 30

Tabela 2 - Critérios Padronizados (Standards) do RCPSC e do CFPC A e B ..........34

Tabela 3 - Características dos Avaliadores Entrevistados ..................................... 43

Tabela 4 - Analise Temática: conjunto de itens e subitens elaborados a partir das entrevistas semiestruturadas ..................................................... 44

Tabela 5 - Trechos representativos sobre Recursos Humanos ................................ 48

Tabela 6 - Trechos representativos sobre Estrutura e Processo .............................49

Tabela 7 - Novas ideias para melhorar a eficiência do sistema de acreditação ........50

Tabela 8 - Trechos representativos sobre as Novas Ideias .................................. 52

Tabela 9 - Agenda de uma revisão interna .................................................. 75

Tabela 10 - Neurocirurgiões por habitantes..................................................... 124

Tabela 11 - Programas de neurocirurgia resultantes da avaliação conjunta CNRM/SBN ........................................................................... 125

Tabela 12 - Número absoluto de programas, por região do Brasil, e principais pontos que merecem atenção (assistência, estrutura e processo) .......127

Tabela 13 - Número absoluto de programas, por região do Brasil, e principais pontos que mereceram atenção (Ensino) ........................................ 128

Tabela 14 - Pontos que merecem maior atenção ................................................... 132

Tabela 15 - Distribuição do número de questões, de acordo com o nível do residente (R1 a R5) e o conteúdo avaliado......................................... 133

Tabela 16 - Análise estatística da influência dos programas de residência médica (variável independente) sobre o desempenho dos residentes (variável dependente)

Tabela 17 - Modelos de acreditação e avaliação comparados 145 


\section{Lista de Figuras}

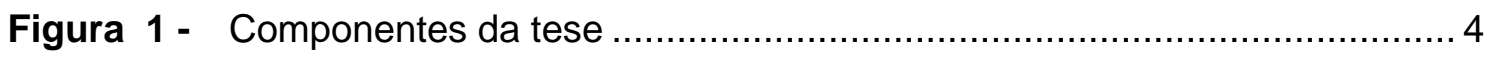

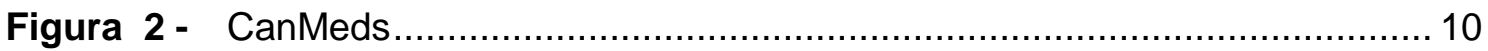

Figura 3 - Modelo Balanceado de Acreditação ….................................................... 53

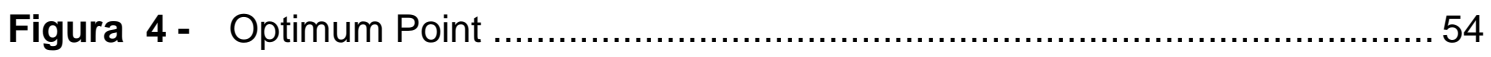

Figura 5 - Posição do Pesquisador ........................................................... 59

Figura 6 - Velocidade no tempo de resposta da avaliação ....................................64

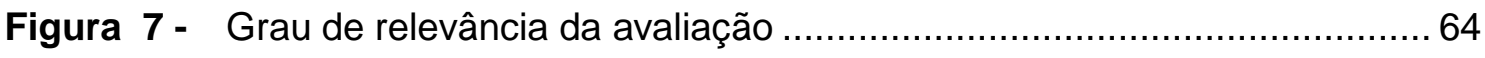

Figura 8 - Captação de dados em estudo de caso .............................................. 73

Figura 9 - Curvas de crescimento de escolas médicas em relação à população

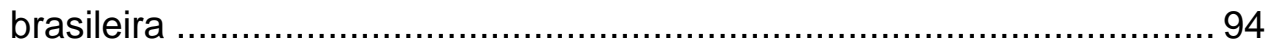

Figura 10 - Programas de residência médica em neurocirurgia criados desde 1982 por região do Brasil, in Sao Paulo Med J. 2015 .......................... 122 


\section{Lista de Fluxogramas}

Fluxograma 1 - Processos internos no sistema de acreditação do RCPSC, em

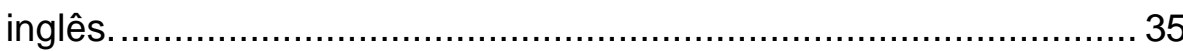

Fluxograma 2 - Formação do médico especialista no Brasil.....................................95

Fluxograma 3 - Processos internos no sistema de credenciamento da CNRM....... 109

Fluxograma 4 - Exemplo de processos para um sistema de acreditação nacional ..... 152 


\section{Resumo}

Santos RA. Acreditação e avaliação de programas de residência médica: concepção internacional e proposta de um modelo nacional [Tese]. São Paulo: Faculdade de Medicina, Universidade de São Paulo; 2016.

A avaliação de programas de residência medica é parte integrante de um sistema maior de acreditação em diversos países. A acreditação é um produto simbólico. Não "vende" um bem concreto, mas um símbolo de confiança na existência de critérios elevados de qualidade em determinado programa que é objeto de sua análise. A acreditação na residência médica é bastante complexa, posto que, além dos conhecimentos em educação médica, são necessários conhecimentos em estrutura, processo e resultados esperados para programas de pós-graduação no ensino superior e também na saúde e no trabalho médico. O resultado final esperado de todo esse sistema deve ser o médico competente. Lições aprendidas com as experiências internacionais podem contribuir com a construção de modelos locais e evitar que erros históricos sejam cometidos. Muitos países direcionam investimentos no campo da educação médica em busca da qualidade de seus profissionais, visando impactar positivamente o sistema de saúde. Ao investigarmos mais profundamente o sistema canadense de acreditação do Royal College of Physicians and Surgeons of Canada, por meio de métodos etnográficos, descrição qualitativa e estudo de caso, observamos que seus processos internos não diferem muito do praticado no Brasil. No entanto, a formação dos médicos especialistas segue de maneira desagregada neste país; Comissão Nacional de Residência Médica, CNRM; avaliações das Sociedades de Especialidades Médicas continuam desintegradas, em um ambiente político desfavorável, de afastamento dos principais interessados e especialistas nesse processo (governo, universidades, entidades médicas etc.). Um projeto piloto realizado neste estudo, conjuntamente, entre a Sociedade Brasileira de Neurocirurgia e a CNRM unificou critérios, realizou avaliações conjuntas e somou saberes com resultados exemplares para o país. O sistema brasileiro, por não ser unificado e não possuir independência institucional,funciona de maneira errática, impossibilitando estabilidade e garantia de qualidade em conformidade com elevados padrões internacionais. $O$ foco na quantidade de médicos, que toma conta da pauta da saúde de boa parte do planeta, não pode impedir o avanço e as garantias de busca pela qualidade. Propiciar desequilíbrio entre qualidade e quantidade na educação médica pode ser catastrófico para o futuro dos profissionais e colocar em risco a população geral. Os resultados desta tese vêm da concepção internacional para a proposta do modelo nacional de acreditação e avaliação de programas de residência. Visa à construção democrática e unida dos principais partícipes do sistema, em que qualidade e quantidade se encontram de maneira harmônica e equilibrada.

Descritores: educação médica; internato e residência; avaliação de programas e projetos de saúde; acreditação; planejamento em saúde; gestão em saúde. 


\begin{abstract}
Santos RA. Residency program accreditation and evaluation: international studies and national proposal [Thesis]. São Paulo: "Faculdade de Medicina, Universidade de São Paulo"; 2016.
\end{abstract}

Residency program evaluation is part of the accreditation system in several countries. Accreditation is a symbolic good. It does not sell a product to take over, but a symbol of trustiness on the high level standards at a specific program. Residency accreditation is away complex. Beyond the knowledge on medical education we have to have skills and knowledge of structure, process and outcomes on post-graduation, health sector and medical work. The final outcome of this system must be a competent physician. Lessons learned from the international experiences might contribute to local models and avoid historical mistakes. Searching for quality of the physicians in order to have positive impact on the health system, several countries have been amplifying the investments on medical education. Further researches about the Royal College of Physicians and Surgeons of Canada residency accreditation system through ethnography, qualitative description and case study methodologies reveal similarities with what would be a Brazilian system. The evaluations of the physician's post-graduation performed by the National Medical Residency Committee, CNRM, and the medical specialty societies have been kept apart. The political environmental and relationship among the stakeholders (government, physicians' institutions, university, etc.) does not help consensus. A pilot project unified standards, made joint evaluations and add knowledge between the Brazilian Neurosurgery Society and CNRM providing exemplary results. The Brazilian system is not unified or independent. It jeopardizes the stability of the system's performance and turns the comparison within the international high level standards impossible. There have been a lot of efforts on the health sector to plan the quantity of physicians. However, it can't build a barrier to meet and improve the quality of the physicians. The lack of balance between quantity and quality in medical education might be destructive to the professional and put on risk the general population. From international experiences and studies, the results of this thesis propose a national model for residency program evaluation and accreditation. Bringing balance and harmony between quantity and quality through democratic and unify bounding of the stakeholders.

Descriptors: education, medical; internship and residency; program evaluation; accreditation; health planning; health management. 


\section{Résumé}

Santos RA. L'accréditation et évaluation des programmes de résidence médicale: études internationales et proposition national [Thèse]. São Paulo: "Faculdade de Medicina, Universidade de São Paulo"; 2016.

Dans beaucoup de pays, l'évaluation des programmes de résidence médicale fait partie d'un plus grand système d'accréditation. L'accréditation est un bien symbolique. II ne s'agit pas d'un produit concret, mais un symbole de confidence sur l'existence des normes élevées pour avoir de la qualité dans un produit ou programme spécifique. L'accréditation de programmes de résidence médicale est un domaine complexe. En plus de la connaissance en matière d'éducation médicale, il est nécessaire d'avoir aussi de connaissance sur le structure, processus et le résultat post graduation, services de santé et travail médicale. Le résultat espéré par le système 'est nécessairement un médecin compétent. Les enseignements des expériences internationales peuvent contribuer avec la construction d'un système local et éviter que des erreurs ne soient commises. Plusieurs pays dirigent leurs investissements en éducation médicale afin d'améliorer la qualité de ses professionnels et avoir impact sur les services de santé. La recherche profonde du système d'accréditation des programmes de résidence médicale du Royal College of Physicians and Surgeons of Canada, par des méthodes ethnographiques, description qualitative et des études de cas, révélé que, au bout, le système brésilien aurait été très semblable au système Canadian. Cependant, il y a la désagrégation de la formation des médecins spécialistes entre la Commission Nationale de Résidence Médical, CNRM, les évaluations des Sociétés des Spécialités Médicales, et de tous les intéressés dans le processus (gouvernement, université, représentation médicale, etc.). Un Projet pilote réalisé par la société brésilienne de neurochirurgie et par la CNRM qui a unifié les critères, a fait des évaluations conjointes et a promue l'intégration de connaissances pour avoir un résultat exemplaire. Le système brésilien n"est pas unifié et indépendant. II ne fonctionne pas très bien parce qu'il n'y a pas de stabilité et de possibilité d'assurer des standards de qualité internationaux. Beaucoup des pays se sont occupés d'étudier a quantité de médecins. Cette préoccupation ne peut pas être responsable pour bloquer le développement et l'étude avec le but d'améliorer la qualité. Le déséquilibre entre quantité et qualité pourrait être une catastrophe pour le futur des professionnels et causer des risques pour la population. Le résultat de cette thèse provient des études et des expériences internationales afin de proposer un modèle pour l'évaluation et l'accréditation des programmes de résidence médical. Cette proposition peut apporter l'équilibre et l'harmonie entre quantité et qualité' grâce à l'unification démocratique de tous ces intéressés.

Descripteurs: enseignement médical; internat et résidence; évaluation de programme; agrément; planification en santé; politique de santé. 


\section{PREÂMBULO: A JORNADA}

Por que a jornada importa?

A jornada importa aqui porque esse percurso pode ser encarado como uma síntese sobre o que significa pesquisa sobre a acreditação (e, talvez, sobre outras estruturas que envolvem políticas e poder).

Esta tese, como todas as outras, precisou da aprovação ética de uma comissão universitária. Como o departamento de Medicina é alocado dentro do Hospital das Clínicas, houve dúvida sobre a responsabilidade de analisar este estudo entre o Comitê de Ética em Pesquisa da Faculdade de Medicina Universidade de São Paulo ou o Comitê de Ética do Hospital das Clínicas. A dúvida foi sanada após apresentação em ambos os comitês e a pesquisa teve sua aprovação ética (anexo 1).

Já que foram utilizados dados do Ministério da Educação e da Comissão Nacional de Residência Médica, a aprovação do Ministério foi necessária (anexo 2).

A Sociedade Brasileira de Neurocirurgia também necessitou dar sua aprovação para que esta pesquisa pudesse ser realizada, uma vez que existem dados e reuniões provenientes dessa instituição (anexo 3).

Parte desta tese foi desenvolvida em colaboração com o centro de educação médica da McGill University e, logo, uma aprovação IRB, Institutional Review Board, (ética) para desenvolver a pesquisa foi necessária (anexo 4). Como parte dos dados em estudos necessitaram de participação no Royal College of Physicians and Surgeons of Canada, RCPSC, sua aprovação e permissão também foram necessárias (anexo 5). 
No caso do RCPSC, uma curiosidade importante aconteceu após as primeiras reuniões do comitê de acreditação do RCPSC. O convite e a autorização para participar foram suspensos. Eu estava muito interessado em uma infinidade de aspectos do processo de acreditação e do sistema. Após algumas sessões entre perguntas e discussões por telefone ou on-line com a equipe RCPSC, a instituição retirou a possibilidade de convite para pesquisadores em geral. Apesar de o motivo não ter sido verbalizado, aparentemente 0 RCPSC percebeu que a presença de um pesquisador dentro de uma estrutura de acreditação poderia mostrar não só para a própria instituição, mas também para o público os pontos fortes, mas em especial os pontos que merecem maior atenção comuns ao processo. O que, naturalmente, pode não ser desejável.

É relevante, no entanto, afirmar aqui que é natural e esperado que todo sistema tenha pontos fracos. Quando não aparentes, eles podem representar perigo, posto que, se ocultos, os responsáveis não poderão atuar na solução deles.

O sistema RCPSC, de maneira geral, tem muito mais pontos fortes do que fracos a serem revelados. Uma vez que concordei com a confidencialidade proposta, as citações capturadas durante as reuniões não puderam ser transcritas nesta tese. No entanto, como acordado com a própria instituição, as reflexões e as impressões que foram fruto da minha pesquisa realizada dentro do comitê de acreditação do RCPSC podem ser usadas, o que foi feito no capítulo referente à esse comitê.

Há mais de sete anos, comecei a fazer avaliações de residência como avaliador da Comissão Nacional de Residência Médica, em seguida, tornou-se consultor do Ministério da Educação para residência médica. Há cerca de quatro anos, esta tese se iniciou com capacitação em Avaliação de Programas, 
Gestão em Saúde, Desenvolvimento e Planejamento de Pesquisas na Universidade de São Paulo. Na época, a tese se chamava: "Impacto do Trabalho conjunto da Comissão Nacional de Residência Médica e das Sociedades de Especialidades Médicas no Brasil: Análise Crítica da Experiência da Neurocirurgia" e tinha como foco apenas o que hoje está nos capítulos referentes ao projeto piloto deste trabalho. O período do doutorado foi certamente de crescimento.

No segundo ano desta tese, mudei-me com minha família para Brasília (na época, éramos minha (corajosa e parceira) esposa, Daniela, minha filha Sofia, com menos de 2 anos de idade, e eu), onde eu poderia estar perto do Ministério da Educação e Saúde (e onde a minha segunda filha, Helena, nasceu). No terceiro ano, mudamo-nos para Montreal, com a intenção de adquirir novas habilidades, especialmente em metodologias qualitativas, e estudar não só o modelo canadense, mas também as perspectivas internacionais de acreditação e avaliação na residência médica.

Aprender diferentes metodologias foi um desafio a ser superado. No entanto, já no início deste estudo, a necessidade de utilizar diferentes metodologias se tornou clara, tendo em vista que um único método não poderia ser suficiente para ter um panorama do que é acreditação e avaliação de programas no campo da residência. Além dos cursos de metodologia quantitativa e qualitativa realizados no Brasil, é preciso ressaltar a competência (e a paciência) de minha orientadora (Profa. Patrô) na USP (e também na vida), os conselhos de Prof. Milton Arruda Martins e os conhecimentos estatísticos do Prof. Itamar Santos. O Prof. Peter Nugus me ajudou muito com bibliografia e a supervisão em Etnografia em Montreal. Minha orientadora da McGill University, a Dra. Linda Snell, auxiliou na descrição qualitativa e no 
conteúdo internacional desta tese. Prof. Marcio Gomes (da Ottawa University) com as observações sobre a medicina no Brasil e no Canadá. Prof. Ian Smith (da Universidade de Lancaster, UK) chamou a atenção para estudar Grounded Theory. Dr. Michael Saraga (da Universidade de Lausanne, Suiça), na Fenomenologia, Bourdieu e Foucault. Prof. David Greenfield (da Universidade MacQuarie, Austrália) me auxiliou a lidar com pesquisas no campo da acreditação. Prof. Robert Whitley me ensinou aplicar métodos mistos. Em cada metodologia de uma forma particular, tive pelo menos uma influência ou apoio (além de minha orientadora) na forma de analisar meus dados.

Esta tese passou a ser composta de cinco estudos (figura 1), que se inter-relacionam para compor o resultado final:

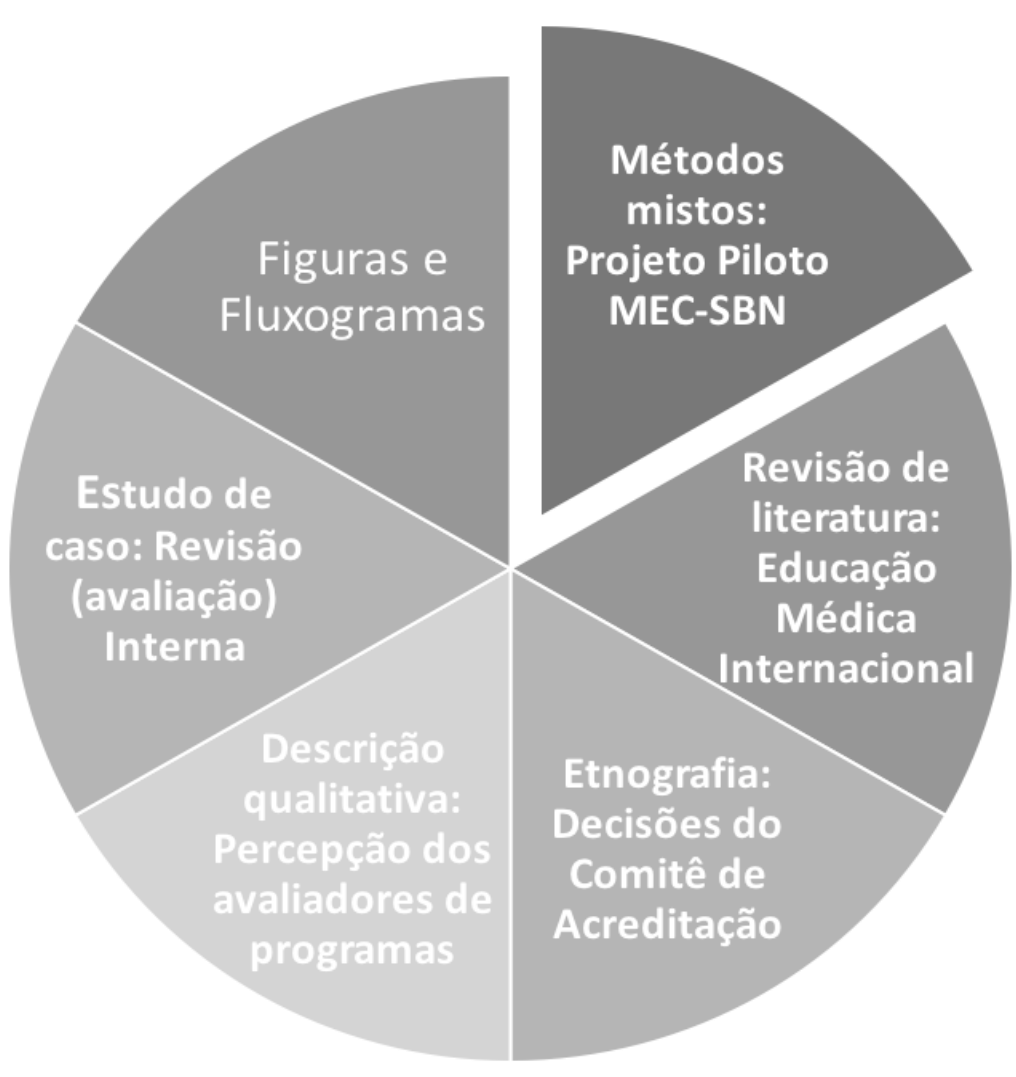

Figura 1 - Componentes da tese 
Os capítulos desta tese abordam:

- O que é: "Acreditação e Avaliação de Programas de Residência Médica" (PRMs)?

- A importância de realizar estudos em modelos internacionais (Educação Médica no Mundo).

- Estudos sobre a acreditação de PRMs no Canadá.

- Residência e especialização médica no Brasil.

- Em busca de aprimoramento: projeto piloto de avaliação conjunta.

- Proposta de um modelo nacional para acreditação e avaliação de PRMs.

É claro que nenhuma metodologia sozinha (ou mesmo diversas delas agregadas) poderia compreender e explicar todas as perspectivas e a complexidade do sistema de acreditação e avaliação de programas de residência médica. A tentativa nessa jornada foi olhar para algumas de suas principais características como processos dentro de um sistema, utilizando lugares e culturas diferentes, a fim de juntar informação suficiente para ser capaz de contribuir com modelos futuros e, quem sabe, melhores dos que possuímos hoje. 


\section{CAPITULO I: SOBRE RESIDÊNCIA MÉDICA, ACREDITAÇÃO E PODER}

\section{Acreditação e Avaliação}

Acreditação vem do latim credere e tem o significado de dar crédito, autoridade ou confiança [1]. Acreditação pode ser entendida como prestação de contas (accountability) e está presente em diversos tipos de instituições e múltiplos campos de conhecimento. Avaliação é parte indissolúvel e integrante do processo de acreditação. Não existe acreditação sem avaliação, mas existem diversas formas de avaliação sem acreditação (ou certificação). Por tratar de conceitos e terminologias comparadas em diversos sistemas e países, mesmo compreendendo as diferenças entre os conceitos neste estudo, ambos serão tratados como sendo (quase) sinônimos. Historicamente, o processo de acreditação foi desenvolvido para auditar e certificar um produto que mantivesse padrões mínimos e resultados desejados [2].

\section{Acreditação na educação superior}

Gerenciamento de "qualidade total", aprendizagem do estudante e acreditação estão necessariamente presentes nos mecanismos de prestação de contas no ensino superior. Nos Estados Unidos, por exemplo, a história da acreditação do ensino superior data mais de 100 anos e nos dias de hoje envolve mais de 80 tipos diferentes de instituições[3]. No modelo norteamericano, a acreditação se baseia em sistemas privados (agências), refletindo 
variadas perspectivas, como as agências de acreditação de caráter religioso, de associação profissional ou de determinada região, entre outras. Muito embora, todas tenham por meta a qualidade acadêmica e a prestação de contas existe grande variedade filosófica e ideológica agregadas às diferentes acreditações. O que poderia não responder às necessidades e aos interesses da sociedade de maneira geral. Nos EUA, o governo abriu discussão sobre a transparência do sistema de acreditação no ensino superior vigente no país [4].

\section{Acreditação na saúde}

Acreditação e avaliação de programas e serviços de saúde não é um campo novo de estudo, no entanto, muito ainda precisa ser feito em termos de pesquisa.

"There have been many calls in the international literature for research into accreditation" [5].

Recente revisão de literatura demonstrou que a relação entre qualidade e acreditação ainda não está bem definida [6]. A avaliação da qualidade em saúde pode ser desmembrada em estrutura, processos e resultados, como na clássica tríade proposta por um dos mais importantes pesquisadores dessa área, Avedis Donabedian [7]. Ainda hoje, essa metodologia é considerada uma das mais importantes e qualificadas para avaliação de programas e serviços médicos[8]. No entanto, o mesmo autor nos adverte quanto à necessidade de crescimento dessa área de estudos.

"We are still in the infancy of the assessment of quality. Much more basic research is needed, especially in measuring health status, and in modelling the clinical decision-making process." [9] 


\section{A educação médica}

A sociedade em que vivemos, assim como a prática médica, estão em constante transformação, por isso, mesmo sendo o estudo e a pesquisa em educação médica um campo bem estabelecido [10], há permanente necessidade de novas pesquisas [11]. Existem revistas científicas especializadas em todo o planeta, como a Medical Teacher, Academic Medicine, Medical Education, Perspectives in Medical Education, International Journal of Medical Education, Medical Education online, Health and Education, e no Brasil a Revista Brasileira de Educação Médica, entre outras. O investimento em pesquisa em educação médica nos diversos países é bastante variado e constata-se associação entre o financiamento e a qualidade das publicações [12], o que nos leva a crer que a qualidade das pesquisas e o conhecimento produzido podem estar relacionados ao grau de investimentos em educação médica.

Assegurar a qualidade é, em grande parte, o foco das pesquisas realizadas no âmbito da avaliação de programas na graduação e pós-graduação médicas. Nesse setor, a clássica avaliação CIPP ("Context, Input, Process and Product") de Stufflebeam [13] se assemelha ao proposto por Donabedian, havendo foco também nos resultados a que o programa se propõe atingir. O curioso é que na residência médica o "produto final" não é nada fácil de avaliar, tornando a tarefa ainda mais complexa e o investimento ainda mais necessário, pois esse "produto" deve ser um "médico competente" [14].

Ao se questionar "A competent physician must be competent to do what? "[9] Donabedian, por exemplo, considera o campo das responsabilidades médicas como complexo e em permanente expansão. Manejar a doença pode 
estar no centro da responsabilidade médica, no entanto, hoje, é de fundamental importância também o conhecimento e a administração da situação cognitiva, qualidade de vida, aspectos econômicos, psicológicos e sociais nos quais aquela condição clínica se insere. Há ainda grande variedade de estruturas, processos e resultados, inerentes de cada especialidade em avaliação.

Avaliação e acreditação na residência médica é um campo complexo. Há necessidade de conhecimento sobre avaliação do ensino superior (pois se trata de segmento de pós-graduação, lato senso), dos serviços de saúde (dada a inseparável ligação entre cenário ou local de prática e processo de formação médica) e do programa em si (especialidade médica). Entre outros elementos, deve-se somar, ainda, a expectativa da sociedade no que se refere ao médico competente [15].

Apesar de muito pouco ter mudado dos conceitos iniciais de Lee e Jones sobre as competências necessárias no setor saúde e do médico competente publicados em 1933, a tarefa ainda continua complexa:

"Good medical care is limited to the practice of medicine that incorporates the basic sciences, emphasizes prevention, requires intelligent cooperation between the lay public and practitioners of science medicine, treats the individual as a whole person, maintains a close and continuing personal relationship between physician and patient, integrates with social welfare work, coordinates all types of medical services, and implies the application of all the necessary services of modern, scientific medicine to the needs of all the people." (Adaptado de [16])

Nestes quase 100 anos, a forma de ensinar mudou consideravelmente e competências, antes presentes apenas no currículo informal ou no currículo 
oculto [17], hoje estão cada vez mais declaradas e presentes no currículo formal, nas metas e nos objetivos da formação de um médico competente. Prova disso é que o rol de competências necessárias para tal vai muito além da técnica e do conhecimento científico disponíveis na literatura médica. Hoje, na formação, pretende-se que o egresso do curso médico e da residência médica sejam capazes de integrar, aos clássicos saberes médicos, habilidades de comunicação, práticas colaborativas, atuem como líder em defesa da saúde, comunicando-se eficazmente com a equipe de saúde, pacientes e familiares, portando-se de modo científico e profissional ("professional, communicator, collaborator, leader, health advocate and scholar") como nas conhecidas CanMeds [18, 19], tendo por meta aprimorar o atendimento à sociedade na qual se insere, conforme figura a seguir, transcrita da literatura original [20]:

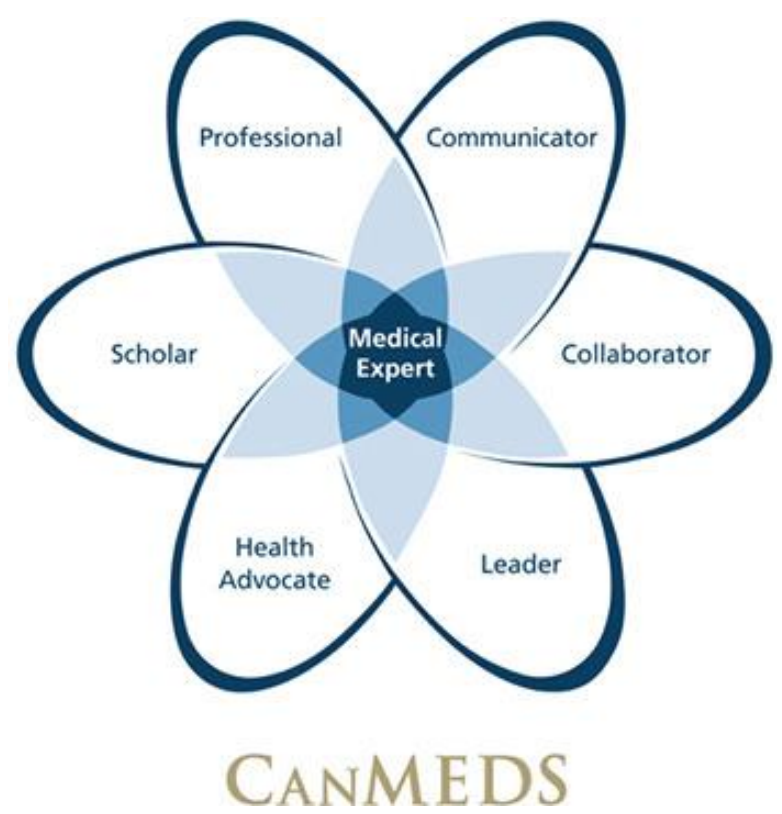

Figura 2 - CanMeds 
Realizar acreditação dos programas de residência médica em um cenário de constantes transformações e fundamentando-se nos conceitos inovadores é, inevitavelmente, cada vez mais complexo.

As pesquisas encontram ainda dificuldade em comprovar a ligação entre acreditação e a qualidade oferecida no ensino ou pela prática médica (ambos presentes na residência médica).

"To the best of our knowledge there are no data linking quality of physician practice to the accreditation status of the medical school attended." [21]

"There is limited evidence of direct linkages between accreditation of graduate medical education and patient outcomes." [22]

\section{Acreditação e poder}

Na obra de Pierre Bourdieu [23], o poder se manifesta muitas vezes por meio de símbolos, emanados de determinada cultura, posicionando o indivíduo dentro ou fora de seu campo (ou classe). Pequenos sinais emitidos nas relações sociais, afetivas, econômicas, entre outros, posicionam o sujeito em determinada classe, por exemplo.

Os "símbolos do poder" podem ser aprendidos desde a infância na maneira de se portar em um cenário específico, como um museu. Os pares, inicialmente pertencentes à família, e a seguir escola, vizinhança ou profissão, ensinam e reforçam tal comportamento. Expressar esses símbolos, nem sempre fáceis de serem compreendidos ou identificados, é o que permite ao indivíduo de cultura dominante (ou erudito) exercer poder de maneira invisível, impondo um modo de se comportar ao outro, externo à cultura dominante [24]. 
Um exemplo utilizado pelo autor é a diferença arbitrária e intangível entre o artesão e o artista, ou entre a produção erudita dedicada aos conhecedores de arte e a produção da indústria da arte, direcionada à população em geral.

Efeito semelhante pode ser entendido ao se distinguir instituições acreditadas ou não acreditadas. Acreditação não é um item concreto, ao contrário, trata-se de um bem simbólico. É preciso ter crença, ou seja, firme convicção, além de estar inserido em determinado campo para dar fé à sua validade.

Existe um efeito imediato de respeitabilidade e de poder proveniente de um "selo de acreditação", que inspira confiança e segurança na população àquele que obedeceu e se adaptou (submeteu-se) à acreditação.

Ainda que as pesquisas não sejam capazes de atestar o impacto direto na qualidade do produto no setor saúde [6], a existência de acreditação por si só é capaz de alterar, positivamente, comportamentos e atitudes em uma instituição, por intermédio do mesmo mecanismo de poder [25]. Não há dúvidas de que o elemento invisível, de vigilância, disseminado e presente na acreditação [1], é o poder.

Michel Foucault identifica a presença de poder na medicina [26], no trabalho e na educação, campos indissolúveis e intrínsecos à existência da residência médica. Segundo o mesmo autor, as relações de trabalho no capitalismo, desde o início do século XIX, transformam o corpo do trabalhador em força de trabalho, como meio de supressão da condição de individuo, transformando-o em parte de um coletivo, uma massa, sob a qual o poder pode ser exercido. Segundo o autor, a medicina pode ser uma estratégia biopolítica, quando pensada enquanto medicina social, para exercer poder sobre os sujeitos, com leis inquestionáveis e de obediência incorporada, ditadas, por 
exemplo, pelas políticas de bem estar social [27]. Um bom exemplo são as normas provenientes de resultados científicos as quais todos se submetem. Estas se apresentam ditando o comportamento humano e alterando o que se deve fazer para se manter saudável. Devemos ressalvar aqui que o exercício de poder não é necessariamente negativo ou positivo sobre a vida de cada um, mas definitivamente presente. Por isso, é fundamental ser considerado e apresentado como existente nesse tipo de pesquisa. Um exemplo atual é a mudança de comportamento, talvez global, em relação ao uso de tabaco, em locais públicos. O que antes poderia ser considerado um ato de elegância hoje foi incorporado como prática incômoda que compromete a saúde do outro, havendo pressão de constrangimento.

Exemplos de identificação da existência de poder nessas relações são comuns; há muito se discute as relações de poder do médico sobre o paciente[28]. Conforme tratado por vários autores, com destaque para Paulo Freire [29], outro exemplo está na função da educação como meio de manutenção da ordem social e "adequação" do sujeito à sociedade em que vive (função esta, curiosamente, também exercida pela psiquiatria) [30].

\section{Discussão}

Nesse contexto de permanentes mudanças, ampliação da complexidade de responsabilidades, incremento de competências do produto final (médico competente) dentro de múltiplas relações de poder é que se insere a acreditação da residência médica. 
É indubitável que mecanismos externos, que possam padronizar critérios e assegurar qualidade, são necessários e a acreditação é a ferramenta primária para busca da qualidade nesse setor [25, 31].

Este capítulo reconhece que a acreditação, muito além de uma avaliação simples, é um sistema complexo no qual o entendimento da noção de poder existente e atuante é peça-chave para a compreensão de seu funcionamento.

A avaliação de programas de residência médica e, em especial, a acreditação, traz benefícios na padronização de critérios e parâmetros, aumentando a qualidade e a confiança das instituições e dos programas de educação em saúde.

No entanto, o exercício do poder deve ser moderado. Quando em excesso, o poder da acreditação é capaz de atrair tamanha importância para si próprio que pode desviar a atenção do objetivo central do programa (formar médicos competentes) para responder aos anseios da avaliação [32], possibilitando ou até mesmo causando prejuízos nos aprendizes [33] e supervisores do programa [34].

A ausência de acreditação independente, no entanto, leva à "escuridão total" do que está ocorrendo nas instituições, na formação dos médicos e nas práticas em saúde. Consequentemente, há algum tempo, diferentes nações discutem métodos globais de acreditação, em diversas etapas da formação médica, na busca de assegurar qualidade[35]. Sem acreditação é impossível conhecer e comparar a formação ofertada em cada país, sua preocupação com a qualidade nos aspectos educacionais e de saúde nem mesmo o seu resultado final: formar um médico competente. 


\section{CAPÍTULO II: EDUCAÇÃO MÉDICA NO MUNDO}

Para realizar este estudo de concepção internacional dos processos de acreditação e avaliação da residência médica foi preciso buscar e entender o significado dado por diferentes países para cada palavra. $O$ que significa graduação em medicina, pós-graduação, internato e residência médica por vezes difere entre países.

Neste capítulo buscamos estudar educação médica de países bastante diferentes, espalhado pelos cinco continentes do mundo visando entender 0 que pode significar formar um médico.

\section{A importância das concepções internacionais}

Um grande número de lições pode ser aprendido e, principalmente, erros podem ser evitados ao se estudar, comparar e talvez aplicar (com adaptação cultural) modelos internacionais. Como exemplo, podemos citar a importante discussão sobre a restrição de carga horária dos médicos residentes nos EUA [36-39]. Enquanto os norte-americanos ainda debatem o impacto na formação de uma carga de 80 horas semanais na residência médica, a Europa forma médicos especialistas considerados, equivalentemente, competentes em um sistema bem definido pelo "European Working Time Directive" (Council Directive 93/104/EC 1993), de jornada não superior a 48 horas semanais de trabalho em serviço.

"North America and Europe differ quite a bit in working hour restrictions for residents. The USA recently issued a maximum of 80 hours a week, whereas the European regulations call for no more than 48 hours a week. Nevertheless, even with this smaller 
number - still far over the usual 38 hours work week of regular employees - reports of stress among clinical residents keep appearing in the media (Van der Heijden et al. 2007)." [40]

Os debates no caso de restrição de horas para os médicos residentes são tão diferentes quanto interessantes. Alguns países, como a Holanda, discutem redução para 38 horas semanais na residência médica, pois seu foco vai além do serviço prestado, preocupando-se com a pessoa do médico residente.

"The debate focuses, on one hand, on the question how to train residents well enough with fewer hours, and on the other hand, on whether residents should have a regular family life. As the new generation of residents is now predominantly female, requests for even fewer hours or part-time residency training are heard more and more often." [40]

Para além da preocupação com questões socioculturais e de transformação da prática médica (ex: maior número de mulheres na profissão), mais evidências têm sido agregadas a respeito do prejuízo no desempenho de indivíduos cansados. Estudo recente demonstra lapsos de informação clínica por fadiga mental [41].

Outros debates exemplares estão no número de escolas médicas de um país, na velocidade de expansão, ou de quantos estudantes uma escola de medicina é capaz de treinar.

A maior parte dos países concretiza esforços conjuntos em torno de definições sobre o número de médicos ou alunos de medicina, indo muito além da simplista relação de médicos por habitantes (demografia) [42]. A maior parte dos países opera com alguma forma de controle sobre as escolas médicas e sobre o número de alunos de medicina em cada escola. Em busca da 
qualidade na formação, diferenças nos cenários de prática, estratégias de ensino e aprendizagem, investimento em currículo, existência de departamentos de educação médica no organograma da escola, entre outros fatores, podem impactar e ser impactados pelo número de estudantes. No entanto, novamente Europa e EUA também diferem, nesse ponto.

"Most of the medical schools in Europe give admission to less than 200 students per year (53.4\%) (Patricio 1999), while in the USA the average number of admissions per school is of 132 in public universities and 127 in private ones (Barzansky \& Etzel 2005).“ [43]

No caso do Brasil, apenas a Índia possui número um pouco maior de escolas médicas (país que possui cerca de cinco vezes mais habitantes que o Brasil) [44]. O país já superou há muito o número de escolas médicas dos EUA, país onde há, pelo menos, 100 milhões de habitantes a mais. O governo brasileiro planeja expansão maior e mais rápida para atingir metas baseadas em número de médicos/habitantes [45]. O conhecimento de histórico internacional, incluindo os EUA, revela que tentar uma rápida expansão de escolas médicas, para fins de provimento pode levar a resultados trágicos. Há mais de 100 anos, tentativa semelhante resultou no que ficou conhecido como o período de "trevas" da educação médica norte-americana [46].

Diversos países têm realizado mudanças em seus currículos e no controle sobre os números de escolas médicas e graduandos em medicina. As transformações e as reformas no campo da educação médica têm sido bastante rápidas nos últimos anos [47].

Inicialmente, apesar de haver muitas divergências entre os especialistas na área, a necessidade de médicos[48] e a percepção da falta de profissionais 
de saúde[49] desempenham papel importante nesse momento histórico de decisões sobre a formação, suscitando acordos internacionais para controlar o fenômeno de brain draining, que trata da atração de médicos para localidades e países com maior desenvolvimento [50-52]. O intuito é o de planejar o futuro da atenção à saúde de determinada população. Não há dúvidas de que existe importante função da escola médica no que se refere ao número e à qualidade dos profissionais de um sistema de saúde [53].

A variação da duração dos cursos de medicina é outro exemplo das diferenças e similaridades entre os países. Em alguns lugares, como nos EUA [54] e no Canadá, a escola médica abrange apenas quatro anos, no entanto, o acesso à escola de medicina ocorre a partir de um curso anterior (undergraduation, com duração geralmente entre dois e quatro anos), podendo variar amplamente, desde linguística até biologia, o que torna a tarefa de equilibrar o conhecimento dos estudantes em quatro anos um desafio bastante complexo. Na Austrália [55], Irlanda [56] e Holanda [40], o curso médico varia de quatro a seis anos dependendo, ou não, de uma graduação anterior. $\mathrm{Na}$ Holanda, por exemplo, biomedicina é o único curso aceito como pré-requisito para que a formação em medicina ocorra em apenas quatro anos. O Vietnã [57] também possui cursos que variam de quatro a seis anos. Quase todos os estudantes classificados para ingressar na graduação em quatro anos são assistentes de médicos (medical or physician assistants), profissão, atualmente, inexistente no Brasil. No caso de Bangladesh [58], Índia [44], ou Quênia [59], medicina é um curso de cinco anos e na, Suécia [60], o curso abrange cinco anos e meio. Em Taiwan [61], para formação do médico (antes da entrada na residência) são necessários sete anos e no Equador [62] seis 
anos ou sete anos, dependendo da instituição de ensino. No entanto, a maior parte dos países do mundo, para formação do médico, segue a regra de um curso de medicina de seis anos de duração, antes da entrada na residência [43, 63-71]. Há ainda intervalo entre o período de graduação e o início da residência médica, que em muitos países varia de um a dois anos e inclui algum tipo de trabalho social ou rural [56, 67-70].

Durante a reforma do sistema de saúde na Albânia, a educação médica também se transformou. O currículo contemplando, largamente, o conteúdo em medicina de família pôs fim à necessidade de residência médica nessa área, aumentando em muito o número de médicos que se dedica a essa especialidade no país, que ainda está organizando a regulação do número de médicos e das especialidades necessárias [65].

A Austrália possui grande tradição na pesquisa em educação médica, campo bastante desenvolvido no país [72, 73]. Apesar disso, a pesquisa nesse setor ainda é considerada em desenvolvimento. Existem 28 escolas médicas e possibilidades de graduação pelo método britânico (curso de seis anos) ou americano (quatro anos). O período de internato (no curso de seis anos) é de um a dois anos e inclui um período de trabalho social. A chamada clínica rural, ou o trabalho com saúde indígena, são prioridades, na atualidade, para 0 sistema de saúde, o que tem fomentado programas (e currículos) baseados em tais necessidades [55].

Bangladesh possui cerca de 40 escolas médicas, 15 públicas e 25 privadas. Como nas demais localidades do mundo, devido aos altos custos dos cursos privados, estes ficam limitados às classes mais abonadas do país. As escolas públicas são subsidiadas pelo governo e mantidas a um custo mínimo. 
O país adotou a estratégia de currículos que se baseiam em metodologias inovadoras, centrada no estudante, utilizando estratégia de aprendizagem fundamentada em problemas, sistêmica e integrada, com foco na comunidade e empregando estágios eletivos, na sigla em inglês: SPICES (Student Centered, Problem Based, Integrated, Community, Elective and Systematic) [74]. O período de um ano de internato não é considerado parte da graduação. A formação especializada é controlada pelo Bangladesh College of Physicians and Surgeons (BCPS), concedendo titulação com denominação variada ao final, as especialidades médicas formam os doutores - MD (Medical Doctors), enquanto as cirúrgicas, os mestres - MS (Master of Surgery). Tais pósgraduações apresentam duração média, geralmente, de cinco anos.

Equador tem 19 escolas médicas, sendo que apenas 12 oferecem programas de residência médica. Cinco são inteiramente privadas e outras cinco são privadas, mas subsidiadas. O currículo de medicina é composto por dois ciclos (científico e clínico), incluindo dois meses e meio de internato. O sistema prevê ainda um ano de estágio rural para obtenção da licença de médico. Após esse período, seguem-se cerca de três anos de residência médica [62].

Nas 35 escolas médicas da Alemanha, os cursos têm seis anos de duração, todos iniciando com ciências básicas. Os diversos currículos atingem o período clínico em momentos diferentes da graduação. Visando assegurar a qualidade do ensino médico no país, dois exames nacionais são aplicados ao longo do curso. O primeiro é aplicado no terceiro ano, abordando os conteúdos de ciências básicas e clínica. No quinto ano, um novo exame, com conteúdo clínico especializado, é realizado antes da entrada no internato, cuja duração é 
de um ano. A pós-graduação (residência médica) não se baseia no modelo de bolsa de estudos, mas de emprego médico supervisionado (junior doctors). O sistema de formação e especialização médica se concentra na soma de 250 pontos que o jovem médico deve atingir ao longo de um período mínimo prédeterminado (cinco anos), de modo variável e individual. Esses pontos podem ser obtidos de diversas maneiras, em estratégias "pessoais" de aprendizagem como workshops, conferências etc [63].

"In contrast to other countries, postgraduate training in Germany is not attached to academic centres. Both content and duration are unstructured and training is primarily the responsibility of the trainee" [63]

A história do ensino médico na Grécia data dos tempos de Hipócrates, quando a medicina era ensinada sob a sombra de uma árvore platanus orientalis. Local onde surgiu a famosa escola médica de Kós. Modernamente, porém, esse ensino é oferecido em sete escolas médicas, todas públicas, e que oferecem não apenas o ensino gratuito em sala de aula, mas até mesmo os livros necessários à formação são considerados parte integrante do ensino e disponíveis de modo gratuito a todos os estudantes. O país também adota um ano de trabalho social ao término da graduação, após o qual se iniciam os programas de residência médica, que variam de quatro a sete anos [69].

A Índia possui o maior contingente de escolas médicas do mundo. Os números e o modo de expansão são preocupantes. De 156 escolas, sendo 2/3 públicas, o país "pulou" nos últimos 20 anos para 381 escolas, das quais 205 são privadas. Hoje, mais de 50 mil estudantes de medicina são admitidos 
anualmente e 22.349 ingressam na pós-graduação. Não há dúvidas que tamanha transformação causou e vem causando impacto na formação[75].

"The trend of privatization creates unhealthy competition, poor infrastructure, a shortage of teaching faculty, and subsequently generates incompetent medical graduates, with poor scholastics and practical skills. ... The Medical Council of India (MCl) has addressed the matter of faculty shortage by increasing the age limit of retirement, relaxing teacher to student ratios, reducing the requirement for teaching experience and the need for recognition of foreign national's qualification and degrees before their appointment as faculty" [44]

Na Índia, depois de graduado, o jovem médico tem a opção de realizar o estágio rural, cuja duração de dois anos pode render $5 \%$ de acréscimo na nota para admissão em uma pós-graduação no país.

Das 80 escolas médicas existentes no Japão, 29 são privadas. Após os seis anos de graduação, o jovem médico deve fazer dois anos de "residência médica geral" em hospitais de ensino e comunitários, antes de poder ingressar na formação em uma especialidade médica [64].

A Jordânia possui quatro escolas de medicina, todas públicas. Cada uma delas permite a entrada de menos de 200 estudantes de medicina por ano. Esse teto numérico visa garantir qualidade seguindo os números utilizados nos EUA e na maior parte dos países da comunidade europeia [43]. Não é incomum que os médicos graduados na Jordânia realizem testes para poder praticar medicina nos EUA (United States Medical Licensure Examination, USMLE), obtendo bons índices de desempenho naquelas provas.

O Quênia possui um índice de 0,17 médicos por mil habitantes, existem três escolas médicas no país, sendo duas recentemente abertas. A estratégia 
de abertura de novas escolas tem resultado em um grande fluxo de emigração dos médicos formados para praticar medicina em outros países, ou saindo do setor público e das universidades para o setor privado [59].

"Reasons for migration can vary from financial remuneration to an unsatisfactory working environment, such as over congestion in classes, increased workload, poorly equipped and maintained teaching hospitals and reduced opportunities for research "[76]

Não é incomum que um país que não dedica atenção ao trabalho médico desperdice recursos para formar profissionais que irão praticar medicina em outros países.

O Kosovo [68], por exemplo, é o mais pobre e jovem país da Europa, suas escolas médicas estão adequadamente enquadradas no tratado de Bologna, mas as oportunidades para pós-graduação e as condições de trabalho e emprego causam fluxo de emigração para o oeste europeu, onde o profissional encontra melhores oportunidades em sua carreira. Aparentemente, não há razoabilidade em formar médicos para exportá-los para outros países. Se não houver um contra fluxo financeiro, como ocorre no caso de Cuba, que possui um corpo de médicos designados especificamente para praticar medicina no exterior a serviço do próprio país, torna-se difícil compreender o descuido interno dos países nas condições de trabalho e de oportunidades de pós-graduação.

Até os anos 1970, não havia escolas médicas na Líbia. Duas foram criadas àquela época e nos anos 1990 também foi utilizada a estratégia de rápido aumento do número de ingressantes. Hoje, a Líbia tem dez escolas médicas e o número de estudantes admitidos saltou de 50/escola para mais de 
1.000/escola. Os resultados dessa estratégia, no entanto, repetem-se. Aliado à falta de atenção ao mercado de trabalho o país vem observando e sofrendo com o aumento de fluxo emigratório [77].

"It is therefore estimated that $8.9 \%$ of all Libyan physicians are practicing outside Libya" [78]

Na Palestina, existem quatro escolas médicas. Todas elas possuem currículos semelhantes, havendo um primeiro ciclo pré-clínico com três anos de duração e um segundo ciclo, clínico, com mais três anos. Depois de graduado, o médico pode optar por realizar internato ou ir diretamente para um programa de residência médica, que possui duração de quatro a cinco anos, dependendo da especialidade[66].

Nas 12 Universidades que oferecem curso de medicina na Polônia, o curso tem seis anos de duração e é sucedido por um ano de trabalho social, para só então se pleitear ingresso em programas de residência médica, cuja duração varia bastante, de um mínimo de quatro, podendo a chegar aos dez anos. Dependendo da especialidade, o acesso será direto ou ocorrerá em dois ciclos, por meio de pré-requisitos. Um primeiro ciclo básico (clínica medica, cirurgia geral, entre outros) e um segundo ciclo especializado (cirurgia pediátrica, cirurgia torácica etc.) [67].

Apesar do rápido aumento do número de escolas médicas na Arábia Saudita, que, atualmente, possui 31 cursos de medicina, o país tem investido em qualidade e mantido fortes relações com diversos outros países para melhoria constante do ensino. Sua alta capacidade de investimento em 
pesquisa e na qualidade das instituições tem resultado na produção e na incorporação de avançado conhecimento no campo do ensino médico[79].

A Espanha manteve públicas 26, das 28 escolas médicas, e hoje todas possuem sistemas similares seguindo a declaração de Bolonha. Nos anos 1970, no entanto, o país também utilizou a estratégia de aumento rápido do número de escolas médicas com consequências que perduram até os dias atuais. O resultado da política foi a inconsistência entre o ensino médico e a prática da medicina no país, falta de homogeneidade e perda dos objetivos de formação, emigração e declínio do prestígio e reputação da profissão, na sociedade.

"One important point to establish is whether or not the number of students admitted to Spanish Medical Schools should be increased. A $6 \%$ rise in admissions has been recorded in each of the last two years. This is a controversial question; though numbers of doctors are low in some specialties, many Spanish doctors migrate to other European countries where salaries are higher."[71]

Na Suécia, a graduação é atualmente de cinco anos e meio de duração, no entanto, seguindo a declaração de Bolonha, o país vem estudando adequação para seis anos, facilitando a mobilidade internacional. O internato tem duração de um ano e meio e diferentemente de outros países é oferecido pelo County Council [60].

A medicina tradicional tem espaço no mundo acadêmico e é ensinada em cursos de graduação com duração de cinco anos em Taiwan. Além destas, 12 escolas médicas oferecem cursos de medicina nos moldes ocidentais sob forte influência desses países. A formação do especialista é gerenciada pelas sociedades de especialidades, com programas variando entre dois anos 
(medicina de família) até seis anos (neurocirurgia) de duração. O sistema de saúde local mantém cuidadosamente o equilíbrio, regulando o número de médicos e estudantes de medicina, ao redor do objetivo de um número em 1.7 médicos/1000 habitantes. Outro ponto de atenção é manutenção de convivência harmoniosa entre a prática de medicina tradicional chinesa, com as mais modernas técnicas, práticas e evidências da medicina ocidental [33, 61].

A Holanda é conhecida pela modernidade de sua sociedade e projetos. Também na educação médica a Holanda se apresenta como um país avantgarde, em relação à maioria do planeta.

"Medical Education in the Netherlands is a dynamic field"[40]

Em vez de utilizar estratégias quantitativas na produção de médicos, a Holanda vem se ocupando nas últimas décadas com a qualidade do ensino e da formação. As reformas no ensino médico começaram na década de 1980. O alto investimento e nível das pesquisas se refletem em diversos avanços nesse campo. Os pesquisadores dessa área estão constantemente repensando e publicando importantes trabalhos em revistas internacionais, os quais versam desde a admissão do estudante em um curso de medicina, passando pelo ensino centrado no estudante, avaliação, papel das ciências básicas, ensino por competências, ensino em pequenos grupos, uso da telemedicina, a residência médica, o médico residente, entre muitos outros projetos [47, 80].

O Vietnã possui 12 escolas médicas. O curso tinha seis anos de duração, porém, em resposta à falta de médicos de família, o país optou pela estratégia de instituir também os cursos de quatro anos de duração. No entanto, para frequentá-los os estudantes ingressantes já são, geralmente, "assistentes médicos" (medical assistants). A residência médica tem função e 
status particular no país, não é universal, mas destinada a um seleto grupo de egressos.

"Unlike in the USA, Resident Physicians are expected to become experts in not only clinical practice but research as well. Vietnamese residents are also expected to become medical school faculty following completion of their residency training. Therefore, residency training is highly competitive and only available to a small number of students with outstanding credentials" [57].

Nos EUA, existem 146 escolas médicas alopáticas [81] e 31 de medicina osteopática [82]. Após o ensino médio, o estudante deve completar qualquer curso de (pré) graduação com, geralmente, quatro anos de duração. No caso dos estudantes que optam pela (pré) graduação em ciências, os últimos anos podem ser também contados como os primeiros do curso de medicina. Medicina é um curso de quatro anos divididos em dois de ciências básicas (ou pré-clínicas) e dois de ensino em clínicas nos cursos tradicionais. Muitas escolas estão mudando seus sistemas de ensino para exposição dos estudantes, à experiência na clínica, desde o início do curso. Particularmente nos EUA o primeiro ano de residência ( $P G Y 1)$ é também chamado de internato. Depois do primeiro ano (PGY2) em diante são chamados de residentes, por um período bastante variável de tempo, dependendo da especialidade e subespecialidade desejadas.

"Currently, there are 93,000 residents training in 4100 programs and 18,000 fellows training in 4800 programs [83]. Residents are paid a salary and nearly all programs are at least partially publically funded." [54] 


\section{Discussão}

Até setembro de 2014 existiam no mundo 2409 escolas médicas reconhecidas e funcionando em 180 países[84]. Nelas estão presentes uma grande variedade de modelos de formação dos futuros médicos. Diversos fatores devem ser considerados para poder comparar a educação médica ministrada no mundo. Até mesmo a linguagem e o significado de uma mesma terminologia (internato, por exemplo) difere entre os países. Esses fatores vão influenciar a organização das escolas médicas, as competências necessárias para a prática médica, os modelos de pós-graduação e de formação, tanto do médico generalista quanto do especialista, moldando os processos de acreditação da pós-graduação lato senso (residência médica).

Cabe ressaltar que o conceito ou o significado do indivíduo que será explicado pela etimologia da palavra médico deve derivar da mesma construção de conteúdos no mundo. Esse mesmo "agregado" de informações e

vivências deve ser semelhante em qualquer parte do mundo para que a denominação "o médico" tenha o mesmo significado. 


\section{CAPÍTULO III: LIÇÕES APRENDIDAS COM MODELOS DE ACREDITAÇÃo DA RESIDÊNCIA MÉDICA NA AMÉRICA DO NORTE}

\section{Lições do modelo de Acreditação da Residência Médica nos EUA (Accreditation Council for Graduate Medical Education- ACGME)}

Nos EUA, a residência médica é acreditada pela ACGME (Accreditation Council for Graduate Medical Education). Essa agência funciona de maneira independente e possui a missão de responder às necessidades da sociedade, dos 9.500 programas de residência e fellowships existentes e das 693 instituições responsáveis pelos programas. Destas, 262 instituições são responsáveis por um único programa e 431 são responsáveis por múltiplos programas. Cerca de 27 mil novos residentes ingressam nos diversos programas de residência médica, todos os anos [85].

Recentemente, foi lançado o chamado "The Next Accreditation System" que pretende evoluir, de um modelo baseado em critérios mínimos, para um sistema de melhoria continua da qualidade; deixando um modelo focado no processo, para um modelo centrado no resultado [86].

Buscar constantemente assegurar qualidade aos programas de residência médica não é tarefa fácil nem tão pouco possível sem investimento, organização e seriedade. Os custos administrativos para a manutenção do sistema gerenciado pelo ACGME giram em torno dos 40 milhões de dólares por ano. Aproximadamente $80 \%$ desse valor é custeado pelas instituições que 
recebem a acreditação (Tabela 1). Salários, benefícios, organização do serviço e viagens são responsáveis por $72 \%$ das despesas anuais.

Tabela 1 - Planilha de custos para gestão dos PRMs nos Estados Unidos por meio da Accreditation Council for Graduate Medical Education discriminando ações e valores correspondentes

\begin{tabular}{|c|c|c|c|c|c|}
\hline $\begin{array}{l}\text { Receitas } \\
\text { (Revenues) }\end{array}$ & $\begin{array}{c}\text { Dólar } \\
\text { americano } \\
\text { (\$) }\end{array}$ & $\begin{array}{l}\text { Percentual } \\
\text { relativo ao } \\
\text { custo total }\end{array}$ & Despesas & $\begin{array}{c}\text { Dólar } \\
\text { americano } \\
\text { (\$) }\end{array}$ & $\begin{array}{l}\text { Percentual } \\
\text { relativo ao } \\
\text { custo total }\end{array}$ \\
\hline $\begin{array}{l}\text { Taxas dos } \\
\text { Programas de } \\
\text { Residência }\end{array}$ & $35,693,450$ & $78.8 \%$ & $\begin{array}{l}\text { Recursos } \\
\text { Humanos }\end{array}$ & $21,304,141$ & $54.0 \%$ \\
\hline $\begin{array}{l}\text { Conferencias } \\
\text { e Workshops }\end{array}$ & $2,574,598$ & $5.7 \%$ & $\begin{array}{l}\text { Reuniões e } \\
\text { Viagens }\end{array}$ & $7,122,182$ & $18.1 \%$ \\
\hline $\begin{array}{l}\text { Taxas de } \\
\text { Inscrição }\end{array}$ & $1,821,450$ & $4.0 \%$ & Depreciação & $2,974,445$ & $7.6 \%$ \\
\hline $\begin{array}{l}\text { Lucro Livre de } \\
\text { Investimento }\end{array}$ & $4,496,039$ & $9.9 \%$ & $\begin{array}{l}\text { Serviços } \\
\text { Gerais }\end{array}$ & $3,413,976$ & $8.7 \%$ \\
\hline $\begin{array}{l}\text { Receita de } \\
\text { Aluguel }\end{array}$ & 439,974 & $1.0 \%$ & $\begin{array}{c}\text { Serviços } \\
\text { Profissionais }\end{array}$ & $3,022,245$ & $7.7 \%$ \\
\hline Outros & 247,776 & $0.6 \%$ & $\begin{array}{c}\text { Outros, } \\
\text { suprimentos } \\
\text { e utilidades }\end{array}$ & $1,533,573$ & $3.9 \%$ \\
\hline $\begin{array}{l}\text { TOTAL DE } \\
\text { RECEITAS }\end{array}$ & $\$ 45,276,287$ & $100.0 \%$ & $\begin{array}{l}\text { Total de } \\
\text { Despesas }\end{array}$ & $\$ 39,370,562$ & $100.0 \%$ \\
\hline
\end{tabular}

De acordo com tal perspectiva, o ACGME lançou o programa "Caminhos para a Excelência" (The CLER Pathways to Excellence) dentro do Clinical Learning Envorimental Review - CLER committee. Esse comitê é formado por especialistas nas áreas de educação médica, segurança do paciente, qualidade em atenção à saúde, controle de fadiga e administração hospitalar. Além desses especialistas, o comitê inclui membros da sociedade, com conhecimento de políticas e de organizações de pacientes. O programa une diversas expectativas para otimização do ambiente clinico de ensinoaprendizagem. Seis áreas focais são definidas no programa: 
- segurança do paciente;

- qualidade dos serviços de saúde;

- transição do cuidado;

- supervisão;

- carga de trabalho (e sua relação com a fadiga e mitigação);

- tópicos em profissionalismo.

A organização, independência, estabilidade e trabalho desenvolvidos pela ACGME conferem à instituição o poder, por meio da credibilidade, necessário para tornar a acreditação realizada por ela um "rótulo de distinção". Prova disso está no crescimento da acreditação internacional realizada pela instituição.

Em sua divulgação, a missão centrada na qualidade na busca "dos mais altos critérios" fica clara. [87]

Entre os benefícios listados da acreditação no ensino médico estão: profissionalismo; aprendizagem pela experiência; responsabilização gradual; relevante responsabilidade do paciente unida à supervisão especializada; incremento das avaliações formativas com melhora da prática pelos residentes; equilíbrio entre prática clínica e prática educacional; cuidados com o paciente e educação baseadas em equipes; aprendizagem por meio das responsabilidades para os subordinados; estruturação dos cenários de prática; segurança do paciente; aprendizagem baseada em competências; práticas orientadas nos resultados; responsabilidade compartilhada para obter resultados; integração do continuum na educação médica; ênfase na medicina baseada em evidências e prática médica deliberada; desenvolvimento de médicos cientistas e talentos em pesquisa para o país. 


\section{Lições do modelo de acreditação da residência médica no Canadá (Royal College of Physicians and Surgeons of Canada - RCPSC)}

\section{Histórico}

A avaliação e a acreditação dos programas de residência médica no Canadá competem ao Royal College of Physicians and Surgeons of Canada RCPSC, desde 1923, quando o parlamento transferiu aos médicos a avaliação, inicialmente de dois programas, Cirurgia e Medicina [88]. Atualmente, o RCPSC é responsável por acreditar e certificar 55 especialidades e subespecialidades médicas. A única exceção é a Medicina de Família que possui estrutura separada de acreditação, sob responsabilidade do College of Family Physicians of Canada - CFPC [89].

No início, a estratégia foi avaliar os residentes, ao final do programa. Tal estratégia de avaliação do "produto da residência" rapidamente se mostrou insuficiente e incompleta, ficando claro para o RCPSC que os locais de treinamento e programas em si também precisavam ser avaliados, de acordo com critérios unificados e comparáveis. Essa mudança transferiu o foco da avaliação, de apenas o residente, para toda a residência, aumentando sobremaneira a complexidade da tarefa [89].

\section{Estrutura}

$\mathrm{Na}$ atual estrutura, as Universidades desempenham papel primordial na residência médica. Mais do que a instituição que oferece um programa, a universidade é ainda uma parceira e "coguardiã" dos programas. No Canadá, 
não existe programa de residência médica que não esteja sob a responsabilidade de uma Universidade.

A solicitação de uma Universidade ao RCPSC é o primeiro passo para avaliação e acreditação de um programa de residência médica. Assim que recebida pelo RCPSC, este passa as informações com questionamentos aos comitês de especialidades médicas. O comitê de especialidades médicas congrega professores, preceptores, especialistas, de cada especialidade em um comitê específico (ex: comitê de radiologia, de psiquiatria, de neurocirurgia etc.) com intuito de observar as necessidades peculiares da formação de cada especialista.

O comitê de especialistas devolve para o RCPSC as informações comentadas.

$\mathrm{Na}$ Universidade, o diretor do programa de residência médica em análise começa a responder a uma série de formulários, relativos aos critérios (standards) de acreditação. Os chamados A-Standards são critérios bastante gerais, aplicados a todos que ofertam programas de residência, às universidades e aos locais afiliados [90]. Os B-Standards são critérios um pouco mais específicos, sendo exemplos do tipo de preocupação do sistema de acreditação canadense [91], conforme se observa na tabela 2, que mostra os critérios padronizados A e B. 
Tabela 2 - Critérios Padronizados (Standards) do RCPSC e do CFPC A e B

A - CRITÉRIOS Padronizados - Standards

- A1 Estrutura da Universidade

- A2 Locais para Educação Médica Pós-graduada

- A3 Liga (relacionamento) entre a Universidade e os locais participantes

B - CRITÉRIOS Padronizados - Standards

- B1 ESTRUTURA ADMINISTRATIVA - Deve haver uma estrutura administrativa apropriada para cada programa de residência

- B2 METAS E OBJETIVOS - Deve haver um regulamento escrito estabelecendo as metas do programa de residências e os objetivos educacionais para os residentes.

- B3 ESTRUTURA E ORGANIZAÇÃO DO PROGRAMA - Deve haver estágios e rodízios organizados e outras experiências educacionais, eletivos e obrigatórios, elaborados para dar oportunidade a cada residente, de completar os requisitos educacionais e atingir as competências da especialidade ou subespecialidade.

- B4 RECURSOS - Demonstrar recursos suficientes, incluindo corpo docentes, variedade de pacientes, em número adequado, infraestrutura física e técnica, bem como recursos gerais e serviços, necessários para dar oportunidades a todos os residentes do programa em alcançar seus objetivos educacionais, recebendo treinamento pleno, conforme requisitos definidos pelo Royal College ou CFPC.

- B5 CONTEÚdO CLÍNICO, ACADÊMICO E INTELECTUAL DO PROGRAMA O conteúdo clínico, acadêmico e intelectual do programa deve ser apropriado ao curso de pós-graduação, adequadamente preparando, integralmente, 0 residente em todas as competências - CanMEDS/CanMEDS-FM Roles.

A qualidade acadêmica do programa, deve, em parte, conter e desenvolver senso crítico durante as discussões clínicas à beira leito, na comunidade, em seminários, visitas médicas e conferências. A função acadêmica implica em aprofundar o conhecimento básico dos mecanismos de estados fisiológicos e fisiopatológicos e a aplicação do conhecimento em curso, à prática médica. (1. Medical Expert, 2. Communicator, 3. Collaborator, 4. Manager, 5. Health Advocate, 6. Scholar, 7. Professional)

- B6 AVALIÇÃO dO DESEMPENHO DO DESEMPENHO - Devem existir mecanismos locais que garantam coleta e interpretação sistemática dos dados de avaliação de cada residente matriculado no programa.

De volta ao RCPSC, os formulários provenientes da Universidade, dos

diretores de programa e os comentários do comitê de especialidades são todos enviados para o avaliador. O conteúdo de cada programa pode chegar a mil páginas entre documentação e informação. 
Analisados esses documentos será iniciada a visita in loco. Geralmente, as visitas em cada Universidade (são 17 com cursos medicina em todo o Canadá) duram uma semana. Nessa semana, os avaliadores são alocados em duplas ou trios, responsáveis pela avaliação de três a quatro programas. A visita a cada programa, em média, dura de um a dois dias inteiros.

Os avaliadores são o coração, o ponto central, do sistema. São os únicos que detêm todas as informações e a vivência (conhecimento) local, durante a avaliação. As informações provenientes desses avaliadores e colegas de profissão vão alimentar todo o sistema, a partir de então (fluxograma1).

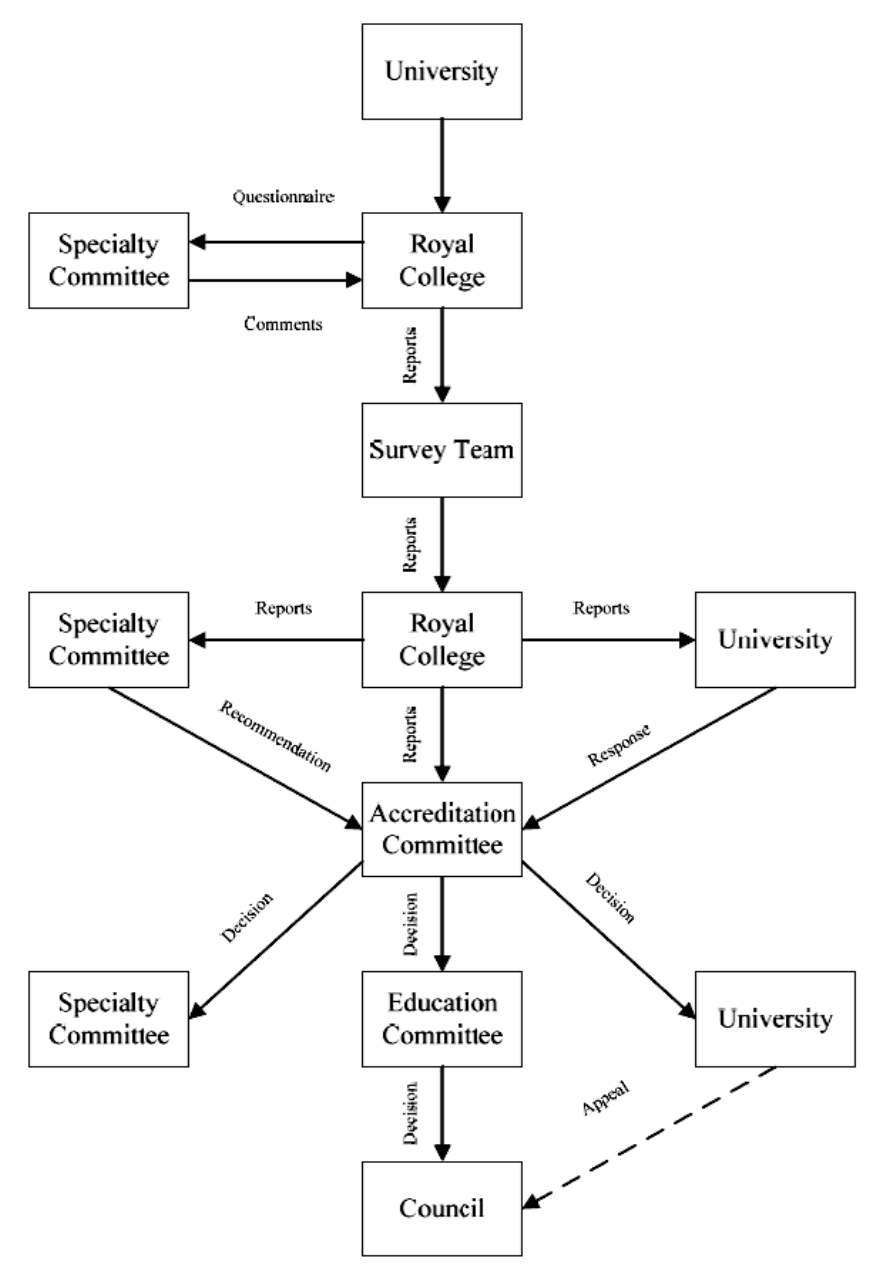

Fluxograma 1 - Processos internos no sistema de acreditação do RCPSC, em inglês. 
Rapidamente, identificamos que os principais detentores de informação e vivência dentro do sistema canadense são os avaliadores (survey team) de programas de residência médica. Esses avaliadores são diretores de programas de residência médica, professores ou desempenham outras funções como educadores médicos [88]. Trata-se de uma via de mão dupla, avaliam outros serviços, mas também são avaliados pelo mesmo sistema, nos locais em que trabalham. Não apenas lidam com um grande número de dados e informações de diversas comissões ao avaliarem ou serem avaliados, como também são os únicos que vivenciam a visita ao local de prática e entrevistam os diversos protagonistas de um programa (supervisores, diretores, residentes etc).

Conhecer o sistema de acreditação "por dentro" pela visão de quem acredita e ao mesmo tempo é acreditado por ele suscitou o projeto de pesquisa integrante dos objetivos desta tese e desenvolvido na McGill University com aprovação da comissão de ética daquela instituição para o mesmo. Detalhamento da elaboração, metodologia e resultados deste projeto serão descritos no Capítulo V.

Após finalizada a visita, os relatórios elaborados são novamente enviados ao RCPSC, que os distribui para a Universidade e para o Comitê de especialistas. A Universidade, o RCPSC e o comitê da especialidade enviam todas as informações para o segundo ponto de grande importância no sistema de acreditação: o comitê de acreditação.

O comitê de acreditação é formado por 16 membros, entre eles, um presidente e cinco membros votantes com mandatos de dois anos que podem ser renovados por no máximo três vezes, sendo constituídos por: 
- dois representantes da associação das Faculdades de Medicina do Canadá;

- um representante da federação das autoridades de regulação médica do Canadá (união dos colégios médicos de cada província);

- um representante da associação canadense de médicos residentes e internos (que está mudando de nomenclatura para: Médicos Residentes dos Canadá);

- um representante dos médicos residentes de Quebec.

Existem membros "observadores" permanentes do Colégio de Medicina de Família do Canadá, Colégio de Medicina de Quebec, da federação das autoridades de regulação médica do Canadá, da associação das organizações de saúde acadêmicas (Instituições saúde-escola) do Canadá e da Canadian Resident Matching Service (CaRMS) ${ }^{\star}$ [91, 92]. Desde 1992, a ACGME decidiu manter um programa permanente de troca de experiências e, por esse motivo, dois membros observadores dessa instituição americana também estão presentes[92].

*[Cabe aqui uma explicação sobre o que vem a ser o CaRMS[93]. Trata-se de um sistema nacional para ingresso de graduados em um programa de residência médica. O CaRMS une informações, de um lado, sobre as avaliações e o desempenho do graduado, bem como a especialidade e a instituição por ele pretendidas e de outro o perfil institucional, do programa e as vagas de cada instituição. Esse sistema direciona candidatos e instituições em duas classificações. O próximo passo é a entrevista e a escolha pelas instituições e pelos candidatos]. 
A decisão tomada pelo Comitê de Acreditação será comunicada ao comitê de especialidades, ao comitê educacional (interno ao RCPSC) e à Universidade. Esta última pode recorrer da decisão em caso de discordância.

O autor, novamente aqui identificou a importância da tomada de decisão do Comitê de Acreditação e, com autorização do RCPSC, realizou estudo observacional e coleta de dados empregando etnografia, sobre a tomada de decisão deste comitê. O acordo de confidencialidade permitia uso dos dados, excetuando as informações pessoais (anexo 5). No entanto, no decorrer do processo o RCPSC, solicitou que todos os dados coletados fossem retirados e mantidos sigilosos, permitindo apenas que dúvidas, pensamentos e conclusões provenientes das observações e coletas de dados realizadas no interior do comitê fossem utilizadas. Respeitando o desejo da instituição, as citações e o material coletados serão destruídos e não serão publicados.

No Capítulo V: O papel do Comitê de Acreditação - Etnografia; estarão descritos os métodos e os resultados elaborados a partir das observações, sem a publicação de nenhuma delas. $O$ pesquisador entende que os dados sigilosos podem ser um dos principais riscos e obstáculos de se realizar pesquisa em acreditação e todos os elementos que a envolvem.

As decisões do Comitê de acreditação podem ser [94]:

- Novo Programa, acreditado;

- Programa acreditado: sem pendências ou alguma pendência, havendo, nesse caso, de acordo com a complexidade do fato, a necessidade de:

- Relatório de progressão (Progress Report, $P R$ ), quando há pendências menores;

- Avaliação interna mandatória (Internal Review, IR), com pendências de maior importância; 
- Avaliação externa (External Review, ER), pendências de maior gravidade e importância.

- Instituição sob aviso de possível descredenciamento;

- Descredenciamento.

Existem dois tipos de avaliação que são, na verdade, duas partes do mesmo sistema de acreditação. $O$ exposto acima se refere à avaliação externa - AE, em que um programa é todo avaliado pelo sistema do RCPSC. Mas existe ainda uma parte da avaliação inteiramente conduzida pela Universidade, para seus próprios programas, a chamada avaliação interna - Al. A avaliação interna costuma ocorrer a cada 24 meses, em média, e é efetuada por membros de departamentos diferentes de cada programa a ser avaliado, sendo todos pertencentes a mesma instituição. Essa avaliação é importante para que a Universidade desenvolva critérios de avaliação, conheça a realidade de seus programas, possa constantemente corrigir rotas e se preparar para a avaliação externa [95]. A confiança na seriedade das instituições nesse tipo de avaliação é fundamental. Espera-se da Universidade que realize seu trabalho, com foco na qualidade de seus programas. Alguns autores defendem que a avaliação interna substitua a externa, passando para as mãos da própria instituição grande parte de sua própria avaliação[96].

Uma Al mandatória pode, por exemplo, ser determinada pelo RCPSC para que a instituição proceda a análise interna, com rigor semelhante ao observado em uma avaliação externa. Por conhecer a instituição, muitas vezes, as visitas aos locais de práticas são dispensadas e a avaliação se baseia nas diversas entrevistas realizadas. 
Como para o autor a avaliação interna não era algo tão comum, foi desenvolvido um projeto de pesquisa baseado na metodologia qualitativa de "estudo de caso" que será descrito no Capítulo VI: Avaliação ou Revisão Interna - Estudo de caso. Este projeto novamente encontra problemas para publicação, tendo em vista o restrito acordo de confidencialidade dos dados. No entanto, diversos dados e observações são públicos, sendo permitido ao autor descrever sua experiência de observador de uma avaliação interna, em seus diversos aspectos. 


\section{CAPÍTULO IV: A RELAÇÃO ENTRE QUALIDADE E ACREDITAÇÃO DE PROGRAMAS DE RESIDÊNCIA - PERCEPÇÕES DOS AVALIADORES}

Pode-se dizer que no sistema canadense os avaliadores se encontram em uma posição privilegiada, na qual podem não apenas contribuir com a acreditação, mas também aplicar o que foi aprendido com a avaliação em seus próprios programas e instituições (avaliação interna - Al). A percepção de tais avaliadores sobre o sistema pode colaborar na elucidação entre a "qualidade percebida" de um programa pelos entrevistados [32] e a "qualidade capturada" pelos dados, processos e o sistema em geral de acreditação da residência médica no Canadá. Em outras palavras, pretendeu-se entender a percepção dos avaliadores no processo de acreditação e na qualidade dos programas de residência médica [97]. Para tanto, as perguntas foram realizadas:

- Quais são as percepções dos médicos avaliadores de programas de residência médica sobre a acreditação no Canadá?

- Como esses médicos avaliadores entendem a relação entre acreditação e qualidade na residência médica?

Métodos para este estudo

A metodologia empregada foi de descrição qualitativa, qualitative description [98-101] por meio de entrevistas semiestruturadas e individuais dos avaliadores de programas de residência médica no Canadá. O recrutamento 
dos entrevistados ocorreu pelo processo "bola de neve" (snowball), partindo de uma única entrevista. Dúvidas foram sanadas antes da entrevista e o consentimento informado foi assinado em cada uma delas (anexo 6). O protocolo de entrevista foi desenvolvido a partir de documentos, revisão de literatura e opinião de especialistas ligados à educação médica e à acreditação de residência médica no Canadá. Antes de serem aplicadas, as perguntas foram revistas por um painel de especialistas e um piloto foi realizado. As perguntas (anexo 7) utilizaram, na maior parte do tempo, respostas abertas, possibilitando aos entrevistados contar histórias sobre suas vivências do processo de acreditação.

Todas as entrevistas foram realizadas pelo presente autor e tiveram, aproximadamente, uma hora de duração. Seus conteúdos foram gravados e transcritos, mantendo-se em sigilo a identidade dos entrevistados (estes receberam um número. Exemplos: 11, 12, 13, ...). A análise dos dados foi realizada com o autor ouvindo o conteúdo das entrevistas e relendo as transcrições. Os comentários mais ilustrativos da riqueza dos dados coletados estão presentes em 3 diferentes tabelas na seção resultados. Durante esse processo, além da organização dos dados, foi feita a classificação e a codificação destes pelo processo indutivo de análise temática como descrito nos trabalhos de Braun and Clark, inductive thematic analysis, e no livro de metodologia de Patton [99] . Como é necessário ao método, parte dos dados foi também analisada por outro pesquisador para análise de convergência de opiniões. Poucas discrepâncias foram encontradas durante o procedimento de análise e quando ocorreram foram resolvidas por meio de discussão e consenso entre os dois analistas. 
O processo de codificação foi realizado repetidamente até sua saturação, ou seja, quando nenhum tema novo emergiu. Categorias foram adicionadas, modificadas ou retiradas ao longo dessa etapa, sempre dirigidas pelo conteúdo dos dados. A relação entre os dados deu origem a um quadro conceitual - conceptual framework.

Resultados dessa etapa

Vinte e um entrevistados foram indicados pelo recrutamento bola de neve. Destes, onze preencheram todos os critérios de inclusão (ter experiência como avaliador e ter sido avaliado, em programas de residência médica). A tabela 3 informa as características dos entrevistados.

Tabela 3 - Características dos Avaliadores Entrevistados

\begin{tabular}{c|l|l}
\hline \multirow{2}{*}{$\begin{array}{l}\text { Função atual em Programas de Residência } \\
\text { Médica* }\end{array}$} & Supervisor de PRM & $6(55 \%)$ \\
\cline { 2 - 3 } & Avaliador & $6(55 \%)$ \\
\cline { 2 - 3 } & Membro de Comitê de PRM & $5(45 \%)$ \\
\cline { 2 - 3 } & Preceptor & $3(27 \%)$ \\
\hline \multirow{2}{*}{ Tempo de experiência como avaliador } & 1 a 2 anos & $9(82 \%)$ \\
\cline { 2 - 3 } & 3 a 4 anos & $0(0 \%)$ \\
\cline { 2 - 3 } & $>5$ anos & $2(18 \%)$ \\
\hline \multirow{2}{*}{ Número de visitas realizadas } & 1 a 3 visitas & $7(72 \%)$ \\
\cline { 2 - 3 } & 4 a 6 visitas & $2(18 \%)$ \\
\cline { 2 - 3 } & 7 a 12 visitas & $2(18 \%)$ \\
\hline Tempo de prática em educação médica & $<5$ anos & $5(45 \%)$ \\
\cline { 2 - 3 } & 15 anos & $5(45 \%)$ \\
\cline { 2 - 3 } & $>20$ anos &
\end{tabular}

*Pergunta que admitiu mais de uma resposta. Ex: supervisor de PRM e Avaliador.

A análise temática resultado das entrevistas se encontra na tabela 4.

Existe uma clara percepção geral de que há impacto positivo na existência de acreditação nos programas de residência médica. Traz benefícios 
pela simples existência de critérios comparáveis e de um sistema que os verifica. No entanto, o sistema, tal qual empregado no Canadá está se tornando muito pesado para os avaliadores e avaliados. Parece apresentar problemas em sua eficiência, no recrutamento de avaliadores e no investimento em recursos humanos. Existe uma percepção geral de que o sistema é essencial, mas precisa de mudanças.

Tabela 4 - Analise Temática: conjunto de itens e subitens elaborados a partir das entrevistas semiestruturadas

\begin{tabular}{|c|c|c|}
\hline Código & Categoria & Tema \\
\hline $\begin{array}{l}\text { Pouco treinamento } \\
\text { Aprendendo com a experiência } \\
\text { O avaliador experiente como Mentor } \\
\text { Oportunidade de aprendizagem para os avaliadores } \\
\text { Experiência de avaliador ensina a ser um melhor } \\
\text { supervisor de programa (SP) } \\
\text { As vantagens de ter sido avaliador e avaliado }\end{array}$ & $\begin{array}{l}\text { Treinamento e } \\
\text { Experiência }\end{array}$ & \multirow{3}{*}{$\begin{array}{l}\text { RECURSOS } \\
\text { HUMANOS }\end{array}$} \\
\hline $\begin{array}{l}\text { Importância dos pares em cada fase } \\
\text { O alto nível de cobrança pessoal } \\
\text { Os SP impactam muito o programa } \\
\text { A presença de pares aumenta a qualidade } \\
\text { O papel dos avaliadores na entrevista com residentes } \\
\text { Bons avaliadores precisam de experiência como SP }\end{array}$ & Sendo um par & \\
\hline $\begin{array}{l}\text { Os avaliadores não têm habilidades e expertise } \\
\text { profissionais para avaliar } \\
\text { Problemas com o modelo voluntário } \\
\text { Falta de pagamento ou outros benefícios para o avaliador } \\
\text { Ser avaliador demanda muito tempo }\end{array}$ & $\begin{array}{l}\text { Habilidades } \\
\text { profissionais e o } \\
\text { reconhecimento }\end{array}$ & \\
\hline $\begin{array}{l}\text { Estresse } \\
\text { Preocupações com os custos } \\
\text { Tempo consumido desnecessariamente } \\
\text { Peso da mediação } \\
\text { As coisas poderiam ser mais "leves" } \\
\text { Agenda extremamente cansativa }\end{array}$ & $\begin{array}{l}\text { O "Fardo } \\
\text { (burden)" (os } \\
\text { documentos e o } \\
\text { tempo) }\end{array}$ & \multirow[b]{2}{*}{$\begin{array}{l}\text { ESTRUTURA } \\
\text { E PROCESSO }\end{array}$} \\
\hline $\begin{array}{l}\text { O sistema precisa de mudanças } \\
\text { Não há dados suficientes qualitativos } \\
\text { Problemas com o foco da acreditação } \\
\text { Não há capacidade suficiente de captura da qualidade dos } \\
\text { programas } \\
\text { Há muita ênfase no processo, mas não nos resultados } \\
\text { Falta de eficiência } \\
\text { A visita de acreditação parece ser um teatro } \\
\text { Há discrepância entre a informação coletada e a realidade } \\
\text { Precisaria se concentrar apenas em dados úteis }\end{array}$ & $\begin{array}{l}\text { Eficiência e } \\
\text { eficácia do } \\
\text { sistema de } \\
\text { acreditação }\end{array}$ & \\
\hline
\end{tabular}


Por estarem na posição de pares, não apenas de avaliadores, mas de médicos avaliadores e participantes do sistema também como avaliados, houve percepção de ambas as perspectivas. À despeito de as questões terem sido direcionadas aos avaliadores, muitas vezes, as respostas dadas parecem refletir suas opiniões enquanto supervisores de programas. Os supervisores de programas - SP (Program Director, PD) costumam entender a acreditação como um teste ao seu desempenho na função.

Da análise temática, seis categorias emergiram: o fardo da acreditação (Burden on Documentation and Time); Eficiência e eficácia (Efficiency and Efficacy of the Accreditation Process); Treinamento e experiência (Training and Experience); Sendo um par (Being a peer); Habilidades profissionais e reconhecimento do avaliador (Professional skills and recognition as a surveyor), conforme a tabela 4 .

Novas ideias para melhorar o sistema se encontram na tabela 7. As cinco primeiras categorias foram agrupadas em dois grandes temas: Estrutura e Processo (Structure and Process) e Recursos Humanos (Human Resources).

\section{Recursos Humanos}

Existe uma percepção geral de que a maneira e a qualidade com que os dados são coletados, integrados e relatados pelos avaliadores promovem impacto na qualidade dos programas. Os entrevistados concordaram sobre a importância do sistema incluir médicos avaliadores, nas visitas de acreditação.

O fato de o avaliador de um programa ser um par, um indivíduo de igual natureza, com as mesmas atribuições, vivências e experiências no treinamento dos residentes é compreendido como uma "medida privilegiada", a qual permite 
que o avaliador se concentre em aspectos de grande importância para a qualidade dos programas, itens que ele próprio percebe em seu dia a dia e em sua vivência com os residentes.

Alguém que já foi residente e agora faz parte da equipe que treina residentes é visto como detentor de um conhecimento muito importante para avaliar e julgar outros programas de residência. Os entrevistados, por consenso, apontaram sobre a necessidade de avaliação por pares como "chave" para o sistema, confiando que a presença de pares é necessária nas diversas fases do processo de acreditação.

No entanto, ser um médico com experiência em formação de residentes não é condição suficiente para ser um bom avaliador de programas de residência. Treinamento e experiência são considerados de grande valor. O clínicos que desempenham papel de educadores [102] também necessitam de treinamento específico e supervisão de suas ações, no início do processo, até se tornarem bons avaliadores. Os entrevistados, na presente pesquisa, acreditam que manter um grupo de profissionais experientes, com boa e contínua capacitação teórico-prática como avaliadores é um ganho para o sistema de forma geral.

Os entrevistados reconhecem os esforços do sistema de acreditação em construir e melhorar, continuamente, elevados parâmetros apresentados na captação das informações, durante o processo de acreditação. No entanto, não identificam a existência de uma política de capacitação e retenção de profissionais experientes nessa área.

Sabe-se que os médicos não possuem tempo protegido e recurso em suas agendas para desenvolver as competências necessárias para ser um avaliador de programa. 
Alguns momentos da avaliação podem ser lembrados como exemplos sobre a diferença em ser um indivíduo de igual natureza (par), ser treinado e experiente. Mais comumente lembrada é a entrevista com os residentes. Considerado o momento mais "precioso" e desafiador por todos é nesse encontro que uma amostra da realidade poderá surgir, fornecendo dados para a acreditação. O avaliador deve saber valorar cada comentário e identificar se existe diferenças entre o que está sendo dito e aquilo que realmente está ocorrendo no programa.

Por ser um par, o avaliador possui vantagem nos julgamentos, pois foi residente, e agora é um médico-educador [102]; se somados treinamento e experiência prática na avaliação de programas, este terá o conjunto de competências necessárias para extrair a verdade dita que, muitas vezes, apenas pode ser obtida após o uso de metodologias apropriadas e ganho de confiança por parte dos entrevistados.

No entanto, ter profissionais dedicados e experientes na acreditação exige planejar um processo apropriado. Atividade voluntária reduz as possibilidades de contar com pessoas que se dediquem ao estudo, ao treinamento e à prática da acreditação de programas de residência médica. A chance de contar com pessoas experientes na tarefa também se reduz. Como observado na Tabela 3, raramente alguém realizou mais de seis avalições na vida. Remuneração e reconhecimento são frequentemente solicitados. $\mathrm{Na}$ Tabela 5, estão descritos alguns dos comentários originais representativos da riqueza dos dados coletados sobre Recursos Humanos. 
Tabela 5 - Trechos representativos sobre Recursos Humanos

"I think the peers are important, and I think there should be much much much more compensation for the program directors for the amount of work they do"[l.11]

"Personally I think I like the idea that it's a colleague that does it in the way that they understand my reality somehow" [I. 09]

"The advantage [accreditation institute has] is that we have clinicians and educators visiting programs."[I.10]

"I think formalizing it and building the expertise would be great. I think for me it's a lack of expertise" [1.09]

"The training process is minimalist to say the least ...। do think that the preparation is inadequate, especially for your first accreditation" [1.08]

"I think you have to teach the surveyor before they survey. You keep a bank of surveyors, they should take a course every 2 or 3 years, but at the same time they should be paired with an experienced surveyor the first time"[I.10]

"I've realized that the perception of the residents is the key. So [as PD] I'm very sensitive to that now, when my residents are unhappy I solve this right away. That's what kills you [in an accreditation]" [l.09]

"You take a week of vacation to do all this work. And it's not just the week. Before, it's the many hours ahead of time preparing, reading the documents, and the hours of writing the documents after you have to write the report so you know I suspect that it's up to two weeks in total, maybe 80 hours which is not paid."[l.08]

\section{Estrutura e Processo}

Eficiência permite que o sistema empregue menos energia para realizar o mesmo trabalho. Eficácia é a habilidade em produzir o resultado esperado [103]. Existe um crescimento constante nas necessidades de tempo e energia requeridas pelo sistema de acreditação. A cada ano mais documentos são adicionados ao processo. O sistema parece, no entanto, esquecer-se de etapas anteriormente necessárias e já superadas, que, talvez, não mais precisem ser cobradas, fazendo com que a estrutura e a documentação necessárias sigam crescendo. A maioria avalia que parte desses documentos poderia ser, por exemplo, suprimida da análise para a visita de avaliação, sem prejuízo do processo. Ao contrário, o sistema poderia ganhar eficiência, sem 
perder sua eficácia. Alguns exemplos de tempo gasto desnecessariamente são as fichas que devem ser preenchidas pelos supervisores de programa, 0 volume de documentação analisada para uma avaliação, a agenda fixa programada para a semana de visitas de acreditação. Geralmente, durante uma semana (não remunerada), o trabalho se inicia às sete horas da manhã, seguindo até meia noite durante toda a semana, entre entrevistas e reuniões para elaboração dos relatórios.

O processo de acreditação torna-se muito pesado e estressante para avaliadores e avaliados. Não é raro que um avaliador receba documentação com cerca de mil páginas (sobre um programa), antes de uma visita em que terá uma semana para todo o processo, implicando que fará a leitura do material, geralmente à noite, após o trabalho diário. Esse acúmulo de informação parece aumentar o fardo do trabalho e contribuir para prejuízo de foco. Na Tabela 6, estão descritos alguns dos comentários originais representativos da riqueza dos dados coletados sobre a Estrutura e Processo.

Tabela 6 - Trechos representativos sobre Estrutura e Processo

"That experience I found very time consuming and the idea of working until 2am doesn't work for me...I was thinking that it was such a waste of my time. It's not a good process..."[109]

"The other thing is that the set-up of the accreditation is very tiring for the surveyors. The early morning pick up, the full day and then the supper at 6 and the deliberations until midnight, and then you go to bed and do it again for five straight days. And I'm not sure that the programs at the end of the week are getting the same attention as those at the beginning of the week."[l.08]

"it's a lot of effort and stress and documentation" [l.03]

"I think the accreditation process needs to be more truthful to this reality of how people learn medicine. I would want to see a lot more attention paid to learning in a clinical environment" [1.05] 


\section{Novas Ideias}

Os participantes foram questionados sobre ideias novas que pudessem estreitar a relação entre a qualidade dos programas e o que é abrangido pela acreditação. As ideias aqui apresentadas tentam tornar a acreditação mais leve, direta, com objetivo principalmente em resultados [85]. Uma das propostas sugere realizar uma miscelânea entre o modelo de acreditação canadense do RCPSC e o modelo norte-americano ACGME [104], adicionando avaliadores profissionais (não médicos) [89] aos avaliadores médicos, como parceiros em algumas atividades.

A Tabela 7 contém as principais ideias para incrementar a eficiência e eficácia do sistema.

Tabela 7 - Novas ideias para melhorar a eficiência do sistema de acreditação

\begin{tabular}{l|l}
\hline $\begin{array}{l}\text { Decompor a avaliação e visitas em } \\
\text { dois conteúdos: }\end{array}$ & $\begin{array}{l}\text { Parte 1: coleta de dados por técnicos avaliadores } \\
\text { Parte 2: avaliações feitas pelos pares }\end{array}$ \\
\hline Decompor a avaliação: & $\begin{array}{l}\text { Parte 1: estrutura administrativa institucional } \\
\text { Parte 2: avaliação individualizada de cada } \\
\text { programa }\end{array}$ \\
\hline Decompor as formas de avaliação em: & $\begin{array}{l}\text { Parte 1: documentação a ser feita de maneira } \\
\text { Partentínua } 2: \text { visitas de avaliação in loco a serem } \\
\text { realizadas em ciclos periódicos }\end{array}$ \\
\hline
\end{tabular}

Médicos e não médicos especialistas em Educação Médica trabalharão em mandatos mais longos na instituição acreditadora, visando à estabilidade

Ampliar o envolvimento do comitê de especialidade

Realizar visitas surpresas, não anunciadas (essa ideia foi controversa) 
Os dados gerais sobre os programas (exemplo: informações sobre o número de professores ou a estrutura do hospital) que são usualmente quantitativos poderiam ser coletados por avaliadores profissionais (não necessariamente médicos) de maneira contínua, eletronicamente, sem necessidade de ciclos. Quando necessários ciclos independentes de visitas poderiam ser estabelecidos, concentrando as informações numéricas. Essa base de dados ficaria à disposição dos comitês de especialistas e dos avaliadores médicos.

Sobre os comitês de especialistas, a maior parte dos entrevistados também concordou com a importância. Cada comitê é composto por especialistas em determinada área do saber médico (radiologia, psiquiatria etc) ligados à educação médica e que opinam durante todo o processo, trazendo o conhecimento e as necessidades privativas de uma especialidade médica específica. Os entrevistados acreditam que mais do que opinar, os comitês de especialidade devem ser ampliados, podendo analisar as informações enviadas pelos diretores de programas, filtrando-as, direcionando os objetivos e tornando a visita mais leve e eficiente.

Todavia, os aspectos educacionais e clínicos, concentrados em dados qualitativos, em ciclos independentes de avaliação para acreditação, seriam realizados pelos médicos avaliadores, tornando o sistema mais profissional e menos exaustivo (factível) para todos os envolvidos. Na Tabela 8, estão descritos alguns dos comentários originais representativos da riqueza dos dados coletados sobre as novas ideias. 
Tabela 8 - Trechos representativos sobre as Novas Ideias

"It helps to be a physician, it gives you insight into the curriculum, trying to link how things work together to make sense, we do ask for consultants from specialties in their everyday lives but I don't think the whole process has to be done by physicians."[l.03]

“Don't forget they give you a link [computer page] and all the appendixes and expect you to write a report with questions so they give it to the program director and that itself is hours and hours of work each time I read one of those. Maybe the specialty committee needs to be paid to do that job since they have a lot of responsibilities." [1.08]

"like there is someone in the university whose job it is to continuously to apply standards and so on"[l.05]

"hundreds of pages that I didn't get much from so I had to ask questions, I felt that I had I was doing too much. I think maybe they need to split the work up differently ...

I think it's a great idea to have a professional accreditor, and it wouldn't even have to be done at the same time. They are probably better at it than we are because they are experienced"[I.08]

\section{Discussão}

Uma revisão sistemática realizada por Greenfield e Braithwaite concluiu que existem dois consistentes achados resultantes da acreditação no setor saúde: desenvolvimento profissional e promoção de mudança. Os mesmos autores observaram a falta de estudos sobre avaliadores[97] (entre outros fatores) para poder elaborar qualquer conclusão [6].

Atualmente, o número de estudos sobre processos de acreditação tem aumentado, focando no desenvolvimento da educação médica, no sistema de saúde, nas competências dos médicos residentes, na segurança dos pacientes e mesmo na formação de avaliadores [105, 106].

Os resultados dessa etapa sugerem algumas estratégias para melhorar sistemas de acreditação. Alguns dos resultados aqui descritos podem ser 
encontrados em outros países como o avaliador profissional (ACGME) [85]; os avaliadores médicos (RCPSC) [107]; e os processos mais leves (como no Brasil) [108]. Os dados se alinham à literatura sobre avaliadores e processos de acreditação.

As entrevistas demonstram por meio das percepções dos avaliadores a necessidade de balancear investimentos entre os "Recursos Humanos" e a "Estrutura e Processo". As figuras 3 e 4 representam graficamente os achados teóricos deste estudo. A figura 3 emerge dos resultados como um conceptual framework mostra a necessidade de equilíbrio entre os recursos, "modelo balanceado".

\section{Distribuição}

de Recursos

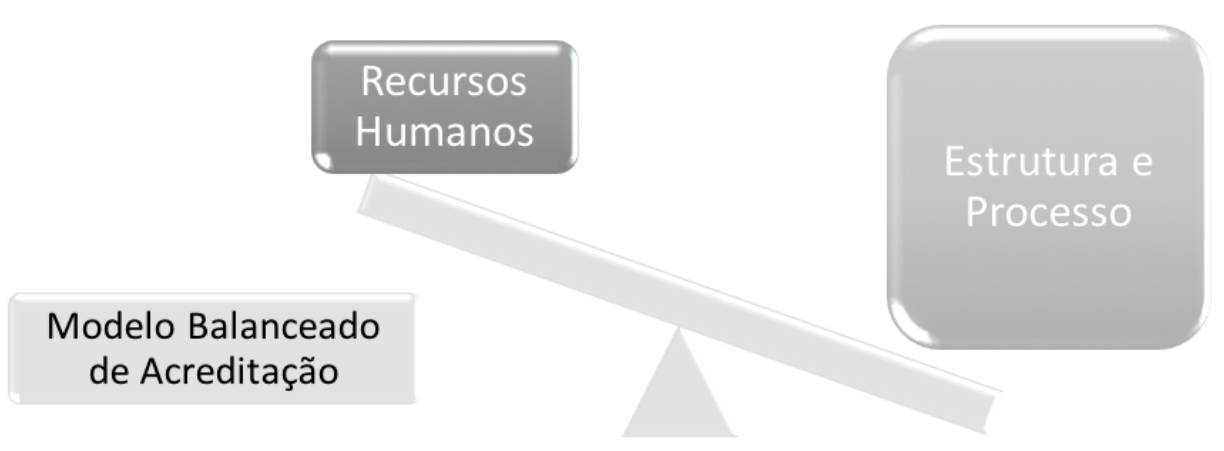

Figura 3 - Modelo Balanceado de Acreditação

Dos resultados, pode-se verificar que tanto as "faltas" de empenho em treinamento, valorização e remuneração (Recursos Humanos) quanto os "excessos" de peso na documentação, tempo (e estresse) necessário para 
desempenhar a atividade (Estrutura e Processo) fazem o desempenho do sistema se afastar de seu ponto de excelência. A figura 4 representa 0 optimum point do sistema.

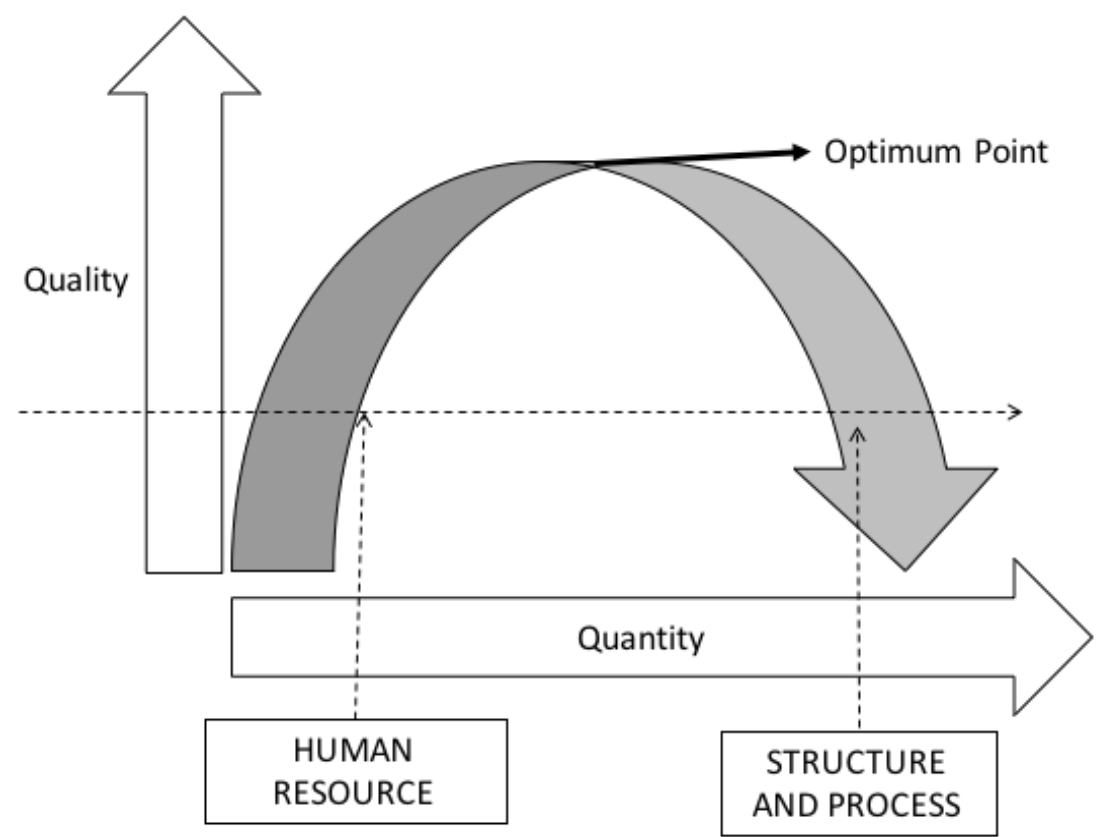

Figura 4 - Optimum Point 


\section{CAPÍTULO V: O COMITÊ DE ACREDITAÇÃO}

"Not everything that can be counted counts, and not everything that counts can be counted." Albert Einstein

O processo de acreditação deve ser o mais objetivo possível, no entanto, esse processo se baseia em relações humanas, em que os julgamentos são naturais [5]. $\mathrm{Na}$ acreditação, observamos paralelos com funções judicantes. No sistema judiciário, juízes, advogados e promotores fundamentam-se em leis para realizar interpretações num processo jurídico. Comitês de acreditação, supervisores de programas e avaliadores seguem critérios e normas pré-estabelecidos pelo sistema de acreditação. Como em um processo jurídico na acreditação também são necessárias diversas perspectivas de análise, visando tentar tornar objetivas as decisões. Não se pode esquecer, no entanto, que componentes subjetivos e emocionais sempre fazem parte de qualquer decisão [109].

Os comitês de acreditação precisam ter esses dados em mente, pois irão tomar suas decisões com apoio de componentes que são frutos da produção humana (relatórios, declarações, entrevistas etc).

No presente trabalho, decidimos por reconhecer a ocorrência de componentes subjetivos e emocionais, a fim de entender melhor a relação entre os dados fornecidos ao comitê de acreditação e os fatores que irão influenciar sua tomada de decisão.

A função do comitê, no processo de acreditação da residência médica, pode ser considerada "chave", ou seja, as decisões tomadas impactam o 
sistema de forma geral. É no comitê que as decisões finais sobre os programas serão tomadas. Ele faz recomendações que influenciam os futuros critérios de acreditação , opina sobre as políticas de acreditação na residência médica, avalia as propostas de novos programas e define os prazos e os tipos de avaliação a serem empregados no processo de acreditação de cada programa determinando a categoria de cada um deles, desenvolvendo, mantendo e disseminando políticas e procedimentos.

O Royal College of Physicians and Surgeons do Canadá estabelece como metas para o seu Comitê de Acreditação de Programas de Residência Médica:

a. Recomendar ao Comitê de Educação políticas, normas e critérios referentes ao credenciamento de programas de residência.

b. Avaliar os pedidos de credenciamento de novos programas de residência ou a modificação de programas credenciados.

c. Organizar revisão periódica e avaliação dos programas de residência credenciados por meio de inquéritos locais e revisões internas.

d. Determinar a categoria de acreditação concedida a cada programa de residência.

e. Desenvolver, manter e divulgar suas políticas e procedimentos.

"a. to recommend to the Education Committee, policies, standards, and criteria relating to the accreditation of residency programs;

b. to assess applications for accreditation of new residency programs or for modification of accredited programs;

c. to arrange periodic review and assessment of accredited residency programs through on-site surveys and internal reviews;

d. to determine the category of accreditation granted to each residency program;

e. to develop, maintain and disseminate its policies and procedures."[92] 
Durante o período de estágio sanduíche concedido pela CAPES, foi realizado o estudo intitulado "Strengths and Weaknesses emerging at residency accreditation meetings: An Ethnographic approach of the Royal College of Physicians and Surgeons of Canada (RCPSC) Committee", como meio de compreensão de como as decisões são tomadas no interior de um comitê de acreditação.

Nas reuniões do comitê de acreditação do RCPSC, observou-se, descreveu-se e analisou-se os pontos fortes e fracos emergentes na comunicação entre os seus membros, referentes ao sistema de acreditação da residência médica em geral.

O pesquisador, por pertencer a outra cultura e vivência, teve um olhar decisivamente externo e de alguma maneira "estranho" aos processos de acreditação canadense; por esse motivo, optou-se pelo estudo qualitativo etnográfico [101]. Sabendo que o pesquisador é parte indissolúvel de sua pesquisa, influenciando-a (mesmo quando tenta se manter distante) e por ela é influenciado, o pesquisador estrangeiro realiza interpretações do que observa a partir de paradigmas diferentes daqueles que vivem inclusos no sistema [100]. Ainda que seja estudioso de processos de acreditação na residência médica, possuir paradigmas primordialmente de culturas diferentes deve levar a questionamentos e soluções de problemas também díspares do praticado no país visitado.

Estudos qualitativos com desenho etnográfico são muito raros em acreditação, mas podem trazer consideráveis contribuições para a melhoria do sistema, ao tentar coletar dados que "não são visíveis" [110]. 
Métodos do Estudo Etnográfico

$\mathrm{Na}$ antropologia a etnografia estuda e revela os costumes, as crenças e as tradições de uma sociedade, que são transmitidas de geração em geração e que permitem a continuidade de determinada cultura ou de um sistema social.

Nesse tipo de estudo, o observador procura descrever o que, na sua visão, ou seja, na sua interpretação, está ocorrendo no contexto pesquisado. Uma das características da etnografia é a presença física do pesquisador e a observação in loco.

Para atingir aos resultados desejados, novamente, iniciou-se a revisão da literatura sobre o processo de acreditação da residência médica, da educação médica, do setor da saúde e do ensino superior. Além da literatura científica, recorreu-se a documentos do RCPSC sobre acreditação, com referência a procedimentos, a pesquisas publicadas em seu sítio eletrônico, aos anais de congressos, ao material instrucional e de apoio, aos questionários e guias, sempre que pertinentes ao tema.

Para coleta de dados, optou-se pela abordagem etnográfica [111], durante as reuniões do comitê de acreditação do RCPSC.

Inicialmente, houve negociação entre 0 grupo de pesquisa e a administração do RCPSC e do comitê de acreditação, visando definir os termos das participações nas reuniões (anexo 5). Planejou-se a observação em quatro reuniões do comitê de acreditação do RCPSC, desde a abertura até o final das sessões, em local previamente designado pelo RCPSC. O pesquisador se manteve à mesa de reuniões, todo o tempo como observador, tomando notas das falas, informações, impressões, expressões e comportamento dos 
participantes. A figura 5 representa a posição (interna-externa) do pesquisador durante a coleta de dados.

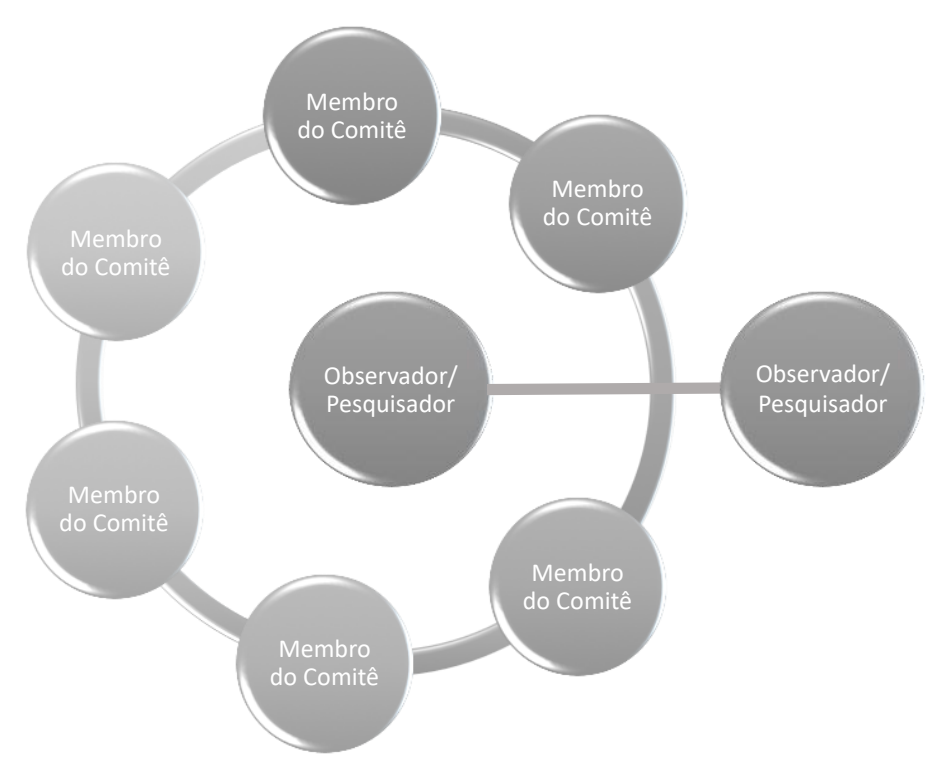

Figura 5 - Posição do Pesquisador

O sujeito da pesquisa neste estudo é o Comitê e não cada um de seus integrantes. As percepções aqui analisadas se misturam e se expressam como provenientes de uma instituição - o comitê, sendo descartadas as percepções interpretadas como sendo de uma única pessoa, tendo como foco de interesse as manifestações do comitê de forma geral. Dentro das limitações desta pesquisa, tentou-se obter a perspectiva de comportamento do grupo. Portanto, não foi objeto deste estudo analisar os componentes do grupo, das relações entre si, o que poderia ser chamado de dados "sociométricos"[112], mas sim do grupo em relação ao mundo, quando, nesse caso, as opiniões dos indivíduos se institucionalizam. Tentou-se focar nos dados quando estes se tornaram, após várias falas, um só corpo, um "corpo social” [113, 114]. 
As reuniões do comitê de acreditação ocorreram na sede do RCPSC, em 2015, na cidade de Ottawa, província de Ontário, Canadá. Nenhum recrutamento ocorreu, já que as reuniões fazem parte da agenda da instituição. As reuniões observadas foram selecionadas aleatoriamente e por conveniência de datas.

Antes das duas últimas reuniões a serem observadas pelo pesquisador e ainda no processo de coleta de dados, in loco, o RCPSC, preocupado com as questões de segurança e confidencialidade das informações, decidiu suspender a presença de pesquisadores, em suas reuniões, permitindo, no entanto, que apenas os dados, fruto das reflexões obtidas a partir do que já fora observado, fossem utilizados neste estudo, desde que não expusessem questões pessoais ou passíveis de identificação. Felizmente, os dados coletados se mostraram suficientes para os objetivos do presente texto.

Nenhum instrumento específico de avaliação foi desenvolvido ou utilizado nesta pesquisa. O material extraído das reuniões não foi gravado. O pesquisador tomou notas tão "obsessivamente" quanto possível, o que é adequado para a metodologia etnográfica[115] sobre o discursos, movimentos, emoções e fatores que poderiam influenciar o processo de tomada de decisão na reunião do comitê de acreditação.

As anotações realizadas durante as reuniões foram cuidadosamente analisadas, tentando extrair informações que suportem o entendimento do objetivo proposto. As notas foram então organizadas por assuntos, temas e categorias, agregando-as, sempre que relacionadas, a uma mesma categoria. Citações e sensações que surgiram durante as reuniões foram organizadas e 
transcritas nas mesmas categorias, porém, na elaboração final deste capítulo foram removidas do texto, preservando o acordo de confidencialidade.

Os resultados são apresentados como pontos fortes e fracos dos processos atuais de acreditação da residência médica no Canadá, de maneira a buscar possíveis generalizações para que as lições aprendidas possam ser utilizadas em outros sistemas de acreditação da residência médica. A discussão pretende dar contribuições e sugestões para futuros sistemas de acreditação na residência médica.

Resultados desta etapa:

\section{Contexto geral}

O ambiente na reunião de acreditação se mostrou democrático. Nenhuma falta de equilíbrio entre os participantes foi notada pelo observador, ou seja, não houve assimetrias. Opiniões de todos, seja de um residente ou do diretor geral do comitê, têm a mesma receptividade pelo grupo.

As discussões sobre os programas e o status do programa (o que inclui a próxima avaliação de cada programa) domina a maior parte das reuniões. Os programas são analisados um a um.

Não há dúvidas de que na discussão de cada caso há preocupação sobre a capacidade dos relatórios e documentos transmitirem a realidade vivenciada na residência em análise.

Os dados da universidade, avaliadores, comissão de especialidade e a história do programa, são avaliados por dois médicos independentes. Os revisores dos documentos provenientes de cada programa, sempre presentes 
na reunião ou por videoconferência (quando a presença não é possível), são fundamentais para elucidar dúvidas do comitê.

Os relatórios dos revisores são sempre focados nos pontos fortes e fracos de cada item da documentação proveniente dos programas. Em um processo quantitativo, demonstra-se numericamente quantos são os pontos fortes e fracos de cada programa. Alguma importância é dada para esses números, mas não são definidores das decisões. O tipo de problema apresentado, bem como o conteúdo e a qualidade da informação descrita são, muitas vezes, mais importantes.

Um programa com pequeno número de fraquezas pode trazer muita preocupação à comissão. Outro programa, quase sem pontos fortes ou de destaque, mas com padrões mínimos alcançados, pode ser totalmente aprovado. Isso acontece porque a análise da qualidade e das características de cada item pode trazer muito mais informações e influenciar a tomada de decisão. Não raro o que foi descrito como um ponto fraco ou forte é removido ou modificado pelo comitê que analisa e debate a pertinência daquele item.

Analisando as citações e anotações foi possível chegar em seis categorias: tipos de avaliação ou classificação, tempo para a avaliação, capacidade de captura da realidade, os avaliadores, a experiência, interpretação essencial e consistência.

\section{Tipos de avaliação ou classificação}

O comitê é muito comprometido com os resultados de suas decisões. Muitas vezes, é colocado em uma situação difícil para tomar decisões. Durante as reuniões, ficou claro que a mistura de classificação e tipos de avaliação 
torna as decisões complicadas e difíceis. Entendendo melhor os documentos oficiais, nos quais o comitê deve basear sua fundamentação, e o fato das decisões considerarem a "classificação", a "penalidade" e tipo de avaliação em um único ato e sob um único título. Isso ocorre porque a classificação de um programa de residência também será o tipo de avaliação que receberá. As opções são:

- Progess Report (PR) - Relatório de progresso;

- Internal Review (IR) - Avaliação Interna;

- External Review (ER) - Avaliação Externa.

Conforme a gravidade e tipos de problemas apresentados, aumenta a severidade da avaliação.

No entanto, existe um fator complicador na tomada de decisões: o tempo para que uma nova avaliação seja realizada.

\section{$\underline{\text { Tempo para a avaliação }}$}

Os ciclos de avaliação são parte das mesmas decisões de classificação de cada programa. Às vezes, além da importância ou gravidade do ponto fraco encontrado, uma "inversão" de gravidade na classificação é necessária para dispor de informações tão rapidamente quanto possível.

Nesses casos, o Relatório de Progresso - Progress Report é a classificação que atende à demanda, sendo realizado em poucos meses.

No caso de uma Avaliação interna ou externa - Internal Review e External Review isso só é possível em intervalos de dois anos, o que inverte a lógica das decisões quando se toma a perspectiva de tempo. 
Gravidade dos problemas na perspectiva do tempo para avaliação. Iniciando pelo maior tempo de resposta (em anos) para a maior urgência (em meses), conforme se vê, diagramaticamente, nas figuras 6 e 7:

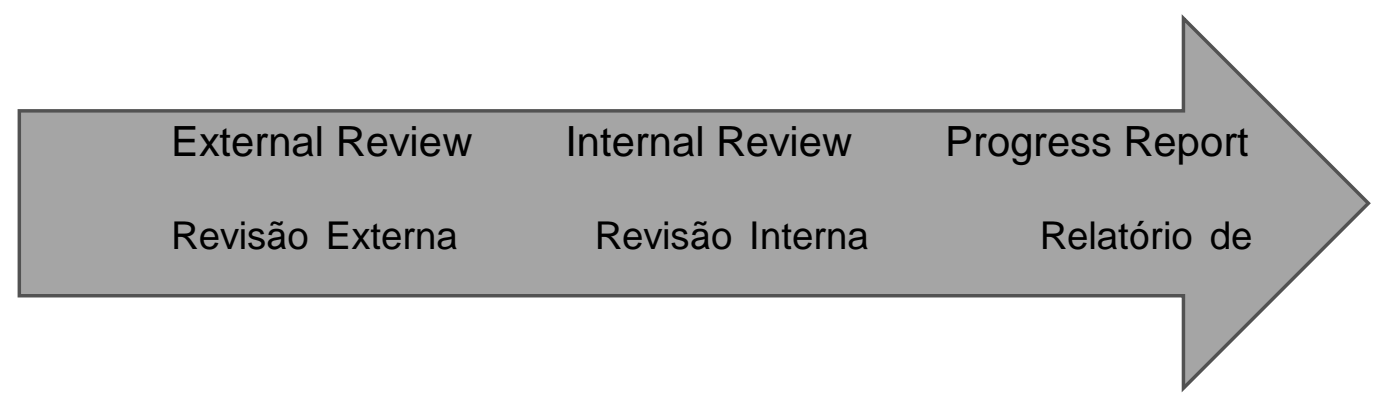

Figura 6 - Velocidade no tempo de resposta da avaliação

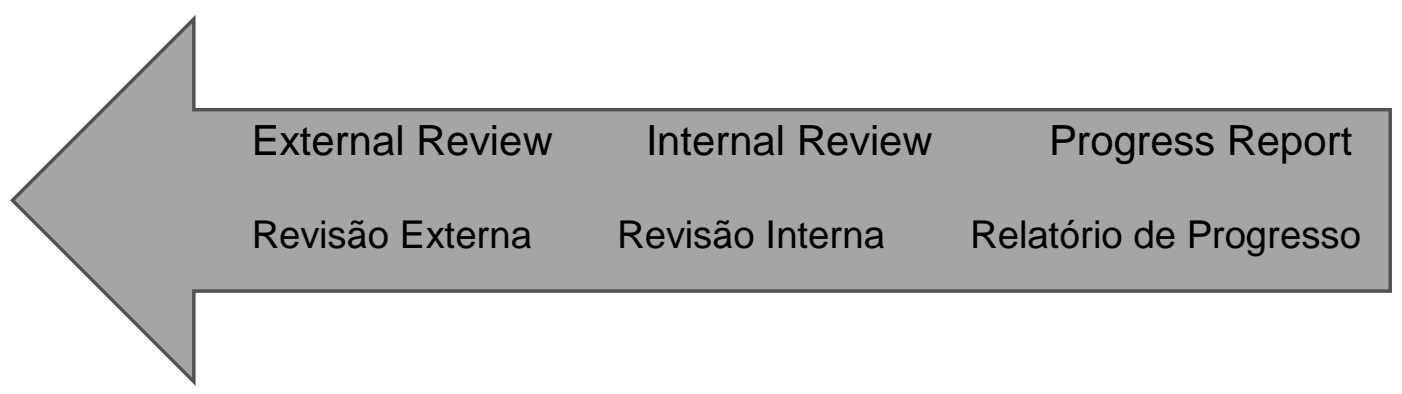

Figura 7 - Grau de relevância da avaliação

O que ocorre é que a estrutura para uma avaliação, em especial externa (ER), é tão grande e pesada que a torna morosa, dificultando ou impossibilitando uma avaliação, Interna ou Externa, para os problemas de emergência. Uma ER exige grande quantidade de documentação e complexidade de efetivação, tornando difícil decidir por esse tipo de avaliação, como resposta no tempo necessário. Outro ponto a se considerar é a utilização de médicos voluntários como avaliadores. A ausência de um banco de avaliadores, com carga horária disponível para a tarefa, torna impossível a agilidade de resposta. 
Aliado à complexidade das classificações e do tempo para a avaliação está o fato do comitê se basear em documentos e relatórios que tentam expressar a realidade.

\section{Capacidade de capturar a realidade}

Desde Platão, temos a dúvida de quanto sabemos do mundo real e quanto temos apenas uma dimensão deformada, sombras, do que vem a ser o real. Portanto, não é exclusividade dos processos de avaliação e acreditação trabalhar com "recortes", "imagens" ou "biópsias" da realidade.

A capacidade dos relatórios enviados ao comitê em capturar e transmitir os dados de um programa pode ser estressante para a comissão. Na acreditação, é importante não apenas recolher uma boa quantidade de informações, mas valorar quão qualificada é a informação obtida. Questiona-se a necessidade de um número maior de perguntas mais abertas, com dados mais qualitativos, para auxiliar o pensamento e o entendimento da situação real do programa.

Um tema delicado e que parece ser preocupação do comitê é a fonte de informação. Nem toda a informação é proveniente da instituição acreditadora (avaliação externa, ER). Na verdade, grande parte dos dados provêm da instituição que está sob avaliação e acreditação (IR ou PR). Apesar de não se conseguir saber se todas as Universidades têm o mesmo comportamento ético na prestação de dados, é esperado que sejam absolutamente confiáveis.

\section{Os avaliadores}

A confiabilidade do sistema de acreditação é bastante influenciada pelo compromisso e compreensão dos médicos avaliadores de programas com a 
avaliação. No entanto, em alguns relatórios, as informações são confusas, incompletas ou anotadas em local inadequado, influenciando a tomada de decisão do comitê de acreditação.

Como o Comitê deve trabalhar com os dados que são fornecidos pelos avaliadores, habilidades como a escrita qualificada, a descrição focalizada e a capacidade de síntese, no relatório, são valiosas para o processo. Não só o que está escrito, mas também como está escrito, pode afetar as decisões das comissões.

Finalmente, o relatório de um avaliador não treinado pode fornecer tão pouca informação que os dados reunidos para apoiar o processo de tomada de decisão não são suficientes. Esse é o momento em que é necessário esforço do comitê para adicionar dados e realizar interpretações na tentativa de compensar a falta, muitas vezes, motivada pela pouca de experiência do avaliador.

\section{A experiência e a interpretação essencial}

As decisões tendem a ser o mais objetivas e diretas possível, pelo menos na maioria dos casos. Em cada programa avaliado, pontos fracos e fortes são abordados seguindo os itens e subitens preconizados pelas normas e parâmetros publicados. No entanto, não se trata de apenas aplicar critérios previamente descritos. A experiência de avaliação dos médicos presentes no comitê faz diferença.

O uso de experiência e interpretação é necessário para analisar as nuances do processo, quando algo parece "estranho" ou os dados do relatório não estão tão claros. A regra é aplicada tanto na análise pontual de dados do relatório quanto quando da avaliação do contexto geral do programa em análise. 
Algumas vezes, as informações isoladas podem ser descritas como um ponto fraco do programa, enquanto a análise da situação de forma geral pode ser, entendida como um avanço, uma melhoria, diante de situações anteriores. Consistência

A consistência é muito importante para manter a validade e a confiança do processo. No entanto, consistência não pode significar repetir a mesma decisão para todos os casos parecidos nem seguir exatamente "a regra do livro".

Novamente, a importância de ter um comitê experiente e competente para a tarefa faz a discussão, caso a caso, ter consistência. Os debates internos tentam atingir um equilíbrio entre as interpretações, as regras e o que é justo para cada caso.

A consistência das decisões acaba por surgir do padrão de decisões que o comitê, sendo relativamente estável, possui ao longo do tempo.

\section{Discussão}

Não restam dúvidas de que a acreditação é um eficaz motor para a constante qualificação dos programas [116]. O trabalho do Comitê de acreditação da residência médica é essencial e deve ser exercido por pessoas experientes com conhecimento e vivencia na avaliação e direção de programas de residência médica. O conhecimento e a vivência permitem que as necessárias interpretações dos dados possam se aproximar da realidade do programa, deixando as decisões mais justas. 
Novamente, observou-se a importância dos avaliadores de programas e a necessidade de treinamento e experiência destes. Seus relatórios são a fonte principal pela qual as decisões serão tomadas.

A análise do comitê trouxe uma interessante e inesperada resposta sobre parte dos processos do atual sistema de acreditação. As categorias em que podem ser alocados os programas da residência médica são crescentes em gravidades. No entanto, são decrescentes no que se refere ao tempo de resposta. Essa oposição de direção torna o trabalho do comitê ainda mais complicado. Problemas muito importantes podem receber "penalidades" (ou categorias ou avaliações) mais leves (progress report) dada a necessidade de se obter informações de maneira rápida. Esses processos, talvez, mereçam ser reavaliados, tornando-os mais ágeis. Inclusão de uma categoria e equipe de resposta rápida pode ser benéfico ao sistema. 


\title{
CAPÍTULO VI: REVISÃO INTERNA - UM ESTUDO DE CASO
}

\author{
A etapa intitulada "ON THE IMPORTANCE AND RULE OF THE \\ INTERNAL REVIEW ON RESIDENCY ACCREDITATION PROCESS: CASE \\ STUDY" surge da curiosidade e de um "estranhamento" do pesquisador. Trata- \\ se uma avaliação, ou de uma meta avaliação [117], sob a forma de \\ autoavaliação, que é autogerida, aplicada pela própria instituição, como parte \\ integrante da acreditação. As avaliações internas (Internal Review - IRs) podem \\ ter vários papéis. Há, por exemplo, as IRs "sugeridas" pelo RCPSC, que podem \\ ser realizadas pela Universidade entre os ciclos de avaliação, com intervalo de \\ seis anos, cujos dados ficam na Universidade e não seguem para a instituição \\ acreditadora. Trata-se de importante autoavaliação para correção de rotas. \\ Para entender tal processo, é necessário compreender melhor os resultados \\ possíveis das decisões do comitê de acreditação: Avaliação Externa - External \\ Review (ER), Relatório de Progresso - Progress Report (PR) e Avaliação \\ Interna - Internal Review (IR).
}

\section{O contexto}

Uma grande ER em todos os programas de uma universidade é realizada como parte da acreditação a cada seis anos. Antes disso, porém, uma ER pode ser realizada por uma decisão do comitê de acreditação quando problemas maiores são identificados em mais de um critério, ou há problemas particulares de uma especialidade, exigindo a presença de um avaliador com a mesma formação, tornando impossível a observação por alguém da mesma 
universidade. A ER também pode ser indicada quando problemas observados em avaliações anteriores se mantêm persistentes; ou ainda quando os pontos fracos de um programa não estão diretamente relacionados com questões educacionais. Após solicitada, a Universidade organiza e conduz uma ER, em um prazo de 24 meses, mas com a presença de avaliadores externos.

Os Progress Reports, PR, são frutos da decisão do comitê de acreditação quando existem preocupações com questões específicas. Os PR são relatórios escritos pelo diretor do programa de residência médica (correspondente ao supervisor de um PRM no Brasil) e enviado no prazo de 12 a 18 meses, com a intenção de obter um acompanhamento do programa [118].

O papel da revisão ou avaliação interna - IR - tem sido discutido em vários sistemas de acreditação [96]. A IR pode ser vista como processo formativo, uma autoavaliação, ou um dos passos na classificação do sistema de acreditação.

Uma IR é baseada em formulários e diversas entrevistas, envolvendo o supervisor do programa (ou PD), professores, residentes, chefes de departamento e de área.

A IR chamada mandatória é parte integrante do processo de acreditação, e é integralmente conduzida pela própria universidade, requerida quando a instituição apresenta um problema mais grave (major issue), em mais de um critério, na última avaliação. A instituição tem então dois anos para preparar e realizar a IR que será considerada e integrará uma das classificações a serem definidas pelo comitê de acreditação.

Raramente a IR terá visitas in loco, (dos locais de prática) porque a equipe, sendo da mesma Universidade, costuma ter algum conhecimento de 
recursos humanos, procedimentos e instalações. As visitas nesses cenários acabam por ser reservadas apenas para as equipes de Avaliação Externa, ER, com algumas exceções.

O grande número de definições da IR é tema tão importante que existem pesquisas que discutem até mesmo a substituição das ER por IR em alguns casos [95], o que implica dizer que a as instituições passariam a serem as principais responsáveis por sua própria avaliação e acreditação.

Métodos para essa etapa

Revisão de literatura e de documentação proveniente da instituição acreditadora e da Universidade objeto de investigação foram analisados no início do presente estudo de caso (5), com o objetivo de responder às perguntas do pesquisador sobre o que é e qual é o papel de uma IR, como é realizada e sua função no processo canadense de avaliação e acreditação de programas de residência médica. Neste capítulo, seguir-se-á a sequência descrita por Yvonna Lincoln e Egon Guba para estudo de caso-Case study [119]. O problema, o contexto e as questões (The problem, the context and the issues) foram apresentados na Introdução deste capítulo, bem como discutido em capítulos anteriores e servirão de base para análise dos resultados coletados e descritos. Como requer a metodologia, a observação de um único caso de Revisão ou Avaliação Interna mandatória foi avaliada por diversos aspectos e perspectivas diferentes, com a intenção de se entender o fenômeno de forma geral, também dividindo e avaliando as partes do processo. 
A população pode ser entendida como todas as pessoas que de alguma maneira estiveram envolvidas, desde a produção dos formulários, passando pela logística das visitas entre outros, ou como o próprio processo "Revisão Interna" que é parte integrante do sistema de acreditação da residência médica e transformou-se no sujeito e no objeto do estudo.

Os dados começaram a ser coletados no interior do comitê de acreditação da Universidade, pela análise de documentos e formulários. Nesse mesmo setor, acordos de sigilo e confidencialidade foram assinados. Uma entrevista livre e aberta, sem a aplicação de instrumentos padronizados, foi realizada com a diretora responsável pelas "Revisões Internas".

O mesmo setor concedeu autorização para participação deste pesquisador no que se refere ao agendamento, definição de equipe, como observador durante a realização da Revisão ou Avaliação Interna, entrevistas e questionamentos sempre abertos e não estruturados, a todos os envolvidos, de acordo com o surgimento de demanda ou dúvida, em cada etapa.

O registro dos dados foi realizado por meio de notas tomadas durante todo o processo pelo pesquisador. Citações e emoções relevantes foram coletadas durante o estudo e aqui transcritas (tradução pelo pesquisador) para exemplificar o que foi observado, como no exemplo ilustrativo:

"Acredito que precisaremos melhorar nisso" [nota-se que o diretor de programa está muito tenso, mexe-se na cadeira todo tempo e reduziu o tom de voz]."

Após finalizado o texto, todo o material transcrito, fruto de citações, foi removido para garantia de confidencialidade. 
Nenhum material foi gravado.

Dúvidas posteriores foram solucionadas via mensagens eletrônicas, telefonemas ou presencialmente com a equipe de avaliadores da revisão interna, diretoria de pós-graduação, comitê de acreditação, funcionários da instituição acreditadora (RCPSC) e especialistas envolvidos no processo de acreditação da Universidade em estudo. A figura 8 ilustra a captação de dados no estudo de caso sobre avaliação interna.

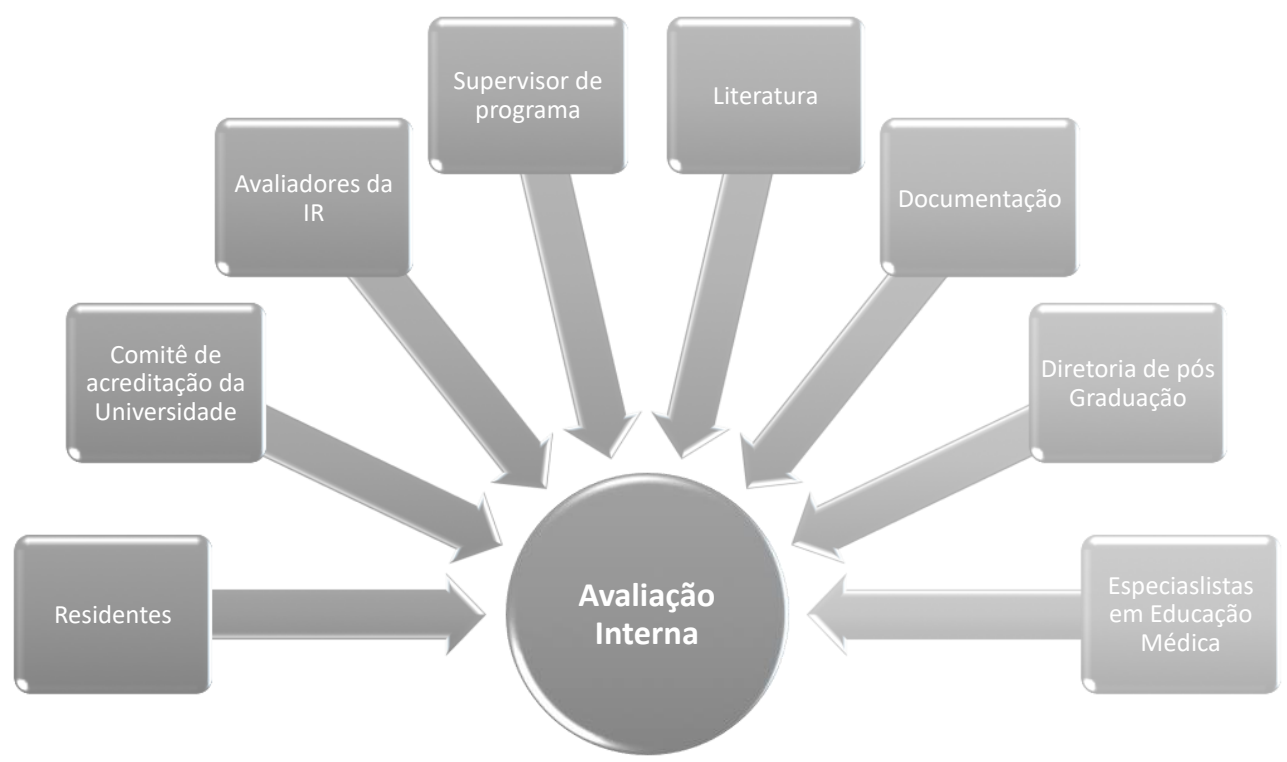

Figura 8 - Captação de dados em estudo de caso

Fornecer os dados relativos ao local e à data poderiam identificar o caso em estudo, portanto, limitamos à informação de que o estudo ocorreu no ano de 2015, em uma universidade canadense.

A informação relativa à interpretação da revisão interna foi recolhida para fornecer uma melhor compreensão dessa ferramenta de avaliação. A conclusão concentrar-se-á em lições aprendidas. 
Análise dos dados de todo material coletado e descrito acima (como documentos e anotações) foi realizada a partir das descrições pormenorizadas da experiência vivida, imediatamente após cada etapa da coleta de dados. Os textos foram compilados neste capítulo e são apresentados em resultados, seguindo a lógica do tempo e dos objetos avaliados pela "revisão/avaliação interna".

Resultados desta etapa

A agenda de uma Avaliação Interna é muito bem planejada. Existem limites definidos de tempo para cada pequena atividade, inclusive até mesmo as pausas para lanche e almoço são preestabelecidas e pré-definidas pela direção responsável pela avaliação. Pausas para lanches e almoço ocorrem e são fornecidos na própria instituição para que cada minuto seja aproveitado. Esse detalhe simples mantém focada a equipe de avaliação do começo ao final do processo e a avaliação interna pode ser feita, inteiramente, no interior de uma ou mais salas de reuniões. A tabela 9 mostra um exemplo de agenda para a avaliação/revisão interna de um programa de residência médica.

Durante uma IR, a instituição avaliada e avaliadora é a mesma, implicando em raros deslocamentos para verificação de estrutura e dos locais de prática ofertados, costumeiramente já de conhecimento dos avaliadores, os quais, no mínimo, têm uma boa ideia do local. 
Tabela 9 - Agenda de uma revisão interna

\begin{tabular}{l|l}
\hline \multicolumn{2}{l}{ Agenda de uma avaliação ou revisão interna } \\
\hline Tempo & Atividade \\
\hline 30 minutos & Revisão de cocumentos \\
\hline 60 minutos & Entrevista com diretor de programa \\
\hline 60 minutos & Entrevista com residentes \\
\hline 15 minutos & Intervalo - Devem ser servidos itens de um coffee break \\
\hline 30 minutos & Entrevista com chefe do departamento e com chefe da divisão \\
\hline 30 minutos & Entrevista com os docentes \\
\hline 15 minutos & Almoço deve ser servido na instituição em avaliação \\
\hline 60 minutos & $\begin{array}{l}\text { Entrevista com os membros do comitê de residência do programa } \\
\text { em avaliação }\end{array}$ \\
\hline 15 minutos & Intervalo - Devem ser servidos itens de um coffee break \\
\hline 60 minutos & Discussão privada entre os avaliadores \\
\hline 15 - 30 minutos & $\begin{array}{l}\text { Reunião de saída com o diretor de programa (momento do } \\
\text { feedback) }\end{array}$ \\
\hline
\end{tabular}

Seleção da equipe de avaliação interna

A equipe é composta por três avaliadores, sendo um o médico-chefe da avaliação, um médico-residente-avaliador e um médico-avaliador. Nenhum deles pode pertencer ao mesmo departamento ou à mesma especialidade que está sendo avaliada. Todos são avaliadores voluntários e não necessariamente possuem algum treinamento para o desempenho da tarefa.

Muitas vezes, o mais experiente do grupo (como no caso em estudo) é o residente, posto que em cada instituição existe apenas um ou no máximo dois residentes designados como residente-avaliador, o qual realiza quase todas as avaliações. O presente caso em estudo foi a primeira experiência do médico- 
chefe da avaliação, já o médico-avaliador possuía experiência de uma avaliação prévia. Ambos, no entanto, já haviam sido submetidos à acreditação em seus departamentos.

\section{Revisão de documentos}

A Avaliação Interna geralmente começa com a revisão de documentos, com duração de 30 minutos. O tempo é precisamente pré-definido e a equipe de avaliadores divide as tarefas para ler, tomar notas e coletar informações em sete pastas volumosas. Essas pastas contêm informações sobre: metas e objetivos do programa; currículo escolar; decisões do comitê do programa e minutas; clubes de revista, habilidades processuais e clínicas; avaliações realizadas no programa; dados, histórico e demais informações sobre os residentes; políticas relacionadas aos casos de assédio e abuso; defesa da saúde; entre outras informações.

Os avaliadores devem classificar os informes coletados em pontos fortes e fracos.

Normalmente, os médicos-avaliadores da equipe não analisam a pasta sobre os residentes e o residente-avaliador não tem tempo para ver as outras documentações, além da pasta contendo as informações específica dos residentes.

\section{Entrevista com diretor do programa}

O momento inicial da avaliação parece ser mesmo o mais estressante. Durante 60 minutos, o supervisor de programa (PD) explica os pontos fortes e fracos de seu programa. Os avaliadores se mantêm todo tempo em silêncio. 
O PD mostra sinais de estresse como leve gaguejar, boca seca, agitação discreta das mãos, uso de frases ou palavras repetitivas durante 0 discurso, mesmo quando o programa não apresentou (como no presente caso) nenhuma fraqueza reconhecida pelo processo de revisão interna. Esses sinais podem ser o resultado do esforço anterior que o PD realizou para conduzir o processo até esse ponto. Também podem demonstrar a seriedade, o peso e 0 respeito de uma avaliação interna, revelando que a revisão interna não é encarada como algo leve, "café com leite" no jargão do português no Brasil, mas como (qualquer outra avaliação) em consequentes repercussões (positivas ou negativas) na imagem e acreditação do programa.

Depois de algum tempo de explanação, os avaliadores passaram a obter mais informações sobre a experiência e capacidade do PD para dirigir o programa, bem como o interrogaram sobre os pontos fracos que reconhecia (e com menor preocupação os fortes), sobre o que deveria ser melhorado e qual seria o plano de ação para as mudanças.

Detalhes importantes como a relação do PD com os residentes, se os defendia, se havia proximidade, se os conhecia bem, com que frequência se reunia com eles foram capturados e demonstraram o grau de conhecimento do PD sobre o programa de residência de maneira geral, muita além do estágio que coordenava ou do "ambulatório" em que atuava. Ainda, foi avaliada a sua capacidade em lidar com problemas relacionados com o corpo docente, médicos do hospital, responsáveis em cada rodízio.

O PD explicou ainda se havia algum tipo de trabalho sendo desenvolvido para além das normas básicas solicitadas pela acreditação: avaliações complementares e formativas, tipos de feedback, rodízios adicionais, cursos especiais, oportunidades de aprendizagem em outras 
Universidades, países ou projetos inovadores; do mesmo modo informou qual era o valor e como vinha sendo feito o financiamento de pesquisa, participação em congressos etc.

O clima estressante da entrevista tendeu a diminuir apenas na final. No caso em estudo, isso só ocorreu quando um avaliador mais experiente expressou empatia pelo PD, compartilhando suas próprias experiências vividas em casos semelhantes e encerrou a entrevista.

\section{Entrevista com residentes}

Durante 60 minutos, os residentes são entrevistados de forma objetiva. Normalmente, os avaliadores são mais ativos do que nas demais entrevistas, ofereceram espaço relativo para respostas do grupo e continuaram a fazer perguntas diretas. Não houve tempo para debates, assuntos ou explicações muito longas.

Os avaliadores tentaram obter a maior diversidade possível de respostas a partir das informações fornecidas. A técnica de entrevista usada evitou a centralização do discurso em um ou em poucos residentes, havendo provocação, pelos avaliadores, o tempo todo, para que os mais quietos se expressassem. Até mesmo residentes que estavam realizando estágios em outras localidades, como em área indígena ou rural, foram chamados a participar, via teleconferência ou, em caso de indisponibilidade, por telefone. $\mathrm{O}$ ambiente foi calmo, tranquilo e amigável todo o tempo, mesmo quando alguns problemas ou pontos fracos do programa estavam em discussão.

Nessa reunião, assim como em todas as outras do processo de acreditação, cada informação foi sempre classificada em pontos fortes e fracos. 
Entrevista com chefe de departamento e chefe de divisão

Nesse ponto, o clima é de muita calma, a entrevista tem apenas 30 minutos de duração. Os avaliadores tenderam a fazer perguntas, reservando tempo para que os chefes contassem histórias e fizessem comentários livremente. O foco da entrevista se concentrou nos pontos fracos e pontos fortes. Na verdade, nesse momento, os avaliadores trataram de confirmar ou não as informações recolhidas nas demais entrevistas.

Durante todo o tempo o nível de engajamento do chefe de departamento e do chefe de divisão em que insere o programa em análise é observado. Os avaliadores esperam que os chefes demonstrem plena compreensão dos pontos fracos e fortes do programa, em alinhamento com o PD, principalmente no que se refere ao plano de ação para busca de qualidade e soluções para os problemas.

Ao final do caso em estudo, o programa demonstrou bom desempenho, o que abriu espaço para que os avaliadores se sentissem livres para trocar experiências e dar sugestões para melhoria do programa.

Nesse ponto da entrevista, a estratégia de coleta de dados e verificação deles passa a ser repetitiva. Não há dados novos e não se espera que apareçam novidades.

\section{Entrevista com docentes}

O clima foi de muita calma. Nenhum estresse pareceu estar presente. [Os avaliadores pareciam estar cansados]. A sensação de que nenhuma nova informação seria adicionada parecia dominar a equipe de avaliação e foi 
necessário esforço para manter o ritmo. O foco nos pontos fracos e fortes e as informações fornecidas, até então, foram verificadas novamente.

Porém, além da verificação das informações, a integração da faculdade no programa foi questionada nesse momento. Surgiram questões como: tempo protegido para ensinar, diferentes papéis de que os docentes precisam desempenhar, questões salariais e de reconhecimento, papel do docente e do residente na defesa da saúde global e local, sistema de saúde e plano de carreira.

Verificou-se, nesse ponto, que não apenas o cansaço, mas também a identificação dos avaliadores, enquanto pares, com as temas dos docentes (os dois médicos avaliadores nesse caso em estudo eram docentes) fez com que a rigidez, que vinha sendo imposta até aquele momento nos questionamentos, fosse atenuada, possibilitando alguma troca de experiências.

\section{Almoço e tempo de discussão privativa}

Nesse momento, o pré-relatório começou a ser discutido pelos avaliadores. Isso ocorreu porque o citado texto deveria ser apresentado no mesmo dia.

No almoço, servido pelo departamento avaliado, a equipe de avaliadores se mantém isolada dos avaliados e em discussão sobre o programa. Nesse momento ,as impressões de cada um foram compartilhadas. Os avaliadores falaram sobre suas preocupações ou fizeram elogios sobre temas específicos do programa de residência em avaliação. 
Interessante ressaltar que no caso em estudo os avaliadores permaneceram "confinados" na mesma sala todo o tempo. Incluindo o almoço. Entrou-se na referida sala às sete da manhã até o final da tarde.

Entrevista com os membros do Comitê de Residência do Programa em Avaliação

Nesse ponto, a reunião de 60 minutos foi nitidamente percebida como pesarosa. Parecia, mais uma vez, que não havia novas informações. A informação foi apenas verificada novamente e as mesmas perguntas foram repetidas.

Nesse ponto, o PD, que é também membro do comitê, retornou à presença equipe de avaliadores. Interessante notar que dessa vez o PD pareceu diferente. Talvez protegido pelo grupo, ou porque o estresse da apresentação inicial havia sido "removido de suas costas", a reunião ocorreu mais solta e o PD estava mais leve para falar dos mesmos temas apresentados. Os sinais de estresse observados anteriormente não estavam mais presentes.

Intervalo (cofee break) e discussão privada

Os 15 minutos de pausa e 60 minutos privados de discussão dos avaliadores foram utilizados para preparar o pré-relatório. O primeiro intervalo (da manhã) não foi descrito, pois foi dedicado sobretudo para questões pessoais de cada avaliador (telefonemas, banheiro etc). Preparar o prérelatório em conjunto é um processo interessante. Surgiu, o tempo todo, questionamento de como encaixar as informações capturadas até aquele ponto, no relatório padronizado pelo RCPSC. Muitas das informações 
consideradas importantes pelos avaliadores não se enquadravam em nenhuma das opções, assim como outras consideradas de pouca relevância para o programa apareciam no relatório com "intenção", ou direcionamento, diferente do que foi visto. Houve receio dos avaliadores de que um ponto, que todos consideraram como positivo, pudesse ser interpretado negativamente pelos revisores ou pelo comitê de acreditação.

Algumas vezes, a decisão da equipe foi deixar algumas informações fora do relatório para que o programa não corresse risco de ser mal interpretado ou quando não se encontrou local específico para que os dados fossem descritos.

Transportar os dados para o relatório é uma tarefa mais difícil do que parecia à primeira vista.

É curioso que quando estavam sozinhos os avaliadores passaram a debater os pontos fracos e fortes do programa e a trocar soluções e sugestões para correção de rota, de acordo com suas experiências prévias em seus programas. Para o pesquisador, tratou-se de momento de grande aprendizagem para os avaliadores.

\section{A brecha}

Houve um momento em que o tempo privativo dos avaliadores estava terminando e a discussão final com o diretor do programa prestes a começar.

Uma pequena brecha no tempo que não faz parte do cronograma padrão da Revisão/Avaliação Interna representou, ao olhar do observador/pesquisador, como o momento mais importante da experiência de troca entre os pares. Sugestões e soluções discutidas pelos avaliadores foram compartilhados com o PD, o qual foi esclarecido de se tratar de momento informal, out of records. 
Nesse momento, ocorreu aprendizagem para todos e, provavelmente, possibilidade de incremento na qualidade do programa.

Falou-se muito do que não se encaixou nos relatórios e o porquê.

Por ter noção da existência de uma assimetria de poder entre o avaliador e o avaliado, essa conversa ocorreu de maneira muito polida, como um relato das próprias experiências e vivencias, removendo-se qualquer tom de aconselhamento ou apontamento do que deve ser feito.

\section{$\underline{\text { Reunião final com diretor de programa (momento do feedback) }}$}

Entre os avaliadores, a tensão de como preencher o relatório e finalizá-lo ainda estava presente, mas 0 ambiente foi em geral mais leve, com o PD compreendendo quais eram os pontos fracos identificados e repetindo o plano de ações e soluções que já havia sido apresentado no início do dia. A equipe de avaliadores definiu e comunicou em qual categoria o programa de residência foi classificado. Explicou para o PD o que constará no relatório e como será descrito. Nesse momento em que há "reversão da tensão" no caso em estudo, foi o PD quem tranquilizou os avaliadores, apontando que colocar pontos fracos no relatório funcionará como motor para acelerar as mudanças necessárias.

\section{Comitê de Acreditação}

Importante notar que as Revisões Internas mandatórias são tratadas pelo Comitê de Acreditação como parte integrante do processo de acreditação. Nenhuma diferença pôde ser observada entre o tratamento dos dados fornecidos pela Revisão Externa (ER), Revisão Interna (IR) ou Relatório de Progresso (PR). 


\section{Local de avaliação}

Se por um lado é menos custoso e prático que os avaliadores estejam em suas próprias cidades, por outro, observou-se que, como as revisões internas ocorrem na própria instituição do avaliador, elas foram interrompidas várias vezes com questões locais, durante a avaliação.

É frequente que algum dos avaliadores tenha de sair da sala durante uma entrevista a fim de atender uma chamada, pois ao permanecerem nos seus locais de trabalho têm de manter, pelo menos em parte, a sua disponibilidade para responder às necessidades de seus departamentos.

Discussão e lições aprendidas com essa etapa

Revisão Interna é uma ferramenta muito importante para avaliar programas de residência médica. A existência da IR em todos os programas parece ser uma grande vantagem dos processos de acreditação do RCPSC. No entanto, a posição indefinida entre um processo formativo, um processo de autoavaliação ou, quando mandatória, como parte do processo de acreditação, pode contribuir para tornar a IR estressante e sem direção clara.

Considerada a sua face de ferramenta de autoavaliação para a Universidade, um processo formativo, a IR atua como parte essencial do ponto de vista de capacitação para todos os envolvidos e poderia permitir mais momentos de troca, no entanto, colocaria em risco o empenho e a isenção de todos os profissionais na avaliação. 
Se considerada sua face de avaliação mandatória como parte integrante da acreditação, como no caso em estudo, o rigor aumenta, mas limita a possibilidade de troca e aprendizagem.

O relatório poderia ser mais aberto, dando maior margem para explicações dos avaliadores. Quando a IR ocorre como autoavaliação, o relatório permanece na Universidade, suprimindo o receio de "consequências inesperadas" ao programa e dando a oportunidade para que a instituição corrija seus pontos fracos, de modo independente. Por outro lado, quando o processo se torna meramente formativo e a IR permanece apenas na Universidade, 0 empenho e "a energia" empregados na avaliação podem não ser suficientes para as devidas correções. Devemos lembrar que a sensação de desconforto proveniente do poder de uma acreditação pode ser um "motor" útil para mudanças.

As equipes de avaliação das IRs precisam ser treinadas. O processo de formação de avaliadores poderia ser centralizado pela RCPSC para garantir a uniformidade entre os pares, não apenas na informação a ser capturada, mas também em dados a serem fornecidos pelos relatórios. Em verdade existe um workshop ofertado pelo RCPSC durante o International Congress of Residency Education - ICRE, porém, como descrito em capítulos anteriores, esse treinamento não é obrigatório e considerado insuficiente pelos médicosavaliadores. Ao treinar e assessorar os avaliadores, estes podem se sentir mais confortáveis na elaboração do relatório e na gestão dos dados recebidos, qualificando o material que será enviado ao Comitê de Acreditação.

Poderiam ser incentivadas as trocas de experiências, as sugestões e as ideias entre os avaliadores e os avaliados. Esse momento é mantido fora dos 
registros, mas pode ser compatível com a IR. Os docentes têm vocação educadora por excelência e parecem estar ávidos por ajudar uns aos outros, mas não existe espaço oficial para isso.

Esse espaço poderia ser oficializado e incluído da agenda final. No treinamento dos avaliadores, poderia haver espaço para seleção e qualificação das informações a serem compartilhadas. $O$ tom de apenas sugestões e conversa deve ser mantido para que não se transforme em "julgamento antecipado", mas um espaço tão rico, aqui chamado de brecha, não pode ser perdido, pois parece ser em grande parte responsável por qualificar os programas, não apenas na opinião do pesquisador, mas também de muitos médicos avaliadores entrevistados durante esta pesquisa.

O processo de revisão interna poderia ser redesenhado. Este estudo de caso demonstrou que os dados pareciam saturados no início do período da manhã. A repetição de perguntas, sem novas informações, torna o processo cansativo e pesaroso.

Se o objetivo é testar as informações com diferentes atores, algumas entrevistas, com professores, chefes de divisão e de departamento poderiam ser feita separadamente, mas ao mesmo tempo, em salas diferentes, cada qual conduzida por um avaliador e depois comparadas na reunião privativa. Esse tipo de estratégia possibilitaria tempo para visitar o ambiente de aprendizagem do programa, como ambulatórios, enfermarias etc. (visita in loco), ainda que o ambiente seja ou devesse ser previamente conhecido, passaria a ser observado sob olhar do, agora, avaliador.

O autor acredita na importância de se implantar a Revisão Interna nos países onde ela ainda não é realidade por seu potencial de autoconhecimento 
e qualificação de um programa de residência. Porém, deve funcionar como meta de avaliação, de caráter formativo, sob assessoria e treinamento da instituição independente, acreditadora, com correção e comentários de comitês de revisão ou câmaras técnicas formadas por especialistas. 


\section{CAPÍTULO VII: BRASIL - ASPECTOS GERAIS E A EDUCAÇÃO MÉDICA}

O Brasil é o maior país da América do Sul. Em março de 2016, a estimativa populacional era de 205.611.125 habitantes[120]. Em 2014 o Produto Interno Bruto (PIB) foi de USD \$ 3,28 trilhões, a taxa de desemprego foi de 4,8\% em 2014 e a renda per capita em USD \$ 16.200[121], sendo por isso considerado upper middle income country [122].

Recentes abalos políticos no país têm impactado fortemente na economia, elevado a inflação e a taxa de desemprego, bem como reduzido a taxa de crescimento do país. No cenário internacional, a queda do preço do barril de petróleo para cerca de $25-30 \%$ dos preços praticados há 10 anos ameaça reduzir as verbas futuras destinadas aos Ministérios da Saúde e Educação, porque os investimentos futuros nas pastas estão atrelados a royalties de petróleo. Este e outros motivos atemorizam sobre o futuro da qualidade na educação médica em nosso meio.

\section{O Sistema de Saúde}

A 8a Conferência Nacional de Saúde assume, em 1986, as reinvindicações do chamado "movimento sanitarista". Dois anos mais tarde, em 1988, a Constituição Federal é promulgada, concebendo o sistema único de saúde (SUS) e garantindo que "saúde é direito de todos e dever do Estado" [123, 124]. O SUS é um sistema público de saúde e tem como princípios doutrinários: a universalização (todas as pessoas têm direito à saúde enquanto 
componente fundamental da cidadania), a equidade (para dirimir as desigualdades) e a integralidade (observar as pessoas de forma geral, integrando ações nos diversos níveis de saúde). Além dos princípios doutrinários, o SUS também possui princípios organizativos: regionalização e hierarquização; descentralização e comando único; participação popular [125]. O SUS apesar de possuir um único fim que é a saúde das pessoas não é inteiramente público. O sistema permite ainda que empresas privadas e conveniadas de saúde tenham ações complementares ao setor público de saúde. Esse sistema, uma vez complementar nas ações de saúde, pode participar direta ou indiretamente, estabelecendo um sistema privado, paralelo e regulado pela Agência Nacional de Saúde Suplementar. O setor vem crescendo rapidamente com presença de grandes companhias seguradoras no controle dos negócios, prestando cuidados de saúde a mais de 50 milhões de pessoas atualmente [126]. Os médicos formados no país e os que revalidam seus diplomas servirão ao SUS, seja no setor público exclusivo, suplementar

exclusivo ou em ambos. É possível ainda o desempenho, exclusivamente privado da profissão, executado, atualmente, por uma minoria de médicos, formados há mais de três décadas [127].

\section{Educação médica no Brasil}

No Brasil colonial, inicialmente, excetuando a medicina indígena, a medicina tradicional era praticada por poucos profissionais formados na Europa, sobretudo na França. Grande parte da atenção à saúde era realizada por práticos, curandeiros ou religiosos. 
No século XVII, houve invasão de Recife pelo povo holandês, por exemplo. Na época, a Holanda despontava como terra de grandes artistas, anatomistas e cientistas com consideráveis avanços para a medicina mundial. O médico holandês Guilherme Piso esteve no Brasil entre 1637 e 1644, e escreveu o primeiro livro de medicina "História Natural do Brasil", em que descreveu, principalmente, doenças infectocontagiosas.

A medicina começa, enquanto ensino superior no Brasil apenas durante a invasão de Portugal por Napoleão e consequente mudança da família real portuguesa para o Brasil. Uma das primeiras ações do Rei, no novo continente, foi lançar as bases da educação superior no país. Duas escolas médicas foram criadas com a chegada de D. João VI em, 1808, a Escola de Medicina da Bahia (atual faculdade de medicina da Universidade Federal da Bahia) e a Escola Anatômica, Cirúrgica e Médica do Rio de Janeiro (atual faculdade de medicina da Universidade Federal do Rio de Janeiro). A educação médica no Brasil tem mais de 200 anos de história [128].

Hoje, o país tem mais de 260 escolas médicas registrados no Ministério da Educação e Cultura, e está em ritmo crescente e acelerado. (www.escolasmedicas.com.br)

Durante o século $X X$, a influência europeia dividiu espaço com a norteamericana sendo de grande impacto, para a educação médica brasileira, o chamado relatório Flexner, que tratou do ensino médico no Canadá e EUA [129]. As escolas médicas no Brasil possuíam currículos baseados em três anos de ensino em ciências básicas e um segundo ciclo de ensino clínico centrado em hospitais, como principal campo de prática[130]. 
As Universidades no Brasil gozam de algum grau de liberdade na implementação dos seus currículos para distribuição de conteúdos e cargas horárias. No entanto, há diretrizes curriculares nacionais para medicina, estabelecidas em âmbito federal. A graduação em medicina no país deve ter seis anos de duração, geralmente divididos em três ciclos: dois anos de ensino pré-clínico (40 horas por semana), dois anos clínicos (40h por semana) e dois anos de internato (60h por semana).

Também no século $X X$ algumas instituições passaram a investir no desenvolvimento de modelos mais inovadores de ensino médico. Três cursos destacam-se como inovadores, entre 1964 e 1988, na educação médica brasileira, na Universidade de São Paulo, Universidade de Brasília e da Universidade Federal de Minas Gerais[131]. Podemos citar como exemplo o curso implementado nos anos 1960 na Universidade de São Paulo. O primeiro "curso centrado no estudante" integrando a medicina social e clínicas desde os primeiros anos do curso médico, e, diferente do modelo baseado em Flexner sem "divisões artificiais do conteúdo". Esse curso, no entanto, sofreu enorme pressão política e terminou alguns anos após o seu início [132].

"A Faculdade de Medicina foi incapaz de reconhecer o Curso Experimental como sua extensão ..., perdendo a primazia de ser a única Escola Médica no mundo que criou um centro experimental de educação médica" [132]

$\mathrm{Na}$ virada do século $\mathrm{XX}$ para $\mathrm{XXI}$, cursos já utilizando os modelos de Aprendizagem Baseada em Problemas, da Universidade de Maastricht na Holanda e Universidade McMaster no Canadá, começam a ser desenvolvidos no Brasil, na Faculdade de Medicina de Marília - Famema, em 1997 [133], na 
Universidade de Londrina - UEL em 1998 e na Universidade São Francisco USF em 1999.

Tendo em vista as experiências exitosas e as mudanças do ensino médico em todo o mundo, em 2001, foram publicadas as Diretrizes Curriculares Nacionais [134]. Essas diretrizes podem ser consideradas um ponto de virada simbólico na educação médica brasileira, com novos objetivos e orientação para metodologias ativas de ensino e aprendizagem.

O que parecia estar em um efeito crescente de qualidade, no entanto, vinha acompanhado de aumento quantitativo no número de escolas médicas e, em 2010, o país já contava com um dos maiores números de escolas médicas por habitantes do planeta - 179 cursos de medicina estavam ativos no Brasil, sendo 96 privados e 83 públicos [135].

Entre 2010 e 2016, houve incríveis curvas de crescimento no número de escolas médicas, sobretudo escolas privadas, a maioria com fins lucrativos, colocando o Brasil na segunda posição em número absoluto de escolas médicas no mundo, perdendo apenas para a Índia [75]. O Brasil possui, porém, população cinco vezes menor que a Índia. Em janeiro de 2016, haviam 267 escolas médicas [136].

A motivação para a política de incremento no número de escolas médicas foi justificada pelo governo federal como consequente a insatisfação populacional com o SUS (em especial em sua vertente pública) e com a taxa de médicos/habitantes. A taxa global de número de médicos por habitantes no Brasil era de aproximadamente 1,9/1.000 habitantes, o que motivou o governo brasileiro a colocar em prática um programa com diversas ações que, mais tarde, tornou-se a Lei 12871/13, conhecida como Mais Médicos [137, 138]. 
Entre as ações colocadas em prática pelo governo, brasileiro está o ambicioso plano de criar 11.400 novas vagas de graduação em medicina ao longo de um período de três a cinco anos. Com esse plano, a taxa esperada de médicos por habitantes será de 2,7/ 1.000 habitantes [45].

"Ao longo dos dois anos de programa, foram criadas 5,3 mil novas vagas de graduação, sendo 1,7 mil em universidades públicas e 3,6 mil em instituições privadas em todas as regiões do país. Essas novas vagas foram criadas em 81 municípios de 24 estados e no Distrito Federal. Já foram autorizados 47 novos cursos, sendo 23 em universidades federais. A meta do Mais Médicos é alcançar a marca de 11,4 mil novas vagas de graduação até 2017, com foco em municípios do interior que ainda não possuem faculdade de Medicina." [45]

Se por um lado nesse momento histórico ainda não se tem conhecimento dos resultados desse programa, sabe-se que as estratégias baseadas exclusivamente no número de médicos por habitantes não parecem surtir efeito satisfatório. Exemplo disso está no próprio Brasil, onde o Distrito Federal, já em 2011, possuía taxas de 4,09 médicos/1.000 habitantes e mesmo assim não oferecia, como até atualmente, a melhor atenção à saúde do país [139], ainda que esse número tenha se elevado para 4,28 em 2015 [140]. No Canadá, estima-se que o número de médicos por habitantes seja de 2,5/1.000 habitantes e alguns estudos começam a mostrar desemprego de especialistas no país [141]. O mesmo pôde ser visto no México e na Espanha [142, 143]. Segundo o estudo da demografia médica no Brasil - 2015, o país atingiu 2,1 médicos/1.000 habitantes, com feminização e juvenescimento de sua população médica [144]. Na figura 9, o gráfico mostra as curvas de criação de escolas médicas em relação ao aumento da população nos últimos 50 anos. 


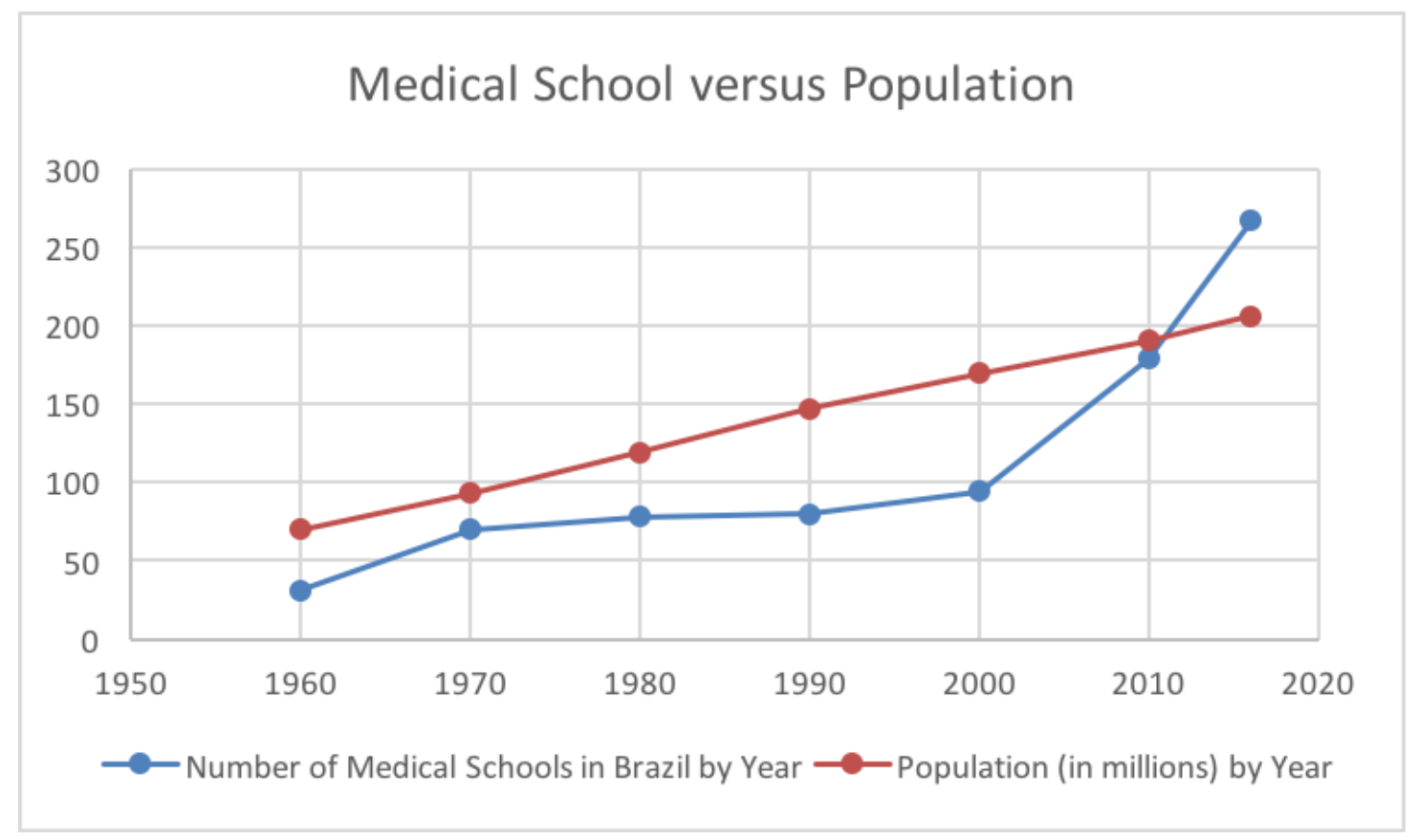

Figura 9 - Curvas de crescimento de escolas médicas em relação à população brasileira

Talvez mais importante que as discussões sobre quantidades de médicos é o debate sobre como garantir o acesso da população ao sistema de saúde e, principalmente, sobre a qualidade da formação. Um crescimento tão rápido do número de escolas e vagas em medicina torna difícil a garantia de qualidade, mesmo no início da curva de crescimento. Não é possível preparar professores capacitados, estruturas curriculares, cenários de prática e de ensino suficientes para tal expansão, em tão curto período de tempo, especialmente quando as diretrizes curriculares nacionais e o governo direcionam para o ensino na rede de serviços, rede esta muito criticada pela população e pelos profissionais de saúde, devido a condições inadequadas de infraestrutura, reconhecimento, capacitação e valorização de recursos humanos. 
Há mais de 100 anos, os EUA realizaram processo de rápida expansão de suas escolas médicas e a história mostra que os resultados foram inadequados para a qualidade da educação médica [46].

Para se tornar médico no Brasil, o aluno deve completar seis anos de graduação em medicina em um curso reconhecido pelo Ministério da Educação, ser aprovado e após esse período o recém-egresso é livre para a prática da profissão, como médico generalista. No entanto, são raros os recémgraduados que não desejam realizar residência médica, cuja duração é de dois a seis anos, titulando o profissional a uma especialidade médica, inclusive as especialidades básicas e gerais (medicina de família, clínica médica, pediatria, obstetrícia e ginecologia e cirurgia geral).

Fluxograma 2 A formação do médico no Brasil: da graduação à especialidade

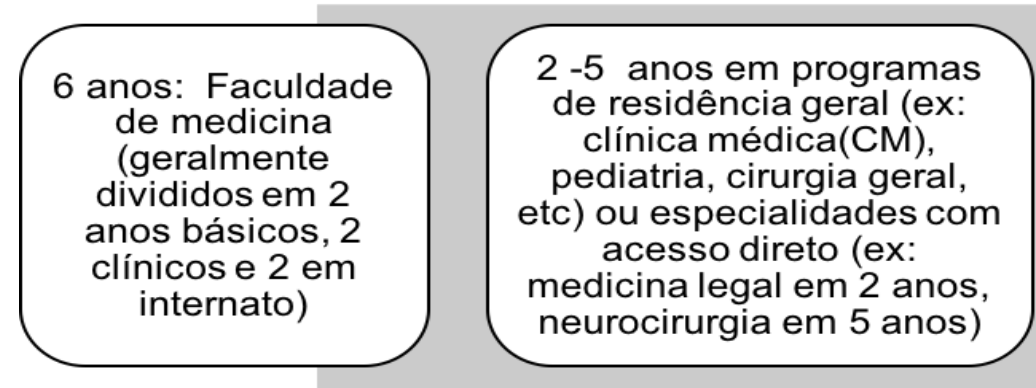

2 a 4 anos em especialidades após residência em área geral (ex: 2 anos em cardiologia após $\mathrm{CM}$, 3 anos em urologia após cirurgia geral)

Fluxograma 2 - Formação do médico especialista no Brasil. 
Diferente do modelo holandês no qual a seleção vai além do desempenho cognitivo avaliando capacidades e habilidades psicológicas e sociais do candidato [40], no Brasil, a admissão em uma escola médica é baseada unicamente nos resultados de concurso público livre a todos os alunos concluintes do ensino médio, o vestibular. O exame abrange diferentes disciplinas do ensino médio (matemática, física, biologia, português, química, história, geografia, inglês, entre outros). Cada escola de medicina é potencialmente responsável por seu processo de ingresso e prova, sendo facultada a agregação de escolas em torno de um único exame. Ao longo dos anos, muitos sistemas diferentes foram postos em prática, incluindo o uso de empresas privadas e fundações especializadas em concursos para aplicação dessas provas. Atualmente, um número crescente de universidades está utilizando um teste cognitivo realizado no âmbito federal, o Exame Nacional do Ensino Médio, ENEM [145], como parte de suas ferramentas para seleção. Curiosamente, o processo de admissão não inclui entrevista ou informações sobre o desempenho curricular dos estudantes no ensino fundamental e médio. São raras as instituições nas quais outras habilidades e competências, não exclusivamente as cognitivas, são testadas. No entanto, isso está sendo questionado. Um exemplo de novos processos de seleção são as múltiplas entrevistas avaliando competências pessoais, como na recém-criada faculdade de medicina do Hospital Israelita Albert Einstein [146], talvez uma versão simplificada do que foi descrito pela McMaster University "An admissions OSCE: the multiple mini-interview" [147].

O currículo no país não é padronizado e o modelo varia muito entre as mais de 260 escolas. No entanto, devem se basear nas Diretrizes Nacionais, 
como citado acima, que servem como um guia incluindo um mínimo de 7.200 horas de estudo/prática, durante um período de seis anos, com pelo menos dois anos de internato em obstetrícia e ginecologia, pediatria, cirurgia, clínica médica, psiquiatria, saúde pública e medicina de família e comunidade [148].

Há uma enorme variação nos métodos de avaliação entre as diferentes escolas. Enquanto algumas escolas estão trabalhando com modalidades como OSCE - Objeticve Structured Clinical Examination e outras estratégias avançadas para a avaliação de alunos $[147,149]$ e da aquisição de competências [150], outras ainda realizam apenas avaliações em habilidades cognitivas e de memória.

\section{O campo da educação médica}

Nesse campo, a Associação Brasileira de Educação Médica - ABEM, fundada em 1962, sucedendo a antiga Associação Brasileira de Escolas Médicas e funcionando inicialmente no interior da Universidade Federal de Minas Gerais é, talvez, a maior representante do campo. A ABEM é também organizadora dos Congressos Brasileiro de Educação Médica, COBEM, e responsável pela Revista Brasileira de Educação Médica, RBEM. A instituição tem como missão:

"Desenvolver a educação médica, visando à formação de um profissional capaz de atender às necessidades de saúde da população, contribuindo para a construção de uma sociedade mais justa e igualitária." [151]

Entre os objetivos da ABEM e sempre no âmbito da medicina e da saúde, estão: 
- Aprimorar a educação médica.

- Aperfeiçoar os métodos de ensino.

- Apoiar e aperfeiçoar a pesquisa científica.

- Aperfeiçoar continuamente o pessoal docente.

- Contribuir para a educação continuada.

- Estabelecer relações de cooperação e participação junto aos órgãos representativos de corpo discente e de entidades filiadas.

- Desenvolver estudos voltados para o estabelecimento de requisitos mínimos para credenciamento dos hospitais que servem às entidades filiadas para fins de internato e residência médica.

- Aperfeiçoar a organização técnica e administrativa das escolas médicas, da gestão em saúde pública, bem como os hospitais que servem ao ensino.

- Participar e colaborar (e/ou criticar), junto aos órgãos de educação e saúde do país, nos níveis nacional, estadual ou municipal.

Em relação aos centros de pesquisa dedicados ao desenvolvimento da educação médica, pode-se dizer que, do total de escolas médicas e institutos de pesquisa, são raras as instituições e Universidades que possuem departamento (ou outra divisão administrativa) voltada para esse fim, o que acaba por amplificar a importância da ABEM já que os especialistas na área de educação médica se encontram dispersos pelo país e se agregam nessa associação. Percebe-se o crescimento da instalação de centros ou divisões de educação médica, no interior das escolas médicas, uma mudança promissora. 
As escolas buscaram medidas renovadoras de suas práticas, como 0 teste do progresso, avaliação seriada, com a participação de estudantes de todos os anos de graduação médica, composto por 120 questões de múltipla escolha, elaboradoras por professores de mais de 80 escolas médicas vinculadas à Associação Brasileira de Educação Médica, por meio de consórcios de escolas médicas. A realização do teste possui dois grandes objetivos: a avaliação externa, que permite visualizar de maneira ampla a qualidade de ensino do curso, na perspectiva nacional, e também a avaliação individual do aluno, possibilitando avaliar o seu progresso. Como a prova é seriada, avalia cada ano do curso, aluno a aluno, possibilita à escola perceber seus pontos positivos e deficitários, planejando ações para melhorá-los. 


\section{CAPÍTULO VIII: BRASIL - A FORMAÇÃO MÉDICA \\ ESPECIALIZADA: OS CURSOS DE ESPECIALIZAÇÃO E RESIDÊNCIA MÉDICA}

\section{Especialização e residência médica}

No Brasil, existem diferentes mecanismos para a formação de médicos especialistas.

A residência não é obrigatória para a prática da medicina no país, por isso, alguns médicos começam a trabalhar imediatamente após o término dos seis anos de escola de medica, geralmente (mas não exclusivamente) em serviços de emergência como o Serviço de Atendimento Móvel de Urgência, SAMU, ou como médicos da estratégia de saúde da família, em programas governamentais. Ambos são empregos públicos com programas próprios de capacitação. A maioria, no entanto, deseja completar a formação e se tornar especialista em alguma área (mesmo que em uma área de competências gerais, como a medicina de família e comunidade) por meio do modelo residência médica. Para os que decidem se tornar especialistas, o caminho não é único, existindo algumas opções [152]:

- residência médica: este é o método "oficial" de formação e segue os moldes internacionais como nos modelos descritos para a formação no Canadá, Espanha ou EUA [54]. Apresenta legislação específica e unificada nacionalmente, com regras e critérios, desde a admissão em um programa, passando pelo currículo, estrutura educacional e 
assistencial de saúde, carga horária, avaliação e competências a serem adquiridas no final de cada ano. A administração da residência médica está localizada no interior do Ministério da Educação, sob a responsabilidade da Comissão Nacional de Residência Médica CNRM;

- cursos de especialização médica: credenciados pelas sociedades de especialidade médicas que regulam essa formação, como ocorre em Taiwan [61], por exemplo. Apesar de seu funcionamento seguir o arcabouço de regras estruturado e aprovado pelo Conselho Científico da Associação Médica Brasileira, AMB, os critérios de seleção, avaliação e titulação são variáveis a depender de cada sociedade de especialidade médica;

- prova de competências: os médicos também podem se inscrever em testes realizados pelas sociedades de especialidades médicas e organizados pela AMB, a fim de receber a titulação em especialidade como ocorre na Alemanha [63]. Para que sejam autorizados a participar dos testes é necessário um período bem documentado de anos em prática clínica, sob a supervisão de especialistas na área e membros da sociedade em questão. Adicionada à prática, deve-se também apresentar documentação comprobatória de atividades teóricas em educação continuada, como congressos, cursos de formação etc. 


\section{A residência médica}

Se a residência médica tem seu programa inicial nos EUA, em 1889 e 1890, respectivamente por Halsted e Osler, no Brasil, os primeiros programas datam de 1944, na Faculdade de Medicina da Universidade de São Paulo e, em 1948, no Hospital dos Servidores do Estado do Rio de Janeiro [153].

Segundo Evandro Guimarães de Souza [154], a história inicial da residência médica no Brasil pode ser dividida em quatro ciclos:

1. Um primeiro ciclo de implantação e consolidação dos primeiros programas de residência médica de 1945 a 1955.

2. O segundo com ampliação gradual do número de programas de 1956 a 1971.

3. O terceiro ciclo de rápida expansão a partir de 1972.

"Devido ao aumento expressivo do número de escolas médicas, motivou a rápida expansão de programas de qualidade duvidosa, criados mais com o objetivo de utilização de mão de obra médica de baixo custo do que de um programa de pós-graduação"[154].

4. Em 1977, surge, concomitante ao terceiro, um quarto ciclo com a criação da CNRM.

[Como descrito no capítulo anterior após o programa Mais Médicos talvez já se possa falar de um quinto ciclo, ainda mais agressivo, de abertura de escolas médicas e expansão meramente quantitativa de residências médicas. Nesse período, há aumento da tensão entre as entidades médicas e o governo; estas se retiraram sistematicamente 
da CNRM, que atualmente sem verba ou apoio segue minguando sua capacidade avaliativa para credenciamentos e recredenciamentos.]

Já o pesquisador José Carlos de Sousa Lima [155] divide a história da residência médica em dois períodos:

- entre 1947 e 1977, com a criação dos primeiros programas aliados à luta pela regulamentação;

- entre 1977 e 2008, tendo como marco o decreto presidencial 80.281 de 5 de setembro de 1977 [156], que cria a Comissão Nacional de Residência Médica (CNRM) e regulamenta a residência médica.

Até 1977, a atuação da ABEM, da Associação Nacional de Médicos Residentes (ANMR), da AMB e os dados apresentados pela Associação de Médicos Residentes do Estado de São Paulo (AMERESP) mostrou-se fundamental para as conquistas legais e consolidação do modelo residência médica no país [153].

Por se tratar de pós-graduação, a CNRM passa a funcionar no Ministério da Educação (MEC), mais especificamente na Secretaria de Ensino Superior (SESU). O secretário executivo da SESU exerce a presidência da CNRM, e em sua ausência o secretário executivo da CNRM preside as seções.

\section{Comissão Nacional de Residência Médica (CNRM)}

Em 2011, a CNRM teve a última modificação em relação aos seus componentes que passaram a ser 12, segundo o Decreto 7.562, de 15 de 
setembro de 2011, que dispõe sobre a Comissão Nacional de Residência Médica e o exercício das funções de regulação, supervisão e avaliação de instituições que ofertam residência médica e de programas de residência médica:

"Art. 4o A Plenária é composta por doze conselheiros, a saber:

I - dois representantes do Ministério da Educação, como membros natos;

II - um representante do Ministério da Saúde, como membro nato;

III - um representante do Conselho Nacional de Secretários de Saúde CONASS;

IV - um representante do Conselho Nacional de Secretários Municipais de Saúde - CONASEMS;

V - um representante do Conselho Federal de Medicina - CFM;

VI - um representante da Associação Brasileira de Educação Médica ABEM;

VII - um representante da Associação Médica Brasileira - AMB;

VIII - um representante da Associação Nacional de Médicos Residentes - ANMR;

IX - um representante da Federação Nacional de Médicos - FENAM;

X - um representante da Federação Brasileira de Academias de Medicina - FBAM;

XI - um médico de reputação ilibada, docente em cargo de provimento efetivo em Instituição de Educação Superior pública, que tenha prestado serviços relevantes ao ensino médico, à residência médica e à ciência médica em geral."[157] 
Pelo sistema residência médica a instituição interessada em abrir um programa de residência médica deve inicialmente estabelecer uma comissão interna denominada Comissão de Residência Médica (COREME) composta por um médico coordenador, eleito a partir do conjunto de médicos supervisores, e um por PRM (estes oriundos do conjunto de preceptores). Após início das atividades, agregam-se à COREME os médicos residentes e profissionais administrativos. A COREME deve seguir as normas do estatuto da própria instituição e sempre respeitar a legislação, as normas e as resoluções da CNRM, elaborando regimento/regulamento próprio.

A COREME pelo Sistema da CNRM (SisCNRM) preenche o Pedido de Credenciamento de Programa de Residência Médica (PCP), com detalhes sobre os objetivos, projeto pedagógico, estrutura, profissionais envolvidos, rodízios propostos, semana padrão, entre outras informações relativas ao ensino e à assistência que serão ofertados durante o programa.

A CNRM seleciona avaliadores a partir do Banco Público Nacional de Avaliadores de Residência Médica. Os avaliadores, dos diversos estados da federação, modo preferencial, são designados para o processo de avaliação em Estados diversos daquele onde atuam profissionalmente e obrigatoriamente sem vínculo de qualquer natureza com as instituições a serem avaliadas, analisando documentos e realizando visita in loco. Tais avaliadores são pares, médicos com experiência em educação médica. Segundo o Decreto 7562/2011:

"Parágrafo único. Os integrantes do Banco Público deverão ser médicos registrados nos respectivos Conselhos Regionais de Medicina (CRMs) com experiência comprovada em ensino médico e na coordenação e supervisão de programas." [157]. 
No mesmo decreto, consta que compete à CNRM:

I - Credenciar e recredenciar instituições para a oferta de programas de residência médica.

II - Autorizar, reconhecer e renovar o reconhecimento de programas de residência médica.

III - Estabelecer as condições de funcionamento das instituições e dos programas de residência médica.

IV - Promover a participação da sociedade no aprimoramento da residência médica no país.

O funcionamento de instituições e a oferta de programas de residências médica dependem de atos autorizativos da CNRM, nos termos do Decreto, nas seguintes modalidades:

I - quanto ao funcionamento de instituições para oferta de residência médica:

a) de credenciamento de instituições;

b) de recredenciamento de instituições.

II - quanto ao funcionamento de programas de residência médica:

a) de autorização de programas;

b) de reconhecimento de programas;

c) de renovação de reconhecimento de programas.

Os atos autorizativos fixam os limites da atuação das instituições públicas e privadas em matéria de residência médica, e devem indicar, no mínimo: 
I - quanto ao funcionamento de instituições para oferta de residência médica;

II - quanto ao funcionamento de programas de residência médica.

Os atos autorizativos possuem prazos limitados, sendo renovados, periodicamente, após processo regular de avaliação.

O processo de avaliação compreende o envio eletrônico de documentos, visita in loco e reunião com os médicos relacionados ao Programa: diretor da Instituição onde se sedia o PRM, coordenador da COREME, supervisor de PRM, preceptores, residentes. Sugere-se ainda reunião com gestores de saúde do município e Estado.

No caso das avaliações dos programas de residência médica já atualmente em funcionamento, é mandatória uma reunião exclusiva com os médicos residentes. Os avaliadores devem realizar ainda conferência de documentações, atas e reuniões da COREME e fazer visita de verificação nas dependências destinadas à assistência (clínica e cirúrgica), ensino, alimentação, repouso etc.

Após a visita, os avaliadores devem elaborar relatório de avaliação do programa. Esse relatório é então encaminhado à Câmara Técnica da CNRM, uma instância auxiliar, consultiva, da CNRM, e composta por médicos experientes na concepção e avaliação de residência médica.

"Art. 12. Compete à Câmara Técnica: I-instruir os processos referentes aos atos autorizativos de instituições e programas; II instruir os processos referentes à supervisão de instituições e programas, quando solicitado pela CNRM; e III-instruir os processos referentes aos demais assuntos de pauta da CNRM, quando solicitado." 
Após avaliação e parecer da Câmara Técnica, o relatório segue para a Plenária da CNRM, onde será debatido pelos membros votantes e não votantes (como presidentes das Comissões Estaduais de Residência Médica CEREMs) com decisão final, deliberativa, pelos membros votantes.

A plenária da CNRM, após avaliar um programa, pode decidir entre as seguintes categorias:

- instituição credenciada;

- instituição credenciada, em supervisão, modalidade Exigência. Problemas importantes no programa que podem exigir nova visita da CNRM ou da CEREM ou apenas relatórios por parte da instituição (o prazo é estipulado pelo plenário e pode ser de uma nova avaliação em apenas 15 dias). Cada problema encontrado na instituição tem prazo específico para correção, a depender da gravidade e viabilidade temporal de correção;

- instituição credenciada, em supervisão, modalidade Diligência. Problemas mais importantes do que os anteriores, ficando suspensa a entrada de novos residentes no programa até que os pontos observados sejam corrigidos. Se persistirem, o programa pode ser fechado - descredenciado. Haverá nova visita da CNRM ou da CEREM em prazo estipulado pela plenário (pode ser em apenas 15 dias). Cada problema encontrado na instituição tem prazo específico para correção, a depender da gravidade e viabilidade temporal de correção;

- instituição descredenciada. 
A decisão final da plenária é enviada para a instituição solicitante. 0 sistema é linear ou circular. Fluxograma 3:

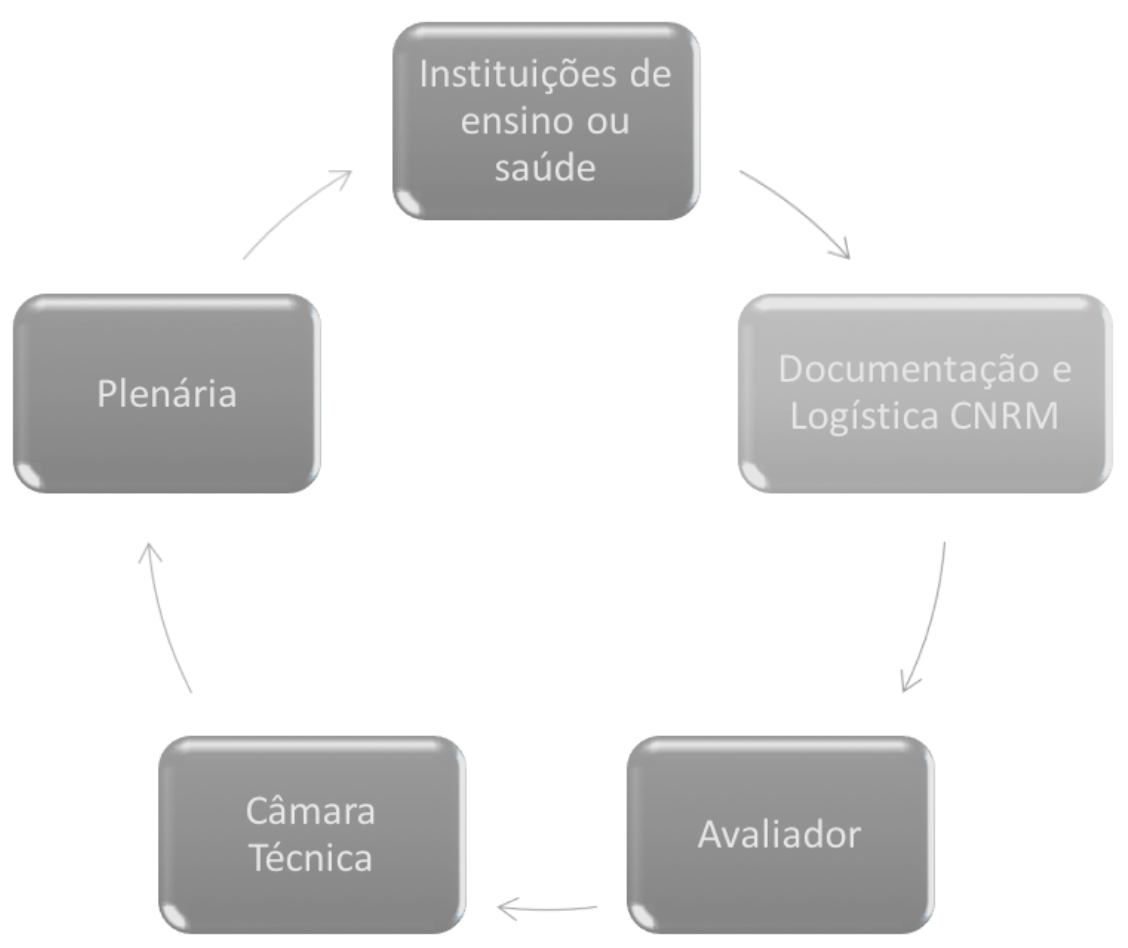

Fluxograma 3 - Processos internos no sistema de credenciamento da CNRM

Até mesmo o processo de admissão por concurso público na residência médica tem regras nacionais determinadas pela CNRM, conforme Lei 6932/81 e resoluções em vigor. As regras incluem a necessidade de um exame, que pode ser realizado em uma ou duas fases [158]. O primeiro passo é um teste cognitivo, obrigatório, que deve incluir Clínica Médica, Cirurgia Geral, Pediatria, Obstetrícia e Ginecologia e Medicina Preventiva e Social. Os candidatos aprovados nessa fase podem realizar uma segunda fase (opcional para a instituição), que consiste novas provas com estímulo para realização de provas práticas, com metodologia do tipo OSCE, seguidas ou não de arguição e análise de currículo, relacionado à formação médica [159]. 
Os PRM possuem carga horária total anual de 2.880 horas, 60 horas semanais, nelas incluídas até o máximo de 24 horas, em regime de plantão. O descanso pós-plantão obrigatório é de pelo menos seis horas [160]. Há proibição de plantões de sobreaviso (ou a distância) para residentes [161] e regras curriculares a serem seguidas como meio de uniformizar a formação especializada ao final do programa [162]. Tudo passa por decisões do plenário da CNRM demonstrando o poder e a importância atribuída a essa Comissão.

\section{Sociedades de especialidades médica}

São próximas as histórias da residência médica a das sociedades de especialidades médicas.

Em 1829, a então denominada "Sociedade Médica" foi fundada no Rio de Janeiro, passando a se chamar Academia Imperial de Medicina, em 1835, e finalmente Academia Nacional de Medicina, em 1889, após a Proclamação da República. Associações regionais foram fundadas em vários locais do Brasil durante o século XIX.

Já em 1897, a primeira sociedade de especialidades médicas foi fundada, a Sociedade de Ginecologia e Obstetrícia do Rio de Janeiro.

Curiosamente, a Associação que hoje congrega as especialidades médicas só surge mais de meio século depois.

No início do século XX, São Paulo se apresentava em plena ascensão econômica tendo em vista ser este um dos períodos de melhor desempenho da economia cafeeira. Com isso, a capital se tornou mais moderna e importante, abrindo espaço para o desenvolvimento científico, cultural e social. Nessa onda 
de desenvolvimento, em 1930, foi fundada a Associação Paulista de Medicina (APM). Conforme consta da ata da sessão inaugural da APM (escrita à mão por Rubião Meira), a APM tem por fim:

"Art.1- Associação Paulista de Medicina, fundada em 29 de novembro de 1930 na Capital do Estado de São Paulo, tem por finalidade: a) promover aperfeiçoamento da cultura médica; b) interessar-se pela união e defesa de classe; c) trabalhar pela solução dos problemas da medicina social.

Art. 2 - Para atingir esta finalidade, a Associação manterá: seções científicas, biblioteca, revista médica, clube médico e fundo de beneficência [163]."

O movimento médico político e científico na cidade foi crescendo, desde então e, em 1951, a Associação Médica Brasileira (AMB) é idealizada e fundada na cidade de São Paulo.

A preocupação com a formação especializada dos médicos começa nas Universidades, pouco antes disso. Em 1883, por exemplo, foram criadas as primeiras cadeiras de clínica psiquiátrica e de moléstias nervosas nas Faculdades de Medicina de Salvador e do Rio de Janeiro [164].

Ainda que a titulação nunca tenha sido necessária, os médicos se agregavam nas sociedades, em busca de conhecimento e possibilidade de trocas.

Cada sociedade de especialidade médica possui normas próprias para formação de especialistas em determinada área. A titulação fornecida é fruto de convênio de cada sociedade de especialidade com a AMB, reconhecida pelo Conselho Federal de Medicina (CFM). 
Como lembra o pesquisador Renato Passini Junior no artigo "Residência Médica X Especialização", o controle sobre a especialização não é o mesmo que a residência:

"[as especializações] São processos seletivos que não seguem, necessariamente, as normativas de acesso à Residência Médica, nem irão conferir o Título de Especialista nos moldes do Ministério da Educação ou da Associação Médica Brasileira.

Os direitos e deveres dos médicos residentes não são os mesmos dos especializandos e aí está um grande problema. Especializandos seguem regramentos das instituições e das coordenações desses cursos. A instituição que oferece tais cursos deve estar credenciada pelo Ministério da Educação, mas os cursos independem de autorização, reconhecimento e renovação de reconhecimento. Há, portanto, autonomia da instituição.

Enquanto os programas de residência médica se submetem a processo de recredenciamento a cada cinco anos, podendo ser antecipado em certas circunstâncias, os cursos de especialização lato sensu regulados por essa Resolução não têm o mesmo tipo de controle, embora possam ser avaliados quando do recredenciamento das instituições que os oferecem[165]".

Apesar dessa modalidade funcionar amplamente no país, é bastante escassa a literatura, mesmo nas pesquisas em grey literature sobre os cursos de espacialização em medicina (que se assemelham à residência) no Brasil. Além da titulação, o único "ancoradouro" legal existente é a resolução do 
Conselho Nacional de Educação (CNE) [166] sobre especializações, como forma de pós-graduação lato sensu nas diversas áreas do conhecimento. $O$ CNE, no entanto, estipula, de maneira geral, o mínimo de 360 horas para curso de especialização. Muito distante de um programa de residência médica, com 2.880 horas/ano, o que redunda na criação de uma terceira via (inapropriada) de especialização no país (embora não reconhecida como tal), gerando demandas administrativas (no CFM) e judiciais de tentativas de equiparação com os modelos admitidos no Brasil. 


\section{CAPÍTULO IX: O IMPACTO DA AVALIAÇÃO CONJUNTA DOS PROGRAMAS DE RESIDÊNCIA MÉDICA PELA CNRM E SBN}

\section{A Sociedade Brasileira de Neurocirurgia (SBN) e o Projeto Piloto de Avaliação e Acreditação Conjunta}

Diante da existência de processos distintos de formação de especialistas no Brasil, a avaliação e acreditação de programas torna-se projeto complexo. Há percepção de divisão (no sentido de fragmentação) entre os principais responsáveis, capazes de qualificar o processo de avaliação e acreditação de programas de residência médica (e especialização), de modo a impactar positivamente sobre o produto final da residência médica - o médico especialista competente. Surgiu então o projeto de colaboração entre a CNRM e as sociedades de especialidades médicas. Convites foram feitos e uma sociedade apresentou condições para desenvolver um projeto piloto.

Diversas sociedades de especialidades médicas do Brasil possuem processos de avaliação e acreditação de programas de residência médica, por meio de cuidadoso e robusto projeto pedagógico curricular e provas de verificação de aprendizagem (conhecimentos e habilidades), utilizando elevados padrões educacionais, visita aos locais de treinamento e acompanhamento dos programas de formação, como é o caso das Sociedades Brasileiras de Anestesiologia (SBA); Sociedade Brasileira de Ortopedia e Traumatologia (SBOT), Sociedade Brasileira de Urologia, entre outras.

Diversos fatores contribuíram para que o a Sociedade Brasileira de Neurocirurgia (SBN) estabelecesse parceria com a CNRM. 
Como nos relata os Prof. Gusmão e Souza no capítulo sobre a "Evolução da Sociedade" no livro "História da Neurocirurgia no Brasil", a SBN, que nasce em Bruxelas, durante o primeiro grande congresso de neurologia cirúrgica, tem a formação como um de seus objetivos principais.

"O controle da formação do neurocirurgião foi um dos objetivos maiores da Sociedade Brasileira de Neurocirurgia. Os pioneiros da Neurocirurgia brasileira foram autodidatas ou fizeram estágios no exterior e ensinaram a segunda geração de profissionais. 0 ensino sistematizado se definiu na década de 1960, quando diversos serviços se organizaram para a formação de residentes, e a Sociedade Brasileira de Neurocirurgia assumiu o controle do processo [164]."

Nos dias atuais, a SBN possui três comissões (aperfeiçoamento, ensino e credenciamento) bem estabelecidas, que atuam de maneira organizada e com empenho de docentes-neurocirurgiões das principais universidades e serviços formadores do país. Esses profissionais se dedicam à formação dos novos neurocirurgiões e estabelecem parcerias internacionais e de cooperação, com o objetivo de promover excelência no ensino e assistência neurocirúrgica no Brasil.

Um importante marco que pode ser mencionado como exemplo de vanguarda na formação de residentes foi a publicação do "Livro do Residente em Neurocirurgia" [167], em que estão presentes objetivos, pré-requisitos para admissão nos programas, competências, programa de estudos, distribuição de carga horária etc.

Para além da preocupação com a qualidade da atuação na avaliação dos programas, com sistema de visitas in loco, com a definição e padronização de critérios de avaliação, a SBN mostrou-se ainda aberta a participar de um 
projeto piloto, respondendo de maneira célere, eficaz e qualificada a todas as solicitações e reuniões propostas pela CNRM. Após a primeira reunião entre os representantes das três comissões da SBN e a secretaria executiva da CNRM restou claro que a parceria entre ambas (SBN e CNRM) poderia ser o caminho mais sábio e responsável. À missão legal da CNRM de credenciar, fiscalizar e acompanhar os Programas de Residência Médica somava-se o cuidado e o zelo com que a SBN acompanha e reconhece a formação de novos especialistas. Naquela reunião, a representação da CNRM conheceu a seriedade e a propriedade das propostas educacionais em neurocirurgia, utilizadas universalmente e defendidas pela SBN.

\section{Projeto piloto parte I}

Surgiu então o projeto piloto "The impact of collaborative work by teams from the National Medical Residency Committee and the Brazilian Society of Neurosurgery", cujo objetivo foi avaliar inicialmente a situação atual dos programas de residência em neurocirurgia no Brasil, à luz da parceria entre a CNRM e SBN, aprovado pelas instâncias deliberativas das duas instituições. Entre os objetivos, analisar a distribuição loco-regional dos programas de residência médica em neurocirurgia e a distribuição dos especialistas nesse campo.

Métodos desta etapa

Estabeleceram-se os limites de atuação de cada parceiro, um cronograma de atividades e reuniões, além do desenvolvimento de uma 
ferramenta (instrumento) comum de avaliação, a partir daqueles já empregados pelas partes.

Novamente foi realizada revisão de literatura por meio de pesquisa bases de dados globais (PubMed e Web of Science), mas também regionais (Lilacs, Scielo e Bireme) centradas no processo de avaliação externa de residência médica realizadas por organismos governamentais, associações profissionais, sociedades científica etc.

Foram incluídos ainda todos os artigos disponíveis e legislação referentes à avaliação, à regulação e à supervisão publicados por órgãos governamentais, como os Ministérios da Saúde e da Educação, ou por associações médicas, o Conselho Federal de Medicina ou outras entidades similares.

Tendo como objetivo a qualidade dos programas de residência em neurocirurgia, um instrumento único de avaliação foi desenvolvido pela CNRM e SBN com foco na estrutura, no processo e nos resultados, com vertentes educacionais e assistenciais em saúde, dentro da área específica da neurocirurgia.

Para uniformizar instrumentos e clarear os objetivos do projeto comum de avaliação, ocorreram pelo menos três reuniões entre os representantes da CNRM (avaliadores) e os da SBN para apresentação e capacitação do processo conjunto de avaliação.

O processo de avaliação dos programas ocorreu de acordo com as seguintes etapas:

1) $O$ instrumento foi enviado às instituições a serem avaliadas de acordo com critérios e cronograma estabelecidos conjuntamente pela CNRM e SBN. 
2) As visitas in loco ocorreram cerca de duas semanas após os responsáveis pelo programa a ser avaliado e sua instituição terem recebido o instrumento unificado (anexo 8).

3) A equipe de avaliação foi composta por pelo menos dois avaliadores (no mínimo um da CNRM e outro da SBN). Essa equipe analisou as condições das enfermarias, ambulatórios, centro cirúrgico, unidade radiológica, unidade de hemodinâmica, laboratórios, sala de emergência, unidade de terapia intensiva, todas as ferramentas necessárias (incluindo microscópios), números e tipos de operações realizadas nos últimos seis meses, biblioteca, acesso a bibliotecas eletrônicas, a existência e o cumprimento de programas teóricos e legislação pertinente.

4) A área geográfica das avaliações se estendeu por todo o território nacional, demandando importante logística para sua realização.

5) A equipe de avaliação realizou reuniões separadamente com os gestores de cada instituição, dos coordenadores de COREME, dos supervisores de programas de residência médica e dos médicos residentes. No intuito de identificar os pontos fortes e fracos de cada programa, conforme instrumento padronizado e entrevista semiestruturada.

6) Um relatório final conjunto foi produzido pela equipe de avaliação após cada visita.

7) Os relatórios foram analisados pela câmara técnica da CNRM e sua plenária, bem como suas duplicatas foram encaminhadas à SBN para suas comissões e colegiados para a devida ciência e análise. 
Nesta pesquisa, optou-se por analisar, além dos relatórios, os processos pareceres e decisões da CNRM.

8) As instituições foram notificadas das decisões da CNRM e as mudanças realizadas após notificação, no espaço de tempo desta pesquisa, foram revisadas e incluídas nos resultados.

As reuniões entre representantes da SBN e CNRM foram realizadas entre abril de 2010 e fevereiro de 2011. As visitas de avaliação ocorreram entre abril de 2011 e janeiro de 2014. Nesse período, e até abril de 2014, a Câmara Técnica da CNRM analisou os relatórios, a plenária da CNRM deliberou sobre as medidas sugeridas e as instituições foram notificadas das ações a serem executadas no prazo estabelecido. Todo o material produzido e modificações (ou não) realizadas fizeram parte do material avaliado no presente estudo, no período citado.

Resultados desta etapa

Os resultados detalhados estão no anexo 9 na publicação "Evaluation of the impact of collaborative work by teams from the National Medical Residency Committee and the Brazilian Society of Neurosurgery. Retrospective and prospective study", cabe aqui, no entanto, ressaltar alguns aspectos importantes, fruto deste trabalho, originalmente desenhado como único aspecto da tese de doutorado de Renato Antunes dos Santos, convertido em outras etapas após produtivo e inspirador estágio de um ano, no McGill University Medical Education Centre, sob supervisão da professora Linda Snell (Bolsa CAPES - Programa de Doutorado - Sanduíche). 
Nessa etapa, verificou-se que entre os 26 Estados e o Distrito Federal que compõe o Brasil, sete unidades da federação não possuíam quaisquer programas de residência médica em neurocirurgia, a saber: Acre, Amapá, Rondônia e Roraima (da região Norte); Maranhão, Paraíba e Piauí (da região Nordeste). Estes sete estados correspondem a regiões com baixo Índice de Desenvolvimento Humano (IDH) [168].

$\mathrm{Na}$ época da análise dos dados, tinha-se que os neurocirurgiões se distribuíam por todas as regiões do Brasil: 94 no Norte, 245 no Nordeste, 171 no Centro-Oeste, 1.197 no Sudeste e 362 no Sul, como demonstrado em estudo Demografia Médica [139].

[Em 2015, os números já haviam se modificado para 151 no Norte, 383 no Nordeste, 256 no centro-oeste, 1.585 no Sudeste e 500 no Sul, como demonstrado na atualização do estudo Demografia Médica 2015) [140]]

Quando correlacionados os números de neurocirurgiões com a população de determinada região, as diferenças na distribuição podem ser mais bem compreendidas.

Calculamos o número de neurocirurgiões por 100 mil habitantes, segundo a região brasileira, como o definido pelo Instituto Brasileiro de Geografia e Estatística[169]:

- 0,59 neurocirurgiões/100.000 habitantes na região Norte;

- 0,47 na região Nordeste;

- 1,49 na região Sudeste;

- 1,40 na região Sul; e

- 1,22 na região Centro-Oeste. 
O número médio de neurocirurgiões por 100 mil habitantes no país foi de 1,09 .

No Brasil, havia 154 vagas para admissão em programas de residência médica em neurocirurgia, distribuídos em 104 programas.

Novamente, dividindo Brasil de acordo com as regiões, o número de programas de residência médica em neurocirurgia por 100 mil habitantes foi:

- 0,03, na região Norte;

- 0,03 na região Nordeste;

- 0,12 na região Sudeste;

- 0,10 na região Sul; e

- 0,06 na região Centro-Oeste.

O número médio de programas de residência médica em neurocirurgia por 100 mil habitantes para todo o país foi de 0,08.

Dezessete novos programas de neurocirurgia foram criados durante 0 período de estudo, o que representou $14,6 \%$ do total. Destes, três estavam no Sul, quatro no Sudeste, três no Nordeste, quatro no Centro-Oeste e três no Norte.

Os dados mostram como neurocirurgiões e vagas de residência médica em neurocirurgia se concentram nas regiões com melhor IDH. O que parece ser uma "bola de neve" de crescimento em desigualdade é explicado pela correlação entre as regiões de pior IDH com serviços que têm estrutura assistencial e educacional precárias, muitas vezes inviabilizando a prática da especialidade. Com a falta de especialistas e estrutura na região é impossível, ou até mesmo indesejável, haver novos programas de residências médicas. Sem campo de treinamento devidamente apropriado ao treinamento e 
capacitação na residência médica, haverá menos especialistas disponíveis, menor pressão e, portanto, menos estrutura, em um círculo vicioso.

A figura 10 representa a evolução dos programas de residência em neurocirurgia criados nas cinco regiões brasileiras ao longo dos últimos 30 anos, desde 1982.

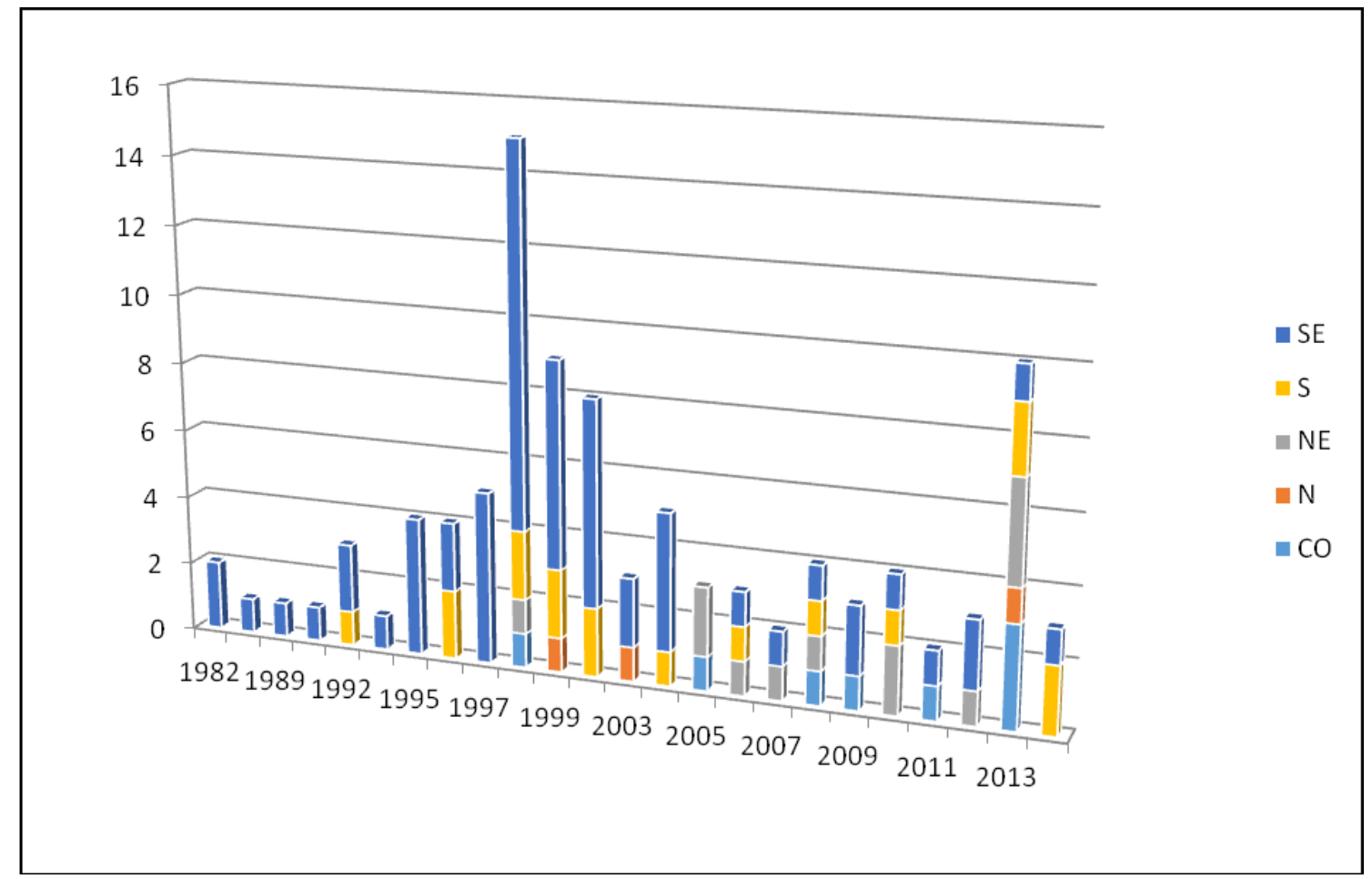

Figura 10 - Programas de residência médica em neurocirurgia criados desde 1982 por região do Brasil, in Sao Paulo Med J. 2015

A figura 10 revela que em 1980 a 1990 houve grande concentração de programas de residência médica em neurocirurgia nas regiões Sudeste e Sul. Durante esse período, a abertura de novos programas em outras regiões do país foi quase uma exceção. De 1999 a 2003, novos programas começam a surgir em outras regiões (Centro-Oeste, Norte e Nordeste). Nos últimos três anos, a distribuição de vagas para residência de neurocirurgia começou a 
mudar. Em particular, houve maior diversidade de abertura de programas, por região, em 2012. Esse período coincide com a atuação dos avaliadores do presente projeto piloto pelo país e da resposta inicial à implantação do programa de incentivo e financiamento à residência médica em regiões e especialidades consideradas prioritárias, o Pró-residência [170] pelo governo federal. Houve pouco impacto de resposta, em termos de número de especialistas formados nas regiões Nordeste e Centro-Oeste.

Tomando por base os dados apresentados pela pesquisa Demografia Médica publicado em 2011 e 2015, temos que houve um incremento de $28 \%$ de neurocirurgiões no período, com aparente melhor distribuição entre as cinco regiões do país.

Obviamente, não é possível atribuir as variações exclusivamente ao projeto piloto em discussão, existindo uma série de fatores que podem explicálas, a começar por critérios de inclusão das amostras entre os dois estudos Demografia Médica.

Para se ter uma ideia global, um relatório europeu traz estimativas de quantos neurocirurgiões/habitantes são necessários, em cada país. Diversos desses países trabalham com o conceito de numerus clausus, um número fixo e regulado de vagas para admissão e formação de residentes em cada especialidade.

Segundo os dados do estudo Demografia Médica [140] e os dados populacionais do Instituto Brasileiro de Geografia e Estatística à época das pesquisas, a relação de um neurocirurgião/habitantes em relação a outras nações era conforme discriminado a seguir [modificado de [171]*: 
Tabela 10 - Neurocirurgiões por habitantes

\section{País}

Relação de 1 neurocirurgião (NC)/habitantes (hab)

Inglaterra

Holanda

1NC: 294.000 hab

\section{Eslovênia}

França

1NC: 151.000 hab

Finlândia

1NC: 115.000 hab

\section{Espanha}

Suécia

1NC: 90.000 hab

Noruega

\section{Brasil}

Itália 1NC: 70.000 hab

Suíça

\section{EUA}
Alemanha
1NC: $62.000 \mathrm{hab}$

\section{Portugal}

Deve-se levar em consideração que as competências e as atribuições desempenhadas pela especialidade e modelo de assistência variam de país para país. Um bom exemplo é o Trauma Crânio Encefálico (TCE), que pode ser atribuição do neurocirurgião ou do cirurgião do trauma (ou de urgência), dependendo do país. Variações de competências e atribuições entre especialistas médicos, com definições claras de funções, nos diferentes níveis de assistência, modificam consideravelmente as necessidades (em número) de especialistas e resulta em números tão diferentes. Para se fazer melhor compreendido o autor sugere que o leitor considere a diferença quando um neurocirurgião se atém aos limites estritos de suas competências, para quando 
é impelido a atender casos de menor complexidade, como os mais frequentes de cefaleia, cujo controle independe de suas habilidades e conhecimentos.

[ ${ }^{\star}$ foram inseridos os dados nacionais aos da pesquisa original europeia] A CNRM reconhece, historicamente, a existência de 127 programas de neurocirurgia. No recorte temporal para o estudo, existiam e foram incluídos no processo de avaliação 104 programas. Vinte e quatro programas de neurocirurgia haviam sido cancelados, antes ou durante o projeto piloto.

No decorrer do período estudado, apenas 28 programas foram aprovados sem necessidade de correções, correspondendo a $26,9 \%$ do total. Entre eles, 22 programas se localizavam no Sudeste, 5 no Sul e 1 no Norte do Brasil. A Tabela 11 mostra a situação dos 104 programas de neurocirurgia resultantes da avaliação conjunta CNRM/SBN.

Tabela 11 - Programas de neurocirurgia resultantes da avaliação conjunta CNRM/SBN

\begin{tabular}{lcc}
\hline $\begin{array}{l}\text { Situação do programa após avaliação } \\
\text { conjunta pelo projeto CNRM/SBN }\end{array}$ & $\begin{array}{c}\text { número de } \\
\text { Programas }\end{array}$ & $\%$ \\
\hline Aprovado & 28 & $26,9 \%$ \\
\hline Mudança de status antes do final & 1 & $0,96 \%$ \\
\hline $\begin{array}{l}\text { Descredenciado } \\
\text { Necessitando de correções e em }\end{array}$ & 4 & $3,85 \%$ \\
supervisão & 37 & $35,6 \%$ \\
\hline Novos & 16 & $15,38 \%$ \\
\hline Dados não disponíveis & 4 & $3,85 \%$ \\
\hline Aguardando nova visita & 14 & $13,46 \%$ \\
\hline TOTAL & 104 & $100 \%$ \\
\hline
\end{tabular}


No artigo, já publicado, são apresentados os principais fatores que podem influir diretamente na qualidade da residência médica ofertada nos campos de saúde e educação, sendo eles: presença de preceptoria; plantões a distância; biblioteca adequada; estágios em microcirurgia, em neurologia, vascular, neurocirurgia pediátrica; reuniões clínicas e anatomopatológicas; número de procedimentos, entre outros. As tabelas 12 e 13 sumarizam os principais pontos identificadas pelos avaliadores que mereciam atenção e alterações pelos programas. Os pesquisadores agruparam as diferentes categorias (pontos fracos) em temas, a saber: assistência (relacionado ao atendimento da população), estrutura (referente às necessidades estruturais para a prestação de assistência) e processos (dinâmica de funcionamento do processo de trabalho na assistência e ensino). 
Tabela 12 - Número absoluto de programas, por região do Brasil, e principais pontos que merecem atenção (assistência, estrutura e processo)

\begin{tabular}{|c|c|c|c|c|c|}
\hline ASSISTÊNCIA & NE & $\mathrm{CO}$ & SE & $\mathbf{S}$ & TOTAL \\
\hline Deixar de apresentar as estatísticas de cirurgia & 1 & 0 & 6 & 0 & 7 \\
\hline Não atingir a meta de 300 cirurgias anuais & 4 & 0 & 6 & 1 & 11 \\
\hline $\begin{array}{l}\text { Precisar aumentar disponibilidade de leitos em } \\
\text { Unidades de Terapia Intensiva }\end{array}$ & 1 & 0 & 1 & 0 & 2 \\
\hline $\begin{array}{l}\text { Apresentar baixo número de cirurgias } \\
\text { pediátricas ou sem termo de convênio }\end{array}$ & 2 & 0 & 5 & 5 & 12 \\
\hline $\begin{array}{l}\text { Apresentar baixo número de cirurgias } \\
\text { vasculares/sem convênio }\end{array}$ & 1 & 0 & 4 & 2 & 7 \\
\hline $\begin{array}{l}\text { Apresentar baixo número de cirurgias } \\
\text { funcionais ou sem termo de convênio }\end{array}$ & 1 & 0 & 2 & 4 & 7 \\
\hline $\begin{array}{l}\text { Apresentar baixo número de cirurgia de } \\
\text { tumores ou termo de convênio }\end{array}$ & 0 & 0 & 1 & 3 & 4 \\
\hline $\begin{array}{l}\text { Apresentar baixo número de cirurgia de coluna } \\
\text { ou sem termo de convênio }\end{array}$ & 1 & 0 & 0 & 1 & 2 \\
\hline $\begin{array}{l}\text { Baixo número de cirurgia em nervos periféricos } \\
\text { ou sem termo de convênio }\end{array}$ & 0 & 0 & 1 & 1 & 2 \\
\hline $\begin{array}{l}\text { Ausência de ambulatório, ou quando presente, } \\
\text { dificuldade agendar operação de pacientes por } \\
\text { essa via }\end{array}$ & 1 & 0 & 1 & 1 & 3 \\
\hline ESTRUTURA & NE & $\mathrm{CO}$ & SE & $S$ & TOTAL \\
\hline $\begin{array}{l}\text { Falta de materiais para cirurgias (clipes para } \\
\text { aneurismas, aspirador ultrassônico etc.) }\end{array}$ & 2 & 0 & 4 & 2 & 8 \\
\hline $\begin{array}{l}\text { Falta ou dificuldade em realizar exames } \\
\text { complementares e diagnósticos }\end{array}$ & 0 & 0 & 2 & 1 & 3 \\
\hline Ausência de biblioteca básica & 1 & 0 & 0 & 0 & 1 \\
\hline PROCESSOS & NE & $\mathrm{CO}$ & SE & $S$ & TOTAL \\
\hline $\begin{array}{l}\text { Escassez de tempo em sala cirúrgica; recursos } \\
\text { humanos em cirurgia (anestesiologistas) ou } \\
\text { salas para cirurgias }\end{array}$ & 2 & 1 & 0 & 0 & 3 \\
\hline $\begin{array}{l}\text { Ausência de um sistema de marcação de } \\
\text { consultas e registro de cirurgias }\end{array}$ & 1 & 0 & 1 & 0 & 2 \\
\hline $\begin{array}{l}\text { Necessidade de supressão de escalas de } \\
\text { plantões de sobreaviso para o médico } \\
\text { residente }\end{array}$ & 2 & 0 & 4 & 0 & 6 \\
\hline $\begin{array}{l}\text { Correção da semana padrão e rodízios dos } \\
\text { estágios }\end{array}$ & 1 & 1 & 9 & 4 & 15 \\
\hline $\begin{array}{l}\text { Correção das condições básicas de trabalho do } \\
\text { médico residente e carga horária }\end{array}$ & 1 & 1 & 8 & 3 & 13 \\
\hline $\begin{array}{l}\text { Falta de organização/documentação na } \\
\text { COREME }\end{array}$ & 0 & 0 & 2 & 0 & 2 \\
\hline
\end{tabular}


Tabela 13 - Número absoluto de programas, por região do Brasil, e principais pontos que mereceram atenção (Ensino)

\begin{tabular}{|c|c|c|c|c|c|}
\hline ENSINO & NE & $\mathrm{CO}$ & SE & $\mathbf{S}$ & TOTAL \\
\hline $\begin{array}{l}\text { Estágio em urgência deficiente, inadequado ou } \\
\text { inexistente }\end{array}$ & 1 & 0 & 3 & 1 & 5 \\
\hline Falta de supervisão e equipe adequadas & 5 & 1 & 8 & 2 & 16 \\
\hline $\begin{array}{l}\text { Correção ou falta do estágio em neurologia } \\
\text { clínica }\end{array}$ & 1 & 0 & 3 & 5 & 9 \\
\hline $\begin{array}{l}\text { Falta do treinamento em laboratório de } \\
\text { neuroanatomia ecCirurgia experimental } \\
\text { para microcirurgia }\end{array}$ & 2 & 0 & 4 & 3 & 9 \\
\hline $\begin{array}{l}\text { Falta da existência de programa teórico e } \\
\text { didático inexistente ou inadequado }\end{array}$ & 1 & 1 & 5 & 3 & 10 \\
\hline $\begin{array}{l}\text { Ausência de visita (pelo menos semanal) aos } \\
\text { leitos dos pacientes de neurocirurgia internados }\end{array}$ & 1 & 0 & 0 & 1 & 2 \\
\hline $\begin{array}{l}\text { Ausência de reunião anatomoclínica/ } \\
\text { anatomopatológica e ou neurorradiológica }\end{array}$ & 1 & 0 & 4 & 1 & 6 \\
\hline $\begin{array}{l}\text { Ausência de reuniões para discussão de casos } \\
\text { clínicos e conteúdo teórico da especialidade }\end{array}$ & 1 & 0 & 2 & 1 & 4 \\
\hline $\begin{array}{l}\text { Existência de mais residentes/ano do que a } \\
\text { capacidade instalada para treinamento }\end{array}$ & 1 & 0 & 3 & 0 & 4 \\
\hline $\begin{array}{l}\text { Ausência de estágio em neurorradiologia } \\
\text { intervencionista }\end{array}$ & 0 & 0 & 6 & 0 & 6 \\
\hline Ausência de avaliação trimestral & 0 & 0 & 4 & 1 & 5 \\
\hline Ausência de estágio em UTI & 0 & 0 & 2 & 0 & 2 \\
\hline
\end{tabular}

**Observa-se que os dados são apresentados em números absolutos e que a região Sudeste possui mais de $50 \%$ dos PRMs de Neurocirurgia do Brasil.

\section{Discussão}

O fato de apenas um quarto $(26,9 \%)$ aproximadamente dos programas ser imediatamente aprovado mostra o quão necessário é realizar o trabalho de avaliação e acreditação dos programas de residência de maneira conjunta. No caso da neurocirurgia, enquanto a equipe de avaliação da CNRM foi reconhecida pelos representantes da SBN como bem preparada para lidar com os aspectos educacionais e legais de residência médica em geral, a equipe da SBN foi avaliada como altamente capacitada na análise do desenvolvimento e conteúdos específicos dos programas de residência; de questões técnicas relevantes e próprias para a especialidade. 
Foi possível demonstrar que trabalhando em conjunto os processos de avaliação e acreditação da residência médica desenvolvidos pela CNRM e pela Sociedade de Especialidade aprimorou os critérios na busca da qualidade da residência médica em neurocirurgia.

\section{Conclusões}

Não se tem notícias de outro projeto de avaliação com avaliadores de programas de residência médica tão qualificados. A presença necessária de um neurocirurgião especialista em avaliação e envolvido com ensino médico aliado à um médico especialista em educação médica, membro do Banco Publico Nacional de Avaliadores para cada visita in loco é, talvez, uma experiência única de excelência em acreditação no mundo.

Ao se analisar sistemas de formação tão complexos com diversos caminhos para se tornar um especialista, como é o caso do Brasil, os dados de alguns profissionais em formação poderiam não ser captados pelo estudo. Acredita-se, no entanto, ser virtualmente impossível exercer neurocirurgia sem a realização de residência médica credenciada pela CNRM ou curso de especialização, de longa duração da SBN, aumentando sobremaneira as chances de o estudo ter capturado o todo da formação desses especialistas no Brasil, com a união de SBN e CNRM.

\section{Projeto piloto parte II}

A segunda parte da parceria de avaliação dos 104 PRMs de Neurocirurgia deu origem ao projeto "Best Residencies Best Residents? Evaluating Residency Programs and Assessing residents, are we comparing 
oranges and apples?". Esse projeto tem por objetivo estudar as relações entre a avaliação in loco dos programas em neurocirurgia e o desempenho dos residentes em suas verificações anuais, promovidas, nacionalmente, pela SBN.

Existe relação entre a qualidade encontrada nas avaliações de programas de residência médica e o desempenho dos residentes nos testes individuais de avaliação?

Será que estamos comparando laranjas e bananas?

Métodos para esta etapa

Para responder a essas perguntas foi desenhado um estudo utilizando métodos mistos e dividido em três etapas. O estudo teve como foco a avaliação dos programas de residência em neurocirurgia - fase 1; na avaliação dos residentes de neurocirurgia - fase 2; e na busca de correlação estatística entre as avaliações de programas de residência e de médicos residentes - fase 3.

Fase 1: os pesquisadores conceberam e realizaram projeto piloto para avaliar programas de residência em neurocirurgia. Conforme descrito médicos, especialistas em neurocirurgia e avaliadores experientes, respectivamente selecionados pela SBN, ou médicos especialistas em educação médica com a experiência de mais de 20 avaliações e visitas in loco cada, selecionados pelo Ministério da Educação, junto ao Banco Público Nacional de Avaliadores da Residência Médica[157], aferiram 104 programas de residência em neurocirurgia. Os dados foram submetidos à análise temática em busca de temas e codificações comuns, identificando áreas que necessitavam atenção e correção (pontos fracos). Os temas foram novamente divididos com foco nas áreas consideradas importantes, visando às competências ou aos conhecimentos na formação de um neurocirurgião [167]. No final deste 
processo, os programas de residência listados receberam uma nota final correspondente ao número de pontos fracos.

Fase 2: para capturar o nível de conhecimentos e habilidades adquiridas pelos residentes em neurocirurgia, de todo o país, ao final de cada ano, a SBN aplica uma avaliação, de acordo com o esperado para um residente $(R)$ em neurocirurgia, para cada nível do programa de residência (R1 a R5). Existem testes com diferentes características e conteúdos para R1, R2, R3, R4 e R5. Os dados coletados a partir dos resultados de desempenho dos residentes foram separados por instituição, por ano de formação e por conteúdo avaliado, mantendo sempre anônimos os sujeitos da pesquisa.

Esses testes são cuidadosamente elaborados pela equipe de médicos da SBN, especialistas em avaliação de residentes, tendo como base a publicação "O Livro do residente em Neurocirurgia" [167].

Fase 3: finalmente, os resultados das avaliações dos programas de residência e os resultados do desempenho dos residentes foram submetidos ao teste de regressão linear. A influência de cada produto foi verificada por análise do $R^{2}$, ou coeficiente de determinação, sendo uma medida de ajustamento de um modelo estatístico linear generalizado, ou seja, quanto mais próximo de um for o valor de $\mathrm{R}^{2}$, mais o modelo aventado consegue explicar os valores observados.

\section{Resultados desta etapa}

Entre os resultados da fase 1 temos que os dados de aproximadamente 104 programas foram novamente analisados e subdivididos por temas, classificando os "pontos fracos", em "Cuidados de Saúde", "Ensinar e Aprender" e "Processo + Estrutura", pontuados por instituição. 
Novamente, os temas de maior fragilidade dos programas de neurocirurgia avaliados com detalhamento estão na tabela 14.

Tabela 14 - Pontos que merecem maior atenção

\begin{tabular}{|c|c|}
\hline $\begin{array}{l}\text { PONTO } \\
\text { FRACO } \\
\text { TEMÁTICO }\end{array}$ & DETALHAMENTO DO PONTO FRACO TEMÁTICO \\
\hline & $\begin{array}{l}\text { 1. Apresentar as estatísticas de cirurgia. } \\
\text { 2. Atingir } 300 \text { cirurgias anuais. } \\
\text { 3. Aumentar disponibilidade de leitos em Unidades de Terapia Intensiva. } \\
\text { 4. Baixo número de cirurgias pediátricas/sem termo efetivado de convênio. } \\
\text { 5. Baixo número de cirurgias vasculares/sem termo efetivado de convênio. } \\
\text { 6. Baixo número de cirurgias funcionais/sem efetivado de convênio. } \\
\text { 7. Baixo número de Cirurgia de Tumores/sem convênio efetivado de convênio; } \\
\text { 8. Baixo número de cirurgias de coluna/sem termo efetivado de convênio. } \\
\text { 9. Baixo número de cirurgias em nervos periféricos/sem termo efetivado de convênio. } \\
\text { 10. Ausência de ambulatório, ou quando existe, o residente não consegue } \\
\text { operar pacientes daquele serviço. }\end{array}$ \\
\hline & $\begin{array}{l}\text { 1. Ausência de estágio em UTI. } \\
\text { 2. Estágio deficiente em Urgência, inadequado ou inexistente. } \\
\text { 3. Falta de supervisão e equipe adequada. } \\
\text { 4. Necessidade de correção ou falta do estágio em neurologia clínica. } \\
\text { 5. Falta de treinamento em laboratório de neuroanatomia e cirurgia } \\
\text { experimental para microcirurgia. } \\
\text { 6. Inexistência ou inadequação de programa teórico e didático. } \\
\text { 7. Ausência de visita semanal aos leitos dos pacientes de neurocirurgia } \\
\text { internados. } \\
\text { 8. Ausência de reunião anatomoclínica/ anatomopatológica e ou } \\
\text { neurorradiológica. } \\
\text { 9. Ausência de reuniões para discussão de casos clínicos e conteúdo } \\
\text { teórico da especialidade. } \\
\text { 10.Existência de mais residentes/ano do que a capacidade instalada de } \\
\text { treinamento. } \\
\text { 11. Ausência de estágio em neurorradiologia intervencionista. } \\
\text { 12. Ausência de avaliação mínima trimestral. }\end{array}$ \\
\hline $\begin{array}{l}\text { Processo + } \\
\text { Estrutura: }\end{array}$ & $\begin{array}{l}\text { 1. Falta de horários em sala cirúrgica. } \\
\text { 2. Falta de recursos humanos em cirurgia (anestesiologistas) ou salas para cirurgias. } \\
\text { 3. Ausência de um sistema de marcação de consultas e registro de cirurgias. } \\
\text { 4. Ocorrência de escalas de plantões de sobreaviso para o médico residente } \\
\text { que precisam ser suprimidos. } \\
\text { 5. Correção da semana padrão e rodízios dos estágios. } \\
\text { 6. Correção das condições básicas de trabalho do médico residente e carga horária. } \\
\text { 7. Falta de organização/documentação na COREME; } \\
\text { 8. Falta de materiais para cirurgias (clipes para aneurismas, aspirador } \\
\text { ultrassônico etc). } \\
\text { 9. Falta ou dificuldade em realizar exames complementares e diagnósticos. } \\
\text { 10. Ausência de biblioteca básica. }\end{array}$ \\
\hline
\end{tabular}


Na fase 2, o desempenho de 534 residentes, em testes, foi utilizado para ser comparado com as avaliações dos programas de residência conforme explicado antes. Os dados incompletos provenientes das avaliações de programas ou da avaliação dos residentes (menos de três níveis de residentes presentes na prova) foram considerados critérios de exclusão e descartados. A tabela 15 mostra a distribuição do número de questões, de acordo com o nível do residente (R1 a R5) e o conteúdo avaliado.

Tabela 15 - Distribuição do número de questões, de acordo com o nível do residente (R1 a R5) e o conteúdo avaliado

\begin{tabular}{|c|c|c|c|c|c|}
\hline $\begin{array}{cc}\text { Temas } & \begin{array}{c}\text { Residentes por } \\
\text { nível }\end{array}\end{array}$ & $\mathbf{R} 1$ & $\mathbf{R 2}$ & R3 & R4 & R5 \\
\hline $\begin{array}{l}\text { Neurologia organizacional } \\
\text { funcional }\end{array}$ & 8 & 4 & 1 & - & - \\
\hline Neurosemiologia & 15 & 21 & 2 & - & - \\
\hline Neurologia & 4 & 12 & 4 & 7 & 1 \\
\hline Vascular/ Hemorrágica & 1 & 2 & 8 & 5 & 8 \\
\hline Neoplasia crânioencefálica & 2 & 6 & 8 & 20 & 15 \\
\hline Vascular/lsquêmica & 7 & - & 1 & 2 & 4 \\
\hline Raquimedular & & 2 & 2 & 2 & 6 \\
\hline Trauma craniano & 10 & 8 & 1 & 11 & 5 \\
\hline Trauma de coluna & & 2 & 8 & & 8 \\
\hline Cirurgia funcional e epilepsia & 4 & - & 4 & 4 & 7 \\
\hline Dor e espasticidade & 2 & - & - & 3 & 4 \\
\hline $\begin{array}{l}\text { Patologia degenerativa da } \\
\text { coluna }\end{array}$ & 3 & 2 & 6 & 6 & - \\
\hline Neurorradiologia & & 7 & 18 & 13 & - \\
\hline Terapia intensiva neurológica & 2 & 2 & - & - & - \\
\hline Técnicas em neurocirurgia & - & 1 & 1 & $\begin{array}{c}\text { Microcirúrgica } \\
\text { (8) }\end{array}$ & - \\
\hline Temas especiais & - & - & $\begin{array}{c}\text { Trauma-dor } \\
(2) \\
\text { Trauma- } \\
\text { Nervos (2) }\end{array}$ & $\begin{array}{c}\text { Microanatomia } \\
\text { Cirúrgica (3) } \\
\text { Estéreo } \\
\text { Radiocirurgia } \\
\text { (4) }\end{array}$ & $\begin{array}{c}\text { Estéreo } \\
\text { Radio } \\
\text { cirurgia } \\
\text { (1) }\end{array}$ \\
\hline
\end{tabular}


Após exclusão dos dados incompletos, na fase 3 , foram incluídos para análise da fase 1 (residências) 38 programas e da fase 2 (residentes), um total de 179 médicos. Entre eles, estavam 37 finalizando o R1; 35 ao final do R2; 37 ao final do R3; 39 ao final do R4 e 31 ao final do R5. Nenhum programa da região Norte pode ser incluído; foi possível incluir 7 programas de Nordeste; 1 programa a partir do Centro-Oeste; 22 do Sudeste e 8 da região Sul.

Cada "ponto fraco" do programa de residência foi avaliado em comparação com a nota dos residentes nas avaliações e divididos por tema correlato, utilizando-se regressão linear. A tentativa foi a de encontrar influência de um item sobre o outro. Como exemplo, buscou-se avaliar se a quantidade de pontos fracos em estágios de neurologia de determinado programa exerceu influência sobre as notas dos residentes daquele local nas questões de neurologia.

Essa tentativa de divisão dos itens por área não encontrou qualquer relação entre os resultados. Em alguns casos, os resultados demonstraram influências aparentemente peculiares.

Decidiu-se então agregar todos os dados de avaliação dos programas, estabelecendo-se uma nota única por programa e não mais por item; o mesmo foi feito para o desempenho dos residentes, agregando-os por nível e por programa (instituição). O teste estatístico de regressão linear foi novamente aplicado procurando a influência de um item sobre o outro por meio do cálculo do $\mathrm{R}^{2}$.

$O R^{2}$, ou coeficiente de determinação, na regressão linear simples fornece informações auxiliares para verificação da adequação de um modelo proposto na explicação de um fenômeno. A variação é entre 0 e 1 , quanto maior o valor, maior a influência de um item sobre o outro. Novamente, a influência entre os fatores foi mínima, como mostra a tabela 16: 
Tabela 16 - Análise estatística da influência dos programas de residência médica (variável independente) sobre o desempenho dos residentes (variável dependente)

\begin{tabular}{lcccc}
\hline Residentes & Número & R-quadrado & $\begin{array}{c}\text { Variável } \\
\text { Explicada }\end{array}$ & $\begin{array}{c}\text { R-quadrado } \\
\text { ajustado }\end{array}$ \\
\hline Total & 179 & 0.015272332 & $1.5 \%$ & -0.001608714 \\
\hline R1 & 37 & 0.042631371 & $4.3 \%$ & -0.044402141 \\
\hline R2 & 35 & 0.123444376 & $12.3 \%$ & 0.038616413 \\
R3 & 37 & 0.036955491 & $3.7 \%$ & -0.05059401 \\
\hline R4 & 39 & 0.075032393 & $7.5 \%$ & -0.004250545 \\
\hline R5 & 31 & 0.153515443 & $15.4 \%$ & 0.059461603 \\
\hline
\end{tabular}

\section{Discussão}

Se por um lado a conclusão pode ser de que, nessa fase, tentamos verdadeiramente comparar laranjas com bananas, por outro lado existe crença geral de que os melhores programas de residência podem formar os melhores residentes. Não nos foi possível comprovar essa percepção no presente estudo.

Sabe-se que os métodos de avaliação, tanto dos residentes quanto das residências, ainda necessitam de muito aprimoramento, pesquisa e investimento. Mesmo as mais especializadas equipes de avaliação e os mais complexos testes ainda não são aptos a captar a realidade por meio das clássicas análises estatísticas de comparação, ainda que se utilizem desfechos diversos dos aqui empregados.

Talvez por esse motivo os estudos relacionando desempenho das avaliações de programas de residência médica com o desempenho dos 
resultados residentes são raros. Os estudos existentes reconhecem que fatores individuais exercem grande influência no desempenho dos residentes.

Ainda são raras as publicações correlacionando desempenho dos programas de residências com desempenho dos residentes. Como exemplo, demonstramos abaixo parte dos resultados da última busca realizada em maio de 2016 utilizando: "Residency accreditation" ou "residency program evaluation" e "resident assessment":

"residency accreditation" [All Fields] AND "resident assessment" [All Fields] = encontrados 0 artigos "residency program evaluation" [All Fields] AND "resident assessment" [All Fields]= encontrados 0 artigos residency program evaluation [all fields] AND (resident[all fields] AND assessment [all fields]) = encontrado 1 artigo ("internship and residency" [MeSH Terms] AND "accreditation" [MeSH Terms]) AND "resident assessment" [All Fields]" = encontrados 5 artigos

"residency" [All Fields] AND "program evaluation" [All Fields] AND "resident assessment" [All Fields]= encontrados 9 artigos "residency" [All Fields] AND "accreditation" [All Fields] AND "resident assessment "[All Fields] = encontrados 20 artigos

Desse universo, podemos citar que Asch e colaboradores em 2007 fizeram um chamado em publicação no Journal of American Medical Association, JAMA, intitulado "Evaluating Medical Training Programs by the Quality of Care Delivered by Their Alumni" [172] para que mais pesquisas busquem correlacionar a formação dos médicos com seus resultados de suas ações. A pesquisa em debate analisou as ocorrências negativas de assistência ao parto via vaginal ou cesárea, de $43 \%$ de locais com programas de residência médica em Obstetrícia e Ginecologia nos EUA. Constatou o risco de 10,3\% para uma complicação maior, nos cinco melhores programas, contra 
$13,6 \%$ naqueles classificados em últimos lugares. No entanto, ao avaliar o desempenho dos residentes nos testes americanos de final de curso, não houve diferenças. Nesse artigo, os autores argumentam que embora intuitivo não é tão linear que bons programas de residência ou cursos de graduação formem médicos mais adequados ao sistema de saúde e na perspectiva do paciente. Por outro, a reputação de um programa de residência médica é muito considerada na vida profissional futura de seus egressos, o que gera um círculo virtuoso. Também é muito provável que os reputados como melhores programas atraiam os melhores residentes. Concluem os autores que 0 processo de avaliação de qualidade de um programa de residência médica depende mais de desfechos analisados nos pacientes atendidos naquele programa e não do desempenho de residentes nos processos avaliativos, devendo os desfechos serem incluídos no ranqueamento do programa. Portanto, à despeito de metodologia muito mais apropriada (tamanho e uniformidade da amostra), Asch e cols. não encontraram correlação entre instituição de origem e desempenho dos residentes, por ocasião de avaliação de conhecimentos e habilidades.

O número de variáveis existentes nesse tipo de análise inclui aspectos pessoais, tipo de seleção dos residentes, currículo desenvolvido, tipo e quantidade de avaliações empregadas ao programa e aos residentes, tamanho do programa, entre muitas outras. Há evidente dificuldade em obter correlações diretas e resultados positivos nesse tipo de pesquisa, o que desestimula as publicações e consequentemente as pesquisas.

Um importante estudo foi realizado por Falcone e colaboradores [173] em 2014 nos EUA, que comparou desempenho dos residentes; resultados na 
acreditação dos programas pelo ACGME e tamanho dos programas. Nesse estudo, o desempenho da avaliação pelo ACGME foi utilizado apenas como critério de inclusão para os programas com pontuação acima de 80\%.

No entanto, o fator tamanho do programa demonstrou, ainda que diminuta, alguma influência sobre os resultados dos residentes. Isso pode ser explicado pela maior possibilidade de investimentos, sobretudo na área de educação médica pelos maiores programas.

"We hypothesize larger residency programs have more resources to invest in curriculum development and learning materials, recruit more highly trained faculty and educators, hire more highlyperforming residents, and provide additional performance incentives[173]."

Também Swick [174], no estudo "Assessing the ACGME Competencies in Psychiatry Training Programs", lista a diversidade de fatores e tipos de avaliações atualmente em uso na educação médica, com foco na avaliação de competências dos residentes e esperadas pela agência de acreditação dos programas de residência nos EUA - ACGME.

No presente estudo, cumpre salientar que existem diversos fatores limitantes para obtenção de reposta favorável da análise pretendida, ou seja, se os melhores programas produzem melhor desempenho dos residentes. Inicialmente, trabalhamos com dados secundários. Secundariamente, podemos concluir que o número de residentes por nível que responderam cada questão (conteúdo) não representou amostra suficiente para a comparação pretendida. 0 mesmo pode se dizer sobre o número de questões por tema (conteúdo). Finalmente, foi necessário utilizar o desempenho em uma avaliação de base teórica como parâmetro (único existente) para definição de melhores residentes. 
Ainda assim, vale ressaltar que, se houver apenas forte influência dos programas de residência sobre o desempenho dos residentes, à despeito das características individuais como se essas, de alguma forma houvessem sido suprimidas, tal resultado seria muito mais surpreendente, o que não se espera obter em um programa de formação, tendo em vista que a diversidade humana tende a enriquecê-la sempre.

Como cautelosamente nos lembra a literatura, sigamos estudando essa curiosa correlação entre processos e pessoas.

\section{Conclusões}

É possível que as melhores residências possam mesmo formar os melhores residentes, no entanto, parece que os fatores que influenciam o desempenho do residente vão muito além dos institucionais, havendo significativo peso dos fatores individuais.

Os programas devem seguir buscando contínua melhora na qualidade da formação de seus residentes. O estudo não retira a responsabilidade dos programas na formação dos profissionais. Ao contrário disso, reforça que, talvez, as responsabilidades dos programas devam ir muito além das técnicas e limites dos portões das instituições. A educação médica atual compreende que o desempenho dos residentes transborda as delimitações dos conteúdos técnicos e cognitivos, o que explica que tantas outras áreas do conhecimento (muitas delas ligadas ao comportamento) mereçam atenção e ênfase como nas já citadas CanMeds. O estudo aponta para a direção de que o trabalho e a responsabilidade dos programas de residência médica, na busca pela 
qualidade dos residentes egressos, parece estar por aumentar muito e em muitas áreas, bem como devamos perseverar buscando outras métricas de qualidade dos programas de residência médica, como desfechos comparáveis por especialidade. 


\section{CAPÍTULO X: INFLUÊNCIAS E COMPARAÇÕES DE MODELOS DE ACREDITAÇÃO DE PROGRAMAS DE RESIDÊNCIA MÉDICA}

\section{A formação médica e o provimento de profissionais}

Atualmente, a necessidade de profissionais de saúde, sobretudo médicos, em todo o planeta, tem influenciado fortemente a formação médica $[11,53,175,176]$. Está cada vez mais claro que a migração dos médicos pelos diferentes países demanda padronização do ensino e das competências adquiridas ao final da formação. Esse processo de padronização e de qualificação da educação médica pode ser feito por meio da acreditação de escolas e residências médicas ao redor do mundo [177].

Os estudos para garantia de provimento de médicos, no planeta, está se deslocando de meros cálculos demográficos, baseados em oferta, necessidades e demandas, para modelos mais elaborados, envolvendo economia, qualidade de vida, sistemas de saúde, oportunidades educacionais, carreira, entre outros fatores [42, 48, 176, 178, 179]. Há exemplos na literatura especializada, comprovando que o desbalanço entre o número de especialistas (em variadas especialidades e momentos) e as demandas e necessidades é dinâmico e não se corrige pelo aumento exclusivo da oferta de formação ou de médicos.

Atualmente, países com características tão diferentes como os EUA, Canadá, Kuwait, Iraque e Uruguai discutem o papel da graduação e regulação como parte fundamental para planejar força de trabalho dos médicos [53, 175, 180-184]. 
Novamente, a residência médica permanece como o modelo mais importante para a especialização médica e é considerada "padrão ouro" de formação [154].

Esse modelo, no entanto, está sob constante transformação, compatível com os avanços da educação. Um exemplo de mudanças é a recente formação médica por competências, do inglês Competency Based Medical Education (CBME) [47].

A importância do modelo, residência médica, deixou de ser motivo de demonstração, por meio de pesquisas, literatura científica, com aceitação generalizada. Os estudos atualmente estão mais centrados em processos de ensino e aprendizagem, currículos, avaliação, acreditação e assim por diante, dentro da modalidade residência médica $[85,86,185]$.

\section{Residência médica de qualidade}

Devemos ter em mente que definir o que é uma residência de qualidade não é tarefa fácil [186], mesmo assim é preciso estabelecer parâmetros para que o profissional tenha conteúdos e competências, minimamente confiáveis e comparáveis no planeta. Um estudo realizado com residentes de sete províncias canadenses tentou responder ao questionamento "what are the characteristics of a high-quality residency program?' [187],resultando em sete componentes de alta qualidade na residência médica, sendo eles:

- ambiente de trabalho;

- atenção na transição para a prática;

- balanço entre ensino e serviço; 
- tutoria/mentoria (Mentorship);

- currículo acadêmico;

- processos de avaliação;

- supervisor de programa.

Elliot [188] defende que a definição de qualidade na residência se estabelece nas múltiplas relações, necessidades e expectativas entre as partes interessadas no programa (costumers). Em sua definição de costumers, foram considerados todos os que, de alguma maneira, sejam afetados. Por exemplo, além dos pós-graduandos, pacientes, familiares, agências financiadoras, funcionários da saúde, instituições de treinamento e organizações profissionais. Ainda que um consenso possa ser muito difícil, este tipo de estudo pretende auxiliar na definição multidimensional da qualidade na residência médica.

\section{Os modelos dos EUA, Canadá e Brasil comparados}

O Canadá e os EUA possuem acordos de acreditação conjunta de escolas médicas e de cooperação na validação dos títulos da residência médica, facilitando o cruzamento da fronteira para que se pratique medicina nos dois países.

No que se refere à acreditação, porém, se comparados os modelos americano e canadense de acreditação, podemos observar similaridades e diferenças. Talvez haja muito mais similaridades entre os modelos de acreditação do RCPSC (canadense) com os processos de avaliação e credenciamento da CNRM (brasileira), do que com a ACGME (norte-americano). 
Quando comparados os processos, vemos muitas similaridades nas funções da plenária da CNRM com o comitê de acreditação do RCPSC; da câmara técnica da CNRM com os revisores do RCPSC; e a avaliação realizada por pares.

Porém, tanto nos EUA quanto no Canadá existem instituições independentes e fortes de acreditação que estabelecem, avaliam e validam critérios a serem atingidos pelos programas de residência médica para melhoria constante da qualidade [92], permitindo acordos, estudos e comparações.

Diferenças importantes também são encontradas como a existência de um processo de revisão interna no Canadá e EUA, mas não formalmente, no Brasil. Outro exemplo é a obrigatoriedade de uma Universidade como responsável por um programa de residência médica no Canadá, mas não nos EUA ou Brasil.

Enquanto na literatura se considera que ainda não chegamos nem mesmo na infância da avaliação em qualidade na atenção à saúde [9], no Brasil ainda não surgiu (ou nasceu) uma agência independente de acreditação que possa padronizar, unificar e certificar todos os programas de formação médica, de modo totalmente independente.

A falta de uma estrutura única e organizada é aparentemente uma grande lacuna na busca e preocupação com a manutenção da qualidade da formação médica e torna comparações impossíveis já que sob o mesmo título (por exemplo, cardiologista) diferentes caminhos, currículos e treinamentos em serviço podem ter sido realizados, em nosso meio, mesmo quando o caminho foi único, como no caso da residência médica. Por certo que se reconhece que tem de haver diferenças regionais na formação. O que se busca aqui é uma formação básica, geral e essencial, comum. 
No Canadá e nos EUA, países que parecem estar no outro extremo os processos de acreditação, é tão importante e pesado que podem ser causa de burnout [esgotamento][34] aos que recebem avaliação deste tipo; tornando a tarefa de supervisionar e guiar residentes, muitas vezes, até mesmo menos importante do que responder aos anseios da acreditação [189]. A experiência nesses países pode ser traumática, não sendo incomum o desejo de um supervisor de programa se demitir após ter sido avaliado [32]. Comparando modelos, vemos que o equilíbrio (muitas vezes muito distante) é fundamental. A tabela 17 resume a comparação entre modelos.

Tabela 17 - Modelos de acreditação e avaliação comparados

\begin{tabular}{|c|c|c|c|}
\hline Atributos & Brasil & Canada & EUA \\
\hline SISTEMA DE SAÚDE & SUS (Público - Misto) & Público* & Privado \\
\hline INSTITUIÇÃO & $\begin{array}{l}\text { MEC ou AMB } \\
\text { registrados no CFM }\end{array}$ & RCSPC & ACGME \\
\hline LOCALIZAÇÃO & Governamental & Independente & Independente \\
\hline $\begin{array}{l}\text { PERFIL DOS } \\
\text { AVALIADORES }\end{array}$ & Médicos & Médicos & $\begin{array}{l}\text { Especialistas } \\
\text { em avaliação }\end{array}$ \\
\hline $\begin{array}{c}\text { APOIO } \\
\text { EDUCACIONAL }\end{array}$ & $\begin{array}{l}\text { Câmara técnica - } \\
\text { Educadores }\end{array}$ & $\begin{array}{l}\text { Câmara técnica - } \\
\text { Educadores }\end{array}$ & $\begin{array}{l}\text { Câmara técnica - } \\
\text { Educadores }\end{array}$ \\
\hline $\begin{array}{c}\text { APOIO } \\
\text { ESPECIALIZADO }\end{array}$ & - & $\begin{array}{l}\text { Câmara técnica - } \\
\text { por especialidade }\end{array}$ & $\begin{array}{l}\text { Câmara técnica - por } \\
\text { especialidade }\end{array}$ \\
\hline $\begin{array}{l}\text { QUANTIDADE DE } \\
\text { ESPECIALISTAS }\end{array}$ & - & Regulado & - \\
\hline FINANCIAMENTO & Público & $\begin{array}{l}\text { Público e } \\
\text { instituições }\end{array}$ & Instituições \\
\hline RESPONSABILIDADE & $\begin{array}{l}\text { Universidades, hospitais } \\
\text { e instituições de saúde }\end{array}$ & Universidades & $\begin{array}{l}\text { Universidades, hospitais } \\
\text { e instituições de saúde }\end{array}$ \\
\hline REVISÃO INTERNA & - & + & + \\
\hline $\begin{array}{l}\text { ESTABILIDADE DA } \\
\text { AVALIAÇÃO }\end{array}$ & - & + & + \\
\hline
\end{tabular}

"Now (the accreditation is over) we can go back to training residents rather than being surveyed"[32] 
A acreditação é muitas vezes encarada como uma "biópsia" da realidade. Se por um lado analisa profundamente o que está em seu tempo e em seu escopo, por outro pode estar longe da realidade e distante do fenômeno de forma geral. A saída, no entanto, não é "desacreditar" a acreditação ou diminuir os investimentos dessas iniciativas, já que, sem essa análise, haverá um vazio (escuridão) sobre o conteúdo e o processo de desenvolvimento do profissional que cuida de vidas humanas. Em vez disso, deve-se engendrar esforços para que a acreditação se torne menos incômoda e se aproxime da realidade vivida na residência, garantindo qualidade dos programas. De fato, as mudanças do next accreditation system e o novo processo de avaliação por competências do RCPSC surgem nessa direção e sentido. 


\section{RESULTADOS EM UM PLANO NACIONAL DE AVALIAÇÃO E ACREDITAÇÃO}

Nesta tese, diferentes estudos foram realizados utilizando metodologias variadas, sempre objetivando somar dados e analisar modelos de avaliação e acreditação de programas de residência médica, seja nacional ou

internacionalmente. Visando dar margem a comparações de processos e sistemas de acreditação na residência médica, os sistemas existentes no Brasil e internacionalmente foram analisados, com destaque para o sistema canadense do RCPSC, que foi escolhido por se tratar de país de dimensões continentais, sistema de saúde público, dificuldades no provimento e distribuição de médicos (dada as regiões de difícil acesso) e polo mundial no estudo, pesquisa e desenvolvimento na área da educação médica.

A união de todos os estudos que compõem este trabalho não poderia ser diferente, se não, resultar em uma proposta nacional de modelo para acreditação e avaliação de programas de residência médica, de concepção internacional.

Apresentou-se até aqui extensa revisão de literatura científica nacional e internacional, bem como de documentos legais em torno de diferentes modelos, estudos utilizando descrição qualitativa, etnografia, estudo de caso e métodos mistos. As metodologias foram escolhidas tendo como base o melhor método para responder às perguntas de cada etapa da pesquisa (the research question). Espera-se que a somatória de conhecimentos adquiridos até aqui seja capaz de apresentar um modelo consistente que se proponha a responder às necessidades sociais, científicas, educacionais, assistenciais, entre outras, para um sistema de 
acreditação e avaliação de programas de residência médica. Um sistema nacional que contribua para equilibrar o atual foco, centrado na quantidade de profissionais médicos, com a necessária convergência na qualidade.

O acúmulo de conhecimentos e perspectivas nos leva a um paradigma ao qual contribui, inexoravelmente, para construção de um modelo que será apresentado. A acreditação não pode perder de vista seu propósito de qualificar programas, objetivando o resultado esperado, isto é, qualificar médicos cada vez mais competentes.

Há uma grande diversidade de modelos que atuam na regulação, acreditação e provimento de força de trabalho na saúde, com impacto na residência médica em diferentes partes do mundo [176, 183, 190]. Direta ou indiretamente, agências governamentais, agências independentes, sociedades médicas, Universidades, departamentos de saúde e educação dividem responsabilidades sobre os resultados no quantitativo e na qualidade do profissional formado de cada país. A proposta aqui apresentada pretende sugerir um modelo definindo papéis e responsabilidades das partes integrantes e interessadas na residência médica no que concerne a acreditação, a regulação e o fornecimento de mão de obra.

A proposta considera a conjunção de possíveis ações e responsabilidades do Estado (Ministérios da Saúde e Educação), as necessidades da sociedade, o papel dos especialistas em educação médica e dos médicos especialistas responsáveis pela formação de seus "futuros colegas de especialidade". Ou seja, espaços democráticos e objetivos que incluam discussão, debate e consenso do conjunto de representação das Escolas Médicas e Universidades, dos gestores em saúde e educação e das sociedades nacionais de 
especialidade médica, chamadas aqui de SNEMs, culminando com titulação conjunta e única, por meio do conceituado padrão residência médica, conforme dados científicos e consensos já firmados.

\section{Os componentes}

Os elementos para o sistema nacional de Acreditação e Avaliação de Programas de Residência Médica seriam:

- A CNRM mantendo suas responsabilidades, atribuições e composição atual, contando com as representações dos estados (os presidentes de CEREMs), porém saindo dos limites hierárquicos do Ministério da Educação e passando a ser a instância máxima de deliberação da instituição acreditadora independente. - Diretrizes e Decisões

- As CTs - Câmaras Técnicas, lembrando que elas devem ser compostas por especialistas em educação médica provenientes de Universidades e Escolas de Medicina. Além de elaborar pareceres sobre relatórios de avaliação, processos e atos autorizativos, passariam à contínua tarefa de repensar e atualizar o sistema residência médica. - Qualidade

- As CNPEs - Comitê Nacional para Especialidades Médicas, composto por especialistas em pós-graduação de cada especialidade médica existente no país (atualmente 54 no Brasil). Esses comitês, que passariam a existir no interior da instituição acreditadora e seriam responsáveis por inserir as particularidades de cada especialidade nos currículos, avaliações e processos de acreditação. - Qualidade 
- As COREMEs, mantendo suas atribuições atuais, mas com estrutura das instituições responsáveis pelos programas de residência mais bem definida, incluindo carga horária necessária para desempenho da função de coordenador de COREME, bem como de supervisores de programas, assim como dimensionamento de infraestrutura física e recursos humanos proporcionais ao número de programas e de residentes. - Cogestão

- As CEREMs, Comissões Estaduais de Residência Médica, além das funções atuais seriam responsáveis pelo diálogo com as "instituições responsáveis" pelos programas de residência médica, auxiliando nos processos de "avaliação interna". Necessário definir função e carga horária protegida para o desempenho da função de presidente de CEREM, bem como de seus diretores, incluindo infraestrutura e recursos humanos, compatíveis com a dimensão (número) dos programas, residentes e da unidade da federação. - Cogestão

- BNRM - Banco Nacional de Avaliadores da Residência Médica. O conjunto de médicos avaliadores deverá ter representação ponderada de educadores médicos, especialistas médicos, representantes dos conselhos de ética, dos sindicatos da profissão e dos gestores de saúde, de modo a constituírem duplas ou trios devidamente equilibrados para consumação da avaliação, responsáveis pela análise dos relatórios de pré-visita e dos formulários preenchidos dos pedidos de credenciamentos de programas, visita de avaliação in loco dos programas e produção de relatórios finais.- Avaliação 
- Cadastro Nacional de Especialistas - CNE, responsável pelo planejamento e provimento do número de médicos para o país. Definindo as necessidades regionais de especialistas para o plano de provimento. É quem regula e alimenta o sistema a partir de necessidades e limites para formação de profissionais em cada estado. - Quantidade

A CNRM, CTs, CNPEs, CEREMs e BNRM fariam parte integrante do organograma de uma Agência Pública e independente de Acreditação de Residência Médica, que para fins didáticos denominaremos AREM.

\section{O Fluxo para regulação}

1. CNE define o número necessário de médicos especialistas e generalistas para cada Estado da federação e comunica a agência acreditadora independente.

2. De posse das informações, a AREM, por meio de seus órgãos de manutenção da qualidade dos programas de residência médica, CT e CNPE, dialoga com as instituições responsáveis e solicitantes dos programas e encaminha proposta de ação para responder ao proposto pela CNE.

3. A CNRM delibera sobre a proposta de ação e decide sobre os modelos e a implantação dos programas, comunicando as CEREMs locais.

4. As CEREMs passam a se comunicar e apoiar as COREMEs para implantação dos programas necessários, conforme definido pela CNRM. 
5. Após sequência inicial de implantação exposta e antes da abertura do programa, o BNRM, em conjunto com avaliadores da sociedade de especialidade específica, conforme o programa, visitam e avaliam, constatando a real capacidade de funcionamento e treinamento. Ou seja, caberia à AREM e às SNEMs a avaliação dos programas, bem como das instituições, de maneira conjunta, por todo território nacional.

6. Os relatórios unificados produzidos pelos avaliadores do BNRM e SNEMs serão então analisados pela CT e CNPE, de maneira independente. Os pareceres serão a seguir encaminhados ao plenário da CNRM que toma a decisão de acreditar, ou não, o programa, definindo sua capacidade de formação e data da próxima avaliação.

7. A CNRM também comunica a CNE dos prazos e propostas para resposta e execução do plano de ação que atinja o quantitativo proposto, mantendo a qualidade necessária.

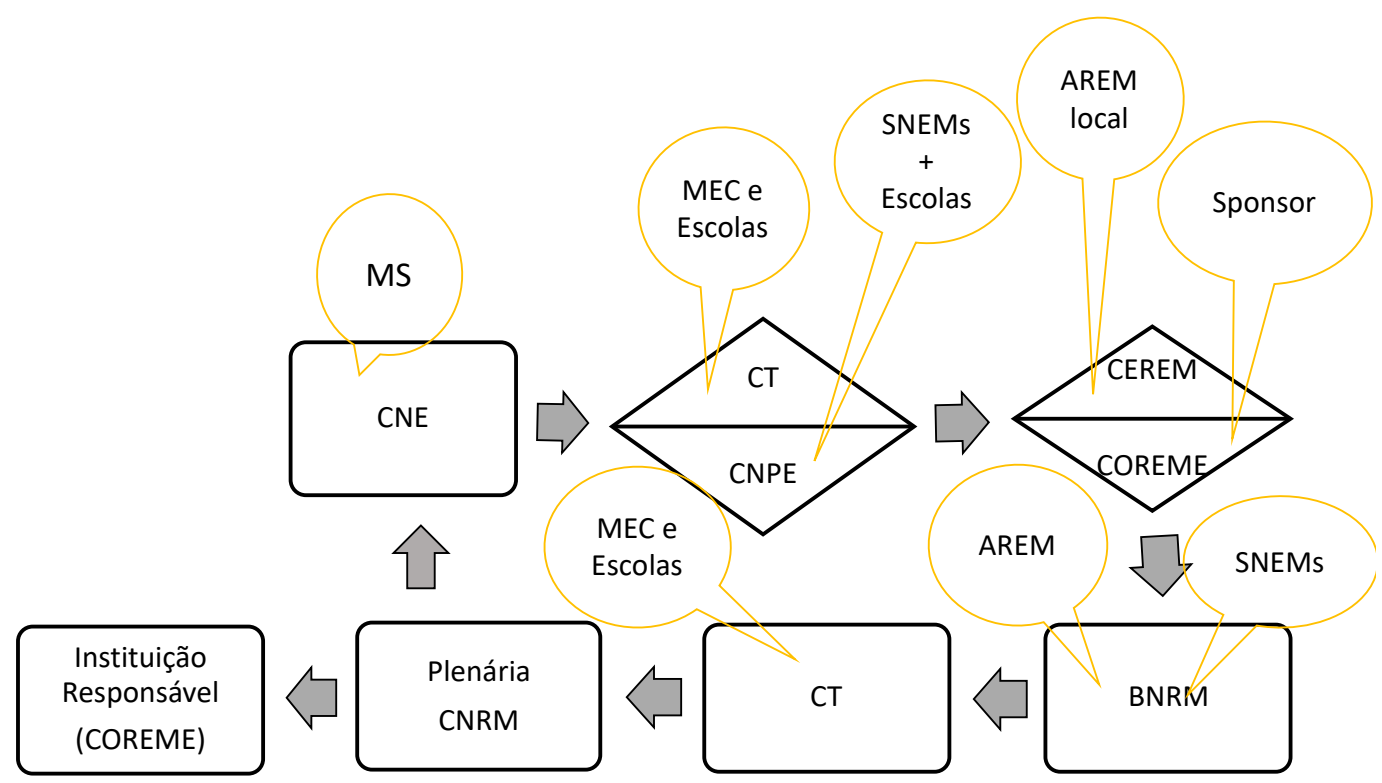

Fluxograma 4 - Exemplo de processos para um sistema de acreditação nacional 


\section{O modelo de avaliação dos programas}

A avaliação dos programas de residência médica será realizada no nível institucional. A tomada e a análise de dados quantitativos serão realizados por avaliadores profissionais (não médicos). As avaliações, por exemplo, das documentações seguirão em fluxo contínuo, por técnicos da AREM, com visitas independentes, quando necessárias.

As avaliações dos programas serão realizadas pelos pares como informado anteriormente. Independentemente do tipo de avaliação, os dados requeridos deverão manter objetividade e leveza, evitando que o processo se torne pesado e desfocado.

A instituição acreditadora deve ser responsável pelo treinamento e capacitação contínua e direta de avaliadores e dos coordenadores de COREMEs. Incentivando e possibilitando às instituições idêntico treinamento contínuo dos seus supervisores de programas, preceptores e docentes.

As instituições credenciadas, responsáveis pela oferta de programas de residência médica, devem apresentar requisitos mínimos de estrutura, recursos humanos e processos de gestão, com vistas a superar, continuadamente, pendências de assistência e ensino, estabelecendo políticas de valorização dos profissionais envolvidos com a residência médica, as quais devem ser incluídas nos critérios de pontuação para a acreditação.

\section{Do modelo e responsabilidade}

A proposta inclui implantação do modelo existente em diversos países, ou seja, responsabilidade sobre grandes instituições (públicas ou privadas) e 
destas sobre aglomerados de programas de residência médica [89]. A vantagem em haver instituições responsáveis por um grupo de programas de residência médica está na possibilidade de realizar avaliações internas, em parceria com a agência acreditadora e também no fortalecimento das atuais COREMEs como parceiras fortes na gerência, implantação e acompanhamento de programas, ampliando as possibilidades de investimento em educação médica.

No caso brasileiro, salvaguardadas as delimitações jurídicas, seriam elas:

- Universidades, Secretarias Municipais ou Estaduais de Saúde, Instituições Privadas, Federais, Estaduais e municipais com vinculação direta ao Ministério da Saúde ou às respectivas secretárias de saúde (ex: Hospitais Federais, FioCruz) ou MEC e Forças Armadas;

- Sociedades Nacionais de Especialidades Médicas, SNEMs: cada uma delas poderia passar a ser responsável direta por programas de residência médica ofertados em todo país, respeitando-se as definições, a autorização e o número de vagas definidos pelo tripé já citado, especificamente de acordo com a necessidade em cada estado, desde que devidamente aprovados pela Comissão Nacional de Residência Médica, após atendimento dos trâmites expostos em regras específicas. Naturalmente que propor que as SNEMs possam solicitar e gerenciar programas de residência médica gerará muitos debates, que certamente aprimorará a proposta.

\section{A união dos saberes}

Nesta proposta, a via de formação do especialista no Brasil passa a ser única. A formação do médico especialista (ainda que nas áreas gerais) só 
poderia ocorrer mediante o cumprimento de Programas de Residência Médica, em instituições de saúde ou ensino reconhecidas pela AREM. Os programas passam a responder a critérios como competências, cenários de prática e ensino e modelos de formação unificados em uma instituição, mas deliberados conjuntamente pelo tripé Escolas Médicas/Universidades - Sociedades Nacionais de Especialidades Médicas (SNEMs) - Estado (Ministérios da Saúde, MS, e Educação, MEC), de acordo com as premissas estabelecidas pelo órgão máximo da AREM, a CNRM, como o ingresso por concurso público, o ensino em serviço, o máximo de 60h/semanais, conforme Lei em vigor, entre outras.

\section{A importância da CNPE}

Tais comitês devem ser "especialidade específica" sendo um para cada especialidade médica reconhecida, de acordo com necessidades de saúde bem definidas. Cada comitê deverá ser composto pelo departamento de ensino e formação proveniente de cada sociedade de especialidade médica no país, de Universidades e escolas médicas, membros da câmara técnica e do banco de avaliadores da CNRM da mesma especialidade, os quais se pautarão em evidências científicas, consolidadas para elaboração e aplicação das matrizes de competência.

\section{A titulação e a avaliação do residente e do profissional titulado}

A titulação do médico residente continua de competência exclusiva do MEC, em acordo com a AREM, com reconhecimento automático pelo CFM, a $\mathrm{AMB}$, as SNEMs e o MS. 
As Universidades, e demais instituições responsáveis pelos programas, manter-se-iam encarregadas das avaliações internas (no mínimo trimestrais) dos médicos residentes.

Uma avaliação anual, nacional, por nível de formação (ano de residência médica, dos residentes, obrigatória em cada especialidade médica, passará a ser coordenada pela parceria entre SNEMs e CNPE. As avaliações seguiriam, por exemplo, o modelo de competências.

A educação permanente e a reavaliação periódica dos especialistas manter-se-ão a cargo das sociedades de especialidades médicas.

\section{O Financiamento}

Cabe às instituições responsáveis pelos programas de residência médica, públicas ou privadas, bem como ao Estado brasileiro, o financiamento do processo de acreditação (diárias, passagens, hospedagem e compensação financeira dos avaliadores) por meio de pagamento de taxa anual de acreditação à AREM.

Tendo em vista o grande aumento do número de egressos de medicina nos próximos anos e a obrigatoriedade de vagas equivalentes nos Programas de Residência Médica (conforme Lei № 12.871, de 22 de Outubro de 2013), planejar e providenciar financiamento é fundamental para a garantia de qualidade dos programas e dos profissionais. 


\section{Da Gestão}

A Instituição acreditadora elegerá, entre os médicos educadores provenientes das Escolas Médicas/Universidades, BNRM e/ou CNRM, com reputação ilibada, formação, experiência e notório saber no campo da residência médica, seu presidente e em comum acordo com ele, seus diretores.

O organograma, bem como as necessidades de recursos humanos, administrativos, de logística, deverão ser estabelecidos, no interior do qual é imperativa a criação de área para fomento, pesquisa, desenvolvimento do conhecimento e gestão em ensino médico nas instituições responsáveis, no organograma da AREM. 


\section{DISCUSSÃO}

O campo de estudo da educação médica é bastante produtivo em diversos países. A literatura e a experiência mundial em educação médica é vasta. Diversos países trabalham com centros de educação médica, multiprofissionais nos quais, além de médicos-educadores, estão pesquisadores nas áreas das ciências sociais, psicologia, pedagogia, antropologia, entre outros. Esses centros são importantes porque, além de qualificar a elaboração e implementação de currículos, metodologias de ensino e aprendizagem, avaliação, entre outros, também produzem novos conhecimentos e publicações com consistência científica. Qualificar a formação médica não apenas pode influenciar positivamente na segurança dos pacientes, mas pode também aumentar sua eficácia e eficiência na escolha de exames complementares e indicação de procedimentos. Indiretamente poupando fundos para o sistema. Já foi estabelecida a relação positiva entre investimento na pesquisa em educação médica e a capacidade de publicar sua produção científica. O Brasil carece de centros de estudos, ensino e pesquisa nessa área.

Os sistemas de acreditação na residência médica estão em constante estudo e desenvolvimento. Exemplos de diversas partes do mundo mostram sistemas já robustos e bem desenvolvidos, muitas vezes chegando a ficar pesados e lentos. Acreditamos que cada país deve montar seu modelo de acreditação compatível com sua história de formação médica. Porém, no mundo globalizado em que há mobilidade não apenas de profissionais de saúde, mas também de usuários dos serviços de saúde, torna-se indispensável 
a padronização mundial dos saberes e competências do médico. Existe expectativa de que acordos internacionais, como o realizado pelos países europeus em Bologna, tornar-se-ão cada vez mais comuns [177, 191]. Nesse novo cenário mundial, um sistema de acreditação independente e confiável é exigência fundamental para o equilíbrio da formação dentro de critérios e padrões internacionais.

Muitas lições podem ser aprendidas dos modelos internacionais de educação médica, avaliação e acreditação. Aprender com os erros e acertos cometidos por outros países pode nos poupar grandes dissabores e até mesmo tragédias educacionais ou de saúde pública no futuro, além de evitar custos desnecessários em projetos infrutíferos.

O Brasil precisa desenvolver seu modelo. A experiência de credenciamento da CNRM pode ser exemplar estando, sem dúvida, na vanguarda em diversos aspectos, como a existência de um banco de médicos avaliadores em um sistema ágil, que pode gerar uma avaliação externa em apenas 15 dias. No entanto, o modelo brasileiro é instável e as avaliações realizadas em épocas e gestões diferentes provavelmente não podem ser comparadas, pois falta independência ao sistema.

O sistema brasileiro precisa ser construído de maneira a incluir todos os atuais partícipes do modelo residência médica e especialização médica. 0 modelo deve ser sem dúvida alguma robusto, porém equilibrado entre "estrutura/processo" e "recursos humanos" com foco no resultado: o médico competente. Mantendo a leveza e rapidez na resposta que lhe é característico.

Realizar pesquisa na área de acreditação não é tarefa fácil. Existem diversas questões éticas envolvendo material confidencial e processos 
simbólicos no campo da acreditação. A falta de investimentos nessa área por parte de alguns países, incluindo o Brasil, pode aprofundar as assimetrias e aumentar as barreiras quando discutimos relações entre países. Mais pesquisas na área da acreditação da residência médica são necessárias a fim de aprimorar, sempre, o sistema.

É preciso incluir na acreditação dos programas de residência medica, além da avaliação do médico residente feita pelas instituições, avaliações nacionais com parâmetros e critérios de qualidade, baseados em competências, matrizes comuns a todos os PRMs da especialidade em questão.

Não há dúvidas de que a acreditação traz efeitos positivos à residência médica. Sabemos que o sistema de acreditação só funciona graças às inúmeras relações de poder existentes na saúde e educação. Em um cenário fragmentado entre MEC, MS, sociedades de especialidades, escolas médicas e demais entidades médicas, o poder necessário para que a acreditação seja o "motor das mudanças" se enfraquece, o respeito interinstitucional se dilui e, consequentemente, nenhum avanço em direção à qualidade dos programas é obtido.

Por estes motivos, atribuímos à criação de uma agência pública e independente de acreditação de programas de residência médica se não a única saída, uma das poucas possibilidades para que o país recupere 0 investimento na busca pela qualidade nesse setor. O atual SAEME [192], Sistema de Acreditação de Escolas Médicas, parece ser uma semente capaz de cumprir esse papel (que didaticamente foi chamado de AREM no capítulo anterior) também na residência médica. Essa iniciativa precisa ser validada pelo tripé da gestão da residência médica: 
- Estado (incluindo necessidades sociais);

- entidades médicas (incluindo sociedades de especialidades);

- Universidades (incluindo escolas médicas independentes).

É necessário que uma agência independente tenha gestão e estrutura cada vez mais sólidas, estabelecendo critérios e estabilidade necessários para a acreditação.

As "confusões" criadas até o momento pelos múltiplos sistemas de formação de médicos especialistas no Brasil parecem estar se aprofundando. Recentemente, observamos o Decreto № 8.497, de 4 de julho de 2015 sobre o Cadastro Nacional de Especialistas ser promulgado, suspenso e substituído pelo Decreto $8156 / 2015$. O decreto $8497 / 2015$ pretendia ampliar ainda mais as possibilidades de rotas, reduzindo controle e critérios sobre a qualidade dos programas. A regulação, a avaliação e o credenciamento de programas podem tomar caminhos que respondem a critérios políticos e meramente quantitativos, em relação aos profissionais em formação. A qualidade na formação e na avaliação pode estar sendo desprezada.

São inimagináveis os impactos da deterioração do ensino médico em um país. Deveríamos aprender com as histórias e relatos existentes de outros países, pois sabemos que os resultados podem ser assustadores. É muito difícil saber quantas pessoas morrem todos os anos por erros médicos, mas estima-se que apenas nos EUA mais de 98 mil pessoas morram, por ano, devido a erros médicos [193]. Devemos ter em mente ainda que os EUA realizam forte investimento na pesquisa em educação médica, na qualificação dos programas, portanto, na qualidade da formação de seus médicos, além de 
investir consideráveis recursos em um consistente sistema de acreditação da residência médica, como já foi apresentado neste trabalho.

Infelizmente, no momento histórico atual, Ministérios da Saúde e Educação têm se debatido em normas e decisões com impactos importantes na formação médica. Nem sempre em ações complementares ou baseadas em evidências, privilegiando exclusivamente o quantitativo de médicos. Enquanto as entidades médicas se afastam das decisões governamentais, o número de escolas e residências médicas crescem, vertiginosamente. Atualmente, os processos dentro da CNRM têm sido despedaçados.

A câmara técnica, por exemplo, é formada por docentes médicos com ampla experiência e expertise na avaliação de programas de residência médica. Esses profissionais atuavam em conjunto, havendo necessária troca de informações e experiências, durante análise de cada processo, além de possibilitar a formação e o treinamento de novos elementos para o próprio sistema. Hoje, a câmara técnica encontra-se dispersa pelo país, empobrecendo as possibilidades de aprendizagem.

Após ter participado por anos da plenária da CNRM, visitado o comitê de acreditação do RCPSC e retornado ao país, minha percepção é que, se antes havia muito pouca diferença na riqueza dos debates entre os praticados no Brasil e no Canadá, hoje a plenária da CNRM encontra-se esvaziada e desempoderada. As avaliações dos programas de residência médica realizados in loco por três avaliadores de estados diferentes da instituição solicitante, hoje são realizadas em grande número em uma única tarde e muitas vezes por um único avaliador com ou sem experiência na tarefa. $O$ resultado é que o trabalho de análise dos relatórios é impossível ou falho, com 
possíveis aprovações de programas que nem sempre têm condições adequadas de funcionamento. Mais estudos precisam ser realizados em nossos sistemas de formação de médicos especialistas, com foco na qualidade. $O$ cenário político institucional em que esta tese foi desenvolvida tendo em vista a profundidade, a dedicação, a qualidade e o empenho no trabalho desempenhado pelas equipes da CNRM e SBN, que culminaram no projeto piloto aqui analisado, talvez não fosse possível no momento atual, onde parece haver desmoronamento do sistema de avaliação, com consequências óbvias para a qualidade dos programas e da formação.

Uma breve descrição de proposta de um modelo de acreditação foi o resultado desta pesquisa. Mais do que isso podemos dizer que do estudo também resulta não apenas a crença, mas a certeza de que unir saberes e interesses genuínos para a formação em quantidade e qualidade adequadas responderá às necessidades do Brasil.

Sem dúvida é possível fazer juntos, mais e melhor. 


\section{CONCLUSÕES}

Tornar-se médico é um longo percurso em qualquer país. Geralmente, é uma das profissões, ou é a profissão, com maior tempo de dedicação e anos de vida empenhados para ser considerado apto à prática por seus pares e pela sociedade em geral [49]. A entrada na faculdade de medicina ocorre em idade muito jovem, quando a identidade do indivíduo ainda está se constituindo. Após cerca de 10 anos de formação profissional, muitas modificações ocorreram na vida de um jovem que ao entrar na faculdade acabara de sair ou ainda vivia a adolescência. O resultado disso é que a constituição da identidade do sujeito se mistura com sua formação e identidade profissional [194]. Não raro, sociólogos e antropólogos observam, por exemplo, a perda do idealismo durante essa transformação, pela convivência e "imposição" dos próprios mestres e pares [195].

É preciso manter com muito cuidado a qualidade do ensino oferecido aos indivíduos desde sua admissão na faculdade de medicina até a conclusão da residência médica. Não há dúvida de que nesse período de vida, a convivência com pares, professores e pacientes, além das competências apreendidas, impactarão não apenas em toda a vida profissional e pessoal dos

médicos, mas também em seu relacionamento com a sociedade, na dependência do contrato social vigente à época [15]. A acreditação das escolas médicas e da residência médica procura assegurar a qualidade em um processo com tantas pressões, relações de poder e transformações. 
Modelos internacionais podem contribuir sobremaneira, embasando processos, reafirmando pontos fortes do sistema em funcionamento e evitando investimentos em projetos cujos resultados indesejáveis já são conhecidos. A experiência internacional comprovou que diversos processos realizados pela CNRM estão à frente de outros modelos de acreditação. Mostrou também que os sistemas, seja no Brasil ou em outros países, precisam engendrar esforços para investir e valorizar os recursos humanos, sob pena de se tornarem estressantes, desfocados e pesados para quem os carrega e lentos na capacidade de reposta.

Definir qualidade na residência médica é bastante complexo tendo em vista o produto final, o médico especialista competente. $\mathrm{O}$ que significa um médico competente tem uma grande variedade de respostas dependendo da perspectiva avaliada (usuários, equipe, pares, gestores) e o resultado final pode muitas vezes ser intangível. *

[Durante a estada no Centro de Educação Médica da Universidade McGill tive a oportunidade de conhecer, aprender e opinar sobre o trabalho do Dr. Michael Saraga, psiquiatra da Universidade de Lausanne (Suíça) que dividiu escritório comigo por um ano. Trata-se de uma analyse phénoménologique de la clinique. Em linhas gerais, o trabalho que ainda se encontra em desenvolvimento versa sobre: o que diferencia a clínica dos médicos vistos como exemplares aos demais?]

No Brasil, os múltiplos sistemas para formação de médicos especialistas existentes podem formar profissionais com percursos formativos, currículos e competências diferentes, mas sob a mesma titulação. Esse tipo de estratégia 
pode impedir o controle da qualidade dos programas e dos profissionais formados.

É dever do Estado garantir acesso à saúde ao cidadão brasileiro, conforme assevera a Constituição Federal [123], Carta Magna que também estabelece o dever de ordenar a formação de recursos humanos. Para tanto, faz-se obrigatório o cumprimento de regular o número e distribuição de profissionais, com base em critérios bem estabelecidos e em carreiras estimulantes.

As entidades médicas têm o papel de zelar pela profissão médica e defender a sociedade no que concerne à sua saúde para garantir a qualidade, a escolha e a implantação de um modelo de formação, que se faz necessário. Exemplo disso está presente na própria legislação 3.268 de setembro de 1957 que cria o Conselho Federal de Medicina.

Trabalhar em conjunto é mais que fundamental, é "a opção" para garantir a formação de qualidade.

A avaliação e acreditação de programas de residência médica visa ao contínuo objetivo de qualidade dos programas acreditados. Temas como segurança do paciente, segurança dos médicos residentes, formação científica, formação em gestão, liderança, trabalho em equipe, capacidade de comunicação, profissionalismo, proficiências e tantos outros temas (muito além da competência técnica específica de cada especialidade) estão em foco na acreditação da residência médica, tornando os padrões cada vez mais elevados.

O debate sobre o futuro da residência médica no Brasil e a inclusão desse novo universo na formação do médico está posto e é possível dentro de um sistema em que existe acreditação independente e especializada. 
A proposta de modelo nacional para acreditação da residência médica, resultante deste amplo estudo internacional procurou ter como base grande parte dos processos já operados pela Comissão Nacional de Residência Médica, no sistema residência médica - SISCNRM. São necessárias, no entanto, inserções de processos, conhecimentos e habilidades do sistema de especialização médica operado pelas sociedades de especialidades médicas. Quase todos os mecanismos necessários e combinados são atualmente existentes em nosso país, mas funcionam separadamente e, portanto, enfraquecidos. Quando associados, estão plenamente de acordo com o que se espera para um modelo com padrões internacionais de acreditação.

É preciso reafirmar que unificar os processos de avaliação e acreditação da residência médica, somando esforços de todos os especialistas para que se espere do médico que recebe o título de especialista o mesmo conjunto de competências.

Cardiologistas, como exemplo, não podem ser formados em quatro anos pela residência médica ou em dois anos pelos cursos de especialização da sociedade de especialidade. As habilidades e as competências adquiridas não podem ser as mesmas ao final desses períodos, no entanto, atualmente a titulação é a mesma. Algo está errado. É preciso chegar ao consenso do que é esperado do especialista e necessário para sua formação, a acreditação pode responder a isso.

O sistema de acreditação deve ser independente.

Sem independência, o sistema de acreditação brasileiro não terá estabilidade para adquirir credibilidade suficiente (e, portanto, confiança e poder) para impelir na mesma direção, com qualidade necessária todos os que 
participam, investem e atuam com interesse genuíno em residência médica (stakeholders), unificando de vez a formação do especialista.

Os caminhos empregados até o momento parecem crer que é necessário sacrificar a qualidade em busca de quantidade. Isso não é real e não pode ser opção na formação de médicos especialistas, posto que implicará colocar a vida dos brasileiros em risco e aumentar os gastos já insustentáveis. 


\section{REFERÊNCIAS}

1. Engebretsen, E., K. Heggen, and H.A. Eilertsen, Accreditation and Power: $A$ Discourse Analysis of a New Regime of Governance in Higher Education. Scandinavian Journal of Educational Research, 2012. 56(4): p. 401-417.

2. Charlton, B., Audit, accountability, quality and all that: The growth of managerial technologies in UK Universities. Education, 2002: p. 13-28.

3. Gorman, B.B., Governmentality in higher education : a critical analysis of the National Survey of Student Engagement. Michigan Technological University, 2012.

4. Greenberg, M., What administrators should know about accreditation. The Chronicle of Higher Education, 2001.

5. Greenfield, D., et al., Are accreditation surveys reliable? Int J Health Care Qual Assur, 2009. 22(2): p. 105-16.

6. Greenfield, D. and J. Braithwaite, Health sector accreditation research: a systematic review. Int J Qual Health Care, 2008. 20(3): p. 172-83.

7. Donabedian, A., A founder of quality assessment encounters a troubled system firsthand. Interview by Fitzhugh Mullan. Health Aff (Millwood), 2001. 20(1): p.137-41.

8. Donabedian, A., Evaluating the quality of medical care. Milbank Mem Fund Q, 1966. 44(3): p. Suppl:166-206.

9. Donabedian, A., Evaluating physician competence. Bull World Health Organ, 2000. 78(6): p. 857-60.

10. Lee, K., et al., 50 years of publication in the field of medical education. Med Teach, 2013. 35(7): p. 591-8.

11. West, D.C., L. Robins, and L.D. Gruppen, Workforce, learners, competencies, and the learning environment: Research in Medical Education 2014 and the way forward. Acad Med, 2014. 89(11): p. 1432-5.

12. Reed, D.A., et al., Association between funding and quality of published medical education research. JAMA, 2007. 298(9): p. 1002-1009.

13. Stufflebeam, D.L., The CIPP model for program evaluation, in Evaluation models. 1983, Springer. p. 117-141.

14. Canada, R.C.o.P.a.S.o., Fellowship matters, annual review. 2014.

15. Cruess, R.L. and S.R. Cruess, Expectations and obligations: professionalism and medicine's social contract with society. Perspectives in Biology and Medicine, 2008. 51(4): p. 579-598. 
16. Lee, R.I., and L.W. Jones, The Fundamentals of Good Medical Care. 1933.

17. Hafferty, F.W., Beyond curriculum reform: confronting medicine's hidden curriculum. Academic Medicine, 1998. 73(4): p. 403-7.

18. Warren, A.E., et al., Understanding, teaching and assessing the elements of the CanMEDS Professional Role: canadian program directors' views. Med Teach, 2014. 36(5): p. 390-402.

19. Frank, J.R. and D. Danoff, The CanMEDS initiative: implementing an outcomes-based framework of physician competencies. Medical teacher, 2007. 29(7): p.642-647.

20. Canada, R.C.o.P.a.S.o. CanMEDS: Better standards, better physicians, better care. 2014 [cited 2016 January 22]; Available from: http://www.royalcollege.ca/portal/page/portal/rc/canmeds/framework.

21. Davis, D.J. and C. Ringsted, Accreditation of undergraduate and graduate medical education: how do the standards contribute to quality? Adv Health Sci Educ Theory Pract, 2006. 11(3): p. 305-13.

22. Kennedy, M., et al., 11 Accreditation of Postgraduate Medical Education. 2011.

23. Bourdieu, P., Le marché des biens symboliques. L'Année sociologique (1940/1948-), 1971. 22: p. 49-126.

24. Cappelle, M.C.A., M.C.d.O.L. Melo, and M.J. de Brito, Relações de poder segundo Bourdieu e Foucault: uma proposta de articulação teórica para a análise das organizações. Organizações Rurais \& Agroindustriais, 2011. 7(3).

25. Alstete, J.W., Accreditation Matters: Achieving Academic Recognition and Renewal. ASHE-ERIC Higher Education Report. Volume 30, Issue 4. 2004: ERIC.

26. Jones, C. and R. Porter, Reassessing Foucault: Power, medicine and the body. 2002: Routledge.

27. Foucault, M., P. Rabinow, and J.D. Faubion, The essential works of Foucault, 1954-1984. 1997, New York: New Press.

28. Donetto, S., Medical students' views of power in doctor-patient interactions: the value of teacher-learner relationships. Med Educ, 2010. 44(2): p. 187-96.

29. Freire, P., Pedagogia do oprimido. 17ª̣. Ed. Rio de Janeiro: Paz e Terra, 1987. 3.

30. Foucault, M., L'évolution de la notion d'" individu dangereux" dans la psychiatrie légale. Déviance et société, 1981. 5(4): p. 403-422.

31. Kassebaum, D.G., E.R. Cutler, and R.H. Eaglen, On the importance and validity of medical accreditation standards. Acad Med, 1998. 73(5): p. 550-64. 
32. Van Melle, E., Key stakeholder consultation report. Royal College of Physicians and Surgeons of Canada/ Canadian Family Physicians of Canada, April 18, 2012. Accreditation Task Force.

33. Ho, M.-J., et al., Effects of hospital accreditation on medical students: $A$ national qualitative study in Taiwan. Academic Medicine, 2014. 89(11): p. 1533-1539.

34. De Oliveira, G.S., Jr., et al., Anesthesiology residency program director burnout. J Clin Anesth, 2011. 23(3): p. 176-82.

35. Heidemann, E.G., Moving to global standards for accreditation processes: the ExPeRT Project in a larger context. External Peer Review Techniques. Int J Qual Health Care, 2000. 12(3): p. 227-30.

36. Fargen, K.M., et al., Follow-up on a national survey: american neurosurgery resident opinions on the 2011 accreditation council for graduate medical education-implemented duty hours. World Neurosurg, 2014. 81(1): p. 15-21.

37. Oakley, S.H., et al., Resident burnout after the 2011 accreditation council for graduate medical education duty-hour restrictions: a cross-sectional survey study. Obstet Gynecol, 2014. 123 Suppl 1: p. 117S-8S.

38. Dacey, R.G., Jr., Editorial: Resident duty hour regulations: time for reassessment and revision. J Neurosurg, 2015: p. 1-2.

39. Kohlbrenner, A., et al., Of duty hour violations and shift work: changing the educational paradigm. Am J Surg, 2015.

40. Ten Cate, O., Medical education in The Netherlands. Med Teach, 2007. 29(8): p. 752-7.

41. Flindall, I.R., et al., The Preservation of Cued Recall in the Acute Mentally Fatigued State: A Randomised Crossover Study. World J Surg, 2016. 40(1): p. 56-65.

42. Ono, T., G. Lafortune, and M. Schoenstein, Health workforce planning in OECD countries. 2013.

43. Tamimi, A.F. and F. Tamimi, Medical education in Jordan. Med Teach, 2010. 32(1): p. 36-40.

44. Solanki, A. and S. Kashyap, Medical education in India: current challenges and the way forward. Med Teach, 2014. 36(12): p. 1027-31.

45. BRAZIL. mais medicos para o Brasil. 2015 [cited 2015 december 29]; Available from: http://maismedicos.gov.br/cursos-de-graduacao.

46. Robinson, G.C., Confidências de um Médico. 1966: Bloch. 307.

47. Malone, K. and S. Supri, A critical time for medical education: the perils of competence-based reform of the curriculum. Adv Health Sci Educ Theory Pract, 2012. 17(2): p. 241-6. 
48. Dodoo, M.S., et al., Excess, shortage, or sufficient physician workforce: How could we know? American Academy of Family Physician, 2005. 72: p. 1670.

49. Sheldon, G.F., et al., The global health workforce shortage: role of surgeons and other providers. Advances in surgery, 2008. 42: p. 63-85.

50. Initiative, T.H.W.A. Addressing the Health Workforce Crisis: A Toolkit for Health Professional Advocates. 2008; Available from: http://www.healthworkforce.info/advocacy/HWAl advocacy toolkit.pdf.

51. Vaughan, J.P., et al., External evaluation of the Global Health Workforce Alliance (GHWA). 2011.

52. Dussault, G. and M.C. Franceschini, Not enough there, too many here: understanding geographical imbalances in the distribution of the health workforce. Human resources for health, 2006. 4(1): p. 12.

53. Babcock, J.M., B.D. Babcock, and M.Z. Schwartz, Maintaining a Sufficient and Quality Physician Workforce: The Role of For-profit Medical Schools. Health Serv Insights, 2013. 6: p. 87-98.

54. Dezee, K.J., et al., Medical education in the United States of America. Med Teach, 2012. 34(7): p. 521-5.

55. Prideaux, D., Medical education in Australia: much has changed but what remains? Med Teach, 2009. 31(2): p. 96-100.

56. Thakore, H., Medical education in Ireland. Med Teach, 2009. 31(8): p. 696-700.

57. Fan, A.P., et al., Medical education in Vietnam. Med Teach, 2012. 34(2): p. 103-7.

58. Amin, Z., et al., Medical education in Bangladesh. Med Teach, 2008. 30(3): p. 243-7.

59. Ndetei, D.M., et al., University medical education in Kenya: The challenges. Med Teach, 2010. 32(10): p. 812-5.

60. Lindgren, S., et al., Medical education in Sweden. Med Teach, 2011. 33(10): p. 798-803.

61. Chou, J.Y., et al., Medical education in Taiwan. Med Teach, 2012. 34(3): p. 187-91.

62. Joffre, C.P., et al., Medical education in Ecuador. Med Teach, 2013. 35(12): p. 979-84.

63. Nikendei, C., et al., Medical education in Germany. Med Teach, 2009. 31(7): p.591-600.

64. Suzuki, Y., T. Gibbs, and K. Fujisaki, Medical education in Japan: a challenge to the healthcare system. Med Teach, 2008. 30(9-10): p. 846-50. 
65. Turkeshi, E., Medical education in Albania: Challenges and opportunities. Med Teach, 2011. 33(6): p. 437-42.

66. Kerr Winter, B., R.M. Salamma, and K.A. Qabaja, Medical education in Palestine. Med Teach, 2014: p. 1-6.

67. Janczukowicz, J., Medical education in Poland. Med Teach, 2013. 35(7): p. 537-43.

68. Raka, L. and I. Dedushaj, Medical education in Kosova. Med Teach, 2011. 33(4): p. e173-7.

69. Georgantopoulou, C., Medical education in Greece. Med Teach, 2009. 31(1): p.13-7.

70. Kurdak, H., D. Altintas, and F. Doran, Medical education in Turkey: past to future. Med Teach, 2008. 30(8): p. 768-73.

71. Pales, J. and A. Gual, Medical education in Spain: current status and new challenges. Med Teach, 2008. 30(4): p. 365-9.

72. McNeil, H.P., et al., An innovative outcomes-based medical education program built on adult learning principles. Med Teach, 2006. 28(6): p. 527-34.

73. Hamilton, J., Two birds with one stone: addressing interprofessional education aims and objectives in health profession curricula through interdisciplinary cultural competency training. Med Teach, 2011. 33(4): p. e199-203.

74. Harden, R., S. Sowden, and W. Dunn, Educational strategies in curriculum development: the SPICES model. Medical education, 1984. 18(4): p. 284-297.

75. Sood, R., Medical education in India. Med Teach, 2008. 30(6): p. 585-91.

76. Kirigia, J.M., et al., The cost of health professionals' brain drain in Kenya. BMC health services research, 2006. 6(1): p. 1.

77. Benamer, H.T.S. and O. Bakoush, Medical education in Libya: The challenges. Medical Teacher, 2009. 31(6): p. 493-496.

78. Mullan, F., The metrics of the physician brain drain. New England journal of medicine, 2005. 353(17): p. 1810-1818.

79. Bin Abdulrahman, K., R. Harden, and M. Patricio, Medical education in Saudi Arabia: an exciting journey. Med Teach, 2012. 34 Suppl 1: p. S4-5.

80. Stranieri, A., R. Collmann, and A. Borda, High definition 3D telemedicine: the next frontier? Stud Health Technol Inform, 2012. 182: p. 133-41.

81. Education, L.C.o.M. Medical School Directory - Accredited MD Programs in the United States. 2015; Available from: http://www.lcme.org/directory.htm. 
82. Medicine, A.A.o.C.o.O. U.S. Colleges of Osteopathic Medicine. 2015; Available from: http://www.aacom.org/become-a-doctor/us-coms.

83. Brotherton, S.E. and S.I. Etzel, Graduate medical education, 2010-2011. JAMA, 2011. 306(9): p. 1015-1030.

84. Research, F.-F.f.A.o.I.M.E.a. Mapping the World's Medical Schools. [cited 2015 December 27 2015]; Number of Operating Medical Schools - International Medical Education Directory (IMED)]. Available from: http://www.faimer.org/resources/mapping.html.

85. Education, A.C.f.G.M., Momentum ACGME Annual Report 2014 - 2013. ACGME, 2014.

86. Nasca, T.J., et al., The accreditation system after the "next accreditation system". Acad Med, 2014. 89(1): p. 27-9.

87. Education, A.C.f.G.M. Accreditation Council for Graduate Medical Education ACGME Internatinal. 2016 [cited 2016 May 05]; Available from: http://www.acgmei.org/.

88. Maniate, J.M., Redesigning a resident program evaluation to strengthen the Canadian residency education accreditation system. Acad Med, 2010. 85(7): p. 1196-202.

89. Cassie, J.M., et al., Accreditation of postgraduate medical education in the United States and Canada: a comparison of two systems. Med Educ, 1999. 33(7): p. 493-8.

90. Royal College of Physicians and Surgeons of Canada, T.C.o.F.P.o.C., Collèges des Médecins du Québec., GENERAL STANDARDS OF ACCREDITATION. January 2011 / Editorial Revision - June 2013 A Standards.

91. Royal College of Physicians and Surgeons of Canada, T.C.o.F.P.o.C., Collèges des Médecins du Québec., General Standards Applicable to All Residency Programs - B Standards. 2013.

92. Canada, R.C.o.P.a.S.o., General Information Concerning Accreditation of Residency Programs $A$ reference guide for those involved in the conduct of postgraduate medical education programs in Canada and for those involved in their accreditation. 2006.

93. Service, C.R.M. Canadian Resident Matching Service. 2016; Available from: http://www.carms.ca/.

94. Royal College of Physicians and Surgeons of Canada, T.C.o.F.P.o.C., Collèges des Médecins du Québec., New Terminology for the CATEGORIES OF ACCREDITATION, in Royal College of Physicians and Surgeons of Canada/ Canadian Family Physicians of Canada. 2012. 
95. Doyle, K., M. Young, and S. Meterissian, Evaluation of residency programs: a novel approach using simulation. J Grad Med Educ, 2014. 6(1): p. 55-60.

96. Flannery, M.T., Internal review and the Next Accreditation System. South Med J, 2014. 107(11): p. 704-6.

97. Greenfield, D., J. Braithwaite, and M. Pawsey, Health care accreditation surveyor styles typology. Int J Health Care Qual Assur, 2008. 21(5): p. 435-43.

98. Sandelowski, M., Whatever happened to qualitative description? Res Nurs Health, 2000. 23(4): p. 334-40.

99. Patton, M.Q., Qualitative evaluation and research methods. 3 ed. 2002: SAGE Publications, inc.

100. Patton, M.Q., Qualitative research. 2005: Wiley Online Library.

101. Creswell, J.W., Qualitative inquiry and research design: Choosing among five approaches. 2012: Sage.

102. Sherbino, J., et al., A national clinician-educator program: a model of an effective community of practice. Med Educ Online, 2010. 15.

103. McKean, E., Compact Oxford dictionary. Rev. ed. 2007, New York: Spark. viii, 678 pages.

104. Lee, A.G. and A.C. Arnold, The Next Accreditation System in ophthalmology. Surv Ophthalmol, 2015. 60(1): p. 82-5.

105. Abou Elnour, A., et al., Surveyors' perceptions of the impact of accreditation on patient safety in general practice. Med J Aust, 2014. 201(3 Suppl): p. S56-9.

106. Lancaster, J., J. Braithwaite, and D. Greenfield, Benefits of participating in accreditation surveying. Int J Health Care Qual Assur, 2010. 23(2): p. 141-52.

107. Royal College of Physicians and Surgeons of Canada, T.C.o.F.P.o.C., General Information Concerning Accreditation of Residency Programs. A reference guide for those involved in the conduct of postgraduate medical education programs in Canada and for those involved in their accreditation. June 2006.

108. Antunes dos Santos R, S.L., Nunes MPT, Evaluation of the impact of collaborative work by teams from the National Medical Residency Committee and the Brazilian Society of Neurosurgery. Retrospective and prospective study. Sao Paulo Medical Journal, inpress.

109. Damásio, A.R., O erro de Descartes. 2012: Editora Companhia das Letras.

110. Braithwaite, J., et al., A prospective, multi-method, multi-disciplinary, multi-level, collaborative, social-organisational design for researching health sector accreditation [LP0560737]. BMC Health Serv Res, 2006. 6: p. 113. 
111. LeCompte, M.D., R. Tesch, and J.P. Goetz, Ethnography and qualitative design in educational research. 1993: Academic Press.

112. Moreno, J.L., Who shall survive? Foundations of sociometry, group psychotherapy and socio-drama. 1953.

113. Rotelli, F. and F. Nicácio, A instituição inventada. Desinstitucionalização, 1990. 2: p. 89-99.

114. Rotelli, F., et al., Deistituzionalizzazione, un'altra via. Salute mentale: pragmática e complessità, 1992: p. 55-69.

115. LeCompte, M.D. and J.J. Schensul, Designing and conducting ethnographic research. Vol. 1. 2010: Rowman Altamira.

116. Pomey, M.-P., et al., Research article Does accreditation stimulate change? A study of the impact of the accreditation process on Canadian healthcare organizations. Implementation Sci, 2010. 5(31): p. 1-14.

117. Scriven, M., Evaluation thesaurus. 1991: Sage.

118. Royal College of Physicians and Surgeons of Canada, T.C.o.F.P.o.C., Collèges des Médecins du Québec., New Terminology for the CATEGORIES OF ACCREDITATION. Royal College of Physicians and Surgeons of Canada/ Canadian Family Physicians of Canada, 2012.

119. Lincoln, Y.S. and E.G. Guba, Naturalistic inquiry. Vol. 75. 1985: Sage.

120. IBGE. instituto brasileiro de geografia e estatística. 2016; Available from: http://www.ibge.gov.br/home/.

121. Agency, U.C.I. The World Fact Book. 2016 [cited 2016 january 10].

122. Bank, T.W. Country and Lending Groups. 2016 [cited 2016 January 10].

123. Brazil, C., Constituição da república Federativa do Brasil. 1988, Centro Gráfico do Senado Federal Brasília.

124. Civil, P.d.R.-C., Dispõe sobre as condições para a promoção, proteção e recuperação da saúde, a organização e o funcionamento dos serviços correspondentes e dá outras providências. 1990: http://www.planalto.gov.br/ccivil 03/Leis/L8080.htm.

125. Paim, J., O que é o SUS. 2009: SciELO-Editora FIOCRUZ.

126. Suplementar, A.N.d.S., Caderno de Informação da Saúde Suplementar Beneficiários, Operadoras e Planos. 2014: http://www.ans.gov.br/images/stories/ Materiais_para_pesquisa/Perfil_setor/Caderno_informacao_saude_suplementar/ 2014_mes12_caderno_informacao.pdf. p. 57. 
127. Salesll, T.B., et al., Multiplicidade de vínculos de médicos no Estado do Ceará. Rev Saude Publica, 2010. 44(5): p. 950-6.

128. Amaral, J.L.d., Duzentos anos de ensino médico no Brasil, in Instituto de Medicina Social. 2007, Universidade do Estado do Rio de Janeiro. p. 207.

129. Flexner, A., Medical education in the United States and Canada. From the Carnegie Foundation for the Advancement of Teaching, Bulletin Number Four, 1910. Bull World Health Organ, 2002. 80(7): p. 594-602.

130. Falavigna, A., C.T. Canabarro, and G.S. Medeiros, Health system and medical education in Brazil: history, principles, and organization. World Neurosurg, 2013. 80(6): p. 723-7.

131. Sobrall, D.T., Três Casos de Inovação Curricular no Panorama recente (19641988) da Educação médica Brasileira: Subsídios de um retrospecto Baseado na revisão De Documentos Three Cases of Curricular Innovation in. Revista BRasileiRa de educação Médica, 2014. 38(4): p. 493-501.

132. Raw, I., Reformulação do ensino médico: Faculdade de Medicina e a USP. Revista USP, 1994(20): p. 131-137.

133. de Moraes, M.A.A. and E.J. Manzini, Concepções sobre a aprendizagem baseada em problemas: um estudo de caso na Famema. Revista Brasileira de Educação Médica, 2006. 30(3): p. 125-135.

134. BRAZIL. Resolution CNE/CES no 4 from november 7th, 2001. 2001 [cited 2015 December 29]; Available

from: http://portal.mec.gov.br/cne/arquivos/pdf/CES04.pdf.

135. IMS/UERJ, O.E.d.T. Medicina - Indicadores das Graduações em Saúde. 2013 [cited 2015 December 28]; Available from: http://obsnetims.org.br/uploaded/4 $72013 \quad 0$ Medicina.pdf.

136. Brasil, E.M.d. Placar com o número de escolas médicas no Brasil. 2016 [cited 201623 January]; Available from: http://www.escolasmedicas.com.br/estado.php.

137. República, B.-P.d., LEI № 12.871, DE 22 DE OUTUBRO DE 2013. Institui o Programa Mais Médicos, altera as Leis no 8.745, de 9 de dezembro de 1993, e no 6.932, de 7 de julho de 1981, e dá outras providências., C.C.-S.p.A. Jurídicos, Editor. 2013, http://www2.camara.leg.br/legin/fed/lei/2013/lei-12871-22-outubro2013-777279-publicacaooriginal-141521-pl.html.

138. Campos, G.W.d.S., A Saúde, o SUS e o programa" Mais Médicos". Revista do Médico Residente, 2013. 15(2). 
139. Scheffer, M., A. Biancarelli, and A. Cassenote, Demografia médica no Brasil: dados gerais e descrições de desigualdades. São Paulo: Conselho Regional de Medicina do Estado de São Paulo, Conselho Federal de Medicina, 2011. 1 e 2.

140. Scheffer, M.B., Aureliano.Cassenote, Alex, Demografia médica no Brasil São Paulo: Conselho Federal de Medicina e Conselho Regional de Medicina do Estado de São Paulo, 2015.

141. Fréchette, D., et al., What's really behind Canada's unemployed specialists? Too many, too few doctors? Findings from the Royal College's employment study. The Royal College of Physicians and Surgeons of Canada, Ottawa, 2013.

142. González López-Valcárcel, B. and P. Barber Pérez, Dificultades, trampas y tópicos en la planificación del personal médico. Gaceta Sanitaria, 2008. 22(5): p. 393-395.

143. López-Valcárcel, B.G. and P.B. Pérez, Oferta y necesidad de médicos especialistas en España (2006-2030). Grupo de Investigación en Economía de La Salud. Universidad de Las palmas de C G. Espanha, 2007.

144. Medicina, C.F.d. Demografia Médica 2015: População médica cresce mais que a geral, mas persistem desigualdades na sua distribuição. 2015 [cited 2016 Março 16]; $\quad$ Available from: http://portal.cfm.org.br/index.php?option=com content\&view=article\&id=25867.

145. de Castro, M.H.G. and S. Tiezzi, A reforma do ensino médio e a implantação do Enem no Brasil1. Desafios, 2004. 65(11): p. 46-115.

146. Einstein, H.I.A. Graduação em Medicina - Sobre o Vestibular. 2016 [cited 2016 March 09]; Available from: http://www.einstein.br/Ensino/graduacaomedicina/Paginas/vestibular.aspx.

147. Eva, K.W., et al., An admissions OSCE: the multiple mini-interview. Med Educ, 2004. 38(3): p. 314-26.

148. Educação, M.d., Resolução CNE/CES no 3/2014 - Institui Diretrizes Curriculares Nacionais do Curso de Graduação em Medicina e dá outras providências, C.N.d. Educação, $\quad$ Editor. 2014: http://portal.mec.gov.br/index.php?option=com docman\&view=download\&alias= 15874-rces003-14\&category slug=junho-2014-pdf\&Itemid=30192.

149. MAZZONI, C.J. and L.A.D. BRACCIALLI, Exercício de avaliação da prática profissional como estratégia de ensino e aprendizagem. 2011.

150. Frank, J.R., et al., Competency-based medical education: theory to practice. Medical teacher, 2010. 32(8): p. 638-645. 
151. Médica, A.B.d.E. A Missão da Associação Brasileira de Educação Médica. 2016 [cited 2016 March 09]; Available from: http://www.abemeducmed.org.br/missao.php.

152. Santos, R.A., L. Snell, and M.D. Nunes, Evaluation of the impact of collaborative work by teams from the National Medical Residency Committee and the Brazilian Society of Neurosurgery. Retrospective and prospective study. Sao Paulo Med J, 2015.

153. Michel, J.L.M., R.A.B.d. Oliveira, and M.d.P.T. Nunes, Residência médica no Brasil. Cadernos Abem, 2011. 7: p. 7-12.

154. Sousa, E. and K. HA, Avaliação dos programas de residência médica em radiologia. Avaliação dos programas de Residência Médica em Radiologia, 2000.

155. Lima, J.C.d.S., A residência médica: articulações entre a prática e o ensino. 2009, Universidade do Estado do Rio de Janeiro. Instituto de Medicina Social.

156. Brasil, P.d.R., Casa Civil, Subchefia para Assuntos Jurídicos, DECRETO No 80.281, DE 5 DE SETEMBRO DE 1977, Regulamenta a Residência Médica, cria a Comissão Nacional de Residência Médica e dá outras providências. 1977: http://www.planalto.gov.br/ccivil 03/decreto/1970-1979/D80281.htm.

157. Brasil , P.d.R., Casa Civil, Subchefia para Assuntos Jurídicos, DECRETO No 7.562, DE 15 DE SETEMBRO DE 2011; Dispõe sobre a Comissão Nacional de Residência Médica e o exercício das funções de regulação, supervisão e avaliação de instituições que ofertam residência médica e de programas de residência médica. 2011: http://portal.mec.gov.br/index.php?option=com docman\&view=download\&alias= 8959-decreto-7562-2011\&category slug=setembro-2011-pdf\&ltemid=30192.

158. MÉDICA, S.D.E.S.-C.N.D.R., RESOLUÇÃO No 3, DE 16 DE SETEMBRO DE 2011 Dispõe sobre o processo de seleção públicados candidatos aos Programas de Residência Médica. 2011: http://portal.mec.gov.br/index.php?option=com docman\&view=download\&alias= 8950-res-cnrm-03-2011\&category slug=setembro-2011-pdf\&ltemid=30192.

159. Educação, M.d., Adequa a legislação da Comissão Nacional de Residência Médica ao art. 22 da Lei 12.871/2013, acerca do processo de seleção pública dos candidatos aos Programas de Residência Médica., C.N.d.R. Medica, Editor. 2015, Brazil - Governo Federal: http://portal.mec.gov.br/escola-de-gestores-daeducacao-basica/247-programas-e-acoes-1921564125/residencia-medica2137156164/13079-resolucao-residencia-medica.

160. MÉDICA, S.D.E.S.-C.N.D.R., RESOLUÇÃO CNRM No 1, DE 16 DE JUNHO DE 201, Dispõe sobre o estabelecimento e condições de descanso obrigatório para - residente que tenha cumprido plantão noturno. 2011: http://portal.mec.gov.br/index.php?option=com docman\&view=download\&alias= 8948-res-cnrm-01-2011-1\&category slug=setembro-2011-pdf\&ltemid=30192. 
161. MÉDICA, S.D.E.S.-C.N.D.R., RESOLUÇÃO No 4, DE 12 DE JULHO DE 2010, Proíbe o plantão de sobreaviso para Médicos Residentes no âmbito da Residência Médica. 2010: http://portal.mec.gov.br/index.php?option=com docman\&view=download\&alias= 6128-resolucao-4-2010\&category slug=julho-2010-pdf\&ltemid=30192.

162. MÉDICA, S.D.E.S.-C.N.D.R., RESOLUÇÃO CNRM No 02 /2006, de 17 de maio de 2006, Dispõe sobre requisitos mínimos dos Programas de Residência Médica e dá outras providências. 2006: http://portal.mec.gov.br/dmdocuments/resolucao02 2006.pdf.

163. Medicina, A.P.d., Conquistas e Desafios 80 Anos da Associação Paulista de Medicina. 2011, Sao Paulo, SP: SMS Editora LTDA. 160.

164. Gusmão, S.N.S. and J.G. de Souza, História da neurocirurgia no Brasil. 2008: Sociedade Brasileira de Neurocirurgia.

165. Júnior, R.P., Residência Médica X Especialização. Revista do Médico Residente, 2011. 13(3).

166. MINISTÉRIO DA EDUCAÇÃO, C.N.D.E., CÂMARA DE EDUCAÇÃO SUPERIOR, RESOLUÇÃO N 1, DE 8 DE JUNHO DE 2007 Estabelece normas para o funcionamento de cursos de pósgraduação lato sensu, em nível de especialização. 2007: http://portal.mec.gov.br/cne/arquivos/pdf/rces001 07.pdf.

167. Paulo Andrade de Mello, L.R.A., Carlos Henrique Ribeiro, Maria Carolina de Lima, José Carlos Esteves Veiga, Wen Hung Tzu, Livro do Residente em Neurocirurgia - Sociedade Brasileira de Neurocirurgia 2010, http://www.sbn.com.br/files/downloads/residencia/livro-doresidente/Livro do Residente.pdf: Sociedade Brasileira de Neurocirurgia - SBN.

168. de Toni Junior, C.N., Análise do IDH do Brasil, de suas regiões e de outros país: um enfoque comparativo. 2010.

169. IBGE, I.B.d.G.a.e.E.s.-. Indicadores sociais mínimos. Aspectos demográ cos Informações gerais. 2015 [cited 2015 January 07]; Available from: http://www.ibge.gov.br/home/estatistica/populacao/condicaodevida/indicadoresmi nimos/tabela1.shtm.

170. Petta, H.L., Formação de médicos especialistas no SUS: descrição e análise da implementação do programa nacional de apoio à formação de médicos especialistas em áreas estratégicas (PRORESIDÊNCIA). 2011.

171. Reulen, H.-J., et al., A report on neurosurgical workforce in the countries of the EU and associated states. Acta neurochirurgica, 2009. 151(6): p. 715-721.

172. Asch, D.A., A. Epstein, and S. Nicholson, Evaluating medical training programs by the quality of care delivered by their alumni. JAMA, 2007. 298(9): p. 1049-1051. 
173. Falcone, J.L. and J.D. Gonzalo, Relationship between internal medicine program board examination pass rates, accreditation standards, and program size. International journal of medical education, 2014. 5: p. 11.

174. Swick, S., S. Hall, and E. Beresin, Assessing the ACGME Competencies in Psychiatry Training programs. Acad Psychiatry, 2006. 30(4): p. 330-51.

175. Al Mosawi, A.J., Medical education and the physician workforce of Iraq. J Contin Educ Health Prof, 2008. 28(2): p. 103-5.

176. Kindig, D.A., Strategic issues for managing the future physician workforce. Baxter Health Policy Rev, 1996. 2: p. 149-82.

177. Karle, H., Global standards and accreditation in medical education: a view from the WFME. Acad Med, 2006. 81(12 Suppl): p. S43-8.

178. Cooper, R.A., Perspectives on the physician workforce to the year 2020. JAMA, 1995. 274(19): p. 1534-43.

179. Lau, T., et al., Factors affecting recruitment into psychiatry: a canadian experience. Acad Psychiatry, 2015. 39(3): p. 246-52.

180. Barondess, J.A., Specialization and the physician workforce: drivers and determinants. JAMA, 2000. 284(10): p. 1299-1301.

181. Arnett, J.C., Jr. and J.M. Orient, Physician workforce and trainee planning. Chest, 2002. 121(4): p. 1376-7; author reply 1377.

182. Craig, D., R. Byrick, and F. Carli, A physician workforce planning model applied to Canadian anesthesiology: planning the future supply of anesthesiologists. Can J Anaesth, 2002. 49(7): p. 671-7.

183. Alvarino, F., et al., Medical education and the physician workforce in Uruguay. J Contin Educ Health Prof, 2007. 27(2): p. 80.

184. Al-Jarallah, K., M. Moussa, and K.F. Al-Khanfar, The physician workforce in Kuwait to the year 2020. Int J Health Plann Manage, 2010. 25(1): p. 49-62.

185. Ashby, D.M. and P.O. McMahon, Need for changes in the residency practice model. Am J Health Syst Pharm, 2011. 68(1): p. 19.

186. Klessig, J.M., et al., A pilot survey study to define quality in residency education. Acad Med, 2000. 75(1): p. 71-3.

187. Tran, L., et al., Features of high-quality residency programs: A Canadian perspective. 2010.

188. Elliott, R.L., et al., Quality in residency training: toward a broader, multidimensional definition. Acad Med, 1996. 71(3): p. 243-7. 
189. Nasca, T.J., et al., The next GME accreditation system--rationale and benefits. $\mathrm{N}$ Engl J Med, 2012. 366(11): p. 1051-6.

190. Gupta, R., O. Zad, and E. Jimenez, Analysis of the variations between Accreditation Council for Graduate Medical Education requirements for critical care training programs and their effects on the current critical care workforce. $\mathrm{J}$ Crit Care, 2013. 28(6): p. 1042-7.

191. Association for Medical Education in, E., A. European Medical Students, and A. International Federation of Medical Students, The Bologna Process and its implications for medical education. Med Teach, 2010. 32(4): p. 302-4.

192. SAEME, S.d.A.d.E.M.-. Sistema de Acreditação de Escolas Médicas Defendendo a ética e a qualidade no ensino. 2016 [cited 2016 Março 19].

193. James, J.T., A new, evidence-based estimate of patient harms associated with hospital care. Journal of patient safety, 2013. 9(3): p. 122-128.

194. BECKER, H.F., et al., Boys in white. Academic Medicine, 1962. 37(4): p. 406.

195. Becker, H.S. and B. Geer, The fate of idealism in medical school. American Sociological Review, 1958: p. 50-56. 


\section{ANEXOS}

\section{Anexo 1}

HOSPITAL DAS CLÍNICAS

DA

FACULDADE DE MEDICINA DA UNIVERSIDADE DE SÃO PAULO COMITÊ DE ÉTICA EM PESQUISA DA FACULDADE DE MEDICINA DA USP CEP-FMUSP

\section{CADASTRO DE PROTOCOLO DE PESQUISA}

\begin{tabular}{|l|l|}
\hline \multicolumn{2}{|c|}{ Registro (uso reservado à Secretaria) } \\
№ do Protocolo: 221/14 & Tipo: Humanos $\quad$ Instituto: FMUSP \\
Registro on-line no: 12149 & Data de Entrada: 04/04/2014 \\
\hline
\end{tabular}

Informações sobre o animal:

Quantidade: 0

OGM: Não

Espécies utilizadas: Não informado

\section{Este projeto envolve:}

Pacientes $\mathrm{HC}$ Não

Médicos ou Funcionários HC (como sujeitos de pesquisa) Não

Documentos HC(Prontuários e Outros) Não

Materiais estocados no $\mathrm{HC}$ Não

Peças anatômicas de cadáveres Não 
IMPACTO SOCIAL DO TRABALHO CONJUNTO DA COMISSÃO NACIONALDE RESIDÊNCIA MÉDICA E DAS SOCIEDADES DE ESPECIALIDADES MÉDICAS: Análise Crítica da Experiência da Neurocirurgia

\section{Palavras-chaves que caracterizam o assunto da Pesquisa}

educação médica, residência médica, neurocirurgia, distribuição de força de trabalho na saúde.

\section{Resumo do Protocolo de Pesquisa}

A residência médica é considerada o padrão ouro da formação especializada. O impacto que ela pode promover vai muito além da formação médica de um especialista. Implantação ou fechamento de um sítio de formação pode qualificar o serviço, modificar a prática clínica e até mesmo alterar a distribuição de médicos especialistas no país. A Comissão Nacional de Residência Médica (CNRM) é a responsável por normatizar, regular e fiscalizar este sistema de formação. No entanto, ele não é o único e convive, por exemplo, com os sistemas de especialização das sociedades de especialidades médicas. Em 2011 um projeto piloto de unificação dos sistemas de acreditação e avaliação aproximou a Sociedade Brasileira de Neurocirurgia (SBN) à CNRM.Este projeto tem o objetivo de avaliar os impactos da avaliação conjunta gerados por este projeto piloto nos avaliadores da CNRM e SBN e também na assistência, formação e comportamento dos locais visitados e avaliados.Será utilizada literatura científica específica pesquisada nas bases de dados mais importantes locais e mundiais. Realizada visita e comparação internacional de sistemas de avaliação. Levantados os dados secundários produzidos pelos relatórios de 
visitas, pareceres emitidos, resultados das plenárias e informações do sistema da CNRM. Os resultados das avaliações anuais da SBN aos residentes também serão empregados na análise quantitativa relacionando os principais problemas encontrados. Em todos os casos haverá proteção do sujeito ou instituição, estes, serão codificados e não expostos. Haverá ainda análise qualitativa de entrevistas dirigidas com amostra proposital de avaliadores e preceptores avaliados.Esperase que a correlação dos dados aponte para concordância de resultados entre baixo desempenho, que devem apresentar piores resultados em todos os critérios e que o mesmo ocorra, no sentido oposto, entre as melhores. Será discutido o impacto de possuir modelo e avaliação únicas e conjuntas até mesmo na distribuição e abertura de novas vagas.

\section{Pesquisador Responsável:}

Maria do Patrocínio Tenório Nunes

http://lattes.cnpq.br/9827180410943943

Graduação: medico

Vínculo: FMUSP

\section{Pesquisador Executante:}

Renato Antunes dos Santos

http://lattes.cnpq.br/6220189117154265

\section{Possui co-autores?}

Não, Quantidade: 0

Nome dos co-autores: Não se aplica

\section{Onde a Pesquisa será realizada?}

Departamento: Clínica Médica

Disciplina: Clínica Geral

LIM: Nenhum 
8. Existe entidade externa envolvida?

Sim

Ministério da Educação (CNRM) e Sociedade Brasileira de Neurocirurgia (SBN) Nacional

\section{Possui participação Estrangeira}

Sim

10. O projeto é multicêntrico

Não

11. Outros serviços/ divisões do HCFMUSP envolvidos na pesquisa Não

12. Finalidade acadêmica da pesquisa e classificação

Doutorado

Outros:

13. Investigação

Retrospectiva e Prospectiva (Ambos)

14. Materiais e métodos

Entrevistas e questionários

Outros

Documentos e pareceres emitidos pela CNRM e SBN

15. Gênero, classificação da Pesquisa

Teórica

16. Áreas temáticas previstas na Res. 196/96

Nenhuma das alternativas

17. Patrocínio

Não há patrocínio 
18. Valor do financiamento

0,00

19. Cronograma de execução da pesquisa

Prazo: 47 meses

20. Assinaturas

Assinatura e carimbo do Pesquisador

Aprovado em

Assinatura e carimbo da Chefia com data de aprovação

pelo Conselho do Departamento

Aprovado em I

São Paulo, _15_de _fevereiro_de_2016_ 
$\grave{A}$

COMISSÃO DE PÓS-GRADUAÇÃO

ASSUNTO: MUDANÇA DE TÍTULO

Nome: Renato Antunes dos Santos

Orientador/a: Profa. Dra. Maria do Patrocínio Tenório Nunes

Programa: Ciências Médicas Curso: ( ) Mestrado ( X) Doutorado

Solicito a V. Sạs. análise de mudança do título da minha:

( ) Dissertação de Mestrado (X) Tese de Doutorado.

DE: Impacto social da avaliação conjunta dos programas de Residência Medica pela Comissão Nacional de Residência Medica e a Sociedade de Especialidade: A Neurocirurgia no Brasil

PARA: Acreditação e Avaliação de Programas de Residência Médica: Concepção internacional e proposta de um modelo nacional.

\section{MOTIVO:}

1. SUGESTÃO DA BANCA NO EXAME DE QUALIFICAÇÃO: $\operatorname{SIM} （ ）$ NÃO (X )

2. HOUVE MUDANÇA DE METODOLOGIA: $\operatorname{SIM}(X)$ NÃO ( )

3. HOUVE MUDANÇA/TROCA DE PROJETO: $\quad \operatorname{SIM}(\quad) \quad$ NÃO $(X)$

\section{JUSTIFICATIVA CIRCUNSTANCIADA DA CCP:}

(no caso de mudança de projeto, encaminhar a aprovação do novo projeto pela CAPPesq)

Após o período de pesquisa realizado na Universidade McGill, em Montreal, Canadá, por meio do Programa de doutorado - sanduíche CAPES-PDSE, o projeto de doutorado original sofreu grande ampliação de seu escopo. 
Novas metodologias foram inseridas, bem como dados e concepção de outros países sobre o tema em pesquisa, sem deixar de abordar e utilizar o projeto original, em sua integralidade.

Entretanto, as inovações inseridas, tornam o título anterior muito aquém da amplitude dos aspectos que foram desenvolvidos no período que se seguiu à qualificação nas pesquisas realizadas sob a supervisão do programa de Ciências Médicas com área de concentração em Educação e Saúde, FMUSP, e do McGill University Medical Education Centre.

Cumpre destacar que os capítulos inseridos decorreram de pesquisa realizada mediante parecer de Comitê de Ética da McGill University Medical Education Centre ou são secundárias a revisões da literatura sobre residência médica no mundo.

Sendo assim entendemos não haver necessidade de nova submissão ao Comitê de Ética em Pesquisa da FMUSP. 


\section{Anexo 2}

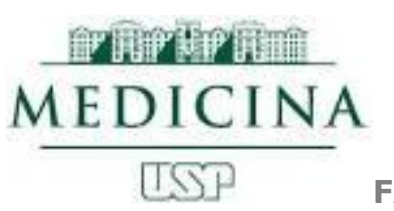

FACULDADE DE MEDICINA DA UNIVERSIDADE DE SÃO PAULO

Relativo ao Processo CAPPESQ online 12149

\section{DECLARAÇÃO}

$\mathrm{Eu}$,

$\mathrm{CPF}$

Coordenadora de

Residências em Saúde do Ministério da Educação, declaro estar ciente e de acordo com os objetivos do estudo, Projeto de Pesquisa $n^{\circ}$ on-line 12149 (CAPPESQ) intitulado "IMPACTO SOCIAL DO TRABALHO CONJUNTO DA COMISSÃO NACIONAL DE RESIDÊNCIA MÉDICA E DAS SOCIEDADES DE ESPECIALIDADES MÉDICAS: Análise Crítica da Experiência da Neurocirurgia", para obtenção do grau de doutor, pelo aluno Dr. Renato Antunes dos Santos, sob orientação da Profa. Dra. Maria do Patrocínio Tenório Nunes, deixando à disposição, conforme previamente tratado com ambos, os relatórios de visita de avaliação aos Programas de Residência Médica em Neurocirurgia, os quais são públicos e encontram-se disponíveis para consulta, via SISCNRM.

Cabe ressaltar tratar-se de estudo de dados secundários.

Profa. Dra. Sonia Pereira

Coordenadora de Residências em Saúde do MEC/SeSu

São Paulo, XX de junho de 2014. 


\section{Anexo 3}

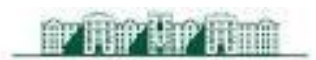 \\ MEDICINA}

TSP FACULDADE DE MEDICINA DA UNIVERSIDADE DE SÃO PAULO

\section{Relativo ao Processo CAPPESQ online 12149}

\section{DECLARAÇÃo}

$\mathrm{Eu}$,

$\mathrm{CPF}$

Professor

da

Disciplina de , do Depto. , da Faculdade de Medicina da Universidade de , e (cargo) da Sociedade Brasileira de Neurocirurgia, declaro estar ciente e de acordo com os objetivos do estudo, Projeto de Pesquisa $n^{\circ}$ on-line 12149 (CAPPESQ) intitulado "IMPACTO SOCIAL DO TRABALHO CONJUNTO DA COMISSÃO NACIONAL DE RESIDÊNCIA MÉDICA E DAS SOCIEDADES DE ESPECIALIDADES MÉDICAS: Análise Crítica da Experiência da Neurocirurgia", para obtenção do grau de doutor, pelo aluno Dr. Renato Antunes dos Santos, sob orientação da Profa. Dra. Maria do Patrocínio Tenório Nunes, deixando à disposição, conforme previamente tratado com ambos, todos os dados relativos à avaliação dos Programas de Residência Médica em Neurocirurgia, bem como as avaliações dos médicos residentes, de maneira sigilosa, sem identificação de quem quer que seja.

Cabe ressaltar tratar-se de estudo de dados secundários.

Prof. Dr.

CREMESP 
São Paulo, XX de junho de 2014.

Anexo 4

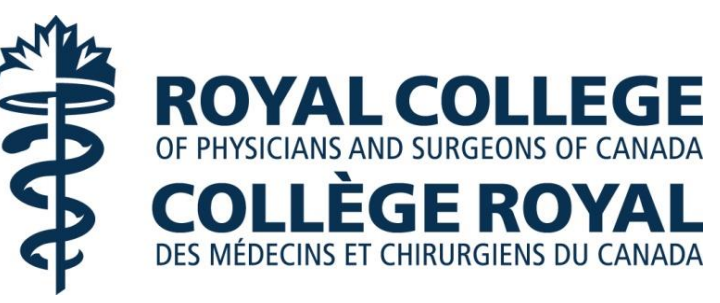

CONFIDENTIALITY AGREEMENT

APPLICABLE TO PERSONAL INFORMATION TO WHICH THE

UNDERSIGNED

MAY HAVE ACCESS IN THE COURSE OF

OBSERVING THE ACCREDITATION COMMITTEE MEETING

March 19-20, 2015

Whereas the Royal College of Physicians and Surgeons is required to ensure the confidentiality of the personal information that it collects and holds;

Whereas I may have access to such information in the course of this on-site survey; 
I, the undersigned, (first and last name):

Undertake to safeguard the confidentiality of any personal information to which I may have access in the course of observing the above noted Accreditation Committee Meeting.

Specifically, I undertake:

1. to use this information only in the course of my observations;

2. not to disclose any personal information to which I may have access in the course of observation unless duly authorized to do so;

3. not to keep or compile any personal information;

4. not to keep at the end of this observation any personal information I may have received or collected and to abide by the confidentiality requirements incumbent upon me concerning said personal information.

IN WITNESS WHEREOF, SIGNED AT OTTAWA, this day of March 19, 2015

Name:

Signature 


\section{Anexo 5}

\section{McGill}

Faculty of Medicine

2555 Promenade Sir Wiliam Osier \#3.33

Montreal, OC H3G 1 Y

April 2, 2015

Dr. Linda Snell

Centre for Medical Education

1110 Pine Avenue West

Montreal, Quebec H3A 2 A3
Fax/Telecopieur (5.14) $398-3870$

TéliTel. 1514$) 398-3124$

RE: IRB Study Number A04-E16-15A

Impact of the accreditation process on quality of medical residency programs: the surveyors perceptions

Dear Dr. Snell,

Thank you for submitting the above study for IRB review on behalf of Dr. Renato Antunes dos Santos.

As this study involves no more than minimal risk, and in accordance with Articles 2.9 and 6.12 of the $2^{\text {nd }}$ Edition of the Canadian Tri-Council Policy Statement of Ethical Conduct for Research Involving Humans (TCPS 2) and U.S. Title 45 CFR 46, Section 110 (b), paragraph (1), we are pleased to inform you that approval for the study, study instruments and consent form (March 2015) was provided by the IRB Co-Chair on April 2, 2015, valid until April 2016. The study proposal will be presented for corroborative approval at the next meeting of the Committee and a certification document will be issued to you at that time.

A review of all research involving human subjects is required on an annual basis in accord with the date of initial approval. The annual review should be submitted at least one month before April 2016. Please inform the IRB promptly of any modifications that may occur to the study over the next twelve months.

Sincerely,

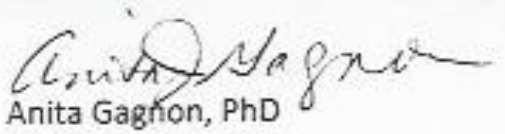

Co-Chair

Institutional Review Board

oc: Or. Renato Antunes dos Santos, CME

A04-E16-15A 


\section{Anexo 6}

\section{CONSENT FORM FOR INTERVIEW}

IMPACT OF THE ACCREDITATION PROCESS ON QUALITY OF MEDICAL RESIDENCY PROGRAMS: THE SURVEYORS' PERCEPTIONS

Dr. Renato Antunes dos Santos

Dr. Linda Snell (Supervisor)

Centre for Medical Education

McGill University

\section{Introduction}

You are invited to participate in this interview-based study looking at accreditation surveyors' perceptions of the residency accreditation process. You have been approached to participate because you are a clinician who has, at least once, been a residency accreditation surveyor on an internal or external review or a formal survey .

\section{Study Procedures}

The interview will be audio-recorded. As the recording is transcribed, any identifiers will be removed, and the subsequent analysis will be done anonymously. Following analysis the the initial themes will be sent to you for member checking, to ensure that the initial interpretation is correct. The interview data will be stored on an external hard drive kept in in a secure locked place, kept for the period of time required by ethics, and then destroyed. 


\section{Risks and Benefits}

There are no benefits, rewards, compensation or incentives for participating. There are minimal risks in participating.

\section{Withdrawal from study}

You may withdraw from this study at any time, without adverse consequences. If you withdraw from participation until data analysis is finished, all data collected from you will be disregarded.

\section{Participants' rights}

Participants' have the right to:

- You can choose whether or not you want to be in this study, and you may withdraw your consent and discontinue participation at any time.

- Whatever decision you make, there will be no penalty to you, and no loss of benefits to which you were otherwise entitled.

- You may refuse to answer any questions that you do not want to answer, and still remain in the study.

- The researcher will not record events, statements or conversations if you request them either not to be recorded or to be deleted during the observations or interviews, or subsequently

\section{Confidentiality}

The identity of the interviewees and identifiers of others will be removed during the transcription process. Any description of the participants' positions and contributions to Medical Education will only be provided as group data, not identifying individuals. 


\section{Contact}

If you have any questions, comments or concerns about the study, you can talk to the Principal Investigator, Dr Renato Antunes dos Santos. who can be contacted at at: renato.antunes@mail.mcgill.ca or on 438-348-3592.

If you have questions about your rights while taking part in this study, or you have concerns or suggestions and you want to talk to someone other than the Pls about the study, please call the Senior Ethical Administrator, McGill University Faculty of Medicine, at 514-398-8302 or write to:

Senior Ethical Administrator McGill University Faculty of Medicine IRB, Room 633, McIntyre Medical Building 3655 Promenade Sir William Osler Montreal, Quebec H3G $1 Y 6$

You will be given a copy of this form to keep.

The study has been explained to me and my questions have been answered to my satisfaction. I agree to participate in this study. I do not waive any of my rights by signing this consent.

Name of participant

Signature of prticipant

Date

Name of person requesting consent siganture of person request consent Date 


\section{Anexo 7}

\section{SAMPLE INTERVIEW QUESTIONS}

Introduction, agreement to be interviewed, identifiers( name,position)

This set of questions is about the Canadian postgraduate medical education / residency system

What are the strengths of the Canadian PGE system?

What could be improved in the PGE system ? Why?

What are the components of a quality residency training program?

This set of questions is about your role in accreditation

Why did you became an accreditation surveyor?

- Please tell me about your experience as surveyor?

- Please tell me about your experience as someone been surveyed?

What was your most memorable moment as a surveyor?

- Why?

- Can you tell me a story about surveying or experience as a surveyor that might explain your point of view?

This set of questions is about evaluating residency program quality / accreditation

How do you think a process of evaluation of residency programs might contribute to quality?

What do you think about the current Canadian medical residency accreditation process or system?

- Is it able to capture quality of the programs? 
9. The accreditation process often is described as a stressful process. What do you think?

- Stressful for whom? Why?

- If so, in your opinion, what could be done to decrease this stress?

Are there data (quantitative or qualitative) other than those requested for accreditation that might provide a different picture about the quality of a program?

Have you any suggestions for changes in the process or method of acquiring these data?

What do you think about changing the current intermittent on-site visit process?

What do you think about splitting the process into two:

-partly done by peers, looking at quality on practical and education activities (part of Canadian Model)

-and partly done by administrators, looking at supporting data (as in the US model)

The RCPSC will soon strat to do international accreditation. In your opinion what can other countries learn from the Canadian PGE accreditation model, and why?

Closure

That is all the questions I have for you. Do you have any other comments about residency accrediatation or quality that you would like to share?

Many thanks for participating in this interview. I want to remind you that any identifiers in this interview will be removed. 


\section{Anexo 8}

\section{Relatorio Para Visita de Verificação a Programa de Residência Médica MEC - SBN}

\section{Dados Institucionais}

\section{Instrumento de Avaliação}

Este instrumento de avaliação é composto por duas partes. A primeira parte se ocupa do dimensionamento da instituição que sedia o(s) $\operatorname{PRM}(\mathrm{s})$, sendo de uso comum a todas as especialidades que estão sendo visitadas.

A parte II conterá quesitos específicos do desempenho do Serviço, a serem avaliados de acordo com a especialidade. Aí se inclui também a avaliação do PRM pelo(s) e dele por seu(s) $\operatorname{MR}(\mathbf{s})$.

As informações consideradas pertinentes para a avaliação dos cursos de residência médica estão organizadas em quatro dimensões, que agrupam categorias de análise, representadas por meio de cada questão

A parte I deve ser preenchida pela Instituição a ser visitada ANTES, assim que notificada da vistoria, documentando as informações prestadas. O avaliador deve visitar in loco a fim de confirmar os dados preenchidos

\section{Dimensões}

\section{Categorias de análise}

São os desdobramentos das Dimensões, organizadas cada uma, em níveis, de acordo com as características consideradas as mais pertinentes em função do processo qualitativo de avaliação, que por sua vez geram os indicadores.

Cada dimensão possui como primeiro componente da avaliação a descrição e o comentário cerca do perfil institucional. Para os demais componentes foi estabelecida uma situação ideal.

\section{Dimensões}

Seção que agrega as informações em quatro níveis amplos, compreendendo: 
- I. Dimensão Institucional

- II. Desempenho das Equipes e Serviços

- III. Avaliação das Atividades Educacionais

- IV. Infra-estrutura e sua utilização

- V. Avaliação do Programa pelo Médico Residente

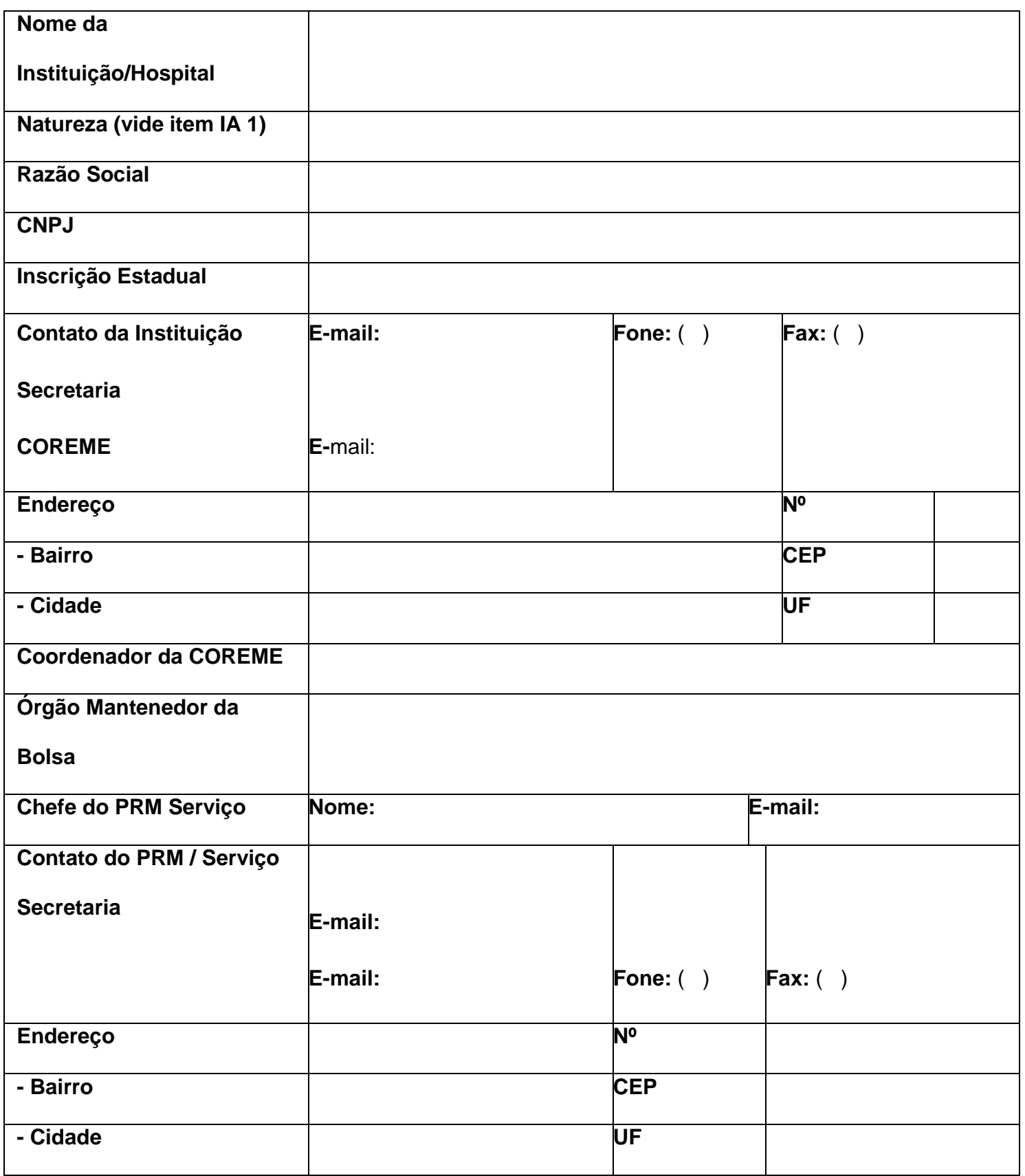


PRMs / Especialidade(s) a ser(em) visitada(s):

\begin{tabular}{|c|c|c|c|c|c|c|}
\hline \multirow[t]{6}{*}{$\begin{array}{c}\text { Nome } \\
\text { Programa }\end{array}$} & \multirow{6}{*}{\begin{tabular}{l}
\multicolumn{1}{c}{$\begin{array}{c}\text { Motivo } \\
\text { Visita }\end{array}$} \\
Credenciamento provisório ( ) \\
Credenciamento ( ) \\
Aumento de vagas ( ) \\
Recredenciamento ( ) \\
Recredenciamento $\quad$ com \\
aumento de vagas ( ) \\
Apurar Denúncia ( )
\end{tabular}} & \multicolumn{2}{|c|}{$\begin{array}{c}\text { Total de } \\
\text { Vagas } \\
\text { Credenciadas }\end{array}$} & \multicolumn{2}{|c|}{$\begin{array}{l}\text { Total de } \\
\text { Vagas } \\
\text { Solicitadas }\end{array}$} & \multirow[t]{6}{*}{ Situação Atual } \\
\hline & & R1 & & R1 & & \\
\hline & & $\mathrm{R} 2$ & & R2 & & \\
\hline & & R3 & & R3 & & \\
\hline & & R4 & & R4 & & \\
\hline & & R5 & & R5 & & \\
\hline & Credenciamento provisório ( ) & R1 & & R1 & & \\
\hline & Credenciamento ( ) & $\mathrm{R} 2$ & & $\mathrm{R} 2$ & & \\
\hline & Aumento de vagas ( ) & R3 & & R3 & & \\
\hline & Recredenciamento ( ) & R4 & & R4 & & \\
\hline & $\begin{array}{l}\text { Recredenciamento } \quad \text { com } \\
\text { aumento de vagas ( ) } \\
\text { Apurar Denúncia ( ) }\end{array}$ & R5 & & R5 & & \\
\hline & Credenciamento provisório ( ) & R1 & & R1 & & \\
\hline & Credenciamento ( ) & R2 & & R2 & & \\
\hline & Aumento de vagas ( ) & R3 & & R3 & & \\
\hline & Recredenciamento ( ) & $\mathrm{R} 4$ & & R4 & & \\
\hline & $\begin{array}{l}\text { Recredenciamento } \quad \text { com } \\
\text { aumento de vagas ( ) } \\
\text { Apurar Denúncia ( )) }\end{array}$ & R5 & & R5 & & \\
\hline \multicolumn{7}{|c|}{$\begin{array}{ll}\text { Equipe de Residentes } \\
\end{array}$} \\
\hline \multicolumn{7}{|l|}{ R1 } \\
\hline Nome: & & & \multicolumn{3}{|c|}{ E-mail: } & \\
\hline \multicolumn{2}{|l|}{ Endereço: } & & \multicolumn{2}{|l|}{ № } & \multicolumn{2}{|c|}{ Fone: } \\
\hline Bairro: & & & \multicolumn{2}{|l|}{ CEP } & & \\
\hline Cidade: & & & UF & & & \\
\hline \multicolumn{7}{|l|}{$\mathbf{R 2}$} \\
\hline \multicolumn{2}{|l|}{ Nome: } & & \multicolumn{3}{|c|}{ E-mail: } & \\
\hline \multicolumn{2}{|l|}{ Endereço: } & & \multicolumn{2}{|l|}{ № } & \multicolumn{2}{|c|}{ Fone: } \\
\hline \multicolumn{2}{|l|}{ Bairro: } & & \multicolumn{2}{|l|}{ CEP } & & \\
\hline \multicolumn{2}{|l|}{ Cidade: } & & \multicolumn{2}{|l|}{ UF } & & \\
\hline \multicolumn{7}{|l|}{ R3 } \\
\hline \multicolumn{2}{|l|}{ Nome: } & & \multicolumn{3}{|c|}{ E-mail: } & \\
\hline Endereço: & & & № & & Fo & \\
\hline Bairro: & & & CEP & & & \\
\hline Cidade: & & & UF & & & \\
\hline R4 & & & & & & \\
\hline Nome: & & & & mail: & & \\
\hline Endereço: & & & № & & & \\
\hline Bairro: & & & CEP & & & \\
\hline Cidade: & & & UF & & & \\
\hline R5 & & & & & & \\
\hline Nome: & & & & mail: & & \\
\hline Endereço: & & & № & & & \\
\hline Bairro: & & & CEP & & & \\
\hline Cidade: & & & UF & & & \\
\hline
\end{tabular}




\section{I - Dimensão Institucional}

\section{I.A - Modo de Relacionamento do Programa}

IA 1- Natureza da Sede do Programa

\begin{tabular}{|l|l|}
\hline \multicolumn{1}{|c|}{ Local } & Assinale a opção \\
\hline Hospital Universitário & \\
\hline Hospital de Ensino & \\
\hline Hospital Estadual & \\
\hline Hospital Municipal & \\
\hline Hospital Privado & \\
\hline Hospital Filantrópico & \\
\hline Órgão de Secretaria Estadual de Saúde & \\
\hline Órgão de Secretaria Municipal de Saúde & \\
\hline Outra & \\
\hline Descreva: & \\
\hline
\end{tabular}

\begin{tabular}{|c|c|c|c|}
\hline \multicolumn{2}{|c|}{ Hospitais de Apoio } & Sim & $\begin{array}{l}\text { Quantos? } \\
\text { (Número) }\end{array}$ \\
\hline \multicolumn{2}{|c|}{ Possui hospitais de Apoio para desenvolvimento pleno do PRM? } & & \\
\hline 1. Nome: & \multicolumn{3}{|l|}{ Cidade: } \\
\hline 2. Nome: & \multicolumn{3}{|l|}{ Cidade: } \\
\hline 3. Nome: & \multicolumn{3}{|l|}{ Cidade: } \\
\hline
\end{tabular}

\section{IA 2 - Relacionamento Acadêmico}

\begin{tabular}{|l|l|}
\hline \multicolumn{1}{|c|}{ Local Sim } \\
\hline Faculdade de Medicina & \\
\hline Instituição com Internato Médico & \\
\hline Instituição já tem PRM(s) autorizado(s) em curso & \\
\hline
\end{tabular}




\begin{tabular}{|l|l|}
\hline Outro & \\
\hline Descreva & \\
\hline
\end{tabular}

\begin{tabular}{|l|l|l|l|}
\hline \multicolumn{1}{|c|}{ Nível de complexidade } & \multicolumn{1}{|c|}{ Sim } & Região do País & Marque a opção \\
\hline Primário & & Norte & \\
\hline Secundário & & Nordeste & \\
\hline Terciário & & Centro-Oeste & \\
\hline & & Sudeste & \\
\hline & & Sul & \\
\hline
\end{tabular}

\section{I.B - Perfil Institucional}

\begin{tabular}{|c|c|c|c|c|}
\hline \multicolumn{3}{|c|}{ - População da região de abrangência da instituição } & & \\
\hline \multicolumn{3}{|c|}{ A instituição serve de referência local na prestação de serviços de saúde? } & Sim & Não \\
\hline \multicolumn{3}{|c|}{ A instituição serve de referência regional na prestação de serviços de saúde? } & & \\
\hline \multicolumn{3}{|c|}{ Possui intercâmbio com instituições de excelência? } & & \\
\hline \multicolumn{3}{|c|}{$\begin{array}{l}\text { Há programas de pós-graduação regulamentados que contribuem para a formação dos } \\
\text { residentes? }\end{array}$} & & \\
\hline \multicolumn{3}{|c|}{ A missão institucional inclui a formação em serviço? } & & \\
\hline \multicolumn{5}{|c|}{$\begin{array}{l}\text { O PRM está incluído no planejamento institucional (plano diretor, plano de } \\
\text { desenvolvimento institucional) }\end{array}$} \\
\hline \multicolumn{5}{|c|}{ Perfil dos Pacientes Atendidos } \\
\hline - SUS : & - Particulares: & Outros Convênios: & $\%$ & \\
\hline - Número de Leitos & - Hospital: & PRM: & & \\
\hline
\end{tabular}




\section{IC - Programa Institucional de Controle de Qualidade}

\begin{tabular}{|c|c|c|c|c|}
\hline & \multicolumn{2}{|c|}{ Existente } & $\begin{array}{c}\text { Não } \\
\text { Existente }\end{array}$ & $\begin{array}{l}\text { To } \\
\text { tal }\end{array}$ \\
\hline \multicolumn{5}{|l|}{ - Regulamentos Internos } \\
\hline \multicolumn{5}{|l|}{ - Termo de Consentimento Pós-Informação: } \\
\hline \multicolumn{5}{|l|}{$\begin{array}{l}\text { - Prontuário Médico: } \\
\text { - Anamnese; } \\
\text { - Evolução Diária } \\
\text { - Descrição Cirúrgica } \\
\text { - Sumário de Alta }\end{array}$} \\
\hline - Escalas de plantão e dias de folga (Afixada) & Afixada & Não Afixada & & \\
\hline - Escala de trabalho de treinandos (Afixada) & Afixada & Não Afixada & & \\
\hline \multicolumn{5}{|l|}{ - Controle de Qualidade e de Riscos } \\
\hline \multicolumn{5}{|c|}{$\begin{array}{l}\text { - Sistema interno de auditoria médica (controle de } \\
\text { mortalidade e morbidade, registro de acidentes) }\end{array}$} \\
\hline \multicolumn{5}{|l|}{ - Comissões Previstas Na Legislação } \\
\hline \multicolumn{5}{|l|}{ - Comitê de Ética Médica } \\
\hline \multicolumn{5}{|l|}{ - Comitê de Ética em Pesquisa } \\
\hline \multicolumn{5}{|l|}{ - Comissão de Controle de Infecção Hospitalar } \\
\hline \multicolumn{5}{|l|}{ - Comissão de Controle do Uso de Antimicrobianos } \\
\hline \multicolumn{5}{|l|}{ - Comissão Interna de Prevenção de Acidentes } \\
\hline \multicolumn{5}{|l|}{ - Comissão de Uso de Radioisótopos } \\
\hline \multicolumn{5}{|l|}{ - Comissão de Destinação de } \\
\hline \multicolumn{5}{|l|}{ - Vigilância Epidemiológica } \\
\hline \multicolumn{5}{|l|}{ - Resíduos - Relatório Anual de Atividades } \\
\hline $\begin{array}{l}\text { - Realização de Necropsias }-100 \% \text { dos Óbitos } \\
\qquad \begin{array}{r}\text { - + de } 50 \% \text { dos Óbitos } \\
\text { - Não realizadas }\end{array}\end{array}$ & & & & \\
\hline - Outras (Cite-as) & & & & \\
\hline
\end{tabular}




\section{I.C - COREME}

\section{I.C 1 - Administração / Gestão}

\begin{tabular}{|l|l|l|}
\hline & Sim & Não \\
\hline Reúne-se regularmente e de forma devidamente comprovada? & & \\
\hline É composta em concordância com a legislação em vigor? & & \\
\hline $\begin{array}{l}\text { Funciona como órgão da formação/ensino, responsável pela avaliação periódica do(s) } \\
\text { programa(s) e do desempenho dos médicos residentes? }\end{array}$ & & \\
\hline Possui regimento interno de acordo com as resoluções da CNRM? & & \\
\hline Realiza auto-avaliação dos(s) PRM(s) pelo médico residente? & & \\
\hline Realiza avaliação interna periódica dos(s) PRM(s)? & & \\
\hline Oferece apoio psico-pedagógico aos MRs? & & \\
\hline $\begin{array}{l}\text { Existe uma política de capacitação permanente e de educação continuada para preceptores e } \\
\text { supervisores, regulamentada e efetivamente praticada? }\end{array}$ & & \\
\hline $\begin{array}{l}\text { Existe suporte técnico e mecanismos institucionais de apoio para a participação em eventos } \\
\text { técnico-científicos e/ou apoio à produção científica? }\end{array}$ & & \\
\hline Os PRM desenvolvem-se em instalações próprias? & & \\
\hline Os PRM desenvolvem-se em unidades documentalmente conveniadas? & & \\
\hline
\end{tabular}

\section{I.C 2 - Avaliação Acadêmica}

\begin{tabular}{|l|l|l|}
\hline & Sim & Não \\
\hline O processo seletivo de admissão de MRs cumpre as normas da CNRM? & & \\
\hline A COREME organiza o processo seletivo através comissão específica? & & \\
\hline O edital de concurso é submetido a instância jurídica competente para autorização de divulgação? & & \\
\hline Existe padronização institucional para a aferição de pontuação específica nas diversas etapas? & & \\
\hline $\begin{array}{l}\text { A Análise de Currículo segue padronização institucional de itens e pontuações específicas para } \\
\text { cada item? }\end{array}$ & & \\
\hline
\end{tabular}

\begin{tabular}{|c|c|c|}
\hline O Processo Seletivo é composto por: & Sim & Não \\
\hline \multicolumn{3}{|l|}{ Prova Discursiva } \\
\hline \multicolumn{3}{|l|}{ Prova Múltipla Escolha } \\
\hline \multicolumn{3}{|l|}{ Prova Multimídia } \\
\hline \multicolumn{3}{|l|}{ Avaliação Clínica Estruturada e Objetiva } \\
\hline \multicolumn{3}{|l|}{ Paciente Simulado } \\
\hline \multicolumn{3}{|l|}{ Paciente Real } \\
\hline Análise de Currículo & & \\
\hline
\end{tabular}


I.D - Produção Científica da Instituição nos últimos 5 anos

\begin{tabular}{|c|c|c|c|c|c|c|}
\hline & \multicolumn{6}{|c|}{ Quantidade } \\
\hline & Zero & Até 5 & 5 a 10 & 10 a 20 & 20 a 50 & $>$ que 50 \\
\hline Artigos publicados em revistas ind & & & & & & \\
\hline Artigos publicados em outras revis & & & & & & \\
\hline Capítulos de livros & & & & & & \\
\hline Autoria de livros (co-autoria de livr & & & & & & \\
\hline Edição/organização de livros & & & & & & \\
\hline $\begin{array}{l}\text { Resumos publicados / Apresentaç } \\
\text { de Congressos Exterior }\end{array}$ & & & & & & \\
\hline $\begin{array}{l}\text { Resumos publicados / Apresentaç } \\
\text { de Congressos da SBN }\end{array}$ & & & & & & \\
\hline Trabalhos apresentados em Congr & & & & & & \\
\hline Apresentações em Congressos a C & & & & & & \\
\hline Dissertações defendidas - mestrad & & & & & & \\
\hline Teses defendidas - doutorado & & & & & & \\
\hline Teses defendidas - livre docência & & & & & & \\
\hline
\end{tabular}

\section{II - Sobre as Equipes e Serviços}

\section{A - Organização dos Serviços}

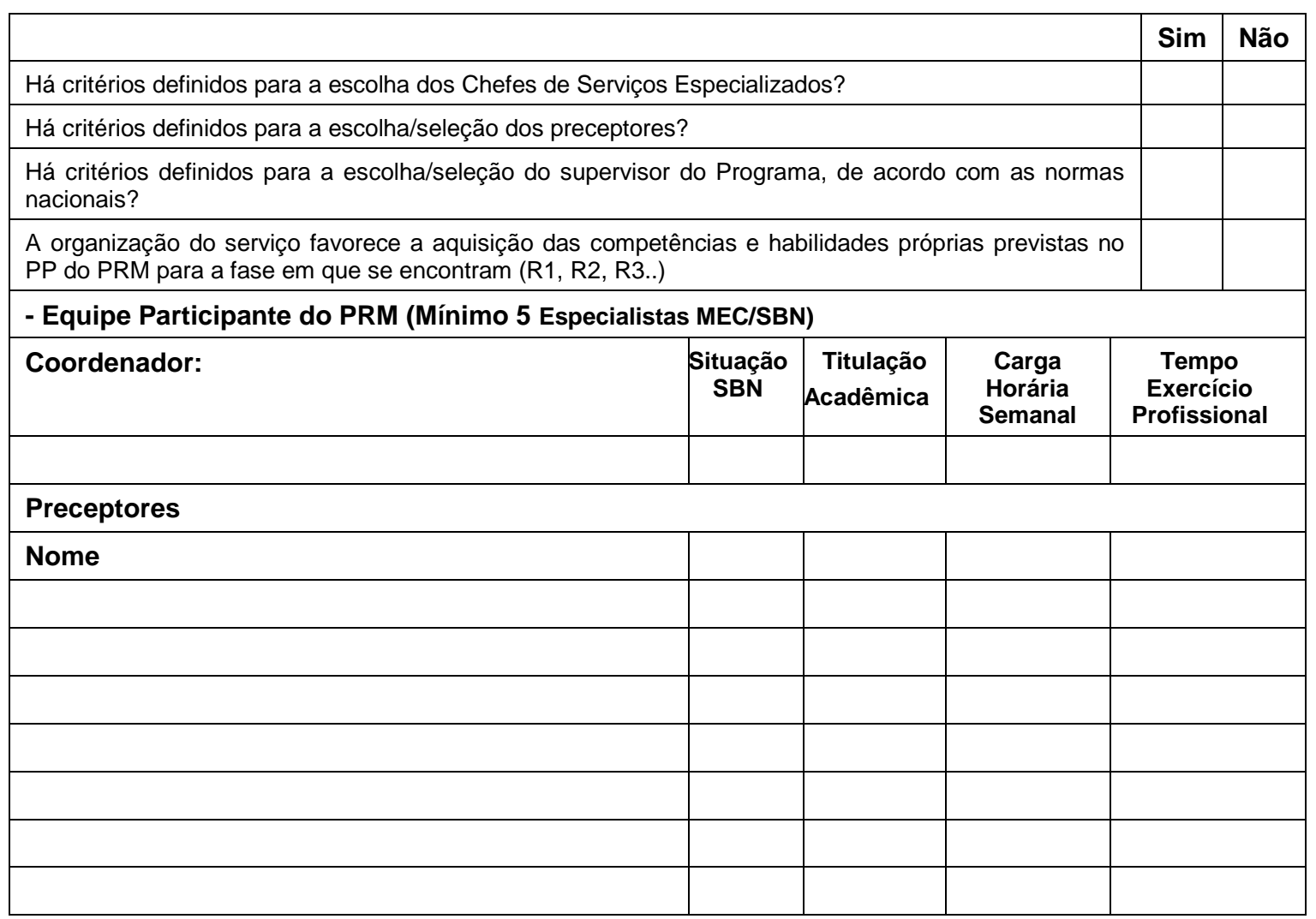

Situação SBN: MT- membro titular; ME - membro efetivo; NM - não membro. Titulação Carga Horária: Livre Docente; Doutor, Doutorando; Mestre, Mestrando. Carga Horária Semanal: < 20h, 20h, 40 horas, Dedicação Exclusiva. Tempo de Exercício Profissional: $<5$ anos após RM, 5-10 após a RM, $>10$ anos após RM 


\section{III - Infraestrutura e sua utilização}

\section{A - Facilitação da atuação dos Serviços/Clientela}

\begin{tabular}{|l|l|l|}
\hline & Sim & Não \\
\hline $\begin{array}{l}\text { Possui capacidade e condições de conforto para os profissionais de saúde nas diversas } \\
\text { unidades da instituição? }\end{array}$ & \\
\hline Existência de sinalização institucional adequada? & & \\
\hline Os profissionais de saúde são devidamente identificados? & & \\
\hline $\begin{array}{l}\text { Possui equipamentos de proteção individuais adequados e que sejam efetivamente } \\
\text { utilizados? }\end{array}$ & \\
\hline A infra-estrutura física permite qualidade no atendimento ao usuário? & \\
\hline $\begin{array}{l}\text { A instituição possui serviços de apoio diagnóstico e de tratamento para as condições } \\
\text { clínicas prevalentes na população? }\end{array}$ & \\
\hline $\begin{array}{l}\text { Os usuários com necessidades especiais recebem tratamento adequado por meio de } \\
\text { instalações físicas e equipamentos? }\end{array}$ & & \\
\hline A instituição possui mecanismos para ouvir e aferir a satisfação da população atendida? & & \\
\hline
\end{tabular}

\section{B - Análise Geral das Instalações}

\begin{tabular}{|l|l|l|l|}
\hline \multicolumn{1}{|c|}{ Instalações Gerais } & Sim & Não & NA \\
\hline Adequadas no que se refere ao espaço físico? & & & \\
\hline Adequadas no que se refere aos equipamentos disponíveis? & & & \\
\hline $\begin{array}{l}\text { Adequadas no que se refere às facilidades de acesso e de } \\
\text { utilização? }\end{array}$ & & & \\
\hline
\end{tabular}

\begin{tabular}{|l|l|l|l|}
\hline \multicolumn{1}{|c|}{ Alojamento para RM } & Sim & Não & NA \\
\hline $\begin{array}{l}\text { Possui alojamento para os médicos residentes em condições } \\
\text { adequadas? }\end{array}$ & & & \\
\hline $\begin{array}{l}\text { Banheiro privativo adequado (higienizado, com chuveiro, pia, } \\
\text { papel, sabonete, lixeira) e considerando as necessidades de } \\
\text { gênero? }\end{array}$ & & & \\
\hline Espaço de Escritório para Residentes & & & \\
\hline Quarto de Plantão com Ar Condicionado & & & \\
\hline Restaurante & & & \\
\hline
\end{tabular}




\begin{tabular}{|c|c|c|c|}
\hline Biblioteca & Sim & Não & NA \\
\hline \multicolumn{4}{|l|}{ Instalações adequadas? } \\
\hline \multicolumn{4}{|c|}{ Acesso à rede mundial de computadores para consulta científica? } \\
\hline Localização & No PRM & $\begin{array}{c}\mathrm{Na} \\
\text { Instituição }\end{array}$ & $\begin{array}{l}\text { Fora da } \\
\text { Instituição }\end{array}$ \\
\hline Horário de Acesso & $\begin{array}{c}24 \\
\text { Horas }\end{array}$ & $\begin{array}{l}\text { Horário } \\
\text { Comercial }\end{array}$ & \\
\hline Acervo adequado e de qualidade? & & & \\
\hline
\end{tabular}

\begin{tabular}{|l|l|l|l|}
\hline \multicolumn{1}{|c|}{ Documentação Fotográfica } & Sim & Não & NA \\
\hline $\begin{array}{l}\text { Possui sistema de coleta de imagens (câmara digital, captura de } \\
\text { vídeo)? }\end{array}$ & & & \\
\hline $\begin{array}{l}\text { Possui sistema de armazenamento, catalogação e facilidade na } \\
\text { utilização das imagens? }\end{array}$ & & & \\
\hline
\end{tabular}

\begin{tabular}{|l|l|l|l|}
\hline \multicolumn{1}{|c|}{ Espaços de Aprendizagem } & Sim & Não & NA \\
\hline O PRM/Instituição tem sala de aula ou local similar? & & & \\
\hline $\begin{array}{l}\text { O PRM/Instituição tem auditório adequado e que seja } \\
\text { disponível? }\end{array}$ & & & \\
\hline Possui acesso fácil a aparelhos de multimídia? & & & \\
\hline Local adequado para estudo & & C/ Peças & C/ Ambos \\
\hline $\begin{array}{l}\text { Laboratório P/Treinamento de Microanatomia } \\
\text { Microcirugia }\end{array}$ & Anatômicas & \\
\hline Da Instituição & & & \\
\hline Do PRM / Serviço & & & \\
\hline
\end{tabular}


IV. D - Serviço de Arquivo Médico

\begin{tabular}{|l|l|l|l|l|}
\hline & Sim & Não & Parcial & NA \\
\hline O Serviço de Arquivo Médico está informatizado? & & & & \\
\hline O prontuário médico é eletrônico? & & & & \\
\hline $\begin{array}{l}\text { O prontuário médico contém os dados oriundos do completo } \\
\text { preenchimento que permitem a qualidade da informação e sua } \\
\text { utilização? }\end{array}$ & & & & \\
\hline
\end{tabular}

Roteiro de Visita de Verificação MEC - SBN

Detalhamento do Programa de Residência Médica

I. Instituição / PRM

\begin{tabular}{|l|l|}
\hline Nome da Instituição & \\
\hline Natureza da Instituição & \\
\hline PRM & \\
\hline Hospital de Apoio & \\
\hline
\end{tabular}

\begin{tabular}{|l|l|l|l|l|}
\hline Período & $\begin{array}{c}\text { Total de Vagas } \\
\text { Credenciadas }\end{array}$ & $\begin{array}{c}\text { Total de Vagas } \\
\text { Oferecidas }\end{array}$ & $\begin{array}{c}\text { Total de Vagas } \\
\text { Ocupadas }\end{array}$ & Observações \\
\hline R1 & & & & \\
\hline R2 & & & & \\
\hline R3 & & & & \\
\hline R4 & & & & \\
\hline R5 & & & & \\
\hline & & & & \\
\hline
\end{tabular}




\section{IA. - Supervisor do PRM}

\begin{tabular}{|c|c|c|c|c|}
\hline \multicolumn{5}{|l|}{ Nome Completo } \\
\hline \multicolumn{5}{|l|}{ CPF/MF no } \\
\hline $\begin{array}{l}\text { Título de Especialista } \\
\text { MEC/SBN (Essencial) }\end{array}$ & Títulos Acadêmicos & Sim & Não & Total \\
\hline$<5$ anos & Mestrado & & & \\
\hline $5-10$ anos & Doutorado & & & \\
\hline$>10$ anos & Livre Docência & & & \\
\hline \multicolumn{2}{|c|}{$\begin{array}{l}\text { Possui substituto devidamente constituído (em casos de férias, afastamentos } \\
\text { etc.? }\end{array}$} & & & \\
\hline \multicolumn{4}{|c|}{ Escore Subtotal } & \\
\hline
\end{tabular}

\section{I.B - Preceptores do Programa em Análise}

\begin{tabular}{|c|c|c|c|c|c|c|c|c|}
\hline № Preceptores & ( $\geq 5$ Especiali & as MEC/SBN) & & & & & & \\
\hline Titulação & Preceptor 1 & Preceptor 2 & Preceptor 3 & Preceptor 4 & Prec & ptor 5 & & \\
\hline Mestrando & & & & & & & & \\
\hline Mestre & & & & & & & & \\
\hline Doutorando & & & & & & & & \\
\hline Doutor & & & & & & & & \\
\hline Livre Docente & & & & & & & & \\
\hline $\begin{array}{l}\text { Título Especialista } \\
\text { SBN/MEC }\end{array}$ & Essencial & Essencial & Essencial & Essencial & Ess & ncial & & \\
\hline $\begin{array}{ll}\text { Carga } & \text { Horária } \\
\text { Semanal } & \end{array}$ & & & & & & & & \\
\hline$<20 h$ & & & & & & & & \\
\hline $20 \mathrm{~h}$ & & & & & & & & \\
\hline $40 \mathrm{~h}$ & & & & & & & & \\
\hline Dedicação Exclusiva & & & & & & & & \\
\hline $\begin{array}{l}\text { Tempo de Exer- } \\
\text { cício Profissional }\end{array}$ & & & & & & & & \\
\hline$<5$ anos Após RM & & & & & & & & \\
\hline $5-10$ anos após RM & & & & & & & & \\
\hline > 10 anos após RM & & & & & & & & \\
\hline & & & & & & Sim & Não & NA \\
\hline $\begin{array}{l}\text { A relação entre o nú } \\
\text { qualidade?* }\end{array}$ & mero de médi & s residentes & preceptor $p €$ & te a formaçã & com & & & \\
\hline $\begin{array}{l}\text { A relação entre a der } \\
\text { residentes do PRM pe }\end{array}$ & $\begin{array}{l}\text { manda de ativ } \\
\text { rmite a formaç }\end{array}$ & $\begin{array}{l}\text { ades realizad } \\
\text { com qualidac }\end{array}$ & $\operatorname{no}_{\star \star}$ Serviço e & húmero de $\mathrm{m}$ & dicos & & & \\
\hline
\end{tabular}

*Mínimo de 1 preceptor em período integral para cada 6 residentes ou de 1 preceptor com tempo parcial para cada 3 residentes.

**Observar as particularidades de cada PRM - Mínimo de 5 Preceptores Membros Titulares da SBN para o PRM em Neurocirurgia 
IC - . Convênios

\begin{tabular}{|l|l|l|l|}
\hline Todo o programa de RM é desenvolvido na Instituição? & $100 \%$ & $75 \%$ & 50 \\
\hline $\begin{array}{l}\text { Possui convênios documentados com outras instituições para } \\
\text { realização de atividades da RM? }\end{array}$ & & & \\
\hline - Neurotraumatologia & & & \\
\hline - Neurocirurgia Pediátrica & & & \\
\hline - Neurocirurgia Funcional & & & \\
\hline - Outro (nominar): convênios em andamento & & & \\
\hline
\end{tabular}

\section{I.D - Produção Científica do PRM nos Últimos 5 Anos}

(Considerar apenas aqueles relacionados ao supervisor, preceptores, residentes e exresidentes)

\begin{tabular}{|c|c|c|c|c|c|c|c|}
\hline & \multicolumn{7}{|c|}{ Quantidade } \\
\hline & Zero & Até 5 & 5 a 10 & 10 a 20 & 20 a 50 & $>$ que 50 & Total \\
\hline \multicolumn{8}{|c|}{ Artigos publicados em revistas indexadas } \\
\hline \multicolumn{8}{|l|}{ Artigos publicados em outras revistas } \\
\hline \multicolumn{8}{|l|}{ Capítulos de livros } \\
\hline \multicolumn{8}{|l|}{ Autoria de livros (co-autoria de livros) } \\
\hline \multicolumn{8}{|l|}{ Edição/organização de livros } \\
\hline \multicolumn{8}{|c|}{$\begin{array}{l}\text { Resumos publicados / Apresentações em Anais } \\
\text { de Congressos Exterior }\end{array}$} \\
\hline \multicolumn{8}{|c|}{$\begin{array}{l}\text { Resumos publicados / Apresentações em Anais } \\
\text { de Congressos da SBN }\end{array}$} \\
\hline \multicolumn{8}{|c|}{ Trabalhos apresentados em Congressos da SBN } \\
\hline \multicolumn{8}{|c|}{ Apresentações em Congressos a Convite } \\
\hline \multicolumn{8}{|l|}{ Dissertações defendidas - mestrado } \\
\hline \multicolumn{8}{|l|}{ Teses defendidas - doutorado } \\
\hline Teses defendidas - livre docência & & & & & & & \\
\hline
\end{tabular}




\section{Avaliação das Atividades Educacionais}

\section{A - Coerência do Projeto Pedagógico}

\begin{tabular}{|c|c|c|c|}
\hline $\begin{array}{l}\text { Há coerência entre o PP apresentado, as condições em que se dá o processo de } \\
\text { formação e o perfil desejado para os egressos? }\end{array}$ & Sim & Não & NA \\
\hline $\begin{array}{l}\text { As condições em que se dá o processo de formação está claramente explicitado } \\
\text { no PP? }\end{array}$ & & & \\
\hline $\begin{array}{l}\text { A carga horária das atividades programadas permite a formação desejada pelo o } \\
\text { PP apresentado? }\end{array}$ & & & \\
\hline Há espaços de conceitualização prática? Se sim, responda ao próximo item & & & \\
\hline - Sessão anátomo-clínica (Semanal= 100, Quinzenal= 50. Mensal= 25, Não Tem=0.) & & & \\
\hline - Sessão de Discussão de Casos (Semanal= 100, Quinzenal= 50. Mensal= 25, Não Tem=0) & & & \\
\hline Discussão de Artigos Científicos (Semanal= 100, Quinzenal= 50. Mensal=25, Não Tem=0) & & & \\
\hline Discussão de Protocolos de Conduta (Trimestral= 100, Semestral= 80 Anual=70, Não Tem=0) & & & \\
\hline Discussão Clínico-Radiológica (Diária = 100, Semanal = 75, Quinzenal =50, Mensal = 25). & & & \\
\hline Discussão de Pacientes Internados (Diária = 100, Semanal = 75, Quinzenal =50). & & & \\
\hline Discussão em Ambulatórios (Diária = 100, Semanal = 75, Quinzenal =50). & & & \\
\hline
\end{tabular}

\begin{tabular}{|c|c|c|c|}
\hline A metodologia de ensino - aprendizagem é: & Sim & Não & NA \\
\hline - Centrada no residente & & & \\
\hline - Centrada no Preceptor & & & \\
\hline $\begin{array}{l}\text { A distribuição das tarefas práticas, torna o PRM prioritariamente }(\geq 50 \%) \text { voltado } \\
\text { para: } \\
\text { - Ensino } \\
\text { - Assistência }\end{array}$ & & & \\
\hline
\end{tabular}

\section{II.B- Atividades Formativas da Prática Profissional}

\begin{tabular}{|c|c|c|c|c|}
\hline & & Sim & Não & NA \\
\hline \multicolumn{2}{|c|}{$\begin{array}{l}\text { As atividades são realizadas em múltiplos locais ajustados para as particularidades } \\
\text { do PRM? }\end{array}$} & & & \\
\hline \multicolumn{2}{|c|}{ Estão de acordo com o projeto pedagógico apresentado? } & & & \\
\hline \multicolumn{2}{|c|}{$\begin{array}{l}\text { As atividades são supervisionadas continuamente, permitindo a qualidade do } \\
\text { programa? }\end{array}$} & & & \\
\hline \multicolumn{2}{|c|}{$\begin{array}{l}\text { Possui preceptores e/ou supervisor presencialmente na Instituição e no Serviço } \\
\text { durante toda a jornada de trabalho e plantões? }\end{array}$} & & & \\
\hline \multicolumn{3}{|c|}{ As atividades do PRM são desenvolvidas na Instituição Sede? } & & \\
\hline Integralmente & Percentual (escreva na casela) & & & \\
\hline Parcialmente & Percentual extra institucional (escreva na casela) & & & \\
\hline
\end{tabular}




\section{II.C - Avaliação e Política de Qualidade}

\begin{tabular}{|c|c|c|c|c|c|c|c|}
\hline \multirow{2}{*}{\multicolumn{5}{|c|}{$\begin{array}{l}\text { O Programa contempla os objetivos da formação de acordo com o perfil desejado } \\
\text { dos egressos previsto no PP? }\end{array}$}} & Sim & Não & NA \\
\hline & & & & & & & \\
\hline \multicolumn{5}{|c|}{ Existem instrumentos de auto-avaliação do Programa? } & & & \\
\hline \multicolumn{5}{|c|}{ A avaliação do médico residente é procedida regularmente? } & & & \\
\hline $\begin{array}{l}\text { Periodicidade da Avaliação } \\
\text { Tipo de Avaliação }\end{array}$ & Diária & Semanal & Quinzenal & Mensal & \multicolumn{2}{|c|}{ Bimensal } & Trimestral \\
\hline \multicolumn{8}{|l|}{ Teste de múltipla escolha } \\
\hline \multicolumn{8}{|l|}{ Prova discursiva } \\
\hline \multicolumn{8}{|l|}{ Prática à beira do leito } \\
\hline \multicolumn{8}{|l|}{ Avaliação Padronizada de Habilidades } \\
\hline \multicolumn{8}{|l|}{ Mini Avaliação Clínica Estruturada } \\
\hline \multicolumn{8}{|l|}{ Outras (descreva abaixo a natureza) } \\
\hline $\begin{array}{l}\text { Há coerência entre o sistema de avalic } \\
\text { verificam o desempenho dos médicos } r \\
\text { sim }\end{array}$ & $\begin{array}{l}\text { io do } \\
\text { ident }\end{array}$ & $\begin{array}{l}\mathrm{RM} \text {, as } \\
\text { e os pr }\end{array}$ & $\begin{array}{l}\text { ndições } \\
\text { ssos de }\end{array}$ & $\begin{array}{l}\text { que se } \\
\text { mação? }\end{array}$ & & & \\
\hline
\end{tabular}

\begin{tabular}{|l|c|c|c|c|c|c|c|}
\hline \multirow{2}{*}{ Avaliações Anuais dos Residentes e Egressos } & \multicolumn{5}{|c|}{ Média das Notas Anuais } & Total \\
\cline { 2 - 7 } & $8-10$ & $6-8$ & $<6$ & & & & \\
\hline Residentes & & & & & & & \\
\hline $\begin{array}{l}\text { Egressos (Títulos de Especialistas/Ano 100 para } \\
\text { cada egresso) }\end{array}$ & & & & & & & \\
\hline
\end{tabular}




\section{Avaliação da Infraestrutura e Equipamentos}

\section{III.A - Centro Cirúrgico}

\begin{tabular}{|c|c|c|c|c|c|c|c|}
\hline & & & & Sim & Nãc & & Total \\
\hline Possui sala de recuperação pós-anestésica? & & & & & & & \\
\hline Quantidade de salas cirúrgicas & № & & & & & & \\
\hline & Exclus & & Disp & $\begin{array}{l}\text { oníbilidade } \\
\text { Diária }\end{array}$ & Não & & Total \\
\hline $\begin{array}{l}\text { Sala cirúrgica disponível com material neurocirúrgico } \\
\text { básico para realizar craniotomias e laminectomias c/ } \\
\text { coagulador bipolar, radioscopia transoperatória (arco em C), } \\
\text { mesa cirúrgica com suporte de cabeça, microscópio } \\
\text { cirúrgico com ocular acessória ou vídeo, sistema para } \\
\text { broqueamento ósseo }\end{array}$ & & & & & & & \\
\hline & Disponí & & Disp & $\begin{array}{l}\text { onibilidade } \\
\text { Eventual }\end{array}$ & Não & & Cotal \\
\hline $\begin{array}{l}\text { Neuroanestesiologistas disponíveis } 24 \text { horas no } \\
\text { Centro de Treinamento }\end{array}$ & & & & & & & \\
\hline $\begin{array}{l}\text { Anestesiologistas com experiência em neurocirúrgica } \\
\text { disponíveis } 24 \text { horas no Centro de Treinamento }\end{array}$ & & & & & & & \\
\hline $\begin{array}{l}\text { Craniótomo Elétrico ou a Ar Comprimido e "Drill" de } \\
\text { Alta Rotação }\end{array}$ & & & & & & & \\
\hline Aspirador Ultrassônico & & & & & & & \\
\hline Sistema de Estereotaxia & & & & & & & \\
\hline Neuro- Video-endoscópio & & & & & & & \\
\hline $\begin{array}{l}\text { Equipamento para Realização de Ultrassonografia } \\
\text { Intra-Operatória }\end{array}$ & & & & & & & \\
\hline Sistema de Neuronavegação & & & & & & & \\
\hline $\begin{array}{l}\text { Monitorização Neurofisiológica Intra-Operatória } \\
\text { (Eletrocorticografia; }\end{array}$ & $\begin{array}{l}4 \text { Moda- } \\
\text { lidades }\end{array}$ & & $\begin{array}{l}\text { loda- } \\
\text { des }\end{array}$ & $\begin{array}{l}2 \text { Moda- } \\
\text { lidades }\end{array}$ & $\begin{array}{l}1 \\
\text { Moda- } \\
\text { lidade }\end{array}$ & Não & \\
\hline $\begin{array}{l}\text { Quantidade de equipamento é adequada ao } \\
\text { funcionamento dos serviços? }\end{array}$ & & & & & & & \\
\hline Qualidade dos equipamentos é boa? & & & & & & & \\
\hline Possui local para Cirurgia Ambulatorial? & & & & & & & \\
\hline
\end{tabular}




\begin{tabular}{|c|c|c|c|c|c|c|}
\hline \multirow{3}{*}{$\begin{array}{l}\text { Número de Cirurgias Realizadas no } \\
\text { Último Ano } \\
\text { Descreva o quantitativo (absoluto e } \\
\text { percentual) de cirurgias por } \\
\text { subespecialidade }\end{array}$} & \multicolumn{6}{|c|}{$\begin{array}{l}\text { - Mínimo de } 300 \text { Cirurgias Não Traumáticas Residente / Ano } \\
\text { - Mínimo } 60 \text { Cirurgias por Trauma / Residente / Ano } \\
\text { - 80\% no Hospital Sede }\end{array}$} \\
\hline & \multicolumn{2}{|c|}{ Hospital Sede } & \multicolumn{2}{|c|}{ Hospitais Apoio } & \multicolumn{2}{|c|}{ Total } \\
\hline & № & $\%$ & № & $\%$ & № & $\%$ \\
\hline Tumores do SNC & & & & & & \\
\hline Doenças Raquimedulares & & & & & & \\
\hline Cirurgias Vasculares do SNC & & & & & & \\
\hline Cirurgias Funcionais & & & & & & \\
\hline Cirurgia dos Nervos Periféricos & & & & & & \\
\hline Cirurgias Pediátricas & & & & & & \\
\hline Cirurgias por Lesões Traumáticas & & & & & & \\
\hline
\end{tabular}

\section{B - Ambulatório}

\begin{tabular}{|l|l|l|l|l|}
\hline & Disponível & Disponibil. Eventual & Não & Total \\
\hline $\begin{array}{l}\text { Possui salas com equipamentos básicos (balança, } \\
\text { estetoscópio, esfingnomanômetro etc.)? }\end{array}$ & & & & \\
\hline $\begin{array}{l}\text { Quantidade de salas é adequada ao número de } \\
\text { PRM desenvolvidos? }\end{array}$ & & & & \\
\hline Possui salas climatizadas? & & & & \\
\hline Ambulatório Regular de Pré e Pós-Operatório & & & & \\
\hline
\end{tabular}

\section{C - UTI}

\begin{tabular}{|c|c|c|c|c|c|c|c|}
\hline \multirow[t]{2}{*}{ Tipo de UTI } & \multicolumn{2}{|c|}{ Especializada } & \multicolumn{2}{|c|}{ Geral } & \multicolumn{2}{|c|}{ Neonatal } & \multirow{2}{*}{ Total } \\
\hline & $\begin{array}{l}\text { Neuroin- } \\
\text { tensivista }\end{array}$ & Não & Intensivista & Não & Intensivista & Não & \\
\hline \multicolumn{8}{|l|}{ Número de leitos } \\
\hline $\begin{array}{l}\text { Número de leitos > } 1 \text { para cada } 100 \\
\text { cirurgias realizadas? }\end{array}$ & \multicolumn{3}{|c|}{ Sim } & \multicolumn{3}{|c|}{ Não } & \\
\hline \multicolumn{8}{|l|}{$\begin{array}{l}\text { Número de atendimentos nos últimos } \\
\text { seis meses }\end{array}$} \\
\hline Leitos para isolamento & \multicolumn{3}{|l|}{ Sim: } & \multicolumn{3}{|l|}{ Não: } & \\
\hline \multicolumn{8}{|l|}{$\begin{array}{l}\text { № de atendimento nos últimos seis } \\
\text { meses }\end{array}$} \\
\hline Taxa de ocupação média dos leitos & & & & & & & \\
\hline
\end{tabular}


III.D - Pronto Socorro

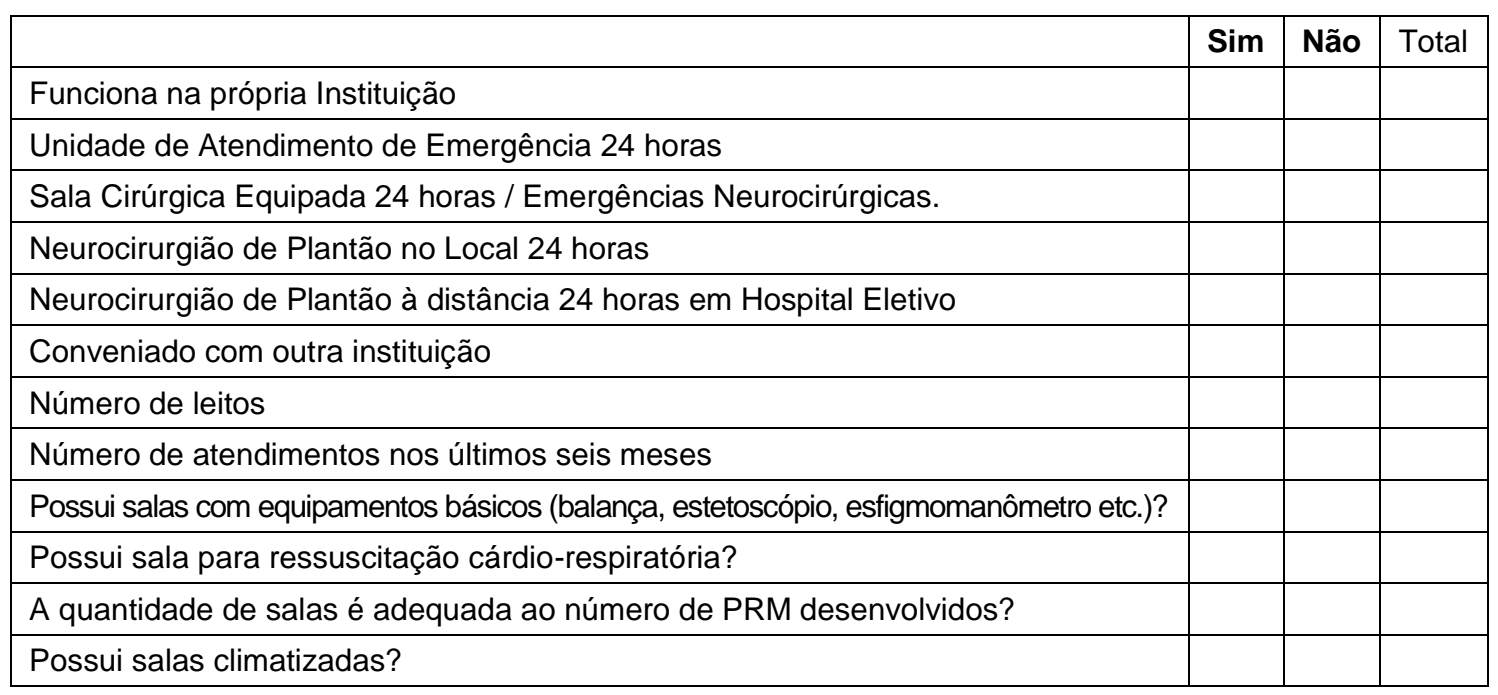

\section{E - Serviço de Apoio Diagnóstico e Terapêutico}

\begin{tabular}{|c|c|c|c|c|c|c|}
\hline \multirow[t]{2}{*}{ Serviço } & \multicolumn{2}{|c|}{ No Hospital } & \multirow[t]{2}{*}{ Acesso Irrestrito } & \multirow[t]{2}{*}{ Acesso Restrito } & \multirow[t]{2}{*}{ Não } & \multirow[t]{2}{*}{ Total } \\
\hline & SIM & Não & & & & \\
\hline \multicolumn{7}{|l|}{ Neurologia } \\
\hline \multicolumn{7}{|l|}{ Eletrencefalografia } \\
\hline \multicolumn{7}{|l|}{ Neurofisiologia Clínica } \\
\hline \multicolumn{7}{|l|}{ Líquido Cefalorraquidiano } \\
\hline \multicolumn{7}{|l|}{ Laboratórios } \\
\hline \multicolumn{7}{|l|}{ Laboratório: hematologia } \\
\hline \multicolumn{7}{|l|}{ Laboratório: bioquímica } \\
\hline \multicolumn{7}{|l|}{ Laboratório: sorologia } \\
\hline \multicolumn{7}{|l|}{ Laboratório: microbiologia } \\
\hline \multicolumn{7}{|l|}{ Diagnóstico por Imagem } \\
\hline \multicolumn{7}{|l|}{ Angiografia convencional } \\
\hline \multicolumn{7}{|c|}{ Neurorradiologia intervencionista } \\
\hline \multicolumn{7}{|c|}{ Tomografia computadorizada } \\
\hline \multicolumn{7}{|l|}{ Ecocardiograma } \\
\hline \multicolumn{7}{|l|}{ Ultra-sonografia } \\
\hline \multicolumn{7}{|l|}{ Ressonância Magnética } \\
\hline \multicolumn{7}{|l|}{ Medicina Nuclear } \\
\hline \multicolumn{7}{|l|}{ Anatomia Patológica } \\
\hline \multicolumn{7}{|l|}{ Serviço de Patologia Geral } \\
\hline \multicolumn{7}{|l|}{ Biópsia de congelação } \\
\hline \multicolumn{7}{|l|}{ Serviço de Neuropatologia } \\
\hline \multicolumn{7}{|l|}{ Serviços Terapêuticos } \\
\hline \multicolumn{7}{|l|}{ Serviço de Radioterapia } \\
\hline \multicolumn{7}{|l|}{ Serviço de Radiocirurgia } \\
\hline Serviço de Oncologia (Quin & & & & & & \\
\hline Serviços Afins & & & & & & \\
\hline Serviço de Pediatria & & & & & & \\
\hline Serviço de Endocrinologia & & & & & & \\
\hline Serviço de Fisioterapia & & & & & & \\
\hline Serviço de Fonoaudiologia & & & & & & \\
\hline
\end{tabular}


TAREFAS SEMANAIS DESEMPENHADAS POR GRUPOS DE RESIDENTES

(Semana Padrão -R1)

Esquematize a semana padrão das atividades dos residentes de cada ano.

\begin{tabular}{|c|l|l|}
\hline & Manhã & \\
\hline Segunda & & \\
\hline Terça & & \\
\hline Quarta & & \\
\hline Quinta & & \\
\hline Sábado & & \\
\hline Sexta & & \\
& & \\
& & \\
& & \\
& & \\
& & \\
& & \\
& & \\
\hline
\end{tabular}




\section{Rodízio do PRM (R1)}

Apresente a escala de estágios para cada ano de residência ao longo do ano, incluindo os períodos de férias de cada residente.

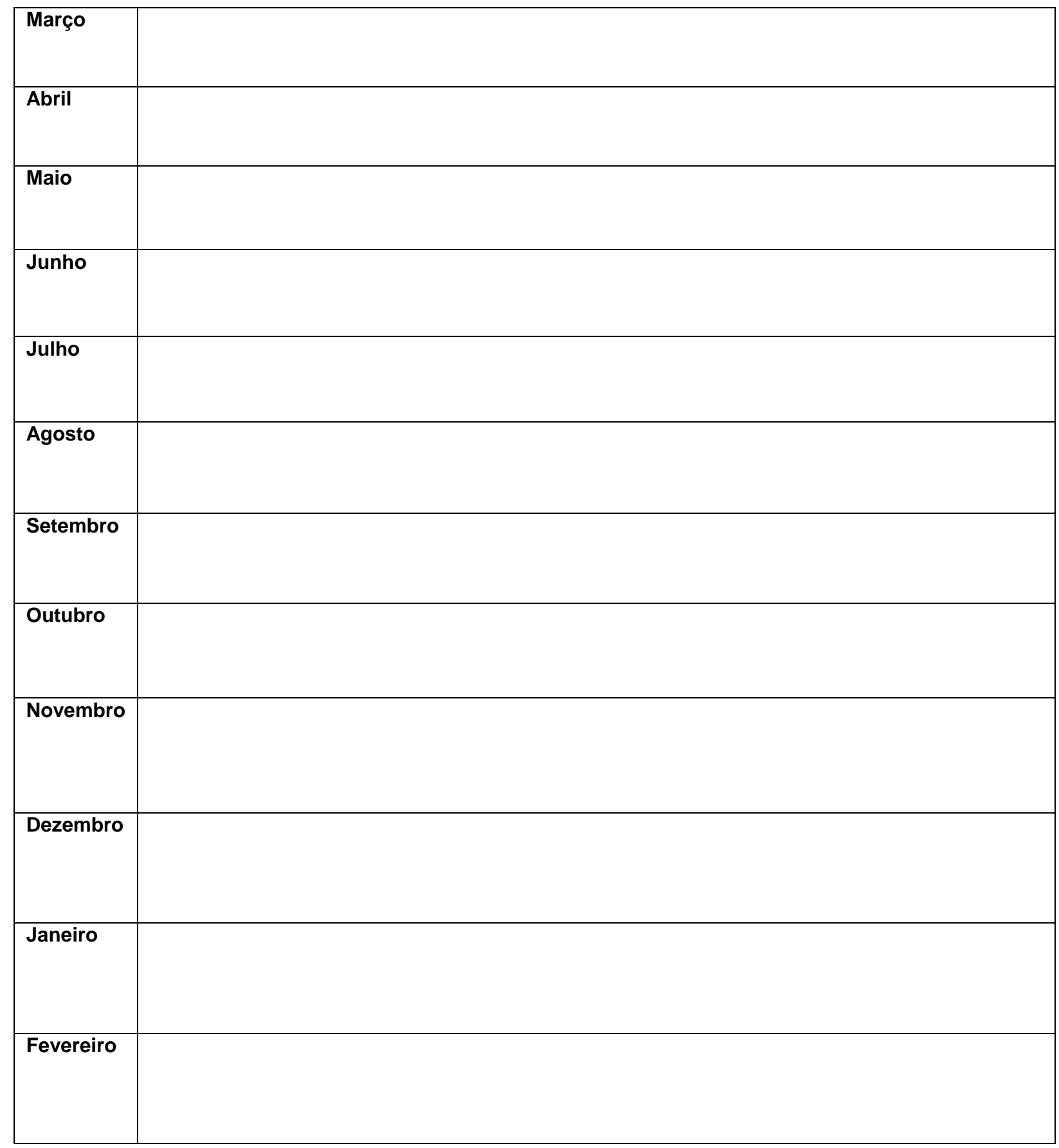


TAREFAS SEMANAIS DESEMPENHADAS POR GRUPOS DE RESIDENTES

(Semana Padrão - R2)

Esquematize a semana padrão das atividades dos residentes de cada ano.

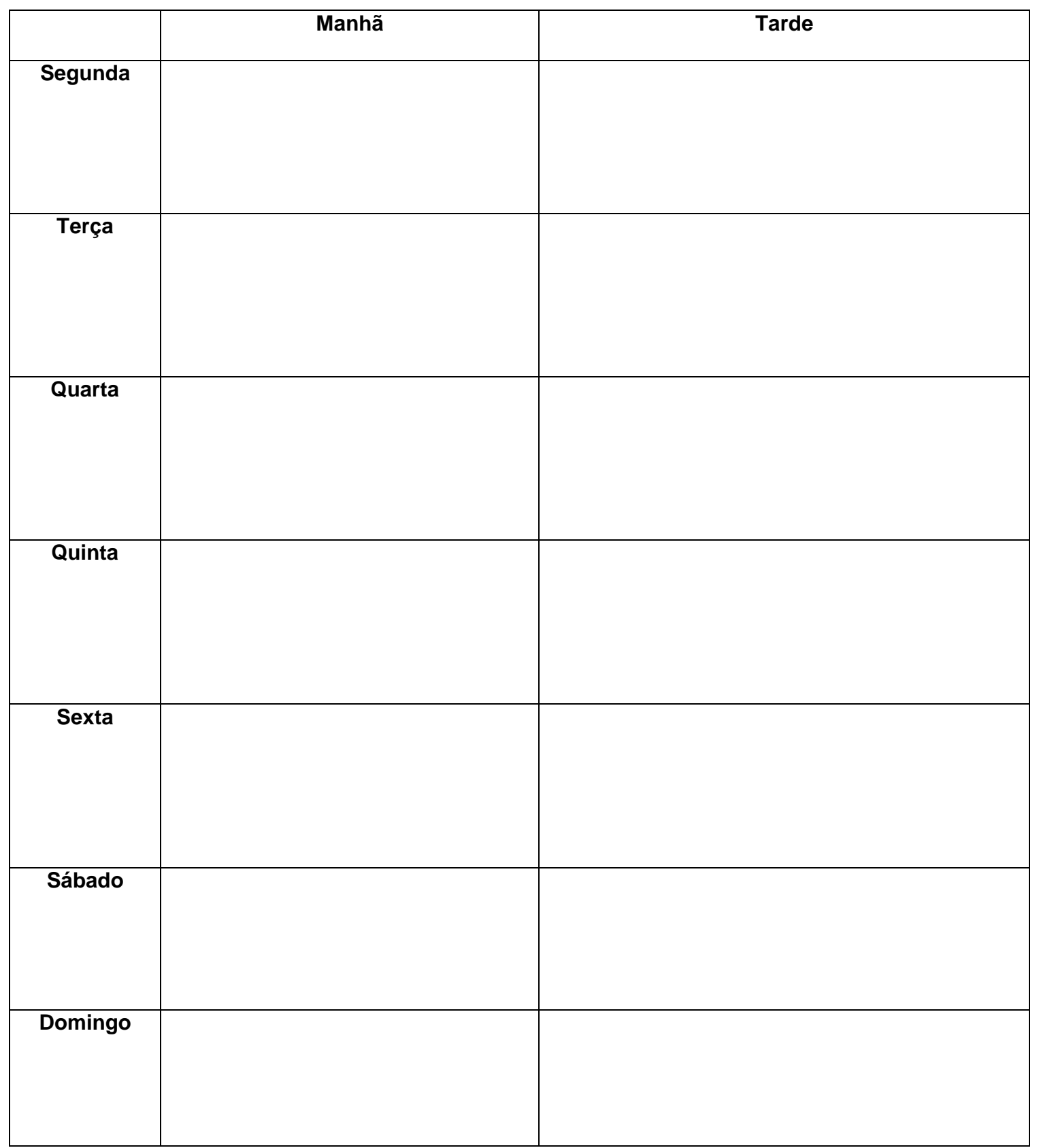




\section{Rodízio do PRM (R2)}

Apresente a escala de estágios para cada ano de residência ao longo do ano, incluindo os períodos de férias de cada residente.

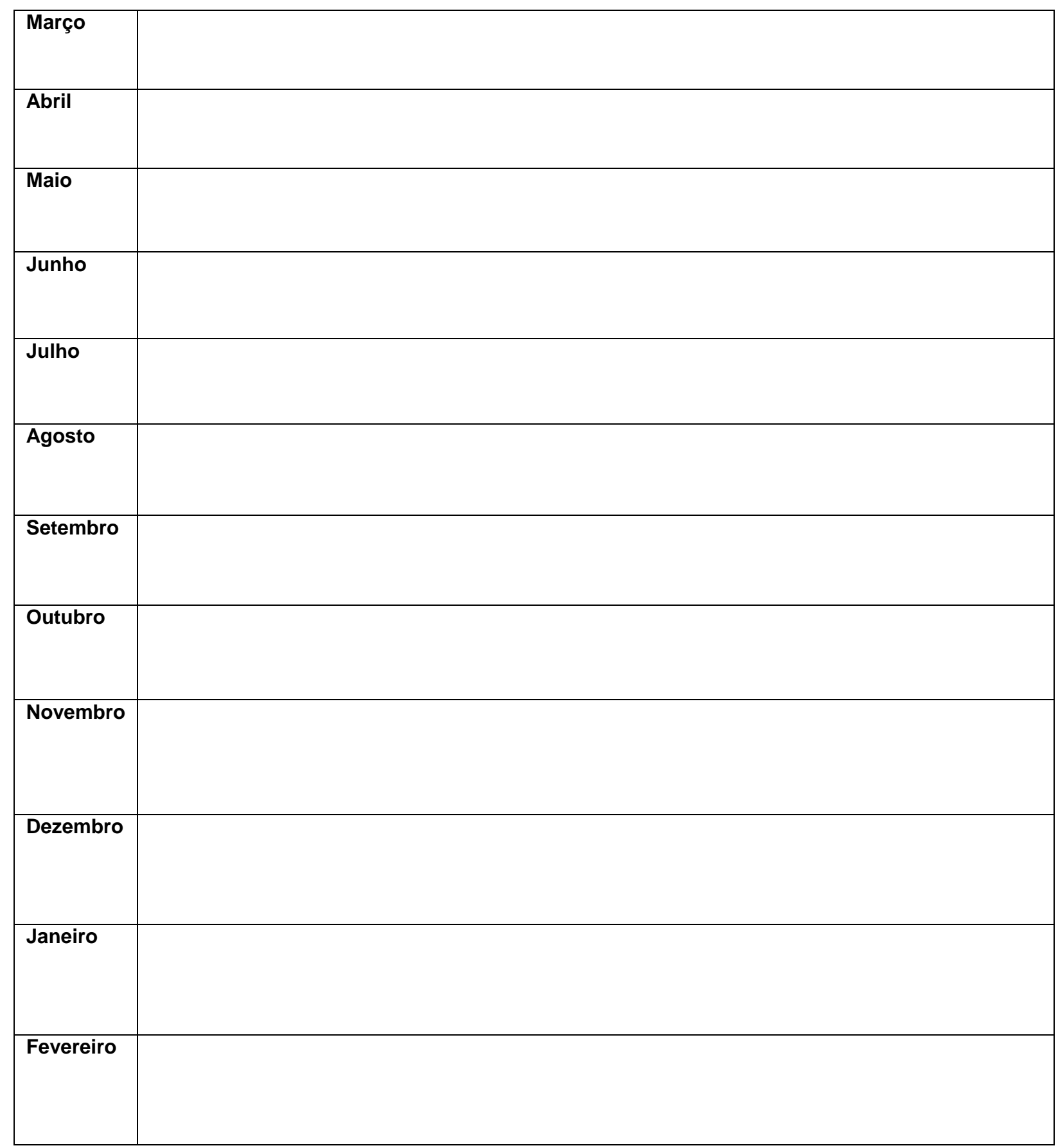


TAREFAS SEMANAIS DESEMPENHADAS POR GRUPOS DE RESIDENTES

(Semana Padrão - R3)

Esquematize a semana padrão das atividades dos residentes de cada ano.

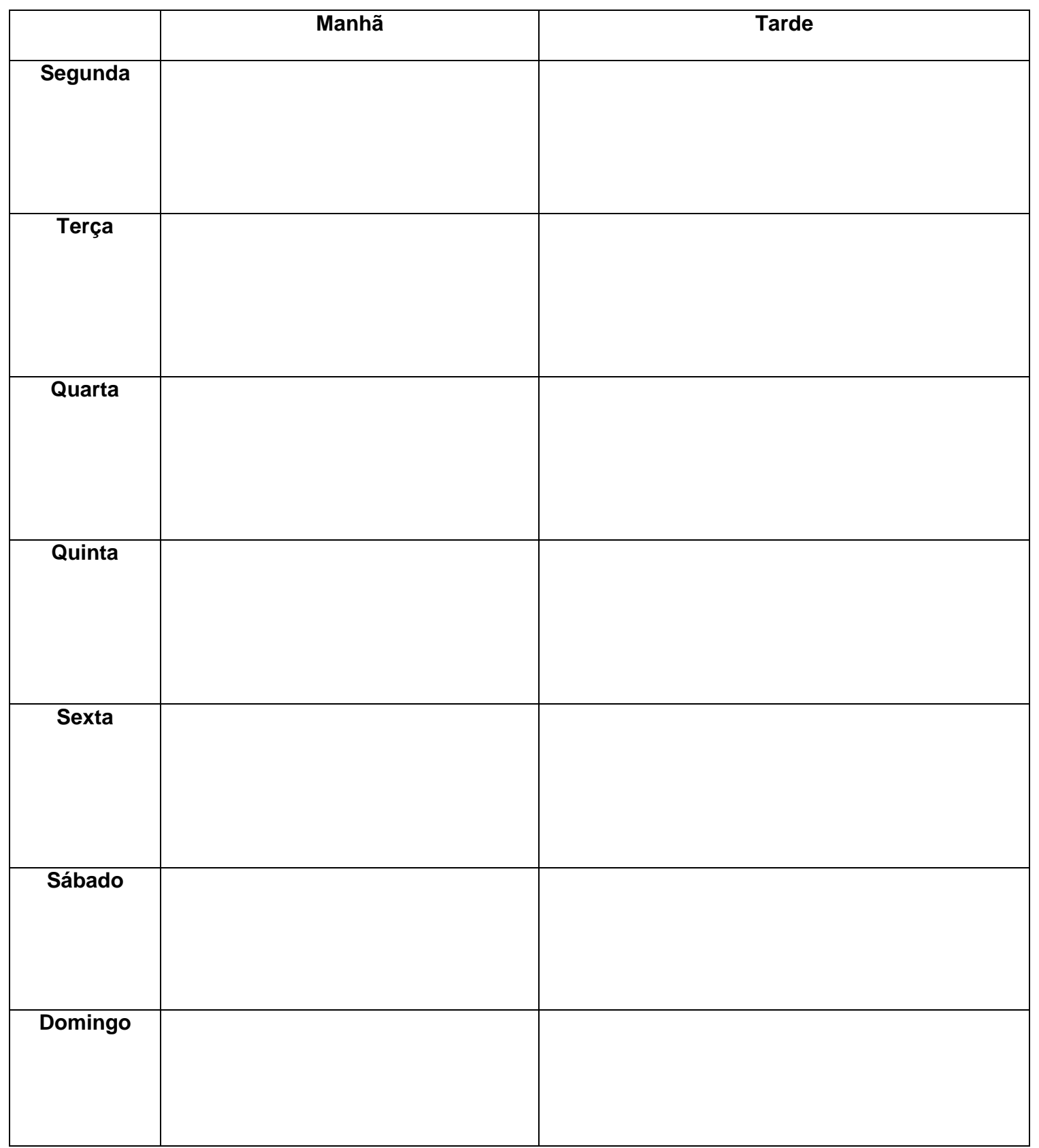




\section{Rodízio do PRM (R3)}

Apresente a escala de estágios para cada ano de residência ao longo do ano, incluindo os períodos de férias de cada residente.

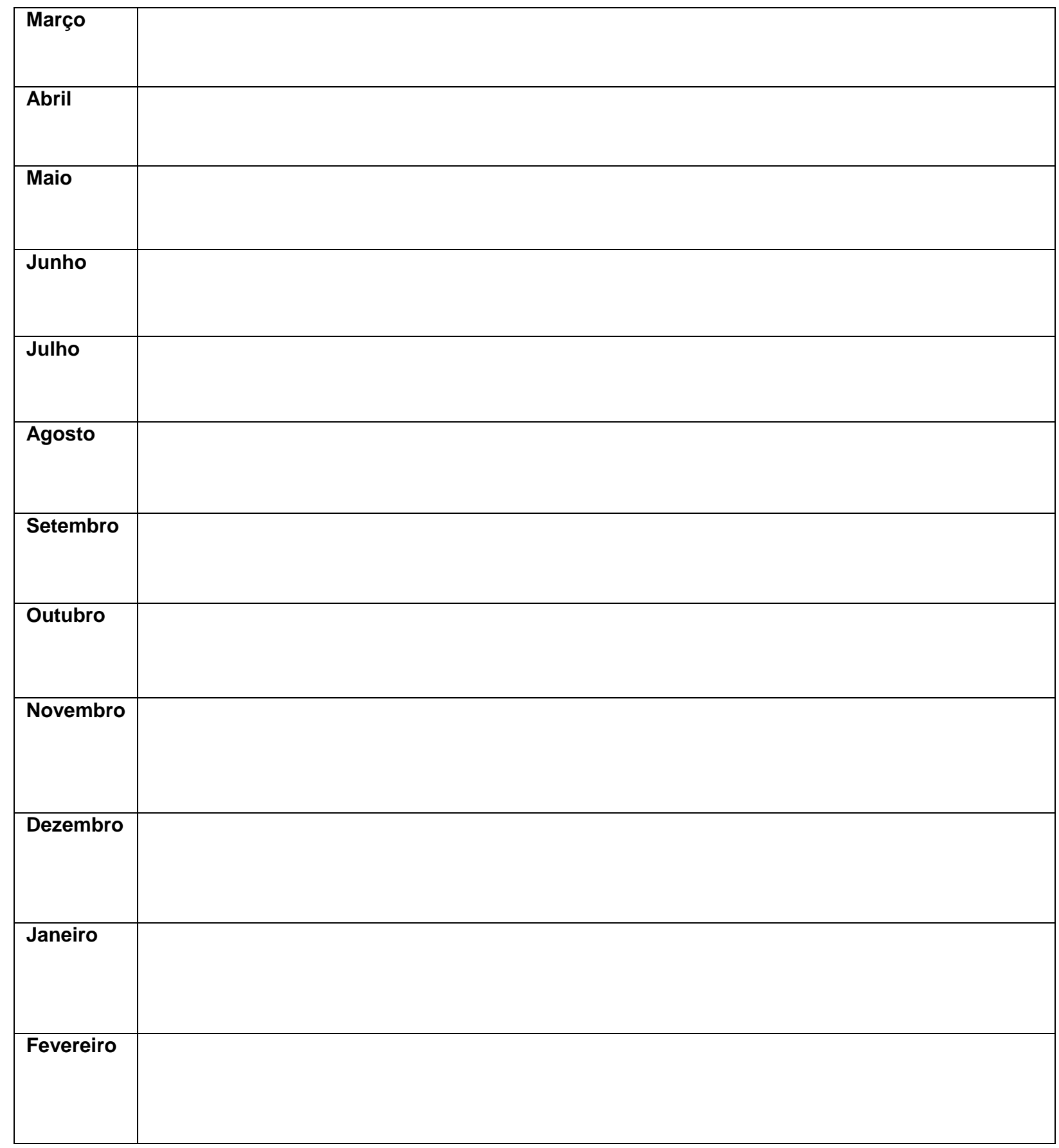


TAREFAS SEMANAIS DESEMPENHADAS POR GRUPOS DE RESIDENTES

(Semana Padrão - R4)

Esquematize a semana padrão das atividades dos residentes de cada ano.

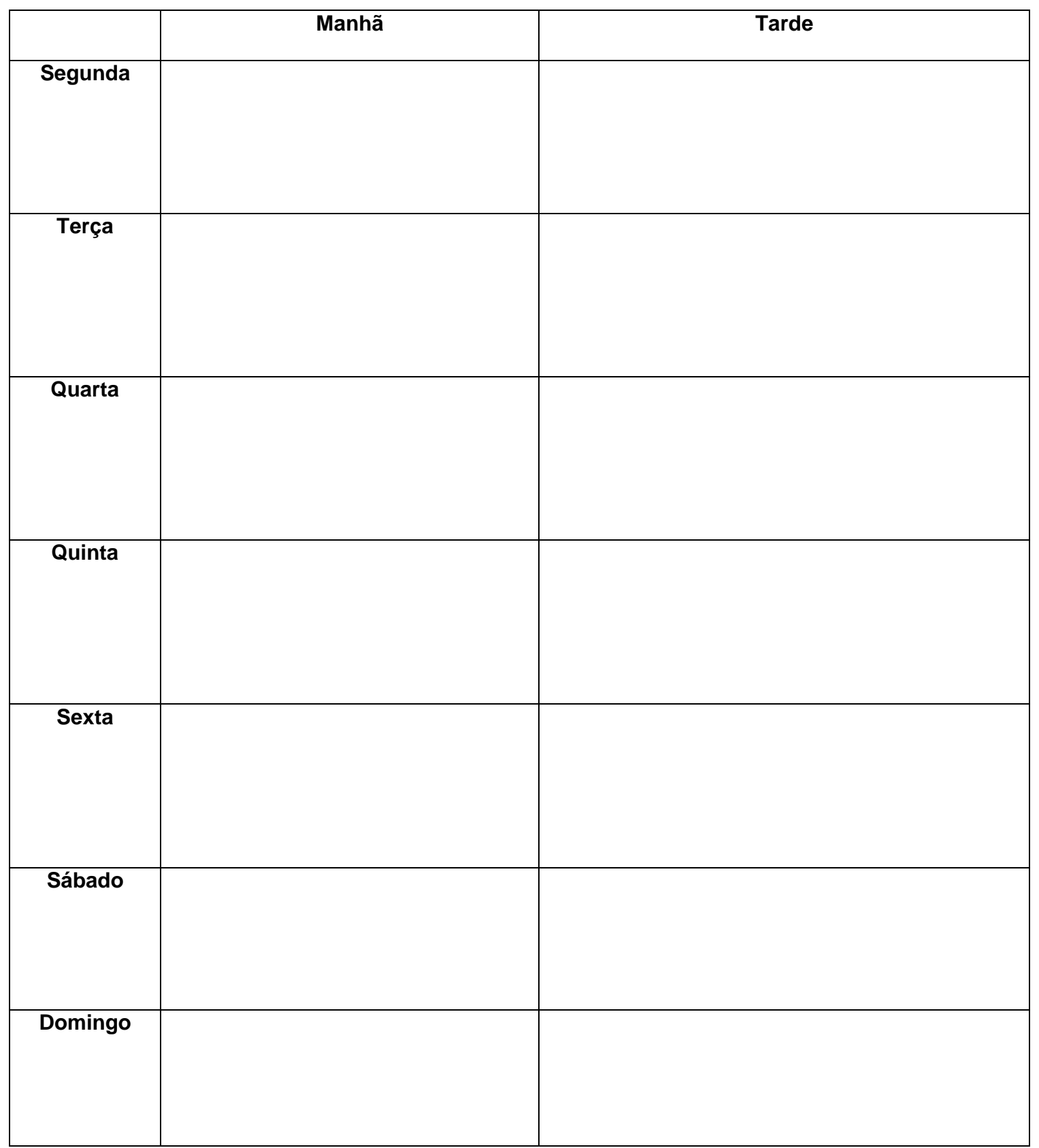




\section{Rodízio do PRM (R4)}

Apresente a escala de estágios para cada ano de residência ao longo do ano, incluindo os períodos de férias de cada residente.

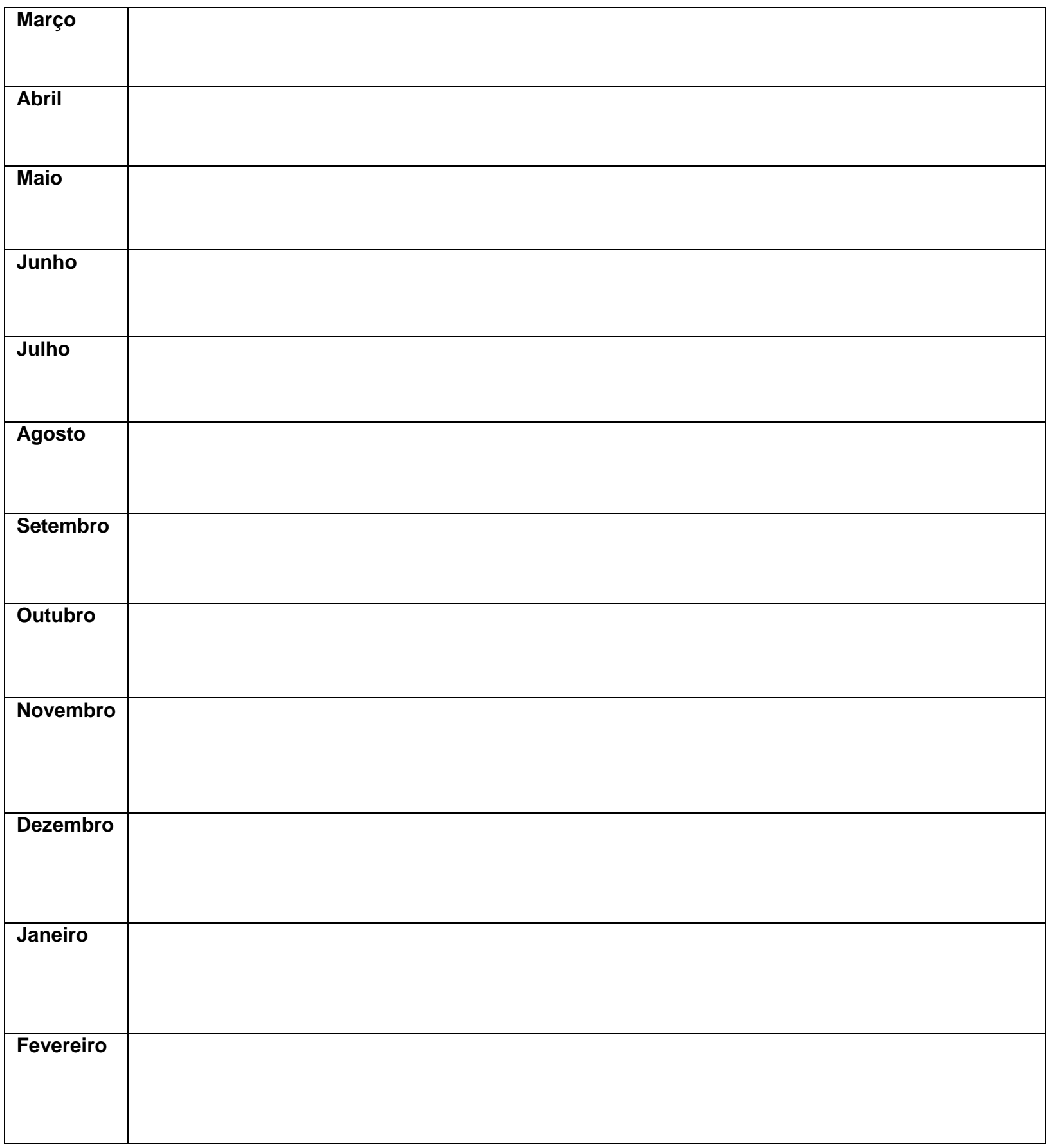


TAREFAS SEMANAIS DESEMPENHADAS POR GRUPOS DE RESIDENTES

(Semana Padrão - R5)

Esquematize a semana padrão das atividades dos residentes de cada ano.

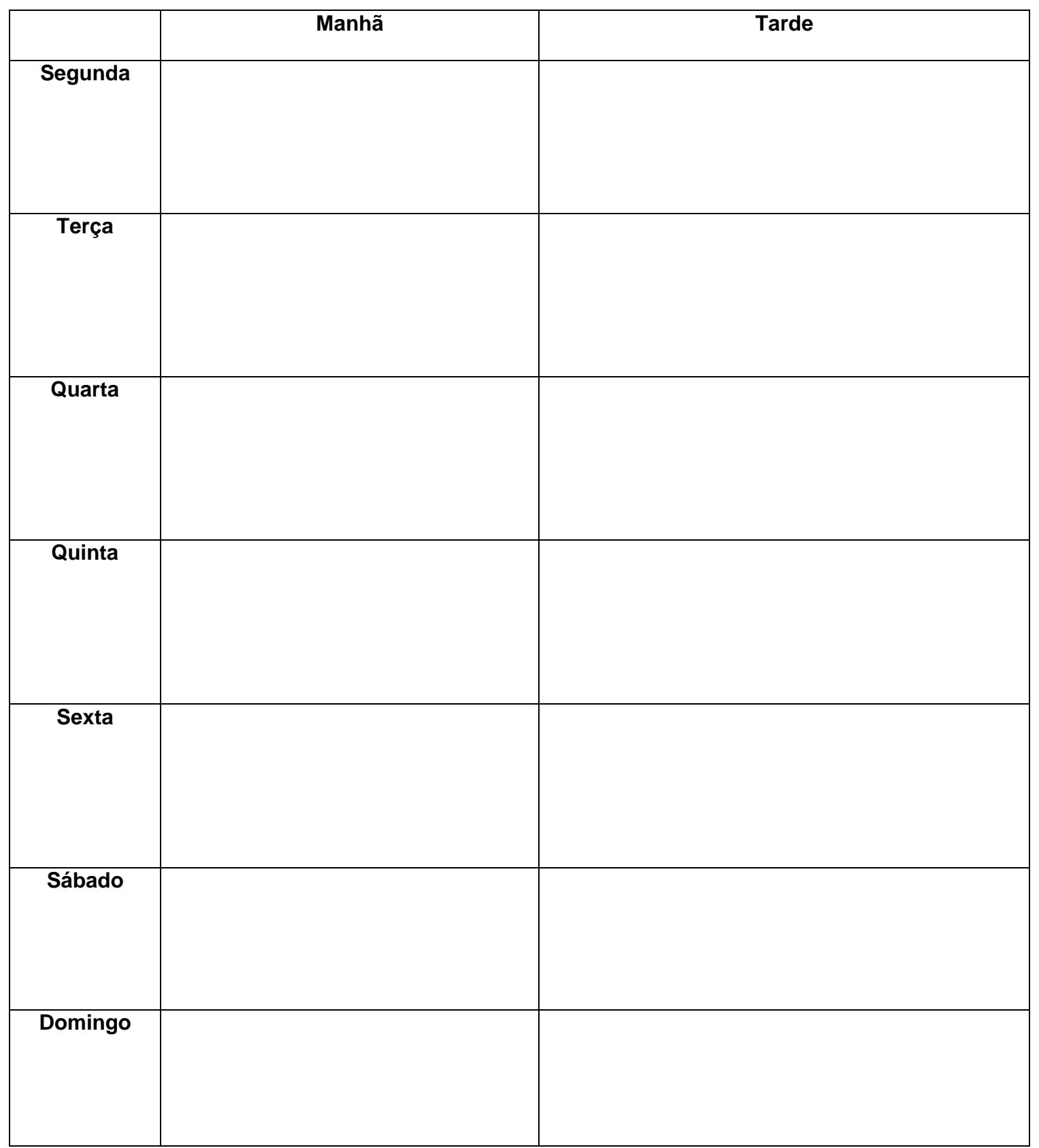




\section{Rodízio do PRM (R5)}

Apresente a escala de estágios para cada ano de residência ao longo do ano, incluindo os períodos de férias de cada residente.

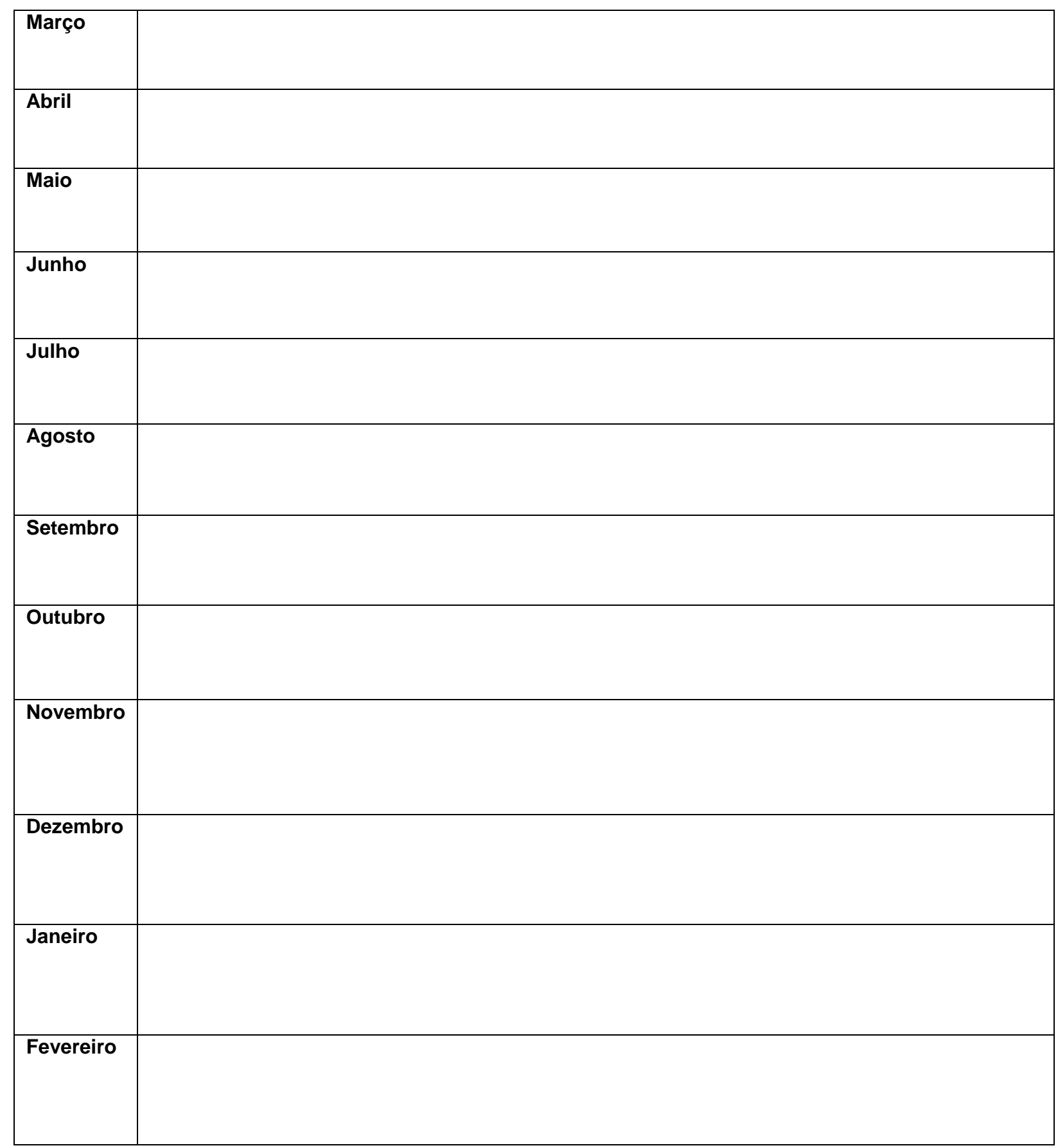


Anexo 9

ORIGINAL ARTICLE

Impact on evaluation of collaborative work teams from the

Brazilian Neurosurgery Society and Medical Residency

National Committee. Retrospective and prospective study

Impacto da avaliação no trabalho conjunto das equipes da Comissão Nacional de Residência Médica e Sociedade Brasileira de Neurocirurgia. Estudo retrospectivo e prospectivo

Renato Antunes Dos Santos', Linda Snell", Maria do Patrocinio Tenorio Nunes ${ }^{\text {III }}$ 'MD. PhD student, Universidade de São Paulo (USP), São Paulo, Brazil. Psychiatrist from Universitary Hospital of Brasília, Universidade de Brasília (UnB), Brasília, Brazil.

"MD. Professor, Centre for Medical Education, Universidade McGill, Montreal, Canadia.

IIIMD, PhD. Full and Association Professor, Discipline of General Practice na Propaedeutics, Departament of Medical Clinic, Universidade de São Paulo (USP), São Paulo, Brazil.

Faculdade de Medicina da Universidade de São Paulo (FMUSP), São Paulo, Brazil

\section{KEY WORDS:}

Education, medical.

Internship and residency.

Educational measurement.

Program evaluation.

Neurosurgery. 


\section{ABSTRACT}

CONTEXT AND OBJECTIVE: There are different ways to training and graduate a specialist physicians in Brazil. The approximation of institutions that perform these training programs and assess these physicians and health institutions can improve the qualification. This article analyzes the impact of the approach and joint working teams of the National Committee of Medical Residency (Comissão Nacional de Residência Médica, CNRM) and Brazilian Society of Neurosurgery (Sociedade Brasileira de Neurocirurgia, SBN) the evaluation of these programs.

DESIGN AND SETTING: A retrospective and prospective study based on the pilot project developed between CNRM and SBN for assessment of the programs across the country, conducted in a public university.

METHODS: Review of most important literature databases, documents from government, legislation and official agencies, training spots visits and reports analyze produced by the assessment team on the residency programs.

RESULTS: Only $26 \%$ was directly approved. Joint assessment found problems related to teaching and service in about $35 \%$ of the programs. "Collateral" result showed that the distribution of programs in the country have strong relationship with the Human Development Index, HDI, regions and shape of the distribution very similar to the distribution of specialists in the country.

CONCLUSION: The approach of SBN with CNRM had positive response in the assessment on neurosurgery medical residency across the country. The low rates of direct approval induced modifications and improvements on the quality of education and care (services). The approximation of other medical specialties in the assessment with CNRM can positively change the scenario of medical education in the country.

\section{PALAVRAS-CHAVE:}

Educação médica.

Internato e residência.

Avaliação educacional.

Avaliação de programas e projetos de saúde.

Neurocirurgia.

\section{RESUMO}

CONTEXTO E OBJETIVO: A formação do médico especialista no Brasil pode ocorrer por diferentes vias. A aproximação das instituições que realizam estas formações e avaliam os médicos e as instituições formadoras, pode trazer benefícios na 
qualificação. Este artigo analisa o impacto desta aproximação e o trabalho conjunto das equipes da Comissão Nacional de Residência Médica (CNRM), e Sociedade Brasileira de Neurocirurgia (SBN) na avaliação destes programas.

TIPO DE ESTUDO E LOCAL: Estudo retrospectivo e prospectivo sobre projeto piloto elaborado entre CNRM e SBN na avaliação conjunta dos programas pelo Brasil, conduzido em uma universidade pública.

MÉTODOS: Revisão de literatura nas principais bases de dados, documentos e legislações produzidas por órgãos oficiais governamentais, visitas nos locais de formação e analise dos relatórios e pareces produzidos sobre os programas de residência médica.

RESULTADOS: Apenas $26 \%$ foram aprovados diretamente. As avaliações conjuntas encontraram problemas relacionados ao ensino e ao funcionamento do serviço em cerca de $35 \%$ dos programas. A distribuição dos programas no país tem forte relação com o Índice de desenvolvimento Humano, IDH, das regiões e forma distribuição muito semelhante à distribuição dos especialistas no país.

CONCLUSÃO: A aproximação da SBN com a CNRM teve resposta positiva na avaliação das residências médicas em neurocirurgia no país. Os índices baixos de aprovação direta forçaram a realização de modificações e melhorias na qualidade de ensino e assistência (serviço). A aproximação das demais especialidades médicas na avaliação em relação à CNRM pode alterar positivamente o cenário da formação médica no país.

\section{INTRODUCTION}

Actually the world is facing a lack and poor distribution of health professionals. ${ }^{1}$ There are numerous institutes and units studying and planning the workforce supply and strategies such as Joint Action Health Workforce Planning and Forecasting Europe Union, ${ }^{2}$ Australian Medical Advisory Committee, ${ }^{3}$ Advisory Committee on Medical Manpower Planning (Netherlands), Belgian Unit Health Workforce Planning, International Medical Workforce Collaborative and others. Distribution, types of specialists, quantity and quality of professionals is a started task around the world on the planning of the future health workforce. ${ }^{4-6}$

The formative process of health professional is very long and complex. For the medical doctors, since the beginning of the medical school until enter the labor market 
can last more than twelve years. ${ }^{7}$ Understand the specialization processes and distribution of medical specialists seems to be essential to a good workforce planning.

Aside all the general complexity, in Brazil there are different mechanisms of a medical expert's formation. There is also singular regulation of the accreditation process of the medical specialization: 8,9

1) Medical Residency. Considered the gold standard method with national unified law, rules and criteria. Medical residency is administered by the National Medical Residency Commission (Comissão Nacional de Residência Médica, CNRM), located in the Ministry of Education and composed by a representative of the Ministry of Education, Ministry of Health, Brazilian Medical Association, Medical Union, Federal Council of Medicine, National Residents Association, Municipal Health Secretaries and State Health Secretaries, constituting the CNRM plenary.

2) Medical Specialization Courses. Accredited services by specialty medical societies are used to train a new specialist. The model has variable criteria that are approved by the Scientific Council of the Brazilian Medical Association. This training process has a historical and significant role in Brazil. It usually has the same training length and part of the content of medical residency programs. The medical specialty societies apply an evaluation process at the end of the training period, although with variable criteria.

After receiving the formal degree of doctor, Brazilian law allows to the physicians practice any medical specialty, long as he or she feels able to do so. After a validated and well documented period (years) of practice in renowned services, under the supervision of experts, the physician can apply to tests in the Brazilian Medical Association to receive a certificate in a specialty. The same certificate is validated at the end of well medical residency training.

Regardless of the way, the physician certificates must be registered in the Federal Council of Medicine that according to a specific law, ${ }^{10}$ regulates and invigilate the medical practice. ${ }^{11}$

Even nowadays health and educational authorities still trying to identify the real number of specialists in the country and the actual needs required in each of the 53 medical specialties recognized in the country, ${ }^{12}$ according to epidemiological data and international parameters. It is also necessary to approximate the training specialists process, recognizing the historical Brazilian medical practice and the specialists training process. The $\mathrm{CNRM}^{13,14}$ initiated a work with the medical specialties associations. The intention was to unify the training process, avoiding the possibility of 
different content (knowledge, skills and attitudes) to the same specialist qualification. Among the 53 recognized Brazilian medical specialties, neurosurgery presented itself for a pilot project.

Neurosurgery was chosen because of the availability of the Brazilian Neurosurgery Society (Sociedade Brasileira de Neurocirurgia, SBN) and facilities access the Assessment Committee of Neurosurgery. The main reason was the good organization of the SBN from all over the evaluation process (institutions, residency program, residents). It was taken into account that it is virtually impossible to practice neurosurgery without a formal training and official recognition.

The CNRM and SBN started by working together, planning assessment tool, and visiting neurosurgery residency programs and neurosurgery services throughout the country.

\section{OBJECTIVE}

This study assesses the current situation of medical residency programs in neurosurgery, in view of the partners - the CNRM and the SBN. Also analyze the loco regional distribution of medical residencies in neurosurgery; the distribution of specialists in this area and current situation after the SBN-CNRM approach is presented.

\section{METHODS}

The work started reviewing the available scientific literature, searching regional database (Lilacs, SciELO, Bireme) and global database (PubMed, Web of science)about external medical residency assessment process (by governmental, association, colleges, etc.). Also articles and legislation on assessment, regulation and supervision available and published by government agencies such as the Ministries of Health and Education, as well as medical associations, Federal Medical Council and others were included.

Focusing in the quality of neurosurgical residency, a single assessment instrument was developed by the CNRM and SBN in relation to the educational process in service, under supervision: infrastructure and characteristics of the institutions, education program and care profile, qualification and dedication of staff, 
clinical demand (number and variety of cases in accordance with the competencies to be developed throughout the residency program) and development (apprenticeship) of medical residents.

The process of educational evaluation in situ occurred as follows:

1) The instrument was sent to the institutions to be evaluated according to criteria established jointly by CNRM and SBN.

2) No more than two weeks after the instrument was sent, institutions across the country were visited by at least a duo of appraisers (at least one person from CNRM and other from SBN), according to a predetermined schedule.

3) The evaluation team assessed the conditions of the wards; ambulatories; surgical center; radiological unit; hemodynamic; laboratory; emergency room; intensive care unit; all necessary tools, including microscopes; number and types of surgery within the last six months; library and access to electronic library; compliance with theoretical program and legislation.

4) There were evaluation team meeting separately with the direction of each institution, with the coordination and supervision of medical residency programs and medical residents for the purpose of knowing the strengths and weaknesses of the program.

5) A final report was produced by the duo of evaluation team.

6) The reports were analyzed by a CNRM technical council, which deliberated on corrective measures to be proposed to residency programs.

7) The CNRM plenary deliberated on the measures suggested by the technical council.

8) The institutions were notified of the measures to be implemented over a period of time set by the plenary CNRM.

9) The compliance of the changes was verified at the end of the deadline proposed by the CNRM plenary.

The researchers evaluated all assessments carried out; all opinions issued by the Technical Council of the CNRM, and try to check their impact on the recent history of each program, the consequences for the health service assistance and to the medical education decisions.

Meetings between representatives from SBN and CNRM were held to establish goals, work process, unification of criteria and of evaluation instruments; train the evaluation team, from April 2010 to February 2011. 
The assessment visits occurred from April 2011 to January 2014. During this period, until April 2014, the CNRM technical council analyzed the reports, the CNRM plenary deliberated on the suggested measures, the institutions were notified of the actions to be implemented in the prescribed period. Finally, changes were checked at the end of proposed period.

\section{RESULTS}

Brazil has 26 states and 1 federal district. There were found seven states with no neurosurgery programs: Acre, Amapá, Rondonia and Roraima (north region) Maranhão, Paraíba, Piauí (northeast region). The seven states without neurosurgery program correspond to regions of low index of human development. ${ }^{15}$

Neurosurgeons are distributed through the Brazilian regions: 94 in the North (N), 245 in the Northeast (NE), 171 in the Midwest (CW), 1197 in the Southeast (SE) and 362 in the South (S), as demonstrated in previous study. ${ }^{16,17}$

Correcting by population the lack can be better understood. The number of the neurosurgeons by 100.00 inhabitants, according to the Brazilian region, (Instituto Brasileiro de Geografia e Estatística, IBGE, 2010). ${ }^{18}$ Observing Brazil by regions 0.59 in of the neurosurgeons are at the North, 0.47 at North east, 1.49 at South east, 1.40 at South and 1.22 at Midwest. The total average of neurosurgeons in Brazil are 1,09 by 100.000 inhabitants.

Across the country there are 154 vacancies for admission to medical residency programs in neurosurgery, distributed in 105 programs. Observing Brazil by regions again 0.03 Medical Residency Programs on Neurosurgery in North, 0.03 at North east, 0.12 at South east, 0.10 at South and 0.06 at Midwest. The total average of medial residency programs on neurosurgery in Brazil are 0.08 by 100.000 inhabitants. $^{18}$

Seventeen $(n=17)$ new neurosurgery programs were created during the studied period and represent $14,6 \%$ of the total (three are in the South, four in the Southeast, three in the Northeast, four in the Centre West and three in the North).

Figure 1 represents the evolution of Neurosurgery Medical Residency Programs (NMRP) installed over the last 30 years, in the five Brazilian regions, since 1982. The colors show that in the 80 s and 90s there was a heavy concentration of NMRP in the Southeast and South regions. In that period the onset of new programs in 
other regions was exception. From 1999 to 2003, new NMRP emerged in other regions. Over the past three years, the neurosurgery positions distribution, by region, began to change. Particularly, in 2012 there was a greater diversity in the NMRP installation with good response from the Northeast and Midwest regions.

The National Commission of Medical Residency acknowledged the existence of 127 programs in neurosurgery along the history. At the time of the present evaluation process there were 105 programs. Twenty-three neurosurgery programs were canceled before or during the process of data analysis.

After assessment twenty - eight (28) NMRP were able to be approved without any restrictions, corresponding to $26,7 \%$ of the total. Twenty - two of those programs are located in the southeast, five in the south and one in the north.

The Table 1 shows the situation of the 105 Neurosurgery programs after CNRM/SBN evaluation. Thirty-seven programs were placed under supervision for correction of irregularities (Table 1): 8 in south, 20 in southeast, 5 in Northeast, and 2 in Midwest and North.

Four neurosurgery programs had to be immediately closed due to lack of appropriate conditions for teaching and medical assistance: three in southeast and one in northeast.

One program was under supervision at technical board, but made quickly corrections, being approved before final CNRM plenary. Four (4) programs were continuous outdated until the end of this paper.

Fourteen were waiting for assessment visit and doesn't have impact or results because they were visited just a few weeks before the project began and could not be evaluate before five years.

The most common problems found in the final reports of the evaluation, technical papers and CNRM plenary chamber are in the Tables $\mathbf{2}$ and $\mathbf{3}$. Observing the results, the problems were divided into two blocks:

- Service faults (Structure, Processes and Outcomes), sub divided on classical triad on health services assessment elaborated by Donabedian ${ }^{19,20}$ here with 19 different kinds of important problems found.

- Learning faults, concerning information and assessment used by Education Ministry to analysis medical residency, with 12 different important features found. 
The authors' defined structure as the material needs (infrastructure, equipment, supplies) to perform the residency program. Processes concerning the relationship between human resource management, learning and healthcare. The results represent the ability and efficiency in surgery and clinical care.

The main problems founded in teaching and learning focused on deficiencies in internships, but there was also shortage of supervision or theoretical program. Table 3 summarizes the teaching and learning problems identified during the CNRM/SBN evaluation.

\section{DISCUSSION}

The evaluation process also detected a huge inequity among aspects as economy, culture, health, education performance and access, Human Development Indices (HDI), and others. ${ }^{15}$ Is known that economy and HDI are linked with the human capital, the development and enabling. ${ }^{21}$ There are a relationship among HDI, number of neurosurgery programs and neurosurgeons. There are a concentration of neurosurgeons and neurosurgery residency vacancies in the regions with best HDI. It seems to be a "snow ball" growing in inequity. Worse HDI relates to services with poor structure. This scenario is not attractive, and sometimes impossible to practice neurosurgery specialization. Lack of specialists and structure turns residency positions impossible, or even desirable. Without medical residency training will be less specialists and structure..$^{22,23}$

There is a federal government policy to induce residency programs since 2009, including neurosurgery. This policy called "ProResidencia" is an important act of Health and Education Ministries. ${ }^{24}$ ProResidencia starts financial input from the Ministry of Health on residency. It is also responsible for putting into practice some discussion about planning and providing doctors (generalists and specialists), and requirements of the population. The choice of certain medical specialties to be induced resulted from the difficulty in hiring specific specialists in the public and private health sectors. ${ }^{25}$

Other strategies are on course like as the supervision and help between an institution that want to improve or initiate new programs and experienced universities. ${ }^{26}$ It is a shy government initiative, with results to be studied. Called "matriciamento", Matrix support, ${ }^{27}$ this strategy were designed to reformulate the teaching and learning on health process. 


\section{CONCLUSION}

CNRM and SBN unified evaluation criteria that showed a very complex scenario, with a large number of needs and failures. It seems clear that the isolated and parallel evaluation processes used in Brazil nowadays has an importance, nevertheless unification makes difference to improve the quality for the future medical practice, teaching and service. Only about a quarter (26\%) were directly approved when the evaluation project started.

The evaluation team of the CNRM are well prepared for didactic and legal aspects of the Medical Residence in general, adding such knowledge in joint assessments.

The evaluation team of the SBN added value to develop the data of the residency programs and technical issues specific of the specialty.

\section{REFERENCES}

1. Sheldon GF, Ricketts TC, Charles A, et al. The global health workforce shortage: role of surgeons and other providers. Adv Surg. 2008;42:63-85.

2. Health program for the European Union, work packages, joint action health workforce planning and forecasting. Available from: http://www.euhwforce.eu/web_documents/JAHWF-PA1/PA1_MDS_a_WP5.pdf. Accessed in 2014 (Mar 20).

3. Australian institute of health and welfare 2013. Medical workforce 2011. National health workforce series no. 3. Cat. no. HWL 49. Canberra: AlHW. Available from: http://www.aihw.gov.au/publication-detail/?id=60129542627. Accessed in 2014 (Jan 22)

4. López-Valcárcel BG, Pérez PB. Dificultades, trampas y tópicos en la planificación del personal medico; EDITORIAL; Gac Sanit. 2008;22(5):393-5

5. López-Valcárcel BG, Pérez PB. Oferta y necesidad de médicos especialistas en España 2006-2030; Grupo de Investigación en Economía de la Salud Universidad de Las Palmas de GC, Mar 2007. Available from: http://www.msssi.gob.es/novedades/docs/necesidadesEspeciales06_30.pdf. Accessed in 2014 (May 15)

6. O'Brien-Pallas L, Birch S, Baumann A, et al. Workshop on global health workforce strategy annecy, France, 9-12 December 2000, INTEGRATING WORKFORCE PLANNING, HUMAN RESOURCES, AND SERVICE PLANNING; World Health Organization, Department of organization of health 
services delivery, Geneva, Switzerland; 2001. Available from: http://www.who.int/hrh/documents/en/Integrating_workforce.pdf. Accessed in 2013 (Dec 10)

7. Crisp N, Chen L. Global Supply of Health Professionals. N Engl J Med. 2014;370:950-7.

8. RESOLUÇÃO CFM № 1.634, DE 11 DE ABRIL DE 2002. Diário Oficial da União; Poder Executivo, Brasília, DF, n. 81, 29 abr.2002. Alterada pela Resolução CFM no 1666/03 (Anexo II) Seção 1, p. 265-66 Alterada pela Resolução CFM no 1.659/03.

9. Sampaio SAP, Mazza T. A Formação de médicos especialistas e a demanda por assistência hospitalar no sistema único de saúde no Estado de São Paulo. São Paulo em Perspectiva. 2008;22(2):104-19.

10. Conselho Federal de Medicina: O médico devidamente inscrito no Conselho Regional de Medicina está apto ao exercício legal da medicina, em qualquer de seus ramos; PROCESSO-CONSULTA CFM no 10.239/11 - PARECER CFM no 18/12. Available from: http://www.portalmedico.org.br/pareceres/CFM/2012/18_2012.pdf. Accessed in 2014 (May 15)

11. Brasil, LEI No 3.268 , DE 30 DE SETEMBRO DE 1957. Dispõe sobre os Conselhos de Medicina, e dá outras providências. Available from: http://portal.cfm.org.br/index.php?option=com_content\&view=article\&id=2 1736:lei-32681957-dispoe-sobre-os-conselho-de-medicina-e-da-outrasprovidencias\&catid=66:leis\&ltemid=34. Accessed in 2014 (Jan 22)

12. RESOLUÇÃO CFM № 2.005/2012 (Publicada no D.O.U. 21 dez. 2012. Seção I, p.937 a 940) (Nova redação do Anexo II aprovada pela Resolução CFM n. 2068/2013) Dispõe sobre a nova redação dos Anexos II e III da Resolução CFM no 1.973/2011, que celebra o convênio de reconhecimento de especialidades médicas firmado entre o Conselho Federal de Medicina (CFM), a Associação Médica Brasileira (AMB) e a Comissão Nacional de Residência Médica (CNRM). Available from: http://www.portalmedico.org.br/resolucoes/CFM/2012/2005_2012.pdf. Accessed in 2014 (Jan 20).

13. Brasil; DECRETO № 80.281 DE 5 DE SETEMBRO DE 1977 Regulamenta a Residência Médica, cria a Comissão Nacional de Residência Médica e dá outras providências. BRASIL; Decreto no 7.562, de 15 DE setembro de 2011 Dispõe sobre a Comissão Nacional de Residência Médica - CNRM e o exercício das funções de regulação, supervisão e avaliação de instituições que ofertam residência médica e de programas de residência médica.

14. De Toni Jr CN. Análise do IDH do Brasil, de suas regiões e de outros países: um enfoque comparativo, [dissertação] São Carlos: UFSCar, 2010. 
15. Scheffer M, Biancarelli A, Cassenote A. Demografia médica no Brasil. Conselho Regional de Medicina do Estado de São Paulo: Conselho Federal de Medicina, São Paulo, 2011.

16. Scheffer M, Biancarelli A, Cassenote A. Demografia Médica no Brasil. (vol.2). Conselho Regional de Medicina do Estado de São Paulo: Conselho Federal de Medicina, São Paulo, 2013.

17. IBGE/DPE/Departamento de População e Indicadores Sociais. Divisão de Estudos e Análises da Dinâmica Demográfica. Projeto UNFPA/BRASIL (BRA/98/P08) - Sistema Integrado de Projeções e Estimativas Populacionais e Indicadores Sócio-demográficos

18. Donabedian A. The quality of care how can it be assessed? JAMA. 1988;260(12):1743-48.

19. Donabedian A. Criteria, norms and standards of quality: What do they mean? AJPH. 1981;71(4):409-12.

20. Galeano EAV, Mata HTC. Diferenças regionais no crescimento econômico: uma análise pela teoria do crescimento endógeno. Revista de economia do nordeste. 2009;40(4):669-83.

21. Cooper RA. It's time to address the problem of physician shortages: graduate medical education is the key. Ann Surg. 2007;246:527-34

22. Nunes MPT, Michel JLM, Brenelli SL,ET.al.. Distribuição de vagas de residência médica e de médicos nas regiões do país, Cadernos ABEM. 2011;7:28-34.

23. Petta HL. Training of medical specialists in SUS: Description and analysis of the implementation of the national programme to support the training of specialists in strategic areas (Pro-Residencia); RBEM. 2013;37(1):72-79.

24. Girard S. Núcleo de Estudos em Saúde Coletiva. Universidade Federal de Minas Gerais. Avaliação nacional da demanda de médicos especialistas percebida pelos gestores de saúde. Belo Horizonte, Mar 2009. Available from: https://www.nescon.medicina.ufmg.br/biblioteca/imagem/2466.pdf. Accessed in 2013 (Feb 14)

25. Granja GF, Zoboli ELCP, Francolli LA. O discurso dos gestores sobre a equidade:um desafio para o SUS. Ciênc. saúde coletiva [online]. 2013;18(12):3759-64.

26. Campos GWS, Domitti AC. Apoio matricial e equipe de referência: uma metodologia para gestão do trabalho interdisciplinar em saúde; Cad. Saúde Pública, Rio de Janeiro. 2007;23(2):399-407. 
Sources of funding: Coordenação de Aperfeiçoamento de Pessoal de Nível Superior (CAPES) Sholarship process number: 6103-14-6

Conflict of interest: None

Date of first submission: September 8, 2014

Last received: November 18, 2014

Table 1. Situation of the 105 Neurosurgery programs after National Committee of Medical Residency (Comissão Nacional de Residência Médica, CNRM)/Brazilian Society of Neurosurgery (Sociedade Brasileira de Neurocirurgia, SBN) evaluation

\begin{tabular}{lc}
\hline Classification impact & Number of programs \\
\hline Approved & 28 \\
\hline Changes before final & 1 \\
\hline Closed & 4 \\
\hline Corrections and supervision & 37 \\
\hline New program & 17 \\
\hline Outdated & 4 \\
\hline Waiting visit & 14 \\
\hline Total & 105 \\
\hline
\end{tabular}


Table 2. The most common problems found in the final reports of the evaluation, technical papers and National Committee of Medical Residency (Comissão Nacional de Residência Médica, CNRM) plenary chamber on services

\begin{tabular}{|c|c|c|c|c|c|}
\hline \multirow[b]{2}{*}{$\begin{array}{l}\text { Healthcare/ } \\
\text { outcomes }\end{array}$} & \multicolumn{5}{|c|}{$\begin{array}{c}\text { Brazilian regions } \\
\text { (number of Neurosurgery programs) }\end{array}$} \\
\hline & $\begin{array}{l}\text { NE } \\
(9)\end{array}$ & $\begin{array}{l}\mathrm{CO} \\
(2)\end{array}$ & $\begin{array}{l}\text { SE } \\
(23)\end{array}$ & $\begin{array}{c}S \\
(9)\end{array}$ & $\begin{array}{l}\text { TOTAL } \\
\text { (43) }\end{array}$ \\
\hline Lack of information about surgeries & 1 & 0 & 6 & 0 & 7 \\
\hline Annual surgery procedures less than $300^{*}$ & 4 & 0 & 6 & 1 & 11 \\
\hline Insufficient Intensive care beds & 1 & 0 & 1 & 0 & 2 \\
\hline Low number of pediatric procedures & 2 & 0 & 5 & 5 & 12 \\
\hline Low number of vascular procedures & 1 & 0 & 4 & 2 & 7 \\
\hline Low number of functional procedures & 1 & 0 & 2 & 4 & 7 \\
\hline Low number of tumor procedures & 0 & 0 & 1 & 3 & 4 \\
\hline Low number of spine procedures & 1 & 0 & 0 & 1 & 2 \\
\hline $\begin{array}{l}\text { Low number of periphery nerves } \\
\text { procedures }\end{array}$ & 0 & 0 & 1 & 1 & 2 \\
\hline Lack or deficiency of ambulatory & 1 & 0 & 1 & 1 & 3 \\
\hline STRUCTURE & NE & $\mathrm{CO}$ & SE & $\mathbf{S}$ & TOTAL \\
\hline $\begin{array}{l}\text { lack or deficiency of materials to perform } \\
\text { surgery }\end{array}$ & 2 & 0 & 4 & 2 & 8 \\
\hline Lack or insufficient neuroimage resources & 0 & 0 & 2 & 1 & 3 \\
\hline Lack on basic library & 1 & 0 & 0 & 0 & 1 \\
\hline PROCESS & NE & $\mathrm{CO}$ & SE & $\mathbf{S}$ & TOTAL \\
\hline $\begin{array}{l}\text { Lack of human resources, materials, or } \\
\text { difficulty programming the operating room }\end{array}$ & 2 & 1 & 0 & 0 & 3 \\
\hline $\begin{array}{l}\text { Lack of a agenda for appointment with } \\
\text { physicians team }\end{array}$ & 1 & 0 & 1 & 0 & 2 \\
\hline Medical residents at distance shifts ${ }^{* *}$ & 2 & 0 & 4 & 0 & 6 \\
\hline $\begin{array}{l}\text { Internships and weekly agenda incorrect } \\
\text { according to CNRM rules }\end{array}$ & 1 & 1 & 9 & 4 & 15 \\
\hline $\begin{array}{l}\text { Lack of minimum working conditions and } \\
\text { disrespect to the number of hours / week } \\
\text { per resident }\end{array}$ & 1 & 1 & 8 & 3 & 13 \\
\hline $\begin{array}{l}\text { Lack of institutional } \\
\text { organizational/documentation }\end{array}$ & 0 & 0 & 2 & 0 & 2 \\
\hline
\end{tabular}

$\mathrm{NE}=$ Northeast CO = Midwest; SE = Southeast; $\mathrm{S}=$ South . 
Table 3. The most common problems found in the final reports of the evaluation, technical papers and National Committee of Medical Residency (Comissão Nacional de Residência Médica, CNRM) plenary chamber on education

\begin{tabular}{|c|c|c|c|c|c|}
\hline \multirow{2}{*}{ TEACHING AND LEARNING } & \multicolumn{5}{|c|}{ BRAZILIAN REGIONS } \\
\hline & NE & CW & SE & S & TOTAL \\
\hline $\begin{array}{l}\text { Lack or deficiency at Urgency and } \\
\text { Emergency internship }\end{array}$ & 1 & 0 & 3 & 1 & 5 \\
\hline $\begin{array}{l}\text { Lack or deficiency on supervision or } \\
\text { preceptorship }\end{array}$ & 5 & 1 & 8 & 2 & 16 \\
\hline $\begin{array}{l}\text { Lack or deficiency of Neurology } \\
\text { internship }\end{array}$ & 1 & 0 & 3 & 5 & 9 \\
\hline $\begin{array}{l}\text { Lack or deficiency on Neuroanatomy } \\
\text { and experimental Microsurgery }\end{array}$ & 2 & 0 & 4 & 3 & 9 \\
\hline $\begin{array}{l}\text { Lack or deficiency of theoretical, } \\
\text { teaching or didactic program }\end{array}$ & 1 & 1 & 5 & 3 & 10 \\
\hline Lack or deficiency of clinical visits & 1 & 0 & 0 & 1 & 2 \\
\hline $\begin{array}{l}\text { Lack or deficiency of } \\
\text { anatomic/clinical, pathology/clinical } \\
\text { or radiological/clinical sessions }\end{array}$ & 1 & 0 & 4 & 1 & 6 \\
\hline $\begin{array}{l}\text { Lack or deficiency of clinical case } \\
\text { discussions }\end{array}$ & 1 & 0 & 2 & 1 & 4 \\
\hline $\begin{array}{l}\text { Excess of residents to be training } \\
\text { according to the service features }\end{array}$ & 1 & 0 & 3 & 0 & 4 \\
\hline $\begin{array}{l}\text { Lack or deficiency of interventional } \\
\text { neuroradiology internship }\end{array}$ & 0 & 0 & 6 & 0 & 6 \\
\hline $\begin{array}{l}\text { Lack or deficiency of residents } \\
\text { assessment }\end{array}$ & 0 & 0 & 4 & 1 & 5 \\
\hline $\begin{array}{l}\text { Lack or deficiency of Intensive Care } \\
\text { Unit Internship }\end{array}$ & 0 & 0 & 2 & 0 & 2 \\
\hline
\end{tabular}


Figure 1. Neurosurgery Residency Training Programs installed over the last 30 years in the five Brazilian regions.

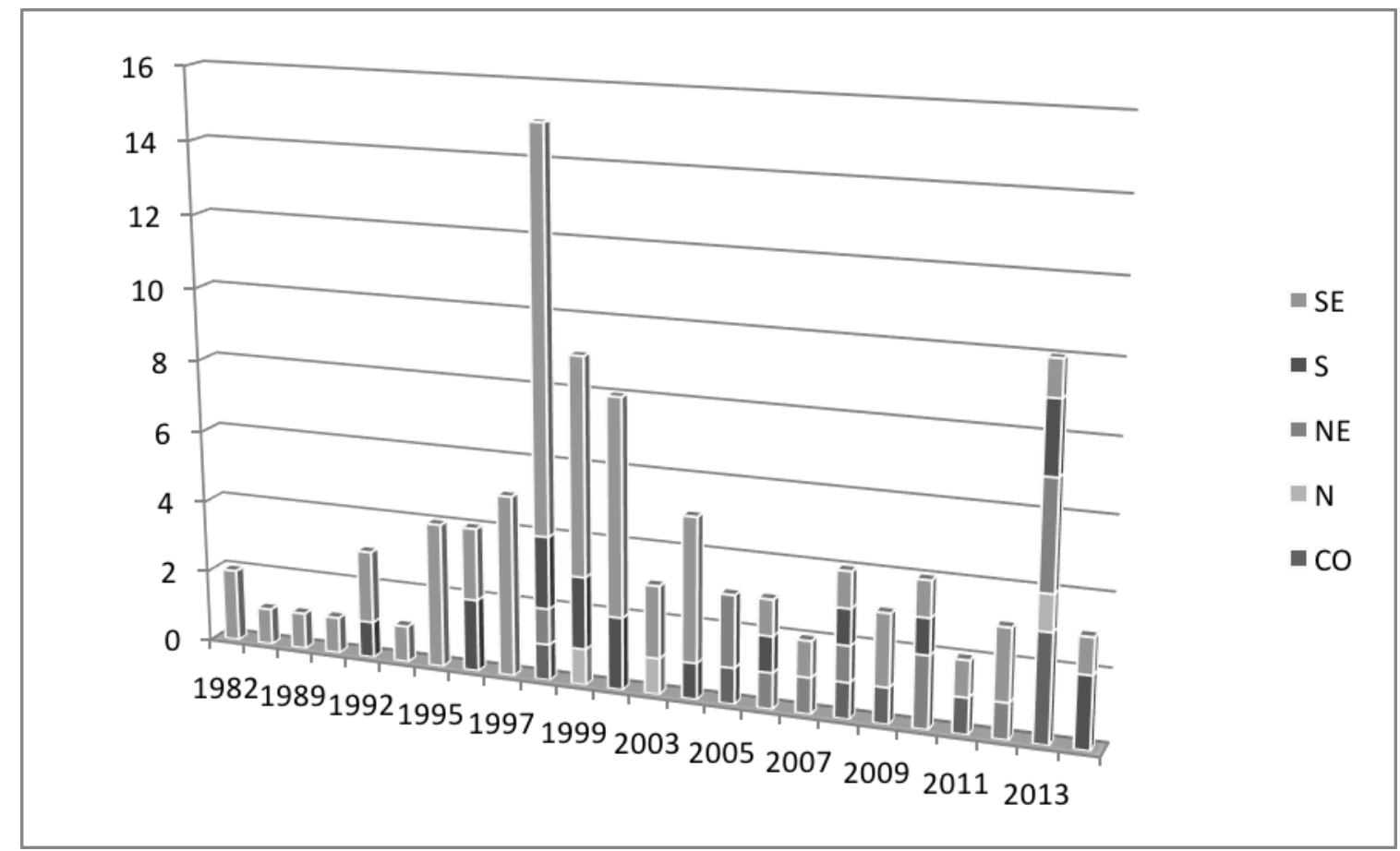

